Western University

Scholarship@Western

Digitized Theses

Digitized Special Collections

1994

\title{
An Activities-based Analysis Of The Space-time Characteristics Of Tourist Travel: The Lions Of Shetland, Scotland
}

David A. Fennell

Follow this and additional works at: https://ir.lib.uwo.ca/digitizedtheses

\section{Recommended Citation}

Fennell, David A., "An Activities-based Analysis Of The Space-time Characteristics Of Tourist Travel: The Lions Of Shetland, Scotland" (1994). Digitized Theses. 2327.

https://ir.lib.uwo.ca/digitizedtheses/2327

This Dissertation is brought to you for free and open access by the Digitized Special Collections at Scholarship@Western. It has been accepted for inclusion in Digitized Theses by an authorized administrator of Scholarship@Western. For more information, please contact tadam@uwo.ca, wlswadmin@uwo.ca. 
AN ACTIVITIES-BASED ANALYSIS OF THE SPACE-TIME CHARACTERISTICS OF TOURIST TRAVEL:

THE LIONS OF SHETLAND, SCOTLAND

\section{by}

David A. Fennell

Department of Geography

Submitted in partial fulfillment

of the requirements for the degree of

Doctor of Philosophy

Faculty of Graduate Studies

The University of Westem Ontario

London, Ontario

February, 1994

- David A. Fennell 1994 
Acquisitions and Bibliographic Services Branch 395 Wellinglon Street Ottawa Ontario KIA ON4
Direction des acquisitions et des services bibliographiques

395. nue Wellin ' $m$

Otlawa (Onlar,

KIA ON4
Your the vorientererence

Dur the nomeroterenxe
The author has granted an irrevocable non-exclusive licence allowing the National Library of Canada to reproduce, loan, distribute or sell copies of his/her thesis by any means and in any form or format, making this thesis avallable to interested persons.
L'auteur a accordé une licence irrévocable et non exclusive permettant à la Bibliothèque nationale du Canada de reproduire, prêter, distribuer ou vendre des copies de sa thèse de quelque manière et sous quelque forme que ce soit pour mettre des exemplaires de cette thèse à la disposition des personnes intéressées.

L'auteur conserve la propriété du droit d'auteur qui protège sa these. Ni la these ni des extraits substantiels de celle-ci ne doivent être imprimés ou autrement reproduits sans son autorisation.

ISBN $\quad 0-315-90551-4$ 


\section{ABSTRACT}

This study evolved as a response to the dearth of empirically-based rescarch within the realm of island tourism. It is an attempt to combine a broad range of geographical concepts (space, time, location, perception, regions, and impacts) in achieving a more holistic understanding of tourist group travel in the region of Shetland, Scotland, through a proposed theoretical model. A total of 100 questionnaire packages were distributed in the study area, with a response rate of 71 per cert. Respondents were placed into one of two groups contingent upon their activity-based interests: Special Interest (birders, fishers, history/archaeology, natural history, and "other", $n=35$ ), or General Interest $(n=36)$.

A triangulation methodology was used that employed two approaches and four distinct data-gathering techniques. The first approach, quantitative, relied on the implementation of a self-administered questionnaire and on a space-time budget. The questionnaire was designed to uncover both socio-demographic data in addition to the characteristics of the Shetland on-site travel experience. Conversely, the space-time budget required respondents to keep a daily record of their spatial and temporal use of attractions, facilities, accommodation and transportation in Shetland. Respondents were 
also required to trace their daily spatial movement on a map for each day of their Shetland vacation. The second approach, qualitative, involved the application of observations and interviews in all regions of the study area.

Data were presented using a number of techniques including tables, the model itself, in addition to maps of Shetland comparing travel groups on the basis of mean centre and weighted mean centre. In general, it was discovered that both groups differed only marginally in their use of attractions, facilities, accommodation, and transportation; in their overall movement through the four access zones of Shetland (Lerwick, Rural Mainland, Car Ferry Isles, and Passenger Ferry Isles); in the results of the questionnaire; and through an analysis of observation and interview data.

Implications of the methodological framework and the theoretical model are discussed in the context of past studies, and future research needs. Particular attention was focused on exploring attractions and their importance in the travel experience. 


\section{ACKNOWLEDGEMENTS}

My chief advisor, Professor Richard Butler, served as ar excellent role model

over the length of the time that I spent at Western. As much as his overall direction, evident throughout these pages, it was the intangibles -- enthusiasm, support, and scholarship -- that contributed so significantly to my education. I suspect that his influence will remain for the duration of my academic career.

I owe a great deal to Professor Bryan Smale who was instrumental in helping me choose this particular road. He has unselfishly extended to me his time, expertise, and friendship throughout this long adventure. I will not lose sight of this kindness. Thanks also to Professor Michael Troughton who remained supportive at key times during the course of this research.

Appreciation is extended to many of the faculty, staff, and students (in particular Steve Bird and Matt Lumsdon) in the department. Also, thanks are extended to George Adamson and family who allowed me to enter into their lives and experience Shetland from: a different perspective.

Special thanks to Dad, Mom, Kim, and Chris, who become more important to me with each and every passing day. Many thanks for your support, knowledge, advice, and understanding. To you I say this: although the puzzle has taken new form, I am secure in the belief that the most important pieces will always be found with you.

Finally, special thanks to Julıe whose constant belief in me and my chosen career was (and is) as strong, and sometimes stronger than my own. I dedicate this study to her and to our future travels. 


\section{TABLE OF CONTENTS}

CERTIFICATE OF EXAMINATION $\ldots \ldots \ldots \ldots \ldots \ldots \ldots \ldots$ ii ABSTRACT $\ldots \ldots \ldots \ldots \ldots \ldots \ldots \ldots \ldots \ldots \ldots \ldots \ldots \ldots \ldots$ iii ACKNOWLEDGEMENTS $\ldots \ldots \ldots \ldots \ldots \ldots \ldots \ldots \ldots$

TABLE OF CONTENTS $\ldots \ldots \ldots \ldots \ldots \ldots \ldots \ldots$ vi

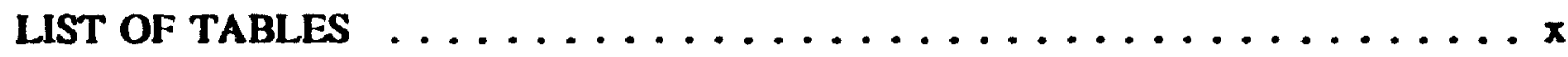

LIST OF FIGURES $\ldots \ldots \ldots \ldots \ldots \ldots \ldots \ldots \ldots \ldots \ldots \ldots \ldots$

Chapter 1: THE GEOGRAPHICAL CONTEXT OF TOURISM $\ldots \ldots \ldots \ldots \ldots \ldots \ldots \ldots \ldots \ldots$

PROLOGUE . . . . . . . . . . . . . . . . .

PURPOSE ........................

OBVECTIVES ......................

THEORETICAL FOUNDATIONS ...............

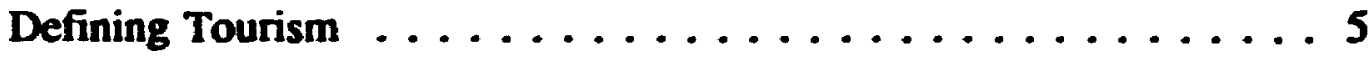

Space, Time and Tourism ................. 10

Core-Periphery . . . . . . . . . . . . . . . . . . 19

Island Peripheries . . . . . . . . . . . . . . 22

Tourist-Tourism Typologies . . . . . . . . . . . . . . 25

Tourist Pressure and the Capacity to

Accommodate Tourism . . . . . . . . . . . . . . 29

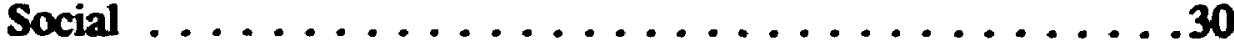

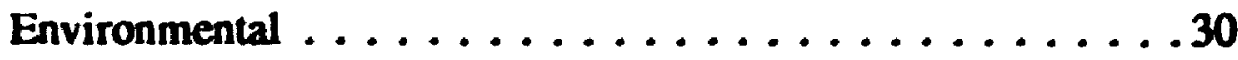

Economic . . . . . . . . . . . . . . . . 31

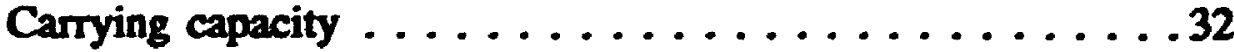

INVESTIGATIONAL PROCEDURE $\ldots \ldots \ldots \ldots \ldots \ldots \ldots \ldots$

CONCLUSION .............................. 
Chapter 2: A MODEL OF TOURIST PRESSURE $\ldots \ldots \ldots \ldots \ldots$

INTRODUCTION $\ldots \ldots \ldots \ldots \ldots \ldots \ldots \ldots \ldots \ldots \ldots \ldots$

THE EVOLUTION OF A THEORETICAL MODEL . . . . . . . . . . 39

THE MODEL . . . . . . . . . . . . . . . . .42

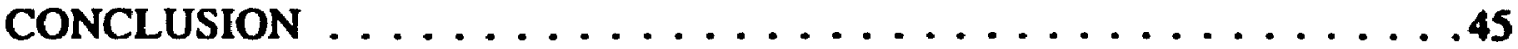

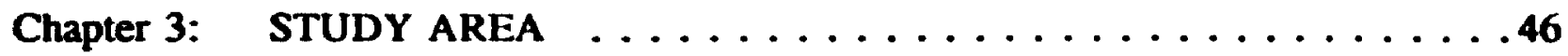

THE SHETLAND REGION $\ldots \ldots \ldots \ldots \ldots \ldots \ldots \ldots \ldots \ldots \ldots$

A HISTORY OF TRAVEL IN SHETLAND: BEFORE $1939 \ldots \ldots \ldots \ldots 54$

POST 1945 TOURISM . . . . . . . . . . . . . . . . 70

SHETLAND TOURISM STATISTICS . . . . . . . . . . 74

THE MODEL WITHIN THE SHETLAND CONTEXT $\ldots \ldots \ldots \ldots . . .85$

The Tourists and Study Regions of Shetland . . . . . . . . . 86

Elements in Space and Time ................ . 88

METHODOLOGICAL FRAMEWORK . . . . . . . . . .90

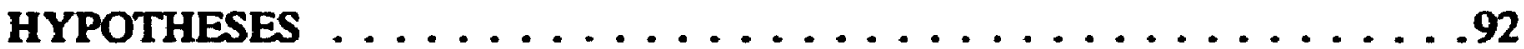

CONCLUSION .......................

Chapter 4: THE STRUCTURE OF INQUIRY . . . . . . . . . . . . 98

TRIANGULATION $\ldots \ldots \ldots \ldots \ldots \ldots \ldots \ldots \ldots \ldots . \ldots \ldots$

METHODS AND SAMPLING $\ldots \ldots \ldots \ldots \ldots \ldots \ldots$

The Quantitative Approach $\ldots \ldots \ldots \ldots \ldots$

The Qualitative Approach . . . . . . . . . . . . . . 108

LIMITATIONS . . . . . . . . . . . . . . . . . 114

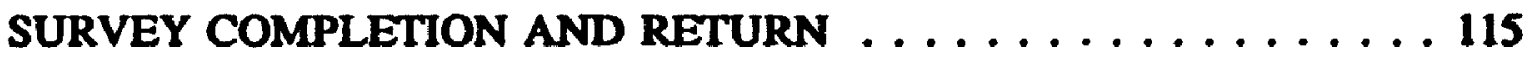

CONCLUSION .......................... 119

Chapter 5: A QUESTIONNAIRE ANALYSIS OF TOURIST

GROUPS IN SHETLAND $\ldots \ldots \ldots \ldots \ldots$

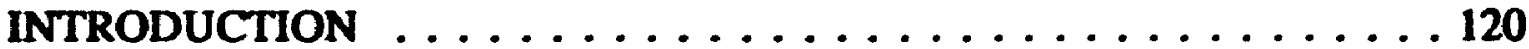

QUESTIONNAIRE RESULTS $\ldots \ldots \ldots \ldots \ldots \ldots \ldots \ldots \ldots \ldots \ldots$

Socio-Demographics .................... 125

Repeat Visitation . . . . . . . . . . . . . . . . . . . 128

Characteristics of a Planned Itinerary . . . . . . . . . 129

Accumulation of Free Brochures . . . . . . . . . . . 130

Information Sources . . . . . . . . . . . . . . . . . . 134

Natural History and Archaeological

Familiarity . . . . . . . . . . . . . . . 136 
Travel Companionship . . . . . . . . . . . . . 138

Travel Mode Characteristics . . . . . . . . . . . . . 140

Regional Visitation ................. 141

Travel Diary . . . . . . . . . . . . . . . . . . 142

Reasons for Visiting Shetland . . . . . . . . . . . 143

Trip Satisfaction . . . . . . . . . . . . . . . 146

Activities Interrupted by Poor Weather . . . . . . . . . 147

Terms Describing the Shetland Travel

Experience .................... 148

Tourist Interaction . . . . . . . . . . . . . . 150

Activity Satisfaction . . . . . . . . . . . . . . 151

Willingness to Return . . . . . . . . . . . . . . . 152

Recommending Shetland to Friends ............. 153

Archaeological Attractions . . . . . . . . . . . . 153

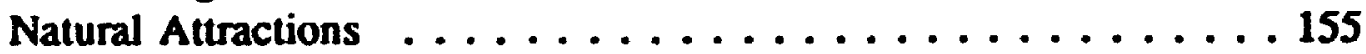

Houses and Buildings of Interest Visited . . . . . . . 158

Places of Industrial Interest $\ldots \ldots \ldots \ldots \ldots \ldots$

Craft Centres Visited . . . . . . . . . . . . . . 160

"Other" Attractions Visited . . . . . . . . . . . . . 162

Attraction Dynamics . . . . . . . . . . . . . . . . . 164

Statistical Tests . . . . . . . . . . . . . . . . . . 166

CONCLUSION ...................... 173

Chapter 6: A SPACE-TIME BUDGET ANALYSIS OF SHETLAND TOURIST GROUPS . . . . . . . . . . . 174

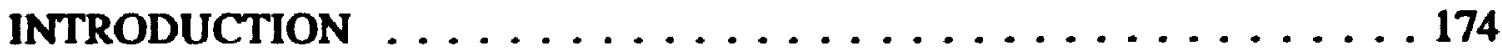

ACCOMMODATION $\ldots \ldots \ldots \ldots \ldots \ldots \ldots \ldots \ldots \ldots \ldots \ldots$

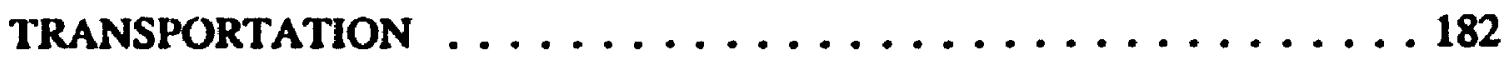

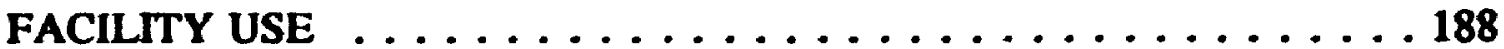

ATTRACTIONS . . . . . . . . . . . . . . . . 193

REGIONAL TRANSPORT VISITATION . . . . . . . . . . 203

CONCLUSION ....................... 208

Chapter 7: INDEPENDENT INTERVIEW AND OBSERVATION

DATA $\ldots \ldots \ldots \ldots \ldots \ldots \ldots \ldots \ldots \ldots \ldots \ldots \ldots \ldots \ldots$

INTRODUCTION ....................211

INTERVIEW DATA . . . . . . . . . . . . . . 212

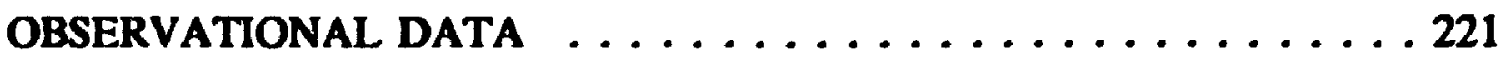

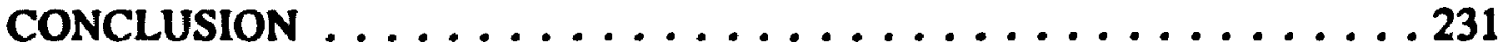


Chapter 8: IMPLICATIONS OF SHETI.AND TOURISM IN SPACE AND TIME

232

INTRODUCTION

THE APPLICATION OF THE MODEL IN SPACE AND TIME . . . . . 38

Tourism Typologies: A New Perspective . . . . . . . . . . . . 239

Travel Groups and Core-Periphery . . . . . . . . . . . . . 243

Facilities and Attractions: Their Importance

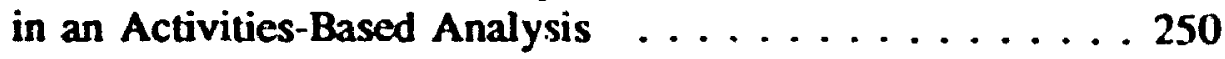

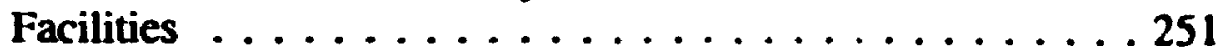

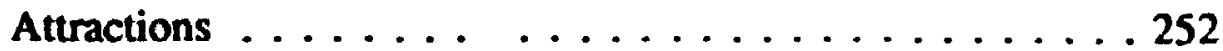

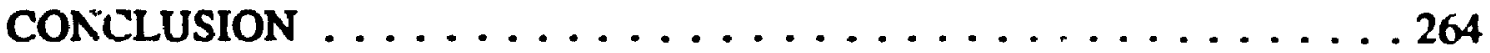

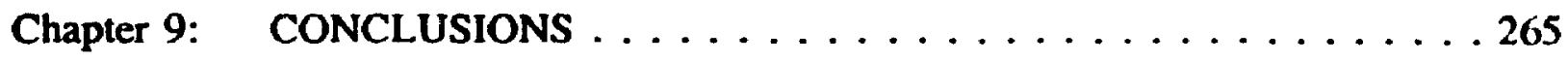

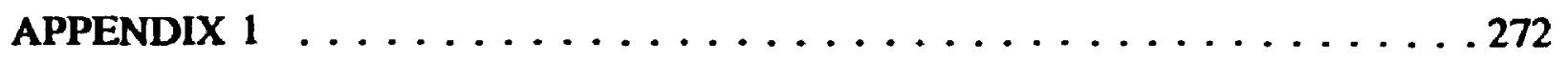

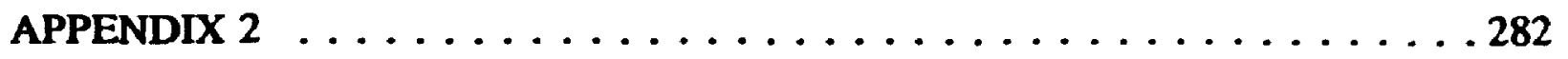

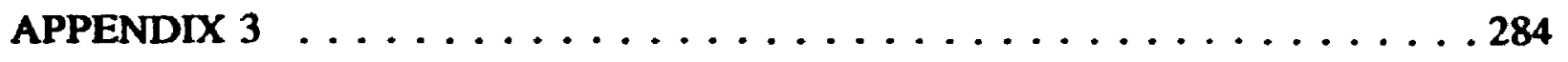

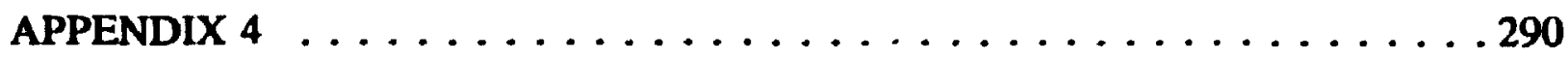

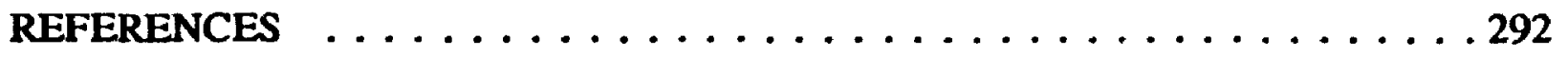

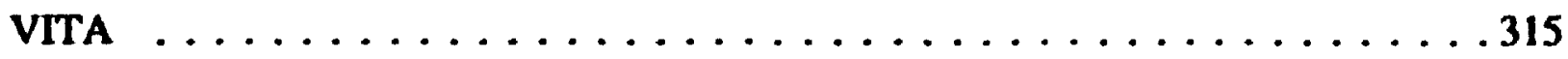

ix 


\section{LIST OF TABLES}

$3.1 \quad$ Accommodation Capacity $\ldots \ldots \ldots \ldots \ldots \ldots \ldots$

3.2 Number of Nights Spent in Shetland $\ldots \ldots \ldots \ldots 2$

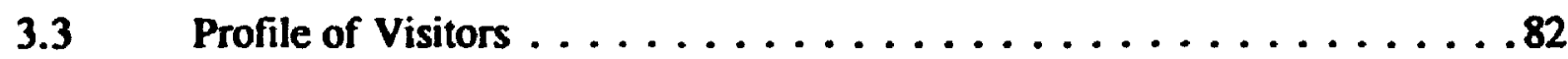

$3.4 \quad$ Origin of Visitors $\ldots \ldots \ldots \ldots \ldots \ldots \ldots \ldots \ldots \ldots \ldots$

3.5 Total Visitor Expenditure in Shetland . . . . . . . . . . . 84

3.6 Membership of Shetland Tourist Organisation $\ldots \ldots \ldots$. . . . 85

5.1 Tourist Group Representation . . . . . . . . . . . . 121

5.2 Socio-Demographic Characteristics by Tourist

Group . . . . . . . . . . . . . . 126

$5.3 \quad$ Characteristics of Repeat Visitors . . . . . . . . . . . . . . 129

$5.4 \quad$ Characteristics of a Planned Personal Itinerary . . . . . . . . . . 130

5.5 Statements Associated with the Accumulation of

Free Brochures . . . . . . . . . . . . . . 131

5.6 Interpretive Material Bought Associated with

Prime Reason for Travel to Shetland . . . . . . . . . . . . . 133

$5.7 \quad$ Information Sources Ranked by Tourist Group $\ldots \ldots \ldots$. . . . . 135

5.8 Familiarity with Natural History/Archaeology $\ldots \ldots \ldots 137$

5.9 Characteristics of Travel Companionship . . . . . . . . . . . 139

5.10 Group Travel Mode Characteristics $\ldots \ldots \ldots \ldots \ldots 1$ 
5.11 Group Propensity to Visit All Regions of Shetland . . . . . . . . . . . . . . . . 142

5.12 Tourist Group Travel Diary Recordings $\ldots \ldots \ldots \ldots \ldots$

5.13 Items Describing Reasons for Visiting Shetland . . . . . . . . . . . 144

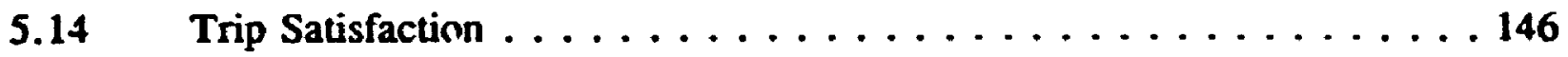

5.15 Tourist Activities Interrupted by Poor Weather . . . . . . . . . . 147

5.16 Terms Used to Describe the Shetland Travel

Experience . . . . . . . . . . . . . . . . 149

5.17 Characteristics of Tourist Interaction $\ldots \ldots \ldots \ldots \ldots \ldots$

5.18 Suitability of Shetland in Satisfying Chosen

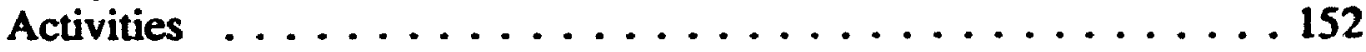

5.19 Willingness to Return to Shetland as a Tourist $\ldots \ldots \ldots \ldots$

5.20 Those Recommending Shetland as a Destination

to Their Friends . . . . . . . . . . . . . 154

$5.21 \quad$ Archaeological Attractions Visited ... . . . . . . . . 285

$5.22 \quad$ Natural Attractions Visited $\ldots \ldots \ldots \ldots \ldots \ldots \ldots$

$5.23 \quad$ Houses and Buildings of Interest Visited $\ldots \ldots \ldots \ldots \ldots$

$5.24 \quad$ Places of Industrial Interest Visited $\ldots \ldots \ldots \ldots \ldots \ldots$

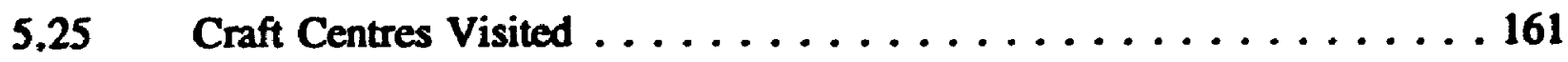

5.26 "Other" Places of Interest Visited . . . . . . . . . . . 163

$5.27 \quad$ Total Attraction Visitation Dynamics by Group $\ldots \ldots \ldots \ldots$

$5.28 \quad$ Chi Square Scores $\ldots \ldots \ldots \ldots \ldots \ldots \ldots$

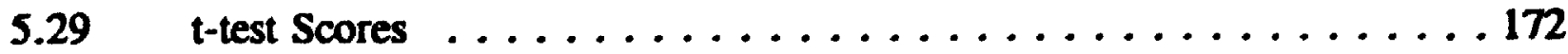

6.1 Group Accommodation Statistics by Unit . . . . . . . . . . 176 
6.2 Tourist Group Accommodation Statistics $\ldots \ldots \ldots \ldots \ldots$

6.3 Tourist Group Accommodation Unit Visitation

by Region . . . . . . . . . . . . . . . . 179

6.4 Travel Mode Characteristics by Tourist Group . . . . . . . . . . 185

6.5 Facility Use by Tourist Group . . . . . . . . . . . . . 189

6.6 Comparison of Group Facility Characteristics . . . . . . . . . . 191

6.7 Comparison of Adjusted Group (grp.) Facility

Characteristics . . . . . . . . . . . . . . 193

6.8 Time Spent by Tourist Groups (grp.) at

Regional Attractions . . . . . . . . . . . . . . . . 194

6.9 Group Attraction Visitation by Regional Area

Percentage . . . . . . . . . . . . . . . . . 198

6.10 Characteristics of Attraction Type Visitation

by Group . . . . . . . . . . . . . . . . . . . . . 199

6.11 Comparison of Group Attraction Characte.istics $\ldots \ldots \ldots 200$

6.12 Compaison of Adjusted Group Attraction

Characteristics ...................... 201

$6.13 \quad$ Regional Visitation by Group (grp.) . . . . . . . . . . . . 204

7.1 Individual and Travel Group Interview Scores $\ldots \ldots \ldots \ldots$

7.2 Experiential Interview Question Scores . . . . . . . . . . . 219

7.3 Tourist Industry Interview Question Scores . . . . . . . . . . . 220

$7.4 \quad$ Lerwick Tourist Office Observations $\ldots \ldots \ldots \ldots \ldots \ldots \ldots \ldots \ldots$

7.5 Major Attraction Observations (Sumburgh Head) . . . . . . . . 225

7.6 Major Attraction Observations (Jarlshof) . . . . . . . . . . . 227

7.7 Major Attraction Observations

(Croft House Museum) . . . . . . . . . . . . . . . . . . . 229 


\section{LIST OF FIGURES}

2.1 Model of the Space-Time Characteristics of Tcurist Group Behaviour . . . . . . . . . . . . . 43

$3.1 \quad$ Shetland Islands $\ldots \ldots \ldots \ldots \ldots \ldots \ldots \ldots \ldots \ldots \ldots . \ldots \ldots \ldots$

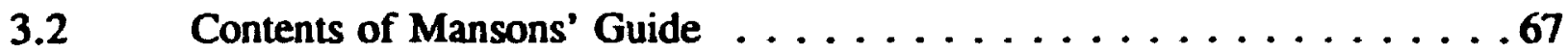

3.3 The Grand Hotel, Lerwick . . . . . . . . . . . . 67

3.4 The St. Magnus Hotel $\ldots \ldots \ldots \ldots \ldots$

3.5 Shetland Steamer Transport $\ldots \ldots \ldots \ldots$. . . . . . . 68

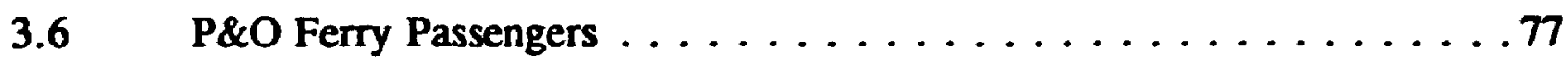

$3.7 \quad$ P\&O Cars Carried $\ldots \ldots \ldots \ldots \ldots \ldots \ldots \ldots \ldots \ldots$

$3.8 \quad$ Nights in Shetland $\ldots \ldots \ldots \ldots \ldots \ldots \ldots \ldots \ldots \ldots$

3.9 Model of the Space-Time Characteristics of Tourist Group Behaviour in Shetland . . . . . . . . . 87

3.10 Methodological Structure $\ldots \ldots \ldots \ldots \ldots \ldots \ldots \ldots \ldots \ldots \ldots$

3.11 The Space-Time Characteristics of Each Tourist Group (Hypothetical) . . . . . . . . . . . .93

6.1 The Space-Time Characteristics of Regional

Accommodation Visitation . . . . . . . . . . . . . 180 
6.2 Accommodation Mean Centre and Weighted Mean

Centre Comparisons . . . . . . . . . . . . . . . . 183

6.3 The Space-Time Characteristics of Regional

Attraction Visitation . . . . . . . . . . . . . . 196

6.4 Attraction Mean Centre and Weighted Mean

Centre Comparisons . . . . . . . . . . . . . . . . 202

6.5 The Space-Time Characteristics of Regional Transport Visitation . . . . . . . . . . . . . . 206

6.6 Transportation Mean Centre and Weighted Mean Centre Comparisons . . . . . . . . . . . . . . . . . . 207

6.7 Overall Space-Time Characteristics $\ldots \ldots \ldots \ldots$. . . . . 209

$7.1 \quad$ Interview Guide Typology $\ldots \ldots \ldots \ldots \ldots \ldots \ldots \ldots \ldots$

xiv 
The author of this thesis has granted The University of Western Ontario a non-exclusive license to reproduce and distribute copies of this thesis to users of Western Libraries. Copyright remains with the author.

Electronic theses and dissertations available in The University of Western Ontario's institutional repository (Scholarship@Western) are solely for the purpose of private study and research. They may not be copied or reproduced, except as permitted by copyright laws, without written authority of the copyright owner. Any commercial use or publication is strictly prohibited.

The original copyright license attesting to these terms and signed by the author of this thesis may be found in the original print version of the thesis, held by Western Libraries.

The thesis approval page signed by the examining committee may also be found in the original print version of the thesis held in Western Libraries.

Please contact Western Libraries for further information:

E-mail: libadmin@uwo.ca

Telephone: (519) 661-2111 Ext. 84796

Web site: http://www.lib.uwo.ca/ 


\section{Chapter 1}

\section{THE GEOGRAPHICAL CONTEXT OF TOURISM}

Everything is rapidly growing these days, sometimes for the worse, sometimes for the better. But nothing is growing as fast as recreational travel, in which the better and the worse effects of growth become intermingled. Upon whatever part of the pattern one concentrates, in whatever part of the tourist world, one finds annual growth rates of 10 , 15, 20 per cent, and rates of 25 per cent and even more are not unheard of (Wolfe, 1966: 3).

\subsection{PROLOGUE}

More than a quarter of a century after Wolfe's observation above, certain realities concerning the global movement of people have emerged. The amalgam of communications (mass media), development, transportation, increased disposable income and time, and improved access, have enabled people to enjoy recreational travel in new and more varied dimensions. This demand has come to focus increasingly upon destinations (supply) that touch the final frontiers of the planet.

There are certain benefits which accrue through this migration: to the host, mostly economic; to the tourist, mostly experiential. In this trade-off, however, there is much more. Over the past two decades, researchers have questioned the manifestations that 
have evolved from travel. Increased concern has emergeo regarding the physical and sociological pressure that tourists exert on remote environments and their populations. Small islands, as examples of peripheral and remote regions, are locations often particularly sensitive to change. This problem, however, has received little comprehensive treatment in a tourist context. Researchers, therefore, need to develop ideas, models, and approaches that empirically evaluate the potential impact that tourists have on a region. As part of such research, in particular, it is necessary to determine where tourists go and what they do at their destinations if we are to identify their effects correctly and comprehensively.

\subsection{PURPOSE}

This research proposes, through a triangulation methodology, to analyze the spatial-temporal characteristics of tourist groups in the Shetland Islands. Triangulation involves the use of a variety of research methods in drawing inferences about a particular research problem. In this study, two quantitative techniques will be applied. The first, a space-time budget, concentrates on how each tourist group uses facilities, attractions, transportation, and accommodation in specified access zones of the study area. The second quantitative technique focuses on eliciting responses through a self-administered questionnaire.

Qualitative techniques used in this study include interviews and observations. A series of informal interviews were conducted at a number of attractions and regional 
settings in the study area. Observations took place at the local Tourist Office and at selected attraction sites in Shetland.

The fundamental premise driving the research is an attempt to graphically outline where and how tourists move, and the pressure they place on an environment. In evaluating pressure, one has to go beyond simply identifying tourist numbers to the point where the movement is accountable both in space and time. Pressurc can be defined, therefore, as including the types of activities, facilities, transportation, and accommodation used in space and time. These components can be empirically measured and, therefore, used to determine the space-time dynamics of tourists in the study area. Consequently, the components (activities, facilities, transportation, and accommodation) offer an alternative to simply identifying tourist numbers in various regions as a measure of pressure.

In addition, the time spent at various locations in the destination has direct implications to host and tourist populations socially, environmentally, and economically. Direct measurement of these factors is, however, beyond the scope of this work, yet each is considered important in tourism research and will be discussed as a means by which to link tourist movement in Shetland with other island case studies.

\subsection{OB,ECTIVES}

The broad focus of this study requires that a number of geographical and humanrelated features be combined and evaluated. Each of these features (including regions, 
behaviour, space-time, and core-periphery), are organised here in a series of objectives to be systematically achieved. These objectives are as follows:

1. To identify the activity-based behaviour of specific tourist groups in space and time through four access zones identified in Shetland.

2. To apply the conventional core-periphery concept as both a locational construct and as a menial construct in assessing the activity-based core and periphery movement and perceptions of different tourist groups in different regions of the study area.

3. To compare tourist groups based on their use of attractions, facilities, transportation, and accommodation in the four access zones of the study area.

4. To draw inferences about the social, environmental, and economic implications of tourist travel for the various access zones of Shetland.

5. To incorporate a number of theoretical concepts (including space-time, regions, perceptions, and impacts) in achieving a more holistic understanding of different types of tourism in the context of Shetland.

The study makes its contribution to the advancement of knowledge in tourism through the holistic nature of the research, bringing together a number of concepts (tourism, space-time, core-periphery, typologies, islands, and capacity) with a common goal of understanding behaviour and, therefore, the activity patterns of individuals and tourist groups. Tourism researchers (Mathieson and Wall, 1982; Pearce, 1987; Wall, 1993) have made reference to the need for a more detailed analysis of the following:

1. How the space-time aspects of demand have an impact on a destination socially, environmentally, and economically; and

2. The differences in tourism groups, for while much has been written on individual tourist types, little is available on tourism typologies.

The research combines the above factors into a theoretical framework which will act as a step towards meeting the objectives of the research which are to be tested empirically. 
Consequently, the study will provide a data base for future tourism studies, as well as serving as a benchmark for Shetlanders in understanding the tourist climate of their region. In order to limit the study to a realistic size, host responses to tourists/tourism in different locations of Shetland (and at different times) could not be considered. Furthermore, the study will - at most - provide general, rather than specific recommendations on the social, environmental, and economic implications of tourist movement.

\subsection{THEORETICAL FOUNDATIONS}

This section focuses on developing a conceptual base for the research in the light of past tourism studies. The underlying framework for the analysis is the space-time relationship; consequently, much of what follows focuses on this type of research. However, the study also makes reference to a number of other themes that are pertinent to the Shetland tourism situation, including the core-periphery concept, and tourist typologies. Other subsidiary components examined include carrying capacity and impacts (social, environmental, and economic) which will be better understood in the context of the analysis of tourist travel in Shetland.

\subsubsection{Defining Tourism}

As the study of tourism evolves, researchers are confronted with the task of organising the component parts of this phenomenon into meaningful theories. However, as is the case with much social science research, identifying sound paradigms has proven 
to be difficult (Smith, 1982). As the world's largest industry (405 million international arrivals, $\$ 209$ billion in international tourism receipts, and almost US\$ 20 trillion in gross national product - Hawkins and Ritchie, 1991), tourism is affiliated with many of the prime sectors of the world's economy. As such, any type of phenomenon that is intricately interwoven into the fabric of life - economically, socio-culturally, and environmentally - and relies on primary, secondary, and tertiary levels of production and service, is difficult to define in simple terms. This difficulty is mirrored in a 1991 edition of The Economist, (Anon.).

There is no accepted definition of what constitutes the [tourism] industry; any definition runs the risk of either overestimating or underestimating economic activity. At its simplest, the industry is one that gets people from their home to somewhere else (and back), and which provides lodging and food for them while they are away. But that does not get you far. For example, if all the sales of restaurants were counted as travel and tourism, the figure would be artificially inflated by sales to locals. But to exclude all restaurant sales would be just as misleading.

Mitchell (1984) and Clawson and Knetsch (1966) stressed that it is difficult to classify tourism studies into research fields due to a critical absence of focus. Similar studies are often placed poles apart in terms of philosophical approach, methodological orientation, or intent of the investigation. This type of fragmentation in tourism research has provided idiographic rather than nomothetic analyses (Hartshome, 1959). Tourism shares strong fundamental characteristics and theoretical foundations with recreation and leisure studies. Jansen-Verbeke and Dietvorst (1987) suggest that when approaching the field of leisure from the point of view of the individual, there is little distinction among aspects of leisure, recreation, and tourism; rather, they represent a type of loose, harmonious unity. Consequently, there are a variety of definitions of tourism each with 
disciplinary attributes that reflect research initiatives corresponding to various fields. Economic definitions generally ignore the human spatial and temporal elements of the concept, while technical and statistical approaches avoid including components related to the destination and the systems responsible for hosting tourists (Leiper, 1979).

Wolfe (1964) was one of the first to look at both demand and supply aspects of recreation/tourism, as well as macrogeographic (national and international), and microgeographic (local and regional) travel patterns. Woife suggested that spatial imbalance was a key factor in determinirig the link between supply and demand: "movement of people from places where they live to the places where recreational facilities are" (Wolfe, 1964: 216).

Leiper (1981) advocated a move away from orthodoxy (alignment to other disciplines), to heterodoxy (a distinct discipline) when referring to tourism research. To Leiper, tourism is an open system of five elements interacting with broader environments: (i) a dynamic human element, (ii) a generating region, (iii) a transit region, (iv) a destination region, and (v) the tourist industry.

Mathieson and Wall (1982) see tourism as comprised of three basic elements:

1. A dynamic element, which involves travel to a selected destination;

2. A static element, which involves a stay at the destination;

3. A consequential element, resulting from the above two which is concerned with the effects on the economic, social, and physical subsystems that the tourist is directly or indirectly in contact. 
Mill and Morrison (1985) define tourism as a system of interrelated parts. The system is "like a spider's web - touch one part of it and reverberations will be felt throughout" (Mill and Morrison, 1985: xix). Included in their tourism system are four component parts - Market (reaching the market place), Travel (the purchase of travel products), Destination (the shape of travel demand), and Marketing (the selling of travel). In coming to grips with the tourism "system", some authors have relied on a combination of existing models. Morley (1990: 7) combined the efforts of Mathieson and Wall (1982) and Mill and Morrison (1985) - among others - in a model that is described as having a "wider, more inclusive coverage of the areas and factors involved in tourism". Morley matched tourist, tour, and "other" factors (external parties such as government, societies, economics, and people), against demand, supply and impacts in his design of a complete framework.

What is important to extract from the above whole systems models, is the geographical inferences of each. Such models all advocate links with a generating region and movement to a selected destination or supply region. Pearce (1987) refers to this "tourism geography" as an origin-linkage-destination system; an effective device for investigating what is inherently a very geographical phenomenon.

From an evolutionary perspective, geographers first became involved in the study of tourism some 60 years ago. It is generally agreed (Mitchell, 1969; Mitchell and Smith, 1985; Pearce, 1979) that McMurry's article in the 1930 issue of the Annals of the Association of American Geographers ("The Use of Land for Recreation") was the first to recognise teurism as a distinct and significant form of land use. 
To many who are strong advocates of tourism as a component of geography, other disciplines fail to concentrate on the questions pertaining to location of tourism phenomena. The "where" questions tend to be ignored by most other disciplines, thus geographers can make unique contributions to the tourism research frontier (Mitchell and Murphy, 1991). The interest in tourism displayed by geographers has been almost universally human. Davidoff, Davidoff and Eyre (1988) imply that there is an interaction factor involving traveller and destination which distinguishes tourism geography from other forms of geography. Yet, as Yefremov (1975) contends, there has emerged a significant, if limited interest demonstrated by physical geographers in tourism research. Warszynska and Jackowski (1986: 656) have written on the composite nature of tourism; a science particularly at home as a sub-discipline of geography:

This science analyses the forms of spatial relationships of tourist phenomena and the processes affecting those phenomena. The research purpose of geographers is to create theoretical foundations for tourism movement without neglecting social, environmental, or economic factors.

Geographers have had a significant impact on the study of tourism, yet the field is open to researchers in a number of other social science fields. As a result, tourism has experienced a recent increase in formally trained professionals and number of travelrelated studies, which in tum, have given-way to an increase in media (e.g., journals) designed to cater to the field. The Joumal of Tourism Studies, is one such periodical that has recently appeared in response to this demand. This journal's first edition was devoted to the importance and difficulty in defining tourism. Of particular interest were works associated with "Research and Scholarship" (Jafari, 1990), "Joumals in Tourism 
and Hospitality" (Sheldon, 1990), and "The Literature of Tourism" (Dartnall and Store, 1990).

Smith (1990) has suggested that because tourism is so broad, consensus in defining the concept may never be achieved, and feels, therefore, that it is more realistic to accept the existence of a number of different definitions, each designed to serve different purposes. For this analysis, tourism is defined as the system that includes tourists and the associated services that are provided and utilised (facilities, attractions, transportation, and accommodation) to aid in their movement, while a tourist is defined as a person travelling for plıasure, internationally and/or nationally, for a period of at least 24 hours, and the associated space-time dimensions of their stay at various locations within the study area.

\subsubsection{Space, Time and Tourism}

Geographers have traditionally found temporal and spatial variables as inherent functions in their varied world views. Kant (cited in Mitchell, 1979) suggested that all things in human experience occur in both space and time dimensions. This mode of conceptualizing has emerged as a critical factor in the geographer's analysis of the tourism industry today.

Carlstein (1982) approached the study of space and time through an analysis of time as a limiled resource. The carrying capacity of terrestrial space-time is defined as the limited ability of a given area to accommodate space-demanding people, organisms and materials, and the activities associated with them. Carlstein goes on to suggest that 
space can be more or less continuously occupied over time: space-time. The space-time concept of carrying capacity may be applied at any scale, including buildings, regions, or the entire globe.

More pertinent to the analysis of tourism is the notion of human time as a resource. Carlstein, in his discussion, implies that human time is a resource because all activities require it as an input, and we have limited capacity to act in relation to time. Time is finite, and only a limited number of activities can be accommodated within a population time-budget. The number of activities that can be accomplished by tourists over time and space will differ between individuals, groups, destination characteristics, and facilities available.

Hagerstrand (1970) described the movement of individuals in space and time as a path, starting at the point of birth and ending at the point of death. This "life path", to Hagerstrand, could easily be delineated into parts such as day paths, week paths, and so on. The life path of a tourist might also be analysed in this vein as temporal and spatial characteristies of vacations. Similar reasoning was followed by Anderson (1971) who felt that the analysis of individuals or groups in time and space provides comprehensive descriptions of activity routines (daily, weekly, etc.) which are not directly observable due to their space-time extent.

Boulding (1985) wrote that organisms, especially human beings, may be conceived as regions. Such regions are patterns in time as well as space. Some regions (humans, for example) move around in space. A region of time may be defined as any system which is recognized as having a beginning and an end (Boulding, 1985). This 
theoretical view sees complete entities of distinct characteristics moving about interacting with (inside and outside) other space-time dimensions of distinct characteristics.

Minkowski (cited in Anderson, 1971) contends that space and time by themselves are doomed to fade away into mere shadows. It is only a kind of union of the two that would preserve an independent reality. The two concepts, therefore, are seen to be more valuable from a synergistic point of reference. Nysteun (1963) identified with this marriage when he referred to space-time tensions. He noted that when a particular activity had an associated deadline, congestion of space was likely. Similarly, when time is short, space is conserved.

From the perspective of tourism, travellers, as regions, follow distinct courses of space-time. In a temporal sense, tourists interact as a function of a distinct period, for example seven, ten or fourteen days of vacation time. This vacation time has a beginning and an end. Given this idea of start and finish, tourists will encounter a variety of regions in space through their movements. The value of time as a dynamic and finite resource (Cooper, 1981) is important and quickly enters the consciousness of the tourist.

Pearce (1987) has maintained that the geographical literature on tourism has not explicitly examined the movement of tourists from the generating region to the destination region. This fact becomes even more pronounced when scale (international, national, regional, and local) is considered. When scale is coupled with the components of tourism that entail spatial properties, one can appreciate the magnitude of the tourism system. Tourists travel to experience and utilise a variety of broadly defined goods and 
services, including attractions, facilities, accommodation, and modes of transport. Each of these, as cogs in the tourism system wheel, when applied to transient individuals (tourists), hold spatial value. Miossec (cited in Pearce, 1989) argued 16 years ago for the need to better understand and :...k generating and destination regions. The impact of such a plea rings clearer today as researchers continue to stuggle with a phenomenon that is consistently changing at macro, meso, and micro levels, along a sociopsychological, economic, and environmental continuum.

More recent studies of tourism space have continued to explore the movement of tourists from a variety of perspectives. Mansfeld (1990) evaluated patterns of international tourist flows by viewing space three ways:

1. Actual space, which denotes the area which accommodates tourist activities and which has clear geographical boundaries.

2. Functional space, which involves the movement of tourists to the supply, and the components of the industry that involve products and services within broader environments.

3. Perceived space, which refers to the personal perceived images of space that tourists have on an individual level.

The measurement of spatial variations in the activities of tourists has been of particular interest to researchers in their analyses of accommodation, transportation, facilities, and attractions. Keogh (1984) attempted to measure tourist activity by looking at problems of using accommodatic capacity figures to identify spatial variations in New Brunswick. Husbands (1986) analysed activity resources and activity space pattern formation in the peripheral resorts of Barbados. His cunclusions state that major resources (resorts) may be viewed by tourists not so much as separate entities, but more 
in terms of their relationship to other resources that can enhance a resort's appeal. Hsich, O'Leary and Morrison (1992) used activity-based segmentation to identify groups of Hong Kong pleasure travellers. Cluster analysis was applied as a tool to illustrate that tourists engaged in sets of activities rather than one particular pursuit.

Referencing the work of Gould on "space-searchers" and "space-sitters", Walmsley and Jenkins (1991) looked at the mental maps of tourists to Coffs Harbour, New South Wales. They discovered that the content of tourist maps was influenced by personal locus of control and activity. From the tourist perspective, "space-searchers" are those people who are active and inquisitive, and who explore places around them. "Space-searchers", according to the authors, may visit a great many attractions, travel widely, and be active participants in a wide range of activities. Conversely, "spacesitters" minimise exploratory travel and are far more passive in nature. Both types of travellers have direct implications for the planning of the tourism industry at a number of scales. Furthermore, tourists may exhibit characteristics of both groups (spacesearching and space-sitting) on the same holiday.

Tourist movement within a destination area can also have environmental implications. In a study that analysed the ecological effects of hill walking, Watson (1984) illustrated that over a period of 35 years individuals have substantially modified the Caimgorms of Scotland through the creation of paths and roads. Not only have such modifications increased in number, but also in length and extent as newer forms of recreational activities appeared (e.g., skiing) in association with existing forms such as walking and hunting. Watson conducted a variety of interviews with locals, counted 
recreational users, and made a series of observations in visually depicting the changes in use patterns over the study period. This type of research indicates that a spatial representation of use, over time, is an effective means by which to understand recreational use and therefore impacts and pressure.

A body of literature has been established that deals with attractions as part of the spatial activity-base of tourists. Attractions may be considered as foundations on which other aspects of the tourism system are developed (including transport, accommodation, facilities, and communication). Attractions can be of a socio-cultural, physical, or environmental nature and, depending on how they are presented or maintained, have an essential role in the success of the industry in a region.

Husbands (1983) drew a relationship between tourist space and tourist attraction in addressing the problem of the measurement of national attractions. He viewed the concept of attraction as having to do with actual levels and patterns of visitation. Attractiveness, on the other hand, has characteristics akin to an innate quality of place. The concept of place carries with it a subjective value, and is therefore difficult to measure in a quantitative sense. The implications of Husbands' work suggests that the marketing of a destination cannot be based on attractiveness alone, but must consider its "relative attraction among a set of competing destinations" (1983: 303). Marketing research, therefore, needs quantifiable data on attractions to aid in understanding what factors are important to tourists when they evaluate attraction choices (Fodness, 1990). Debate continues regarding the properties of attractions, both as objective and subjective features. Lew (1987) provides a review of literature and a framework in 
making an interpretation of these features. To Lew, research on attractions can fall into one of three broad categories:

Idiographic Describes the concrete uniqueness of a site. Sites are individually identified by name and usually associated with small regions. This is the most frequent form of attraction studied in tourism research.

Organisational This form does not focus on the attractions themselves, but rather on the spatial, capacity and temporal nature. Scale continua are based on the size of the area which the attraction encompasses.

Cognitive A place that fosters the feeling of being a tourist. Place is the attraction that gives off feelings of what Relph (1976) termed 'insider' 'outsider', or the authenticity of MacCannell's (1976) front and back regions.

MacCannell broke down the structure of attractions by suggesting that they are "empirical relationships between a tourist, a site and a marker" (MacCannell, 1976: 41). In disagreement, Lew (1987) chose to contend that under these circumstances (tourist/site/marker), virtually anything could become an attraction, including services and facilities. Leiper (1990: 381) added to the debate by adapting MacCannell's model into a systems definition:

A tourist attraction is a systematic arrangement of three elements: a person with touristic needs, a nucleus (any feature or characteristic of a place they might visit) and at least one marker (information about the nucleus).

This modified definition, however, still appears to be confusing with respect to the differentiation between attractions and facilities. Tourists visit facilities, facilities can be a nucleus within a broader system, and facilities are often marked by signs or other pieces of information. There is no meaning, therefore, that embraces the experiential element that differentiates attractions from facilities. 
The discussion of attractions and facilities is important to the outcome of this research. Further consideration will be provided for these concepts, in an effort to more appropriately define the parameters of the movement of tourists in the study area.

If, as Pearce (1987) has suggested, an explicit study of space is lacking in tourism research at the geographical level, temporal studies have been piecemeal at best. Walsh, Sanders and McKean (1990) argued that despite its obvious importance, travel time (as it applies to driving for pleasure, for example) has received little or no attention in the field of recreation. In retuming to the fact that tourism in itself is an extensive user of time, Bull (1991) has suggested that an individual can allocate time in three ways:

1. Pure tourism activities,

2. Travel to and from destinations, and

3. Unallocated time (presumably at home).

These components of time are similar to the five-stage recreational experience framework established by Clawson and Knetch (1966). The "pure tourism activities" component outlined by Bull is a reflection of the "on-site" criteria established by Clawson and Knetch; the "travel to and from destinations" of Bull are similar to Clawson and Knetch's "travel to" and "travel back" criteria; while "unallocated time" suggests a link between "anticipation" and "recollection" established by the latter authors.

Time allocated to travel can be considered to be either negative or positive. When given a negative value, tourists may wish to visit destinations that are geographically closer (Truong and Hensher, 1985). Time considered as a positive value, means that getting there can be half the fun (Cheshire and Stabler, 1976). In this case, tourists may wish to devote more time to the actual excursion, substituting this for less 
time at the destination(s). This application of time can inherently identify different types of travel groups based on the relative importance of the travel and stay components of a trip, as Campbell (1967) and Rajotte (cited in Getz, 1986) did previously.

Heron (1990) applied the differential use of three types of time to tourism analysis (listed below).

1. Sacred time: Time shared with others in the relationship of the community.

2. Profane time: Time that is measured (timetables, meetings, etc.).

3. Personal time: Time used for personal reflection or recreation.

Heron contends that "profane time" is practised by first world nations, while those in the developing world have emphasised "sacred time". Tourism has been a vehicle responsible for instilling "profane time" values on developing nations through the movement of first world travellers to these regions.

Time has also been studied by Bull (1991), in a touristic sense, as one of the three major constraints on tourism demand (the other two being money and political controls). Bull implied that there are relatively few products that demand the expenditure of scarce time and money more than tourism:

Whilst time is not an economically tradeable commodity - tourism suppliers do not 'receive' time from tourists in exchange for their products - the possession of a stock of disposable time, and the allocation of that stock to different tourism, and non-tourism, activities, constrains the ability of the tourist to do all the things desired, even if money is available (Bull, 1991: 35).

Fron' a purely geographical perspective, time is a function to be considered in relation to space. Due to the spatial nature of geography, and of tourism in particular, time budget research can be particularly revealing at the space-time level. The adoption 
of space-time methods in geographical research, however, has received limited attention. Goodchild and Janelle (1984) utilised Halifax space-time budget data to examine pattems of urban ecological structure. They, and Anderson (1971), acknowledge the cost in generating such data, both in time and money, as a real limitation.

The space-time budget provides a key link in uncovering disparities that exist when determining cross-disciplinary involvement in tourism studies. Tourism researchers who are non-geographers might not have the background to have heard of, or become involved in, space-time studies. Conversely, those who have used time budget studies (those, for example, in the recreation and leisure studies discipline) have not been geographers and have generally ignored the "where", while concentrating on the "when" and "what".

\subsubsection{Cone-Periphery}

Freidmann and Alonso (1974) described the core-periphery concept as characterised by a dynamic, growing central region, and a slower growing, or stagnating, periphery. The core is marked by high-growth potential whereas peripheral areas are often marked by declining rural economies with low agricultural production (loss of primary resource).

In a touristic sense, a classic example of the core-periphery idea can be found in Christaller's (1963) analysis of tourism location in Europe. Christaller wrote that tourism by nature avoids central places, but is drawn to the periphery reaching the natural resource base not found in cities. This idea has been further developed by a 
number of authors (Plog, 1977; Butler, 1980; Pearce, 1989). In particular, Battisti (1982) reflected on the principles established by Christaller on tourist space organisation. He noted that tourism is part of the continual process carried out by man in order to specialise and to diversify the exploitation of the soil. Battisti made reference to the distinction between peripheral regions and peripheral places. The first represents a wide range of possibilities in choosing a recreational place. The second indicates real destinations of tourist flows, where the "fruition of space for recreational purposes is accomplished" (Battisti, 1982: 60).

The core-periphery concept has also been applied to the analysis of adventure travel regions. Zurick (1992) suggested that the movement of adventure travellers in Nepal takes place through a complicated hierarchy of gateways. Tourists from the core move through an international gateway (semi-periphery), to a national gateway (periphery), and further to a regional gateway (periphery frontier), said to be the adventure region. Here, it is implied, traditional interests intersect with national development goals. This analysis, however, has other far-reaching implications. It is the intemational significance of tourism as an export agent that thrusts these frontier regions into the international marketplace. As frontier regions succumb to further intrusions, the uniqueness of these areas diminishes, as does the potential for travel to untouched areas in the future as these areas become fewer in number.

Turner (1976) and Tumer and Ashe (1975) implied that there is emerging one single global tourism periphery, stretching through Mexico, Florida and the Caribbean, to the Mediterranean; through East Africa, the Seychelles and India to Bali and Bangkok 
in Southeast Asia; through Pacific Islands like Fiji, Tahiti and Hawaii, to southem California and Mexico. Although this periphery is constantly evolving spatially (new and old destinations falling in and out of tourist favour), there is one associated certainty: core nations such as Canada, U.S., parts of Europe, Japan, and Australia have had a constant interest in both travel and investment within these peripheral regions. The dynamics of this capitalistic investment, to Husbands (1981), is intricately woven into the fabric of the tourism industry. For capitalism to achieve further growth, investment has to surface in new soctors and new places: "Tourism is...an example of such a new activity, and the peripheral space provided by it is an example of the production of space, and the further penetration of the periphery by capitalism" (Husbands, 1981: 51).

The relationship between core and periphery occurs at a variety of scales. Examples include small islands of the "south" controlled by the "north", to huge territories of the north, controlled politically, economically, and socially by decision makers of the core. The Northwest Territories has been identified by Keller (1987) as an example of a peripheral region caught in transition regarding the development of its tourism industry. To Keller, differing authorities in control of development in this region become important actors in both decision-making and implementation of a viable tourist industry. These hierarchies of control occur at local, regional, national, and intemational levels. As the sphere of tourism development moves to international, Keller suggests, the more the periphery has become "a playground for exogenous investors, and the peripheral government an observer of its own fate" (Keller, 1987: 25). It is stated by Keller that to avoid a transgression to the above scenario, the periphery (Northwest 
Territories) must act to control the decision-making in the development of a tourist industry, and limit the development to a scale of growth in tune with the resources, capital, manpower, and culture from within the periphery.

\subsubsection{Island peripheries}

Berry and Johnston (1986) began their natural history account of Shetland by stating that islands have a glamour - usually greater to outsiders than to those who live there permanently. King (1993) has described the appealing romantic and adventure character of islands as a type of "ambience"; attractive to geographers, biologists, anthropologists, historians, cconomists, poets, and painters. This ideal manifests itself through the appeal that islands cast, that relate to perceptions of the real peripheral "escape". Marketing, promotion, and the mass media have clearly defined the paradiselike character of tropical islands (sea, sun, sand, and sex) for tourism. However, remote archipelagos not embellished with trovical climes still manage to draw visitors looking for special, unique attributes (e.g., natural history).

Both Pearce (1987) and Wilkinson (1989) stress that a very significant proportion of internationdl travel occurs to island states, in relative terms - relative in that many islands, over the course of a year, experience visitors in numbers far greater than the indigenous population. The movement of thesc tourists can have a tremendous impact on an island's social and physical realms (e.g., crowding, noise, and pollution).

Insularity and smallness have an important bearing on the structure of tourism in island destinations. In particular, a small land area usually implies a less diverse resource 
base, while a small population means a limited domestic market. This, in turn, can give rise to a heavy reliance on foreign trade based on a limited number of products (Pearce, 1987: 154). For an island with a heavy dependency on tourism (as the primary sector), a steady or expected in-flow of foreign tourists will determine economic prosperity. This type of reliance is subject to a myriad of extemal motivational and socio-economic factors that can cause fluctuations in annual visitation.

Erisman (1983), Jenkins (1982), Britton (1982), Hills and Lundgren (1977), and Tumer (1976) suggest that it is important to realize that metropolitan airline and hotel chains have the greatest influence on tourist movements and undertake the most extensive advertisement campaigns. Sophisticated marketing programs, computerized reservation facilities and established trade links are powerful advantages that metropolitan interests possess over small independent companies. The vertical integration between airlines, tour companies, and hotels has further strengthened the power of the foreign tourism generators vis-a-vis the host country (Jenkins, 1982: 236). Foreign domination does not stop with airlines and hotels. Due to the inability of agricultural and manufacturing producers in most island economies to guarantee a quality supply of goods and services for international luxury tourist facilities, there is often a strong reliance on imported supplies for both the construction and operation of tourist facilities.

The volume of literature devoted to core-periphery theory and tourism development suggests that there is a deep-seated core interest in the tourism industry of peripheral, especially island, nations. The domination resulting from this reflects a relatonship that pits potential economic profitability against import substitution, cligopoly 
(Debbage, 1590), and fluctuating socio-economic external conditions. With these inconsistent circumstances, island destinations are especially prone to a life cycle that progresses through distinct stages.

In evaluating the tourism situation in Malta, for example, Lockhart and Ashton (1991) studied contact ratios (local population over tourist bed capacity). It was noted that less than eight local inhabitants for each tourist is an undesirable ratio and brings social and psychological problems for host societies (Andronikou, 1987). In Malta, the major tourist areas exceeded this critical ratio to such a large extent that the authors concluded that adverse effects such as visual and noise pollution were liable to affect the quality of ife of host communities. Changes to Malta have also been reported by Young (1983). This author illustrated that, from a community perspective, tourism can act as an invasive agent of change, transforming an economy from one based on traditional subsistance, to a service-oriented one reliant on the international tourist market.

Murphy and Andressen (1988) explored the notion of core-periphery as it applied to Vancouver Island. The authors studied the perceptions of residents and evaluated whether the core (Victoria) was willing to share its tourism market/business with the peripheral regions of the island.

In many tourist places, the core-periphery concept (from an economic perspective) may be different to that of Vancouver Island. The presence of a diversified economy may not place a region in a peripheral situation at all, even though, from a geographical and perceptual position, the place takes on a remote character. 
Travel regions are dependent on a variety of national and international markets, as well as their transport modes and schedules. As peripheries in an international context, many tourism areas may also show characteristics of a core-periphery relationship in an intraregional ccuctext. Main urban corridors offer a variable base of goods and services, and infrastructure typical of central places. The diversity of natural and historical attractions in the peripheral frontier, however, offers experiences to travellers markedly different than experiences to be gained in urban areas. Understanding the space-time movement between urban and peripheral regions is a means by which to measure differences between and within select travel groups. St:ch a measure may then have utility in drawing inferences on the importance of attractions in core anci periphera! areas.

\subsubsection{Tourist-Tourism Typologies}

Tourists, analysed over time, have different characteristics both as individuals and as parts of larger groups. Attempting to classify tourists through travel roles, motivations, or niches, may be considered a viable manner by which to identify tourist/tourism "types". Such schemes enable researchers to further categorize travellers based upon the type of experiences sought. The following section briefly examines a number of pertinent motivational/behavioral and social/cultural typologies.

Cohen has established two typologies by which to understand the motivational and behavioral orientations of tourists. His first (1972) was a typology oi tourists based on 
their relationship to both the tourist business establishment and to the host country. Tourists were grouped into four categories:

1. Organized mass tourists;

2. Indiviciual mass tourists;

3. Explorers; and

4. Drifters.

This typolcgy reflected a continuum such that the organised mass tourist is seen as the least adventuresome with little motivation to leave the confinements of his or her home environmental bubble. The drifter, in contrast, shuns the tourist establishment searching for the most authentic travel experiences.

Cohen's second (1979) typology takes a phenomenological view of tourists and their quest for the "centre" -- a zone of absolute reality. Five main forms of touristic experiences include:

1. Recreational,

2. Diversionary,

3. Experiential,

4. Experimental, and

5. Existential.

The idea of a phenomenological typology is important. It suggests that people travel for inherently different reasons, where a tourist's quest for the centre may ultimately change over the course of a particular vacation. This change may be related to any number of phenomena, including time, space, or finances.

Smith (1989b) created a multi-stage typology of motivational/behavioral character. Her typology is also a continuum classifying tourists from those seeking relaxation and good times in new but familiar environments (charter), to those desiring to interact with hosts, accepting local norms in different environments (explorer). Smith's model 
delineates tourists into various types: (i) charter, (ii) mass, (iii) incipient mass, (iv) unusual, (v) offbeat, (vi) elite, and (vii) explorer.

In addressing the :.otivations of travellers, some researchers have found that tourist expectations have been taken for granted (Iso-Ahola, 1982; Pearce, 1982). To Pearce (1982), stronger emphasis is required in linking roles and motivations with social and environmental preference, in order that destinations could be better matched with markets, travel expectations, and accommodation. Iso Ahola (1982) suggested that travel motivation is purely psychological and not sociological in nature. He argued that people travel for basically two reasons: (i) to seek intrinsic rewards (novelty), and (ii) to escape their everyday environments (escape). These two motivations may be sither of a personal nature (personal troubles or failures), or interpersonal (related to co-workers, family, or neighbours). The amalgam of these elements is a four-cell matrix, where a single tourist could theoretically go through one or all aspects during the course of one trip.

Of relevence to the discussion of motivation is the work by Pearce (1993) who formulated a comprehensive review of the fundamentals of tourist motivation. Pearce argued that people have a career in terms of their tourist behaviour which changes during levels or times of their life cycle. Designed after Maslow's hierarchy of needs, the travel career tapestry of Pearce involves five motivational levels:

1. a concern with biological needs,

2. safety and security needs,

3. relationship development and extension needs,

4. special interest and self-development needs, and

5. fulfilment or self-actualisation needs. 
Pearce implied that not only could people be prevented from travelling by money, health, or other people, but they may also retire from the travel career altogether.

In considering the cognitive needs of tourists (perhaps in relation to those needs outlined by Maslow) MacCannell (1989) developed a framework of the social structure of tourist space based on front and back regions. Front regions are those readily open to the visitor and a place where hosts and guests meet. Conversely, back regions are the preserve of the host and are essentially non-tourism oriented in their function. Tourists in search of authenticity penetrate back regions in the hope of securing the authenticity of real day-10-day existences of residents. This concept has clear implications for small peripheral island regions in terms of the core-periphery concept. To what degree tourists are willing or able to penetrate back regions - in identified access zones of tourism areas - may be important to their achieving their overall purpose. Although these "places" are actual locations in the conventional economic/geographical context of core-periphery, in the mind of the tourist or tourist group, they may in fact be interpreted ("places") as mental constructs. In this case, the intended attraction/region takes form as a "perceived" core. Conversely, other "attraction-less" attractions/regions, perceptually, may be considered as peripheral in the context of the overriding purpose of the vacaction. If fishers, for example, are unable to fish certain lochs they may nut secure their central purpose or expected reality. These fishers, therefore, may be forced to angle in what might mentally be a perceived periphery (another loch).

Much has been written on the nature and the consequences of interactions (positive and negative) of hosts and guests as the fundamental premise underlying the 
tourism system (Smith, 1989a). It has become apparent that there are a myriad of destinations, attractions, facilities, and transport options to satisfy the need for intrinsic rewards (and to escape mundane environments). Broadly categorized, tourists socking the same experiences may be partitioned into groups based on shared characteristics. With increased mobility, time, income, and access, mass homogenised travel has burgeoned. At least partly as a reaction to this, there has been a movement of travellers looking for something new. Conversely, this search for the "different" also may be an inherent feature of humanity.

Irrespective of the reason, tourism has blossomed with a rich array of terms describing different types of vacation experiences. However, virtually no research is available to systematically arrange or describe "types" of tourism in a theoretical or conceptual framework. The literature supports reference to tourism in many ways: mass, conventional, adventure, ecotourism, alternative, farm, rural, hostel, urban, peripheral, and so on. In fact over 90 types of tourism have been identified in the past two decades (Boyd, 1991). As types of tourism have increased in numbers, so too have participants in tourism.

\subsubsection{Tourist Pressure and the Capacity to Accommodate Tourism}

Pressure was defined earlier (section 1.2) partly in the context of the activities and spatial-temporal characteristics of tourists on a region. Tourist pressure can have certain direct social, environmental, and economic impacts on hosts. There is a large body of tourism literature devoted to impacts (Mathieson and Wall, 1982; Getz, 1983). Smith 
(1990) defines an impact as any verifiable change in the well-being of humans, or the ecosystem on which human survival depends, resulting from human action. Measuring impacts is not the main purpose of this research; however, this study will provide a vehicle in the form of a conceptual model to describe the implications of the movement of tourists in selected access zones in the study area, which should have general applicability. A brief discussion of the types of impact follows.

\subsubsection{Social}

As tourist visitation increases, the number of tourists may equal or exceed the number of locals in a destination area. The implications of this social encroachment are such that tourism frequently enters and affects the lives of local inhabitants. A notable impact of tourism on traditional values is the demonstration effect (Britton, 1977; Hope, 1980; Mathieson and Wall, 1982). Local patterns of consumption change to imitate those of tourists. Alien commodities are rarely desired prior to their introduction into host communities and, for most residents of destination areas, such commodities can remain tantalizingly beyond reach (Rivers, 1973). The conclusion may often be a host resentment of tourists as enchantment declines (Doxey, 1975).

\subsubsection{Environmental}

As tourism increases, visitation may place certain stresses on the physical environment of the destination. Typically, man-made resources can absorb the onslaught of tourism better than natural environments. Understanding the differences in 
sustainability of different environments and determining appropriate tourist numbers are of prime importance to the tourism industry. Almost inevitably there will be some degree of impact on any physical resource base from tourism. The success of planning can be assessed in terms of the ability of managers to minimise, as far as possible, these disturbances. Many of these tourism effects are universal, but their intensity and severity are more noticeable in small, and especially insular, settings. Islands, because of their small size, often have tenuous floral and faunal vitality. Tourism can stress these systems and visitation at peak times can often exceed the ability of the natural ecosystem to recoup from such stress.

\subsubsection{Economic}

As the volume of visitation increases (and with it, associated tourist spending), so does the accumulation of capital. This accumulation (apart from inherent leakages) can ultimately stimulate certain aspects of an economy. It is these economic benefits (e.g., jobs, foreign exchange) that must be balanced against physical/social effects. Tourism, in specific locations, can grow at phenomenal rates of 10 to 25 per cent and higher per annum (Wolfe, 1966). Limiting growth to a lower, more sustainable level should be a goal of managers/locals/government, in order to reduce yearly and seasonal visitation fluctuations, and contain or reduce physical and social impacts. It is, typically, those smaller destinations with limited economic diversity that come to rely most heavily on various forms of tourism (sustainable or unsustainable) and become most vulnerable to economic downturns. 


\subsubsection{Carrying capacity}

A wealth of literature exists on the carrying capacity concept, steinming from the work of recreation and resource management practitioners of the early 1960s (Lucas, 1964; Wagar, 1964). This work intensified through the 1970s and 1980s resulting in the development of a series of conceptualisations, including the Limits of Acceptable Change (McCool, 1989a, 1989b), Recreational Opportunity Spectrum (Driver, Brown, Stankey, and Gregoire, 1987), Visitor Activities Management Process (Graham and Payne, 1988), and the POLAR model established by Butler, Fennell and Boyd (1992a) emphasising the importance of management, users, and the environment. From its recreation and resource management beginnings, there has be $\mathrm{n}$ a slow but gradual acceptance and utility of the carrying capacity literature by researchers interested in tourism (Butler and Waldbrook, 1991).

The effects of visitation on a destination have prompted researchers to evaluate the capacity of areas to absorb tourism (Mathieson and Wall, 1982; Getz, 1983; Catton, 1987), defined as the amount of use of a given kind a particular environment can endure, over time, without degradation of its suitability for that use, or reduction in the quality of the experience.

Both Miossec (in Pearce, 1987) and Young (1983) modelled the structural evolution of tourist regions through space and time. In the early phases of tourism, there is little or no development. However, as the tourism industry expands, an increasingly complex system of transportation, resorts and social behaviour evolves into a need for planning to control acute changes to the host community. 
Butler (1980) addressed the notion of carrying capacity as it applied to a tourist area's life cycle. He stated that an increase in visitation to an area can be followed by a decrease in this visitation as the carrying capacity of the destination is reached (due to either the capacity of the site, or the response of tourists to perceived overcrowding).

More recently, researchers have focused on deriving empirical measurements of this evolution of a destination, especially island environments (Meyer-Arendt, 1985; Wilkinson, 1987; Cooper and Jackson, 1989; Debbage, 1990; Weaver, 1990). The utility of the life cycle concept has implications in delineating carrying capacity limits, and the social and environmental complications of "over-usage" in islands. Clearly defining the nature and characteristics of use of these areas must be a priority.

Defining and operationalising social carrying capacity is complicated by the necessity of considering management objectives, the effects of use on environmental quality, and the effects of use on user and host desires and expectations (Wall, 1982; Stankey and McCool, 1984; Edington and Edington, 1986; Haywood, 1986; O'Reilly, 1986; and Pitt and Zube, 1987). The findings of Butler, Fennell and Boyd (1992a) and Butler, Fennell and Boyd (1992b), in an extensive review of literature, concur that the concept of carrying capacity requires adept management. No mythical figure exists for limiting the amount of use in an area. Managers might consider normative values in understanding levels of expectations, satisfaction, dissatisfaction, and crowding with respect to different types of users. 
A case in point where visitation is annually increasing beyond the limits set by management personnel is the Galapagos Islands. Groot (1983), Arcos et al. (1988), and Kenchington (1989) call attention to the fact that:

1. Patrol boats do not always control tourism numbers on the islands effectively.

2. The official limit of $\mathbf{9 0}$ tourists on an island at a time is often overlooked.

3. The number of tourists is still increasing. Total visitation has not been, but should be, kept under control.

These researchers suggest that tourism numbers have been controlled ineffectively and inappropriately through airport capacity limits rather than by limits set in accordance with acosystem sensitivity defined by park planning and management. Thus, even in a well known and highly significant area, problems of overuse and visitor management still arise.

A discussion of tourism-related impacts on a region needs to be considered in light of the following question: if the benefits of tourism in economic terms clash with potential sociological and environmental impacts, will residents perceive conflict or pressure? Brougham (1978) measured the social impact of tourism on the residents of Sleat, Isle of Skye, Scotland. He discovered that:

1. tourism impacts were both positive and negative (contrary to expectations, resident perceptions of negative impacts tended to decline as interaction increased), and

2. variation exists in the degree to which different subjects of the population are affected.

His conclusions noted that impact studies needed to be site specific and framed in the context of a number of factors, including social, environmental, and economic 
components, and the interplay of scale in terms of accessibility, development and the willingness to embrace tourism.

As a relatively isolated geographic region, the area chosen for this study (Shetland) provides a suitable case in which to examine tourists. The identification of tourism-generated impacts and the movement of tourists in prescribed zones, coupled with an analysis of the core-periphery concept, is felt to be valuable in formulating a more holistic view of the dynamics of different tourist groups in an area over space and time.

\subsection{INVESTIGATIONAL PROCEDURE}

The model to be used in this study is introduced in chapter two. This framework provides a basis for the representation of tourism in Shetland. Space-time, coreperiphery, regions and the implications of social, environmental, and economic impacts are elements of the model that pertain directly to the focus of this research.

Chapter three provides a background to the study area. General information is first provided on St:- udnd's geographical position, climate, population, and employment patterns. A discussion of travel up to World War II provides an indication of how Shetland was regarded and came to be acknowledged as a tourist destination. A review of post World War II tourism follows to aid in comprehending Shetland tourism in a more contemporary sense. Similarly, selected current statistics are included in order to illustrate visitation, accommodation, and transportation aspects of tourism. Six hypotheses are generated by the researcher -- in the context of the conceptual framework 
-- which apply directly to the focus of the analysis. Study limitations are considered at the end of this chapter.

The methodology, described in chapter four, involves an enhanced description of the techniques utilised to gather data in Shetland. The triangulation approach is discussed and applied through four techniques as noted previously: a space-time budget, a questionnaire, interviews, and observations. Sampling procodures, as they apply to different techniques, are also discussed in this chapter.

Chapters five, six, and seven contain the results of the triangulation methodology. A variety of statistical measures are applied to explain where, and for how long, different tourist groups interact in the four regions of Shetland. In addition, different analytical measures are used to evaluate the qualitative (interview and observation) data.

Chapter eight is devoted to the implications of the results of the study. Comparisons and contrasts are made with past research, in addition to the different approaches and techniques used in this study. A number of conclusions are drawn that pertain directly to the future of Shetland tourism. Lastly, there is a discussion of the validity of both the methodology and the conceptual framework, and their utility and application to other island tourism case studies. Chapter nine, Conclusions, provides an overall summary of the dissertation.

\subsection{CONCLUSION}

Research devoled to tourism studies has intensified over the past decade. Yet, as many researchers have insinuated, there is a dearth of research in all of the aspects 
of the tourism system. While it has been found that no one model or definition of tourism can incorporate all the elements of the tourism system -- whole systems models attempt to organise many of the components, actors, and impacts of tourism into meaningful relationships.

Despite the complexity and contribution of the tourism models discussed in this Chapter, for the most part, they have been based more on the characteristics of the trip than on the tourists themselves. Research, therefore, has fallen short of structuring typologies on criteria that may offer new insight into the dynamic nature of tourism and tourists. Instead of focusing primarily on aspects of the trip, future research nceds to incorporate bro ider concepts such as space-time and core-periphery in understanding the concept of tourism types. This research attempts to pull a number of tourism-related and geographically-related concepts from past research together, in an effort to understar d the time and space characteristics of different travel groups in Shetland. 


\section{Chapter 2}

\section{A MODEL OF TOURIST PRESSURE}

For my part, I travel not to go anywhere, but to go. I travel for travel's sa:ie. The great affair is to move.

Robert Louis Stevenson

\subsection{INTRODUCTION}

The past discussion regarding the theoretical foundation of tourism revealed that there exists a sound foundation of quality research in the tourism field. Yet concern has mounted over the noul for tourism studies to conceptually diversify and improve (Getz, 1986; Mitchell and Murphy, 1991). The interdisciplinary nature of tourism, and the difficulty in creating established definitions, means that the body of literature, models, and linkages required to cover the phenomena need to be broad. From a strictly geographical perspective, Pearce (1987) has identified a large spectrum of tourism-related research areas that need to be addressed (e.g., international, regional, domestic, and island tourism). This chapter presents a theoretical framework that is both sensitive and responsive to some of the needs and queries put forth in past literature. 


\subsection{THE EVOLUTION OF A THEORETICAL MODEL}

The prior description of tourist typologies is useful in coming to grips with the motivations and behaviour of Shetland visitors (Cohen, 1972; Butler, 1980; Iso Ahola, 1982). Each provides a foundation by which to understand the movement of tourists in time and space, and the accommodation, transportation, facilities, and attractions sought by such travellers while in Shetland.

The "q:iest for centre" outlined by Cohen (1979) has other pertinent implications to this researci: Where this reality exists for tourists in Shetland is a matter of psychospatial determinants: what tourists want can be measured, at least partially, in terms of the tine and location characteristics of their travel. This concept also relates to the front and back regions delineated by MacCannell (1989). It will be argued that the further tourists penetrate into the back regions of Shetland -- whether urban or frontier -- the more existential, in MacCannell's terms, and authentic their experiences may be. Smith (1987) identified the need for tourism researchers to concentrate on the analysis of tourism regions as a still underdeveloped field of study. The utility of a functional perspective has also been explored by Smith (1989: 183): "Functional regions are based on the notion that one can identify a set of tourism regions by examining patterns of personal travel". Such regions can be determined by the interconnections of a spatial system (e.g., transportation). Other researchers including Pearce (1987), Jakle (1985) and Murphy and Keller (1990) have argued for research to be intensified at the meso (regional) level.

Klaric (1992: 305) maintained that the establishment of tourism regions is 
necessary in almost all countries for the purpose of organisation, marketing, and data analysis. That author outlines three different types of spatial organisation (regions) applicable in both developed and developing nations.

1. Administration units:

2. Special interest areas:

3. Combination:
The most common in nations with advanced regional administration units (Austria, France, Italy, Spain).

A model applicable to nations where tourism is developed only in exclusive areas. Suitable for lesser developed countries (Indonesia).

Combines the first two models, and is appropriate for states where tourism is spread throughout the whole nation, but with marked concentrations in certain areas.

An example of this third category is Scotand, where the Scottish Tourist Board has established seven tourist regions: The Highlands and Islands (including Shetland), The Northeast, East Central, the Clyde, Edinburgh and the Lothians, Borders, and the Southwest. In Shetland, eleven such regions have been established.

In considering the movement of tourists in Norway, Flognfeldt (1992) has illustrated that present regional statistical data are not suitable for the planning of the tourist industry. He notes that information about hotel arrivals or bednights gives little insight into travel to or in a region. Due to the fact that tourists have different patterns of movement within regions, an intraregional analysis of tourists is more appropriate. Flognfeldt advocates the use of data generated through consideration of day trips, resort trips, round trips, types of accommodation units, commercial and free attractions, and systems of linkage (transportation). He also considered the use of secondary data sources including sales lists from tour operators, exit questionnaires, and daily attraction figures; 
in essence, surveys conducted at as many different places and routes as possible.

A number of indices have evolved to address problems regarding the spatial distribution of tourists within regions. The "Main Destination Ratio" (Leiper, 1989) attempts to differentiate between destinations within a nation or nations. Pearce and Elliot (1983) developed the "Trip Index" as a tool with which to define the spatial distribution of tourist travel within one country. Oppermann (1992) stressed, however, that the Trip Index includes only one of several factors needed for a more complete understanding of international travel behaviour (i.e., the importance of one destination with respect to the whole trip). Oppermann proposed the use of a "Travel Dispersal Index" (TDI) as a method to gain a more complete picture of the movement of tourists within a region. Five variables were used in the TDI.

1. Length of stay in the country,

2. Number of overnight destinations,

3. Number of different types of accommodation,

4. Number of different types of transportation, and

5. Travel organisation (package, individual).

Such an index is felt by that author to have utility both as a segmentation device, and as a method by which to determine tourist typologies. A drawback of the TDI, however, is its inability to adjust the absolute point ranges of variables to different countries with different visitation patterns. Oppermann recognised that since a country like New Zealand has a longer length of stay average than other nations, some form of weighting based on a combined linear scale may be more appropriate. The type of data required for the TDI compares closely with the data to be collected in this study. 


\subsection{THE MODEL}

Figure 2.1 is a representation of the spatial and temporal characteristics that may pertain to both individual tourists and to groups of tourists in any type of touristic locale. The model is an attempt to provide a framework to allow researchers to accurately assess and compare the movement of different tourist groups over space and time. Furthermore, it incorporates a perceptual component that associates traveller's space-time behaviour as a measure of the mental preferences that particular groups maintain in regard to attractions and regions of any study area.

The vertical time axis of the model represents 100 per cent of the time that a group spends on its vacation (one complete trip) in a region. Correspondingly, the access locations represent 100 per cent of the spatial movement of the tourist group over the course of their vacation. Therefore, if particular types of tourists spend 50 per cent of their time in one region (i.e., core), the other 50 per cent of their vacation time would be spent somewhere in the other two access zones (transition and/or periphery). In addition, the longer a tourist group spends at a particular zone (location), the greater the implications to that area regarding social, environmental, and economic (S.E.E.) impacts.

The above factors (time, space, S.E.E.) are central to the core-periphery component. Normally an economic theory, core-periphery is considered in the context of this sudy both as a locational construct and as a mental construct. As illustrated in the model, core-periphery is deemed variable in light of the various tourist groups under consideration; some tourists may wish to travel further out to the periphery in order to secure their touristic experience. To these travellers, it is suggested that the experience 


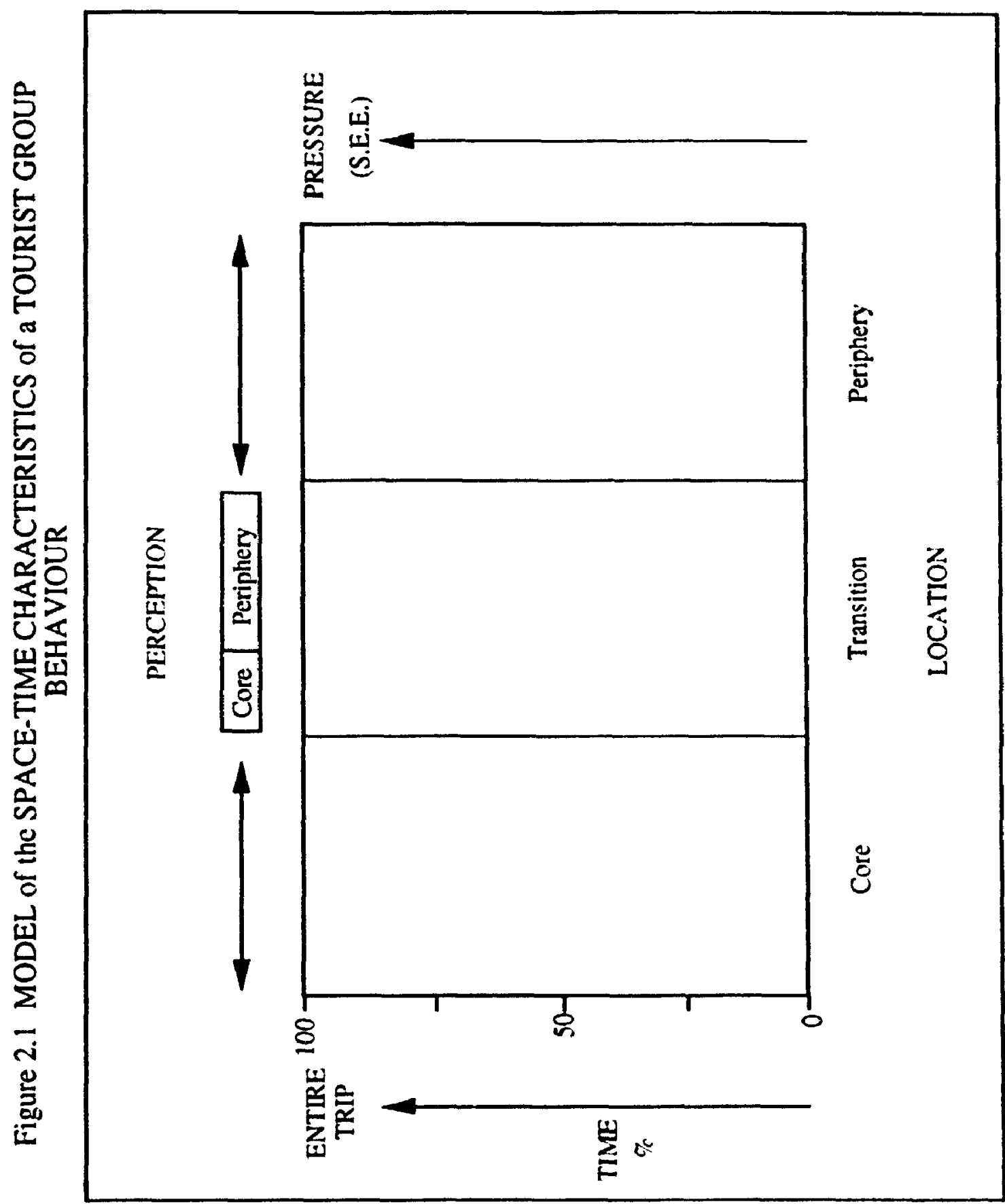


is the core itself -- the zone of absolute reality established by Cohen (1979). Although this is not a perceptual study per se, it is still important to know how core-periphery "essences" change between different tourist groups depending on their inherent activitybased motivations.

Consequently, if birdwatchers (for example) find that their attractions lie in peripheral areas, travel to these areas (their "core") may not fall under the same geographical laws as, for example, the gravity model and distance decay theory imply. Conversely, the urban mainland may be the location more often chosen by another type of tourist group. In this case, the urban mainland would represent both the mental and locational core to this group, while marginal areas would represent the mental and locational periphery.

Mark (1981) was concerned with the universal inverse relation between distance and human interaction. He discovered that for certain types of spatial behaviour (e.g., birding), the attractivity of a destination is positively correlated with distance. Mark discovered that for birders, the further away a place is, the more attractive it will be since it is likely to have a greater number of potential new birds to be listed. Although it is safe to contend that birders have more disposable income than the average individual (Kellert, 1985; Applegate and Clark, 1987; Butler and Hvenegaard, 1988; Fennell and Eagles, 1990), the attractivity associated with distance may be seen to cancel out the inverse relationship between interaction and distance normally induced by travel costs (Mark, 1981).

The core-periphery arrow running horizontally along the top of the model in 
Figure 2.1 depicts the hypothesised degree to which a particular tourist group perceives the core and periphery. This indicator can be useful as an explanation in gauging the perceptions of tourist groups in terms of the "existential centre", by drawing inferences about this perceived centre through the quantifiable activity-based characteristics of the tourists' space-time dimensions. From this perspective, core-periphery is considered location independent of behaviour, and as a mental construct, dependent on preferences and behaviour.

\subsection{CONCLUSION}

The generic model introduced in this chapter provides a foundation for the analysis of different tourist groups in any number of touristic locales, from the perspective of space-time, core-periphery, impacts, and perceptions. The following chapter gives an in-depth description of the study area and the utility of the generic model to the Shetland archipelago. 


\section{Chapter 3}

\section{STUDY AREA}

The use of traveling is to regulate imagination by reality, and instead of thinking how things may be, to see them as they are.

Samuel Johnson

This chapter provides an introduction to the physical and human characteristics of the Shetland region. Travel in Shetland is reviewed from the late 1700 s to the present, through an analysis of themes associated with pre and post 1945 tourism, and selected Shetland tourism statistics.

\subsection{THE SHETLAND REGION}

Travel north far beyond the Pennines, farther north than the Scottish Highlands; leave the stormy Pentland Firth behind and you will come to the land of the Simmer Dim, a large group of islands straggling over 70 miles of seaway; as near to Norway as to Aberdeen; reaching past latitude 60 degrees to draw level with Greenland's icy tip, Cape Farewell. Here are green brown hills, scarred with the dark of peat hags, and splashed with the fleecy grey of diminutive sheep. Look east, look west, and there is the sea.

These are the Shetland Isles, more than 100 of them, about twenty inhabited; and this is as far north as you can go and remain in Britain. 
The Gulf Stream ensures an equable climate. Mild winters with long nights are enlivened by spectacular displays of the Northern Lights, the more bright because the air is crystal clear. The cool summers have remarkably short nights in midsummer; nights that are never totally dark; this the Shetlanders call the Simmer Dim (Higgins, 1971: 13).

This description of Shetland by Higgins provides a sound backdrop to the study region. An overview of the characteristics of Shetland is provided in this section, based on data contained in the Shetland Islands Council's Shetland in Statistics (1992).

Shetland lies to the north of the Scottish mainland, occupying a total land area of 1,468 square kilometres (Figure 3.1). The capital, Lerwick, is located at latitude 60 9' north and 1 9' west, and from this point Aberdeen is $338 \mathrm{~km}$ to the south, while Bergen, Norway lies only $360 \mathrm{~km}$ to the east. The Shetland climate is moderated significantly by an off-shoot of the Gulf Stream known as the North Atlantic Drift. In 1991, the maximum mean temperature was 9.7 degrees Celsius, with the yearly mean minimum being 5.4 degrees C. Also in 1991, the month with the highest mean temperature was July at 15.7 degrees C. (February held the lowest mean temperature in 1991 at 1.0 degrees C). Wind and rainfall have a significant impact on the archipelago. Historically, the wettest month in Shetland has been November, and 1991 was no exception (190mm of rainfall). The month with the least amount of rainfall in the same year was May, with 33mm. The monthly mean wind speed (knots) from 1951 to 1985 was 14.0, with a monthly mean of 13.5 in 1991 . Also in 1991, rain was recorded to have fallen in 253 days.

The human population of Shetland has fluctuated considerably over the past. A hundred years ago the population of the Shetlands was double its current level 


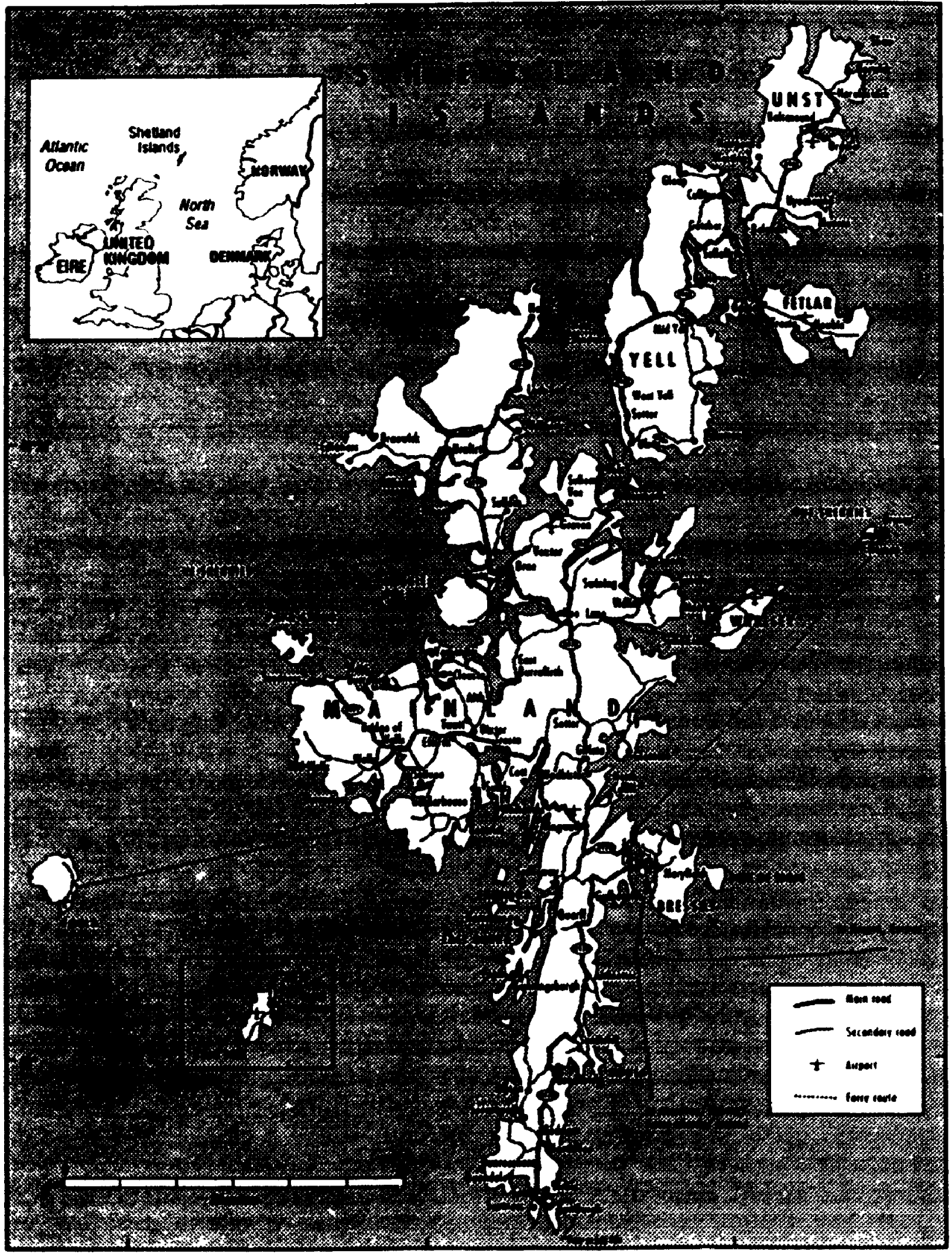

Cartographir Section, Dept. of Geography, U.W.o. 
(McCormick, 1974). Population figures over a forty year period showed a decline from 21,131 inhabitants in 1931 , to 17,812 in 1971 . From the low 1971 figure, population increased to 23,130 in 1981 , and to 23,214 in 1989. Despite this reversal (caused primarily by oil-related development), there has been a recent out-migration of youths looking for opportunities in larger centres. In his quotation, Higgins (1971) mentioned that Shetlanders inhabited "about" 20 islands. Nicolson (1984) states that the Shetland population, in the early 1980s, was scattered over 17 islands. In 1991, the number of inhabited islands was 15 (SIC, 1992).

The above figures seem to echo the contentions of King (1993) related to the propensity of islands, in the global context, to follow an established cycle of landscape change:

The first [stage] is the creation of an intensely-humanized landscape by the build-up of population over time, and espocially during the nineteenth and twentieth centuries. The interconnection between restricted space, dense population and an advanced and elaborate agriculture is a triadic theme repeated in many islands. The second phase is the abandonment and decay of this landscape through emigration and other forces. The third phase is the initiation of a new cycle of landscape transformation by the growth of tourism in the last few decades.

The fact that Shetland has been able to achieve a balance within the economy is reason enough to believe that the third of King's phases has not, so far, been universally entrenched in Shetland as the preeminent economic force. However, statistics (to follow) illustrate that tourism in Shetland is increasing relative to other secturs of the economy. In Shetland, most people (1971) were employed in the service industry (44.8 per cent). This percentage jumped to 59.4 per cent in 1981 , and then to 55.1 per cent in 
1991. Tourist accommodation, for example, represented 6.8 per cent of the total number of employees in 1991.

Shetland's geographical position, at a crossroads in the North Sea, has spawned a very unique human and environmental legacy. The Shetland history of sequent occupance is dynamic as early Europeans, Picts, Vikings, and Celts were all able to carve out an existence in this region. Berry and Johnston (1986) contend that the influence of Viking settlement is still an important characteristic of the Shetlander. The present population of Shetland maintains both a strong psychological and genetic link with Scandenavia. Shetland (like Orkney) was given to Scotland by the King of Denmark as part of the marriage dowry of Margaret, his daughter, to Prince James of Scotland in the fifteenth century. Scottish rule soon resulted in changes that interfered with old Norse laws. A persistant transformation of culture followed as Scottish landowners purchased large parcels of land. In order to pay the rent on these landholdings, the local population became tenents, put to work at sea and on the land as parttime crofters to help lairds pay such rents. The transition further created both a spirit of dependence and a dislike for Scottish rule that has survived to the present day.

A theme that has remained constant over time is the influence of the sea on the livelihood of Shetland. As a remote, peripheral culture, Shetlanders depended solely on the sea for trade (one can go nowhere in the Shetland islands and be furtt : than five kilometres from the ocean). It is the influence of the sea/land continuum that is ingrained in the hearts and minds of Shetlanders to such an extent, that it appears in their place names, their songs, and their verse. The following poem compiled by a 15 -year- 
old native of the archipelago (Blance, 1963: 15) reinforces the strength of the man/land tradition in Shetland:

This land, a warm and friendly home, For all who live beneath its dome. So cool and blue its shimmering waters; So brown, yet clear its flowing streams. Once yearly here I stray and roam, And watch its breakers pound and foam. On rocks, so warm and crushed with age, And waves, that die from tempest rage. To loving ripples on sand of gold, So nature tells its tale of old.

The North Atlantic Drift harbours a unique diversity of sea life including scals, otters, fish and a myriad of resident and migratory bird spocies. As Britain's most northerly outpost, Shetland has been described as holding potential in invoking a certain romance as a travel destination. To know Shetland, is to know something of the majesty of a region molded from a climate that can be relentless and unforgiving.

Norsemen came to Shetland during the second half of the 9th century and contributed much to the industry and culture, largely through their practices of agriculture and fishing. Later, during the 14 th century a fishing trade link was organised with Merchants of the Hanseatic League. These merchants rented bods (booths) by which to trade their food, alcohol, clothing and other goods, with the local Shetland fisherman, who offered the resources of the sea.

In the 16th century, Dutch fishermen began to regularly visit Shetland in an effort to tap the rich populations of herring. The Dutch also traded with the Shetlanders at Lerwick, a town that was coming into its own as the dominant economic centre of the islands. The herring industry attracted visitors well into the 20th century: "In 1905, 
there were 174 herring stations throughout Shetland which produced over one million barrels of herring for export to Europe" (Shetland lslands Tourism, 1992).

Shetland also catered to a regular and substantial flow of whaling ships operating in the North Sea from the 1600s onwards. In 1618 the Dutch whaling fleet agreed to assemble in Shetland before sailing further north, and by the mid-1700s British participation in arctic whaling slowly began to intensify (Flinn, 1989). The whaling industry was important to the economy cf Shetland as ships took on provisions as well as eligible St:etlanders as crew (Lubbock, 1937), and continued as a viable industry for Shetland up until the mid-20th century (Butler, 1994).

The Shetland archipelago continued to be an important geographical centre in the present century (beyond its importance as a trading outpost), during the two World Wars. In World War I a naval base was established in the north mainland (Swarbacks Minn), and in World War II the region of Sullom Voe was established as a Coastal Command base. Shetland became an integral part of the allied forces' efforts in the North Sea, related to the rescue of allied personnel, civilians, refugees, as the headquarters for the Norwegian resistance movement, and as a base from which to ship supplies and protect shipping routes (Howarth, 1985).

Oil was discovered in the North Sea in the early 1960s and because of Shetland's position, it was inevitable that deposits would at some time be brought there for further transhipment (Butler and Fennell, 1992). Exploration began off Shetland in the early 1970s, and air and sea supply bases for the industry were quickly developed in Shetland, along with the largest oil terminal in Europe, at Sullom Voe (operational from: 1978). 
With the oil industry involvement in Shetland on-line, the onomy of the islands changed markedly. A detrimental aspect of ihis industry surfaced, however, in the form of a shortage of labour for local industries such as fishing, agriculture, knitwear, and tourism. The supply of Shetland tourist accommodation in the 1970s was largely given over to the oil firms for the purpose of housing crews flying from the mainland to the offshore rigs during the development period. From the perspective of pleasure tourists, commercial flights to Shetland were difficult to obtain because of the volume of use by oil personnel. As a result, the tourist industry suffered tremendously for appreximately a decade (Butler and Fennell, 1992).

In a positive context the Shetland economy prospered and diversified as a result of the involvement in the oil industry. Spin-off effects included the modemisaton of communications, facilities, accommodation, road systems, and transportation to the overall region, as well as intra-regionally (air and ferry travel). In addition, a series of leisure centres were created in a number of communities to provide an opportunity for local residents to enjoy new leisure-related pursuits.

Shetlanders have managed to survive over the years using the abundant resources of sea "nd land through traditional industries including fishing, knitwear, crofting, and agriculture. However, non-traditional industrics suchi as oil, salmon farming, and tourism have emerged in the last 20 years to transform, in a generally positive context, the economy and the people. Heterogeneity of this sort has been a necessary requirement in order to face challenges brought on by many of the debilitating forces that limit and control peripheral regions. 
A brief look at the legacy of Shetland illustrates that the people, the history, the climate, and the environment interplay as factors that shape the character of Shetland. They are all, each of the above, "lions" that have been experienced by travellers for centuries, but never more frequently than through the tourist industry that has been established to this point in time. As defined by The Concise Oxford Dictionary (1976: 632), "lions" were once considered as "the sights worth seeing in town etc. (from [the] custom of showing country visitors the lions formerly kept in [the] Tower of London)". The term "lions" then, is to be considered here as an umbrella concept, encompassing the Shetland tourism industry: attraction, facility, transportation, and accommodation features that support touristic demand. It will be left to discover from the research which are the lions that are able to draw the attention of individual tourists and tourist groups, in Shetland, both in space and time.

\subsection{A HISTORY OF TRA VEL IN SHETLAND: BEFORE 1939}

Writing on the evolution of tourism in the North of Scotland, Butler (1985) suggested that up to 1750, the Highlands and Islands were virtually terra incognita to the people of the rest of Britain. The Shetland region was no exception. Yet Shetland, as a consequence of its unique position, provided both a geographical and cultural link with Scandinavid to the east, and Great Britain to the south. The contentions of Berry and Johnston (1980) stated earlier concerning the glamour of islands represent an ideology that may explain the historical movement of visitors to Shetland. Flinn (1989) suggests that before 1850, the people who travelled to Shetland were artists, geologists, 
naturalists, physicists, physicians, surveyors, and fishermen. Butler (1985) supports this observation through his description of the first tourists to the Highlands of mainland Scotland from 1746 to 1810 : "Almost all of the early visitors had a serious scientific or economic or religious-educational interest in the country" (Youngston, cited in Butler, 1985: 375). These were voyages of discovery, not brought on by increased disposable income or time, but through exploration challenged by the temporal and spatial limitations of such travel. Flinn contends that after 1850, the nature of the Shetland visitor was somewhat different:

By 1850 Shetland had a frequent steamer service from the south during the summer months, and a trunk road system which made the islands more accessible to tourists of a less hardy and enterprising breed than some of the earlier travellers (Flinn, 1985: 235).

Some of these accounts are presented below, in order that the reader may gain a basis for the understanding of why such travellers felt the need to experience th. : remote region. Particular attention will be paid to travel accounts that reference attractions and specific areas of Shetland.

This chronology reaches back to a manuscript written by Ker in August of 1780 . Ker was a surgeon, and provided detailed descriptions of Lerwick and the Shetland inhabitants (included were sketches of Noss, Scalloway and Lerwick). His log makes reference to the barren nature of Shetland, and establishes that the only trees were to be found in Scalloway:

Here were several willows, horse chessnuts [sic], and planes between 12 and 16 feet high. On the wall of the garden near the sea they were laid down by the wind. The eddy of wind over the top of the wall destroys annually the young shoots as they rise (Ker, 1780: Aug. 22). 
There is no reference, though, as to whether Ker actually moved throughout Shetland, or rather was given notice of the fact that no other trees existed in Shetland. Scalloway, during this period of time, was one of the only villages accessible to Lerwick by road (Scalloway being the historical capital of Shetland, and close to Lerwick).

It is impressive to note the detail with which many of the early Shetland travel accounts were written. In a letter written to a friend in 1797 (Anon.), a number of observations were made concerning the Shetland seasons, women, feudal system, gardens, mining, farming, horses, inhabitants, but mostly of the wildlife:

Plovers, whapes, ducks of several kinds, snipes, starlings, sparrows, larks, doves, lapwings, \&cc, used to visit this spot in greater quantities then they do at present. Swans, herons, and wild geese of several kinds winter here, and retum in autumn...Seals and otters frequent the shores; the rivers abound with trout, \&ec, of a delicious flavour (Anon., 1797: 44).

In 1804, a printer and naturalist ventured to Shetland by the name of Patrick Neill. His book (Neill, 1806) focuses heavily on a description of the inhabitants, in addition to noting the inaccuracies of current charts and maps of Shetland:

It would certainly be worth the attention of Government to cause a nautical survey of these islands to be made, with the same minuteness and accuracy that the Orkney's were laid down in the admirable charts of Murdoch MacKenzie (Neill, 1806).

If problems existed for travellers in finding Shetlard, this would soon change. In fact the notoriety of the region would soon become stenciled in the minds of a vast readership. In 1814, Sir Walter Scott visited Orkney and Shetland and used these islands as the setting for his novel "The Pirate", published in 1821. Simpson (1983) chose to 
benchmark the emergence of this novel as a starting point for his discussion of the modern era of tourism in Shetland. Simpson referred to Scott, then, as the first tourist:

If he [Scott] went somewhere and later used the scenery for that place as the backdrop to one of his novels, then the scenery there became suffused for his readers with the same romance and drama as the novels, and the readers wanted to go and see it for themselve: (Simpson, 1983: 137).

Patrick Neill, mentioned above, provided the illustrations that Scott was to use in "The Pirate" which added to this romantic attraction of Shetland.

In 1821, a recent Oxford graduate and naturalist, Walter Calverley Trevelyan, went to Shetland on route to complete a geological survey of the Faroe Islands. Trevelyan's unpublished diary was compiled by West (1964), who discloses that Shetland had had an increase in the number of writers in the 1820 s, probably as a result of the publication of Scott's "Pirate". According to West, Trevelyan was overtly impressed with the hospitality of the Shetland people:

In Lerwick, Trevelyan was approached by no fewer than two native poetesses, who had volumes of verse to sell. A Miss Campbell pleaded to him to buy a volume at her 'reduced price of $6 /$ - per copy, to the strangers who visit Zetland, and who may be disposed to throw away so much money.'" (West, 1964: 32)

Apparently Trevelyan too was disposed to throw away his money. Flinn (1989) writes that Trevelyan was the son of an English Baronet and the heir to a fortune worth 5,000 pounds a year. Trevelyan nevertheless, recorded his expenditures and these are found in West's article. The whole Shetland stay cost Trevelyan, in pounds, 8 10/- (he stayed from May 10 to June 4). Other typical expenditures included:

* Hen: 8/d

* Eggs: $1.5 d$ to $3 d$ a dozen

* Lodging: 1/- for his bed 
* Breakfast: 1/-

* Dinner: $1 / 6$

* Supper: $1 /-$

* Horses: $1 /$ - to $1 / 6$ per day

Samual Hibbert visited Shetland for a considerably longer period, and his legacy lives on in his writings of Shetland, in particular a geological survey entitled, A Description of the Shetland Islands. Comprising an Account of their Scenery, Antiquities. and Superstitions (1822). However, as the title suggests, this book is more than simply a geology; it is a keen observation of the Shetland region. In order to complete his task, Hibbert visited most parts of the Shetland archipelago over a six month period. Throughout his travels, he was constantly dependent on the hospitality of the Shetlanders. To this end, he was quite reflective:

He who may wish to explore the most secluded parts of Shetland, and to proceed with a true spirit of independence, will find no difficulty in inducing to cottagers to accept of an adequate remuneration for receiving him beneath their roof (Flinn, 1989: 91).

Hibbert's descriptions of regions are magical, often intermingled with a composite of classical literature; in this case Dryden:

As from a steep and dreadful precipice, The frightened traveller cast down his eyes, And sees the ocean at so great a distance, It looks as if the skies were sunk beneath him. If then some neighbouring shrub, how weak soever, Peeps up, his willing eyes stop gladly there, and seem to ease themselves and rest upon it.

This citation is referenced in Hibbert's description of his trip to the Noup (a high cliff overlooking the sea) of Noss:

I now passed to the highest point of a rock named the Noup, which is a dreadful perpendicular precipice, $\mathbf{4 8 0}$ feet above the level of the sea. The 
surge beneath is not contemplated without terror, and to a native rose that attaches itself to the srevices of the rock, a peculiar interest is attached by the Shetlanders, which may have originated from the cause that has been so beautifully explained by Dryden (Hibbert, 1822: 111).

In 1832, George Clayton Atkinson, an ironmaster and naturalist, travelled to Shetland aboard the boat the Magnus Troil. His motivation for travel to Shetland may be summed in his own words as follows:

I have long felt the greatest interest in descriptions of novel and extraordinary scenery, and of the inhabitants and natural productions of regions which have been little known, either from the difficulty of attainment or investigation; or - like many things of great domestic interest - from their being so near to us, as to have been overlooked.

Perhaps Atkinson was referring to Scott's "Pirate" in writing of "descriptions of novel and extraordinary scenery". It is interesting to note Atkinson's reference to the close proximity of Shetland to the British mainland. With the extent of transportation at the time, a trip to Shetland may have taken a week depending on the weather. Travellers were also at the mercy of what were called "regular" services to Shetland. Flinn provides an account of the shi os that travelled between the mainland and Shetland:

The first regular packet service between Leith [Edinburgh] and Lerwick was established by a Post Office contract in 1758 ... The contract called for a packet boat to sail on the first of the month 'wind and weather serving' from Leith, and from Lerwick alternately (Flinn, 1989: 1).

Two such ships included the Lerwick Packet and the Coldstream Packet. Both travelled to Shetland during the early 1800 s:

The Coldstream Packet, an 87 ton Berwick sloop built in 1794, served on the Leith-London route from 1797 to 1811 after which she was sold to $R$. Stones, and from 1812 to 1822 she sailed about six times a year between Leith and Lervick. She was lost with all hands in November 1822 (Flinn, 1989: 2). 
Other ships soon replaced these, mostly in response (as Flinn contends) to the need for a regular postal service to Shetland. As time, and the 1800 s wore on, ships to Shetland were more numerous and the frequency of their round-trips increased.

Atkinson also indicated something of the nature of his business in Shetland, and the joy to be engaging with some of the most hospitable people of the world:

...how was it possible that anything should occur to dis-organise the angelic dispositions of three sanguine young men, in high health $\&$ spirits, within a mile of the scene of their intended exertions, bearing with them the best introductions to the most hospitable people in the world, plenty of fish sauce, guns, books, bully's, clothes, dissecting knives, materials for making pinch, chessboards, \& 1 ... (Atkinson, 1832: 9).

Shipments of such materials were keenly welcomed, in addition to the news of the outside world that accompanied these cargos. Such a dependency played an important part in the lives of Shetlanders.

In July of 1832, the Magnus Troil carried a first-year medical student to Shetland by the name of Edward Charlton. In his diary, Charlton referred to Shetland as "the savage north" (Flinn, 1989). Charlton travelled extensively in Shetland (Mainland, Unst, Foula, Papa Stour), and eventually returned two years later with his cousin. One of the main reasons for his visiting Shetland is revealed in the following excerpt from his diary:

Monday July 30 . Went out about ten a.m. to shoot plovers on the hills to the south-east of Gloup. Killed four plovers and two snipes; the latter appear to be larger and lighter coloured than those of England. Also shot a whimbrel or two, and hunted the wild sheep with our dog Oscar.

Tuesday July 31. Shot some parasitic gulls about Whalleray and Netherton. In the evening collected a few specimens of gamets in the geniss, below the house of Gloup (Charlton, 1913: 189). 
This type of behaviour was repeated during his second voyage to Shetland in 1834. Flinn writes that the "journal of his second visit is dominated by accounts of bird shooting. His enthusiasm for the slaughter makes his journal less pleasant to read than his first joumal" (Flinn, 1989: 190).

While most of the previous accounts are based on trips of some length to Shetland, Catherine Sinclair (daughter of Sir John Sinclair, compiler of the "Old Statistical Account of Scotland") based a book, Shetland and the Shetlanders (1840), on a weekend visit to Shetland in July of 1839 . Sinclair was one of the first to take advantage of a retum voyage on the Sovereign, as a round-tripper (nineteen hours voyage one-way). Her book reflects upon elements of Orkney, and Fair Isle. However, the bulk of her discussion focuses on Lerwick (due obviously to her tight schedule!). The difficulty of domestic travel in Shetland was very evident in Sinclair's time. It seems that because of the unavailability of roads, carriages were used little:

The only road in Shetland goes six miles towards Scalloway Castle, and we are told that but one gentlemail ever had a carriage here, when he used to drive his wife several times up and down the whole distance, to give her an idea what a joumey means (Sinclair, 1840: 101).

Sinclair also made reference to the hospitable nature of Shetlanders (observed in several of the accounts illustrated in this review). For any type of interaction with outsiders, "proprietors and merchants kept open house for all strangers without exception".

The most striking account made by Sinclair, however, was the following teleological/deterministic view regarding the intellect of the northern (Shetland) gentry:

The cold winds here assist in sharpening people's intellects a propos to which I am about to start a perfectly new philosophical theory on this very subject! Warm climates certainly do enervate the mind, as we see that the 
lowest scale of intellect prevails in Africa, China, and the West Indies. Italy and France are greatly inferior to England; Scotland excels them all, and even our great magician, Sir Walter Scott, before writing his Pirate, or his journal, took a sharpening in Shetland. Now this all combines to prove...that peculiar acuteness should be expected in minds nearest the pole...Common phraseology favours my discovery, as every man who makes too clever a bargain with his neighbour, is said to be 'too far north of him' (Sinclair, 1840: 117).

What is also intriguing in this account, is mention of Scott by Sinclair. It illustrates how ingrained his work was in the minds of subsequent Shetland travellers.

Among past visitors to Shetland were members of the Clergy interested in the state of Shetland Christianity. Due to the remoteness of Shetland, these visits were not at all frequent. Visits to the outer isles of Foula and Fair Isle were even less frequent. Clergymen travelled the length of Shetland to many of these remote conmunities, which proved to be uncomfortable and drawn-out, as a Free Church Minister writes in September of 1845 :

We traversed the wild swamps of Lusetter, and had the most fatiguing walk I ever remember to have had, through a perfect wildemess of bogs, whose universal blackness is only relieved by tufts of heather and stinted, sickly moss. Even the Shelties could not accomplish a journey over the hills of Hell, and at every step or two you have a long leap from one knoll to another, across the intervening slough; and this mode of progression we had to accomplish against a furious headwind, with driving sleet and rain, for nine Shetland miles. The same expenditure of physical exertion would carry one over 50 miles of regular pedestrianism.(Anon., 1975).

The weather seems to have been a constant reminder of the rugged remoteness of Shetland. Poor weather, poor seas, poor intemal transport, and limited infrastructure were all regularly recorded characteristics of the Shetland experience at this time. 
As the frequency of visitors increased to Shetland, so too did the number of recorded accounts. In these accounts are clues to some of the unique features of Shetland, other than the standard attractions visited in the past (Lerwick, Scalloway Castle, Noss, and Unst). By 1861, James Wilson, on a tour through the islands of Scotland, wrote of the ancient fortification on the island of Mousa:

The Pictish tower or burgh of Mousa, well known as the finest and most entire example in existence of that peculiar and very ancient style of structure, stands imposingly on a green and swelling slope, immediately above some lowish rocks... We believe the origin and design of these eroctions are involved in darkness, although they perhaps derive additional interest from their mysterious nature and remote antiquity....Mr. Barclay thinks that these towers were the strongholds of a Pirate race (Wilson, 1861: 281).

What is interesting about this account is the reference to Mousa Broch as being of Pictish origin. No further progression is made, though, with respect to the identification of characteristics of the Pictish time period. Similarly, no information is provided on the importance of this archacological feature as an attraction to travellers.

The link between "travel" and "tourism" in Shetland became more pronounced in 1870, as illustrated through Benjie's Tour in Shetland in the Summer of 1870 (Anon., 1870). After making reference to Scott's "Pirate", this small book provides some very pointed remarks regarding what might be considered an overall tourist account of Shetland in relation to Orkney. The usage of the terms "tourist" and "guidebooks" establishes the fact that Shetland, as a tourist destination, was firmly established in a conventional sense. Whatever the accounts suggest up to this point (apart from Sinclair's), these voyages were for purposes other than - or in addition to -- strictly pleasure (admitting the fact that this chronology is in no way close to complete with 
respect to all historical accounts). Those other purposes being especially related to natural history, geological, and religious aspects. Although lengthy, the following passage adequately reinforces this point:

Tourists who are bent on 'doing' Shetland as per guide-book had better stay at home; at least, they need not go so far for grand rock scenery. There is nothing in Shetland equal to [with reference to Orkney] 'the Old Man of Hoy' and the stupendous precipices in its neighbourhood--nothing artificial to match Kirkwall Cathedral, Maeshowe, and the Stones of Stenness. And with all the wildness of its waters, I never encountered in Shetland, nor any one else I believe, foaming billows and cataract currents to equal those of the Pentland Firth. It is not this place and that place in Shetland which impresses the visitor, but the unique character of the climate and scenery as a whole... The tourist who uses his eyes only when the guide-book tells him will never understand or appreciate Shetland (Anon., 1870: 15-16).

The author moves to an account of the particular sights worth seeing in Lerwick:

In speaking of the 'lions' of Shetland, therefore, I would have it understood that the excursionist will do a very stupid thing who confines his attention to the objects of interest he is told to look for... You may visit all the lions of Lerwick in a forenoon (Anon., 1870: 16).

The attractions in Lerwick that are referenced include Fort Charlotte, the Museum, seabirds, and the Anderson Institute (Arthur Anderson, a Shetlander, was a co-founder of the P\&O, one of the largest shipping lines in the world). According to "Benjie", there is nothing else worthwhile to see in Lerwick. It seems, therefore, that by setting expectations on attractions outlined in interpretive literature, a traveller might be unimpressed. The pleasures of travel to Shetland, according to "Benjie", are to be found in the climate, the people, and by chance.

In a sociological and topographical account in 1871, Robert Cowie refers to Shetland as a tourist destination in the broadest terms: 
In 1858, the steamer (a screw) commenced to run all winter, as well as summer; and, in 1866, a bi-weekly boat was added for the summer months. With these facilities for travelling, the number of tourists and businessmen visiting Shetland has greatly increased. (Cowie, 1871: 149)

John Green in 1894, touring through the Orkney and Shetland Islands, found much to comment upon with respect to the Shetland tourism industry:

There are only two hotels, the Royal and the Queen's; but there are in audition numerous lodging-houses, very often full to overflowing in the tourist season, a circumstance easily accounted for when we consider that in 1885 the St. Rognvald--the largest and most powerful steamer owned by the Company-landed in one trip over 500 passengers, nine-tenths of whom were tourists (Green, 1894: 12).

Further that:

To the tourist I say this: among the many items of peculiar interest to be found in the Zetland Archipelago, don't miss seeing the Muckle Flugga [Shetland's most northerly lighthouse]; and if possible get a view from the top of Saxa Vord hill on a clear day.

The wild sublimity and appalling grandeur of the Shetland scenery cannot be surpassed in the whole of Europe, and is perhaps only equalled on the north-west coasts of Norway (Green, 1894: 27).

Note the contrast here with the previous ivicount ("Benjie's Tour"). Both of the above tourists travelled to Orkney and Shetland, yet both write differently on the quality of their experiences. It seems that Green may have gon: 'urther afield than Benjie and thus achieved a better overall perspective of Shetland's outerlying attractions.

Nothing in these past accounts has been mentioned about the promotion of attractions to tourists. Both Orkney and Shelland, being northern extensions of the British mainland, would share in the struggle to attract the tourist market. This competition was evident then, as it is now. 
The advertisement and promotion of Shetland evolved slowly and in response to the needs of the industry and travellers. Simpson (1983) felt that a number of useful publivations (for visitors and Shetlanders) appeared from the mid-nineteenth century onwards. Simpson references the Zetland Directory and Guide, with Road Map, from W.R. Duncan; Orkney and Shetland Almanac and County Directory, and Handbook to the Shetland Islands, by W. Peace and Son, in and after the 1860s; and John R. Tudor's The Orkney and Shetland Islands; their Past and Present State, published in Lor.:-n i1883, as prime examples. However, the Guide to Shetland, by Thomas Manson, published in 1932 and several times afterward, to Simpson, "was something very special".

Figures 3.2 to 3.5 provide excerpts from the 1936 edition. Figure 3.2 is an introduction to the major sections of the guidebook. There is a description of Lerwick, Trout Waters, Birds, Flora, Geology, Archaeology, and Trout and Sea Fishing. These attractions are virtually the sarıe sperial interest attractions outlined in the 1992 "Accommovation Guide" and Official Tourist Guide" publications. Little, therefore, has changed in Shetland with respect to the types of experiences promoted to travellers to Shetland over this time period. Adverisements are included on the services offered by the Grand and St. Magrus Hutels, and steamer transport (Figures 3.3, 3.4, and 3.5).

In the 1930s, two accounts of Shetland were composed by Andrew O'Dell (Professor of Geography at Aberdeen University). The 1932 manuscript briefly explores some of Shetland's geographical characteristics:

It is an illuminating exercise to trace the 60 degree north parallel and to diseover that this passes through or near, iewick, Cape larewell (South 


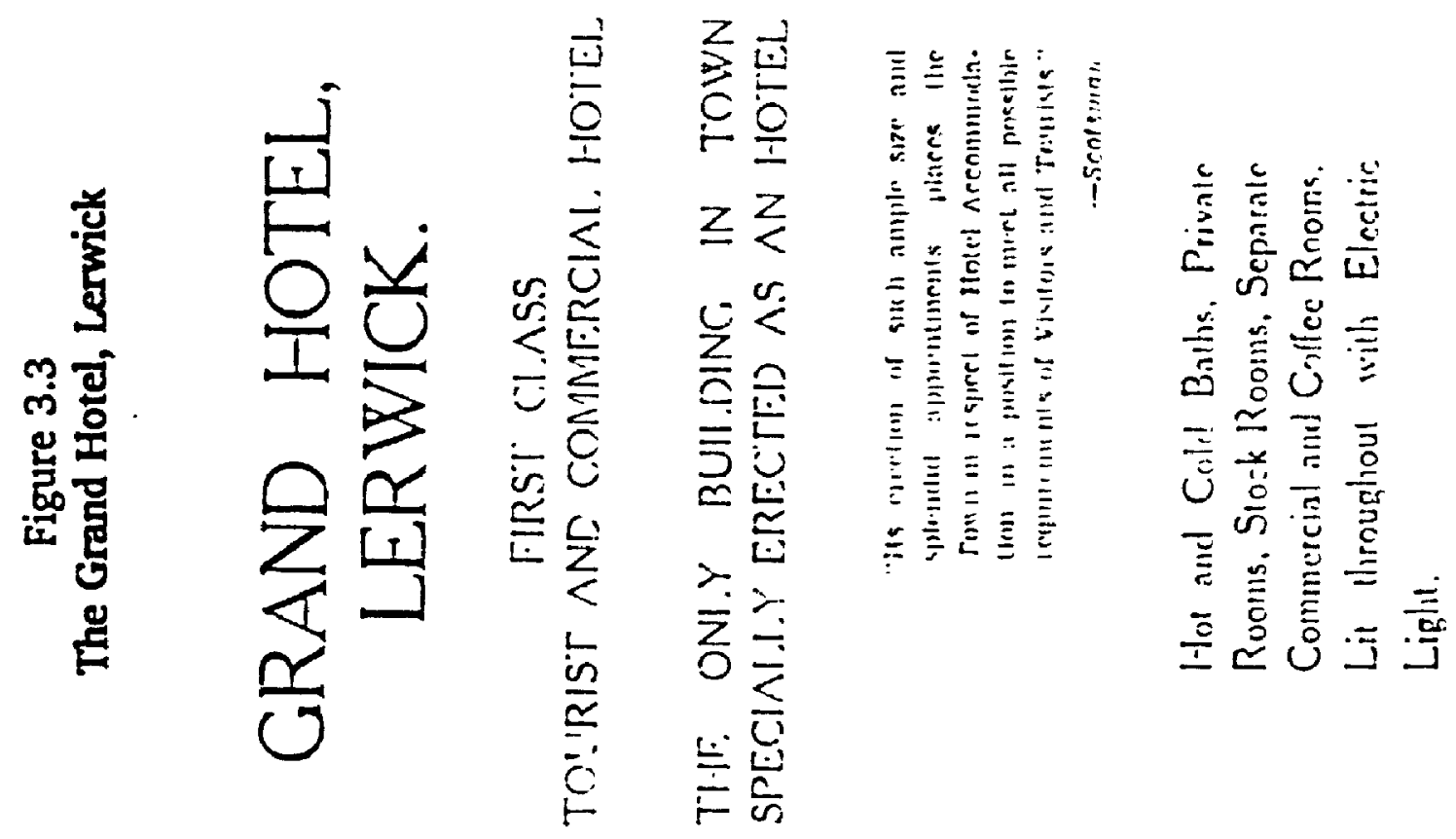

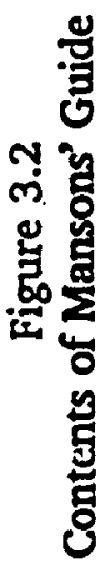

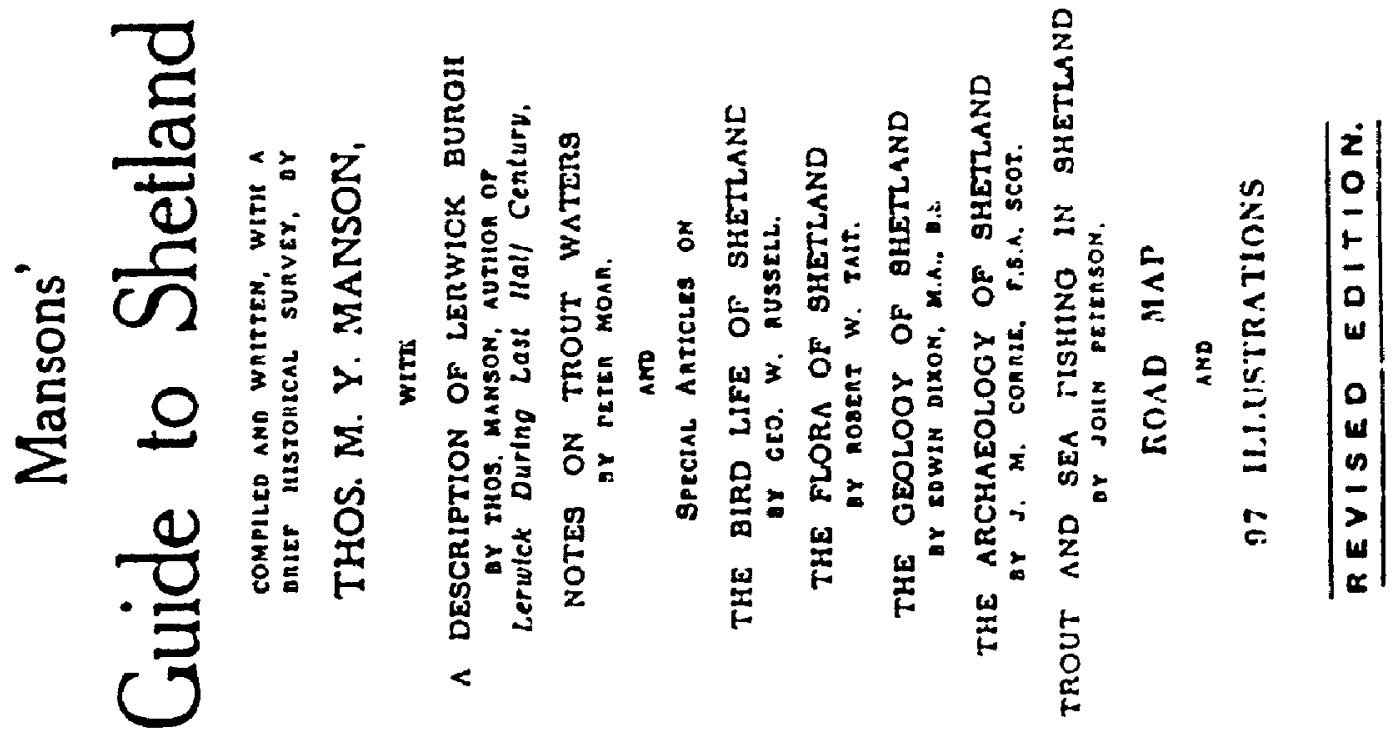



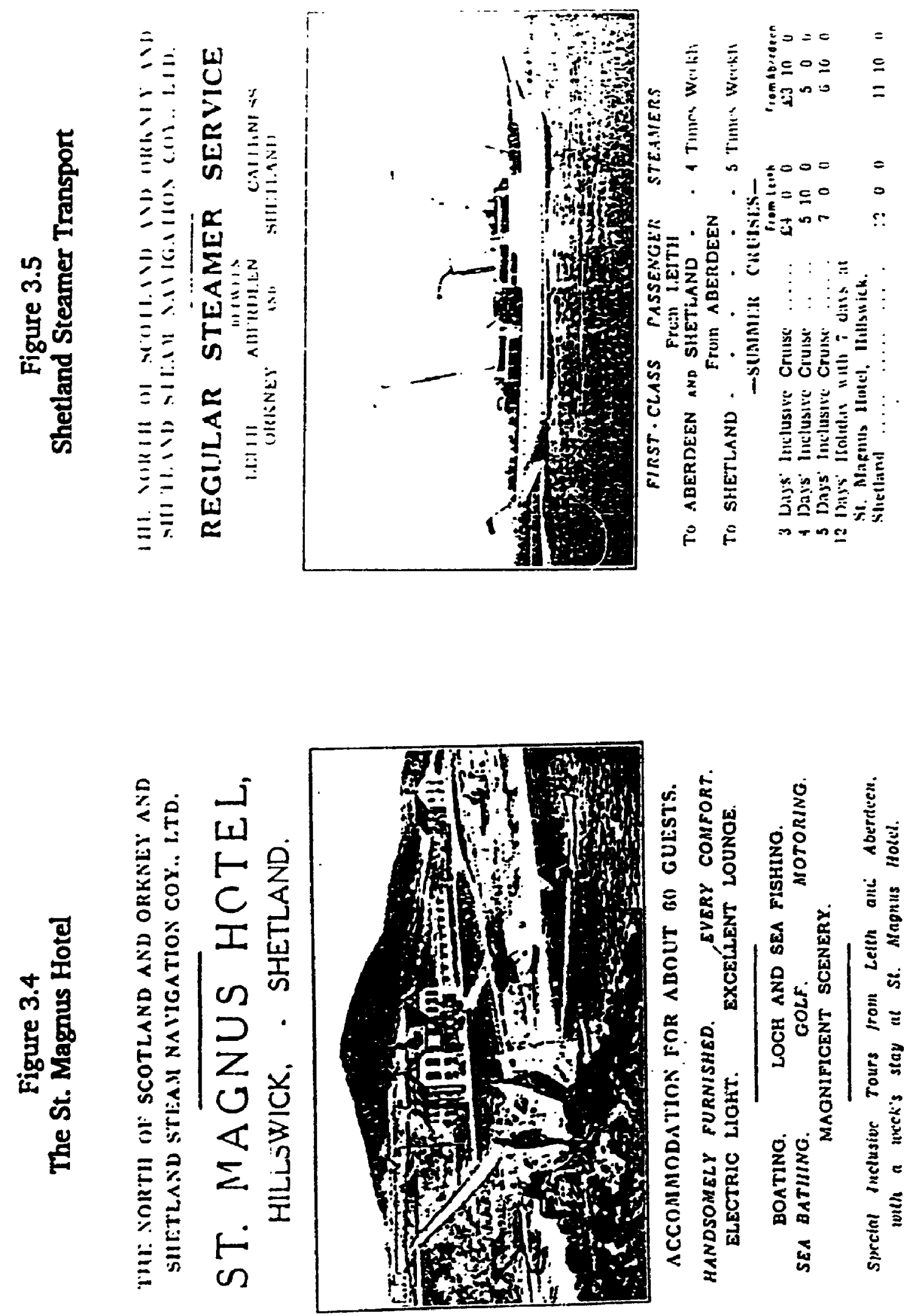
Greenland), Kenai Peninsula (Gulf of Alaska), Okhotosk (Kamchutka Province), Leningrad and Oslo.

As a result of this approach to the Arctic Circle, Shetland is the land of the 'Simmer Dim'; it being light enough at midnight in midsummer to play games and to take photographs. This indescribable twilight has well been likened to:

'A dream, a deathless memory, that gathers glory more and more'(O'Dell, 1932: 14).

O'Dell though enhances his Shetland geographical perspective in a 1939 historical account. Here the author devotes a chapter specifically to the tourist industry:

The modern development of the industry dates from the beginning of this century. The Grand Hotel dates from this period, and together with the Queen's, provided and provides accommodation for the traveller who is not prepared to forego the outward signs of civilisation.

The improvement of communications has given the traveller the ability to cover the ground more rapidly. By means of a motor car it is possible to penetrate easily to the furthermost portion of the Mainland in a day (O'Dell, 1939: 223).

O'Dell's rationale for comment on the modern era of Shetland tourism differs significantly from that of Simpson's (who referred to the Scott period in his argument).

As a comparison, Simpson's account deals more with the initial acknowledgement of Shetland as a destination, through the work of Scott. Transport to Shetland evolved and increased as a response to the travel demands to the region. O'Dell's interpretation, on the other hand, emphasises the establishment of infrastructure for the heightened level of demand. This coincided with the provision of easier transport to Shetland, and within Shetland.

O'Dell travelled extensively in Shetland in compiling his regional geography. Attractions of interest to him included Noss, Foula, Fair Isle, Scalloway and Weisdale 
(for their attractiveness), and Hillswick, Eshaness, Northmaven, Ronas Hill, Hermaness, Saxa Vord, and Muckle Flugga. In concluding, O'Dell wrote that:

Shetland is attracting visitors in search of the relatively simple life, and also the tourist who is anxious to "do" the islands in a day trip from a liner. Both are supplying a much reeded revenue to the islands, but as yet, the islands are not so sophisticated as the Gael, who too often regards the visitor as a person to be mulcted for simple services (O'Dell, 1939: 227).

The account is informative as it provides a reinforcing explanation for the motivational character of travellers at this time. Gone, it seems, are the intrepid travellers of the past. The arrival of the "new-age tourist", interested in the "been there, done that" experience of the Sinclair round-trip of 1839 is fortified here, and intensified over the period of 100 years. The quotation also alludes to the concept of mulcting, or swindling, that appears to have evolvor in other British holiday regions. Past accounts told of the trustworthy, gentle and hospitable nature of Shetlanders. This is a quality of apparent consequence to travellers then, and one of importance to tourists since.

\subsection{POST 1945 TOURISM}

By the late 1950s, it was not only the visitors writing on behalf of the Shetland tourist industry, but Shetlanders themitives. As an industry gaining momentum, concern over the need for planning was exercised in a 1958 issue of The New Shetlander:

Now we siall have to make a job of tourism. building on such firm foundations that, in the future, the industry cannot be wrecked by statutory regulations, Tourist Boards, restrictions on capital expenditure, or other methods adopted by governments to impoverish outlying areas. 
Ve must rely on three main assets: our traditional link with the vikings, our traditional kindness to strangers, and our traditional traits of strong individualism (Smith, 1958: 19).

Smith went on to suggest:

Let our motto be surprise, delight, intrigue, and in this spirit we may even surprise ourselves by building at least one successful industry (Smith, 1958: 20).

The author was making a distinct plea for change in Shetland. A diversification away from traditional industries such as crofting, fishing, and wool, for a chance to organise and implement an industry for the future of the entire region.

Organisation apparently was not of critical consequence, as a later article in The New Shetlander examines. The author complained that it was next to impossible to find any accurate statistics on the tourism industry. Also, that the value of tourism to Shetland must rely on future inferences:

So much nonsense has been spoken about the tourist industry that it is perhaps time for someone, an interested amateur, of course, to try to determine the relative importance of the industry in Shetland'? economy (Anon., 1963: 11).

The article advocated a need for change in how the Tourist Association (founded in 1958) was funded, and how it handled information exchange. Improvements were required of roads, toilets, signposting, parking, drinking establishments, and the quality of food: "good weather is a help, but good food is a must."

The New Shetlander published another article on the tourism industry (McNicoll, 1975). The author explores the economic impact of tourism to Shetland, largely based on statistical information gathered in 1971. The following are some of the findings presented in the article: 
* In 1971, there were 14,000 tourists in Shetland.

* Tourists stayed, on average, ten days.

* Tourist spending amounted to 0.5 million pounds.

* Of this expenditure, half was spent on accommodation.

* Tourism contributed between 1 and 1.5 per cent of the total household income.

* Tourism has the potential to dramatically increase in the future.

McNicoll concluded by stating that tourism was, at the time, relatively unimportant in Shetland, but that it held potential as a potentially lucrative source of income.

The two previous articles illustrate that by the early 1970 s, tourism in Shetland was starting to come of age. The first issue of Shetland in Statistics emerged in 1974. This publication utilised a data base involving social, economic, yolitical, and geographical information. Among this information were some rudimentary data on tourism (Shetland Islands Council, 1974).

* Number of people calling at the Tourist Centre: 5,619.

* Number of British visitors: 13,777.

* Foreign visitors: 1,506 .

* Tours organised to Shetland: 229.

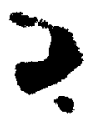

More information, however, was required in addition to more investment, and better development. One of the major stumbling blocks to long-term success was the presence of the oil industry. Some of the problems and successes of the tourism industry in Shetland are documented in the following post 1945 analysis. Three distinct periods of tourism development are highlighted (Butler and Fennell, 1992): 
A. The development of tourism, 1945-1970:

During this period the tourism industry initiated marketing and promotion through the newly established Shetland Tourism Organisation in the late 1950s. Significant improvements occurred in ferry services to Shetland, but internal movements were restricted between larger centres due to limited internal corridors.

B. Tourism and oil development, 1970-1982:

With Shetland acting as the transhipment point for oil rig crews, there emerged a heightened demand for all available accommodation. Block booking of hotels was common in order that oil companies would not have to fly workers back to Aberdeen. One implication of this guaranteed cccupancy was a demand for permanent staff. Tourists, however, found it increasingly difficult to obtain accommodation and conventional tourism declined or at best remained static in so areas. Ultimately this demand resulted in improved tourist relater facilities and infrastructure.

C. Tourism, 1981-1991:

The opening of the Sullom Voe oil terminal in 1981 ended the oil boom along with the oil-related demand for hotel accommodation. In the wake of oil was a mis-perceived image of a scarred Shetland landscape, later confirmed by the oil tanker disaster of January 1993 (Wills and Warner, 1993). The Shetland Tourism Organisation has worked in the past decade to rekindle an appreciation for the natural and historical attractions of this region. Marketing has been intensified 
further through the promotion of omithology, archacology, nature reserves, trout fishing, sea angling, diving, crafts, and festivals, all of which are potentially sound foundations for a thriving tourism industry.

The evolution of the conventional tourism infrastructure in Shetland created the impetus for better organisation. The value of tourism as a non-traditional industry was recognised and integrated fully within the existing economy.

\subsection{SHETLAND TOURISM STATISTICS}

In the early 1980s visitors to Shetland tended to be either students, graduates, academics, or professionals. The reason for visiting the islands varied, but was generally based on a sense of adventure, nature, and/or special interest (Mullay, 1983). Writing on behalf of the Shetland Tourist Association, Mullay also suggested that cost was an important factor in limiting travel to Shetland. These factors combined, represented then a very narrow market segment.

In 1984, a Draft Tourism Development Plan was undertaken (Shetland Islands

Council, 1984). It was noted that six main difficulties needed to be resolved with respect to Shetland tourism. These problems were:

1. The high cost of travel to and from Shetland.

2. The limited range, quality and distribution of accommodation.

3. The neal to develop the range of attractions and activities for the visitor.

4. The question of environmental pollution and rubbish.

5. The very short holiday season which creates problems for the trade. 
6. The lack of knowledge about where Shetland is and what it has to offer.

In an article devoted to an analysis of the Development Plan, Nicolson (1985), stressed that Shetland had consciously to sell its attractions. A big part of getting this message involved:

1. Attendance at trade fairs.

2. Inviting travel journalists to visit Shetland and write features about the islands.

3. A selective advertising campaign, with editorial coverage where possible.

4. Distribution of videos through clubs and organisations.

5. Direct mail shots to previous inquirers.

6. Joint advertising with the Highlands and Islands Development Board and Scottish Tourist Board.

The result of this type of planning and involvement has been an overall increase in tourist numbers and expenditures. Indicative of this increase, Mackay Consultants (1991) reported that seven day package holidays had increased from 276 in 1982 to 1,630 in 1989. Furthermore, Shetland has been able to tap into a network of international tour agencies to bolster the Islands' image, while attracting new markets. Horizon Tours from Canada, for instance, sent three groups in 1989, each numbering over 40 people, and intended to increase the number of tours in future years (Nicolson, 1989).

The following set of figures and tables illustrate the dynamic nature of Shetland visitation between the early 1970 s and the present. Figure 3.6 represents P\&O ferry passengers between the years of 1976-1989 (Shetland Island Council, 1992). Generally, the numbers of passengers have increased steadily with only 1981, 1982 (depression years), and 1986 as exceptions to this increase. Taylor, Allardyce and MacPherson 
(1992) suggest that growth of international travel to Scotland and the U.K., during the 1980s, was gencrally slow. Global recession, international inflation, exchange rate fluctuations and an unstable economy are reasons put forth by the authors as reasons for the downturn. Overall, passenger traffic has increased from 28,172 in 1976 to 73,793 in 1989 (260\%). Cars carried (Figure 3.7) also increased over the years 1977 to 1989 (Shetland Islands Council, 1992). Sharp increases up to 1980 were followed by a general increase to 1989. The number of cars carried doubled from 5,164 in 1977 to 11,268 in $1989(218 \%)$.

Accommodation capacity (bed spaces) is outlined in Table 3.1. As suggested before, the early 1980 s experienced a decrease in demand. This relates to the number of bed spaces available through the latter 1970s and initial 1980s. Prominent accommodation types in 1991 included Self Catering (Country), representing 28.7 per cent of all bed spaces. Count y Hotels represented the next highest number of bed spaces at 16.8 per cent, followed closely by Lerwick Hotels at 16.4 per cent. The fewest bed spaces of all categories in 1991 were Country Caravans, at 0.95 per cent of all spaces. Country establishments represented a total of 71.2 per cent of all Shetland bed spaces, with Lerwick units at $\mathbf{2 9 . 8}$ per cent. Statistics available on overnight stays are based on a 1984 survey of tourism in Shetland (sample size: 585; Shetland in Statistics, 1989). The study was undertaken during the tourist season (May to October), and sampled only tourists associated with shipping (no air travel respondents). The average number of nights spent in Shetland was 10.4. Twenty-nine per cent of visitors spent between 4 to 7 , or 8 to 14 nights, the two highest represented categories. Only 


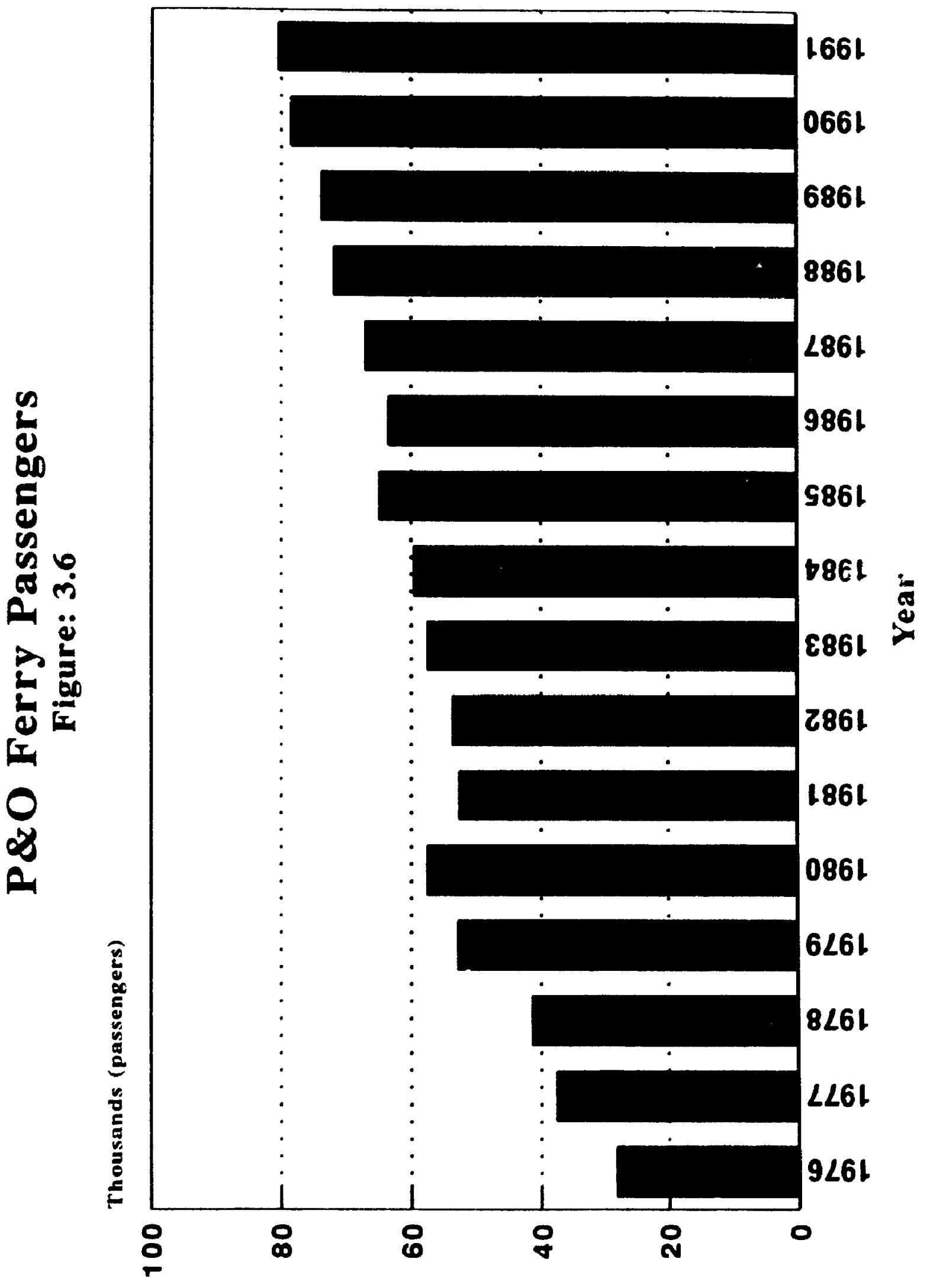




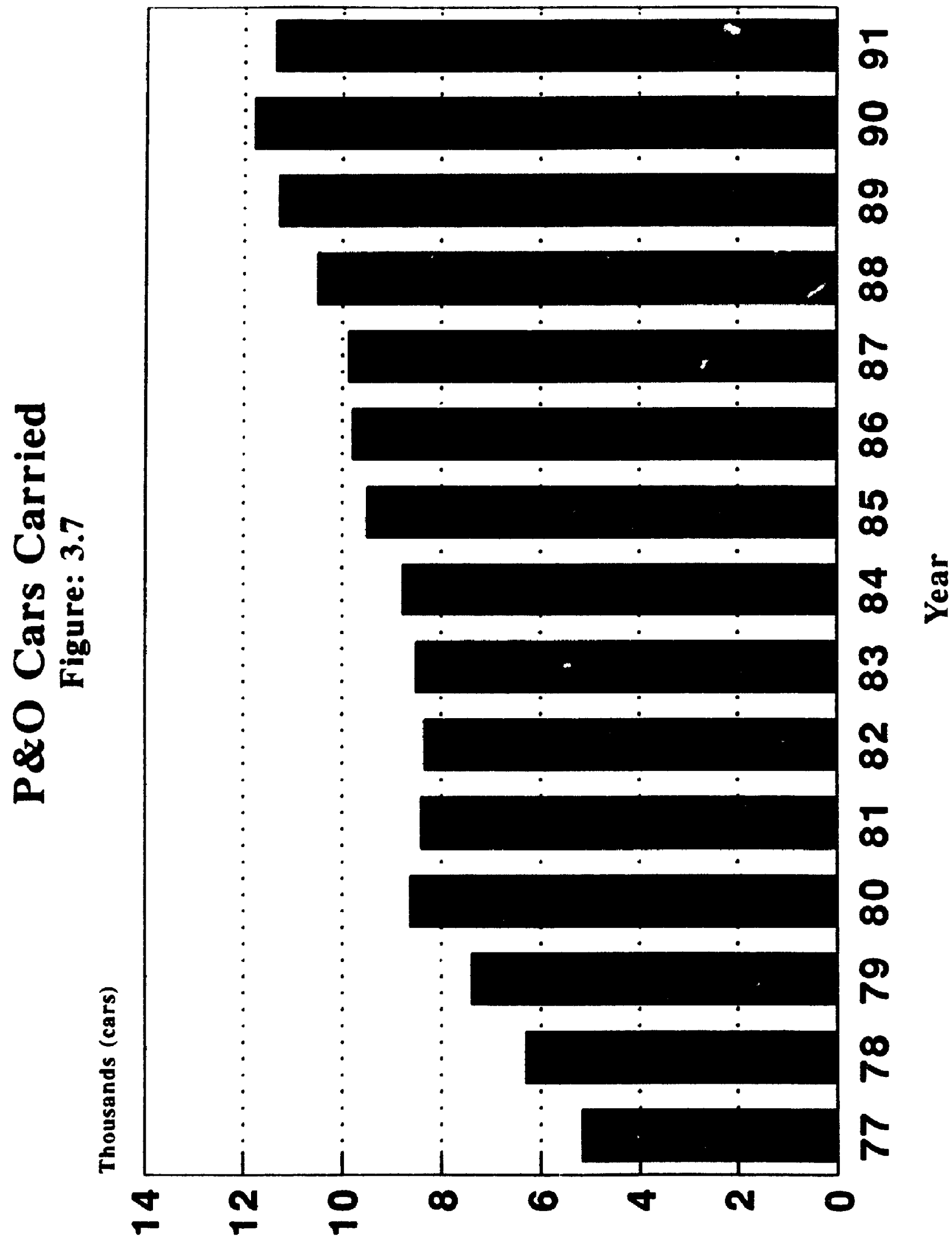




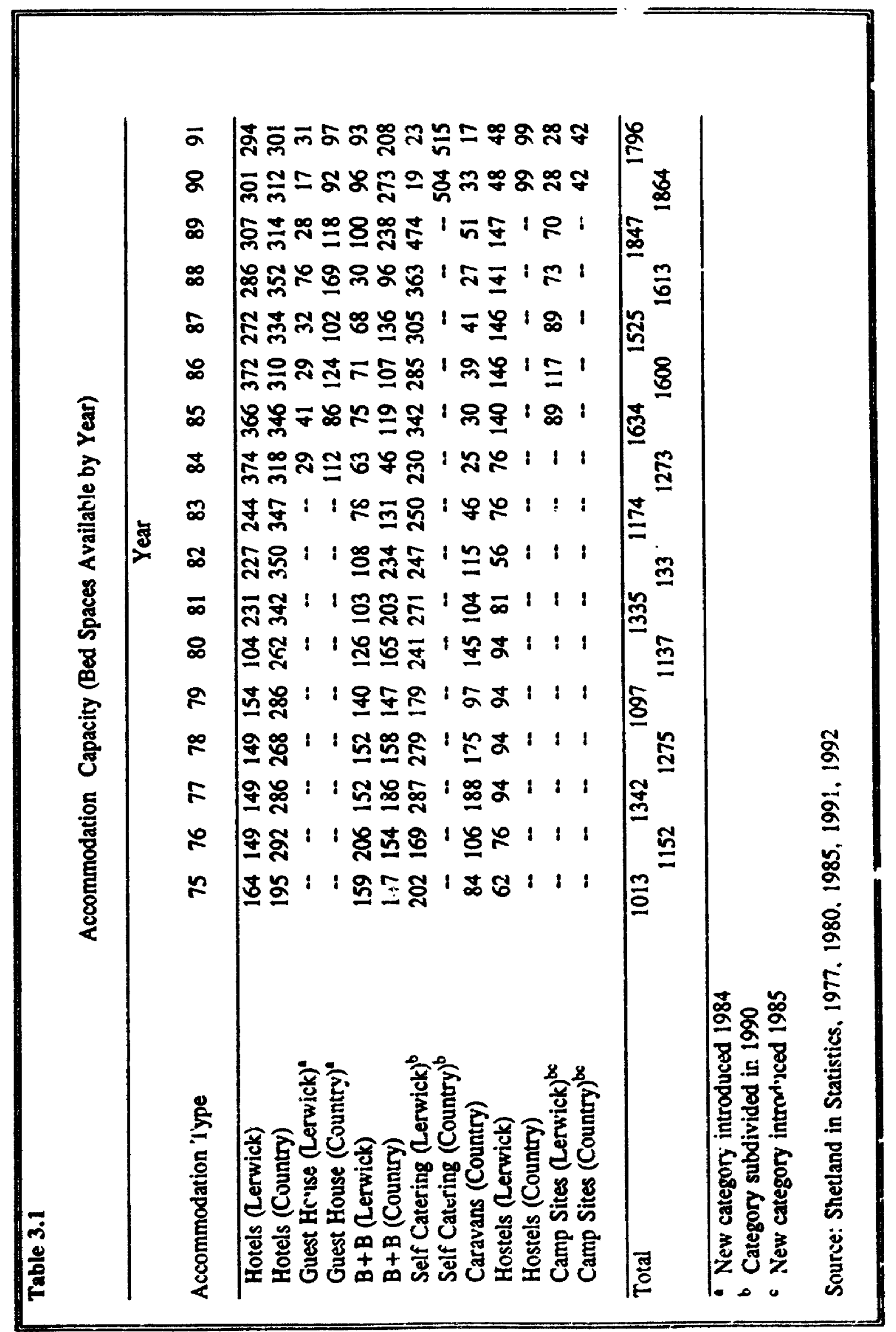


three per cent of the sample stayed 22 to 28 days, while four per cent spent 29 days or more (Figure 3.8). A subsequent survey (System 3 Scotland, 1992) found the maan length of stay in Shetland to be lower, at 7.1 nights for holiday visitors. In this survey visitors, on average, stayed in Lerwick for 2.2 nights; elsewhere on the mainland for $\mathbf{3 . 0}$ nights; and 1.8 nights on Shetland's other islands.

Table 3.2 denotes the breakdown of the number of nights visitors spent in various regions of Shetland. Most of the visitation, by far, was recorded in Lerwick $(n=270)$ and the Rural Mainland $(n=277)$. The average number of nights spent in locations is variable. Lerwick has a low average of 4.7 nights, but not as low as Fetlar, 4.2. Whaisay contained the highest average (10.0). Lerwick may be low due to its role as a transhipment point given the access this centre permits for travel to other areas of Shetland.

A profile of past visitors (Table 3.3) illustrates that age was quite variable. Twenty-four per cent of tourists (the highest group) between the ages of 25 and 34 (Shetland Islands Council, 1989; System Three Scotland, 1992).

Resulv of the 1991 visitor survey (Table 3.4) completed by System Three Scotland (1992) illustrate differences to the 1984 statistics on visitor origins. Findings demonstrate that there had been a slight increase in Scots travelling to Shetland (up to 31 per cent), and a decrease in travellers from the rest of Britain (down to 39 per cent). Overseas visitors represented 28 per cent of this total in 1991. According to other related research (Mackay Consultants, 1991), the majority of Shetland travellers are best described as general interest, despite the presence of a distinct speidal interest 

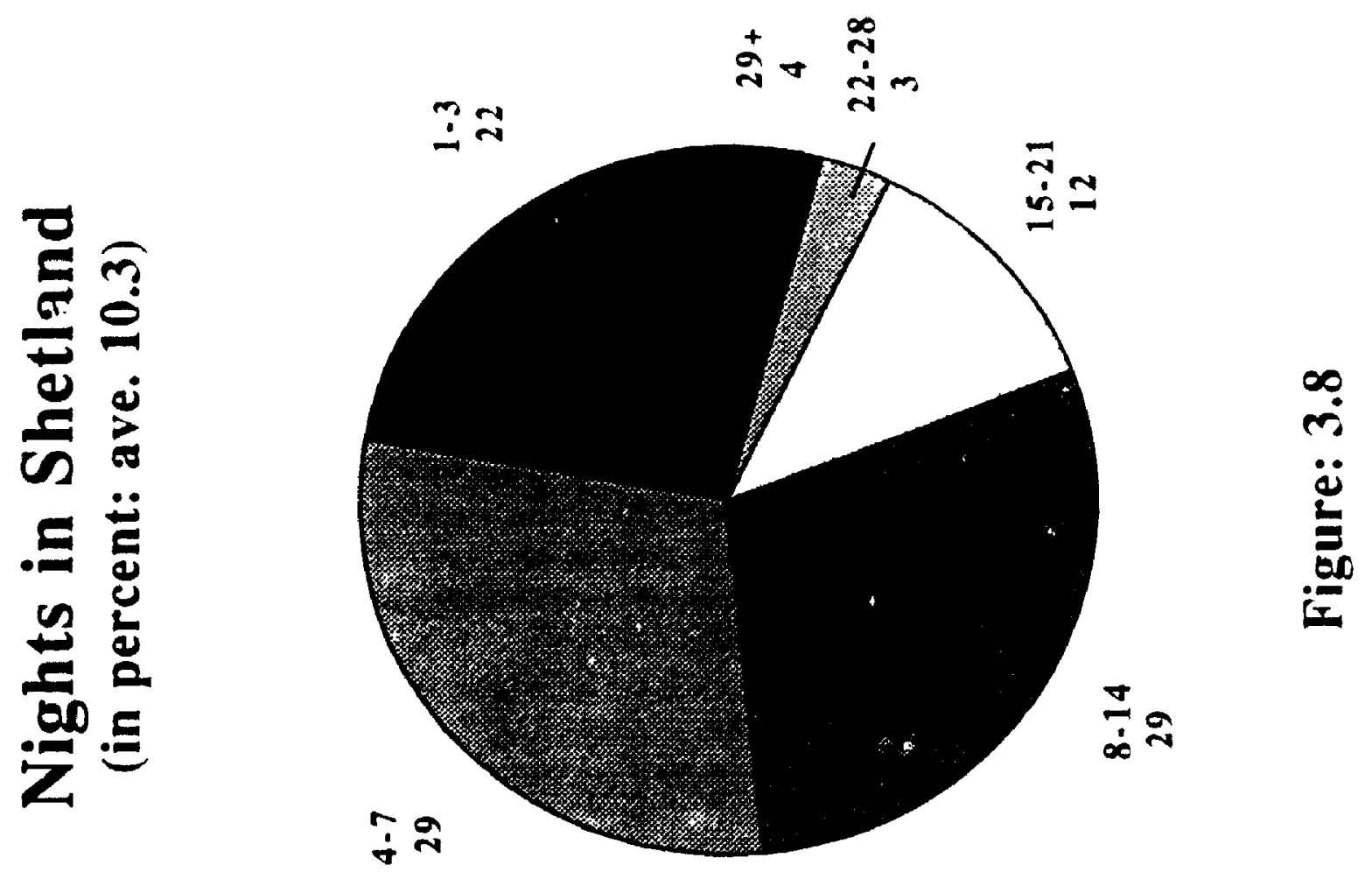
Table 3.2

Number of Nights Spent in Shetland (1984)

\begin{tabular}{lcc}
\hline Region & $\begin{array}{c}\text { Number } \\
\text { Spending } \\
\text { a Night }\end{array}$ & $\begin{array}{c}\text { Average } \\
\text { Number of } \\
\text { Nights Spent }\end{array}$ \\
\hline Lerwick & 270 & 4.7 \\
Other Mainland & 277 & 9.7 \\
Yell & 48 & 6.5 \\
Unst & 105 & 5.2 \\
Fetlar & 33 & 4.2 \\
North Roe & 34 & 5.7 \\
Bressay & 22 & 4.2 \\
Whalsay & 9 & 10.0 \\
Fair Isle & 23 & 9.1 \\
Other Islands & 39 & 7.6
\end{tabular}

Source: Shetland in Statistics, 1989.

Table 3.3

Profile of Visitors

Characteristic

$\begin{array}{cc}\text { Percentage }^{\mathbf{a}} & \text { Percentage }^{b} \\ 1989 & 1992\end{array}$

Age (yrs)

15-24

25-34

$35-44$

45-54

$55-64$

$65+$

20

24

18

14

13

12
11

23

20

19

11

15

'Source: Shetland in Statistics, $1989(n=585)$

bSource: System 3 Scotland, $1992(n=1008)$ 
constituency (e.g., birding). This latter

consultant's report wrote that the Shetland general interest visitor seemed unwilling to pursue a single activity during their holiday, but might be inclined to take part in several events over the course of a day.

\begin{tabular}{|c|c|c|c|}
\hline \multicolumn{4}{|c|}{ Origin of Visitors } \\
\hline Origin & $\begin{array}{c}1984 \\
\text { Per cent }\end{array}$ & $\begin{array}{c}1990 \\
\text { Per cent }\end{array}$ & $\begin{array}{c}1991 \\
\text { Per cent }\end{array}$ \\
\hline $\begin{array}{l}\text { Scotland } \\
\text { Rest of Britain } \\
\text { Overseas Visitors } \\
\text { Overseas Visitors: } \\
\text { Norway/Sweden } \\
\text { Denmark/Faroes } \\
\text { Other Europe } \\
\text { North America } \\
\text { Australia/New Zealand } \\
\text { Other }\end{array}$ & $\begin{array}{r}5 \\
2 \\
8 \\
5 \\
3 \\
\frac{3}{26}\end{array}$ & $\begin{array}{r}8 \\
2 \\
8 \\
3 \\
1 \\
6 \\
28\end{array}$ & $\begin{array}{r}12 \\
3 \\
11 \\
3 \\
2 \\
8 \\
39\end{array}$ \\
\hline \multicolumn{4}{|c|}{$\begin{array}{l}\text { b Shetland in Statistics, 1985, } 1992 \\
\text { c System } 3 \text { Scotland, } 1992 .\end{array}$} \\
\hline
\end{tabular}

Visitor expenditure statistics (Table 3.5) were available through various issues of Shetland in Statistics. In the 11 years from 1980 to 1991, expenditures in pounds had increased 5 fold, from 2 million to 10 million (unajusted) pounds. In no year was there a decline from the year before. However, a recent report on the Shetland economy one year after the 1993 oil spill noted that tourism had declined by ten per cent in that year (The Globe and Mail, 1994). 
Table 3.5

Total Visitor Expenditure in Shetland

(millions of pounds by year)

\begin{tabular}{cccccccccccc}
\hline 80 & 81 & 82 & 83 & 84 & 85 & 86 & 87 & 88 & 89 & 90 & 91 \\
\hline 2.0 & -- & 3.6 & 4.1 & 4.8 & 5.9 & 6.9 & 7.5 & 7.7 & - & 8.1 & 10.0
\end{tabular}

Source: Shetland in Statistics, 1985, 1989, 1992.

Membership in the Shetland Tourist Organisation (Table 3.6) is a good indicator of the number of establishments and businesses that are linked through the tourism industry. It may also be an indicator of the vitality of the economy (service sector) and tourism industry in relation to previous years. The table shows that in 1983, there was a drop in the total tourist organisation membership $(n=194)$, which corresponds to the drop in bed spaces of the same year. There are minor fluctuations in membership totals in the latter 1980s and early 1990s. However, overall there has been an upward trend with respect to membership.

The Tourism Working Group (1990) in forecasting propoutd changes in accommodating tourism in Shetland, advocated four strategy objective iwe were:

1. Improvement of transport/accessibility

2. Development of the product

3. Additionally focused promotion and marketing

4. Expansion and improvement infrastructure.

Currently, transportation costs pose somewhat of a restriction to visitation, which may be partly responsible for the limited pressure on locals and resources (for a family of four in 1991, with car, coming from Aberdeen, it cost 608 pounds by P\&O Scottish 
Table 3.6

Membership of Shetland Tourist

Orgarisation (by Year)

\begin{tabular}{lrrrrrrrrr}
\hline Organisation & 79 & 81 & 83 & 85 & 87 & 88 & 89 & 90 & 91 \\
\hline Hotel & 15 & 16 & 18 & 19 & 18 & 18 & 16 & 16 & 16 \\
Guest House/B+B & 66 & 64 & 46 & 68 & 63 & 78 & 93 & 95 & 87 \\
Self Catering & 37 & 36 & 27 & 46 & 54 & 55 & 67 & 67 & 72 \\
Hostel & 4 & 4 & 2 & 4 & 5 & 5 & 5 & 5 & 5 \\
Business/Trade & 118 & 120 & 101 & 106 & 96 & 136 & 150 & 138 & 153 \\
Camp Site & -- & - & - & 4 & 3 & 4 & 4 & 4 & 4 \\
Caravan & - & -- & -- & - & - & - & - & - & 3 \\
& & & & & & & & & \\
\hline Total & 240 & 240 & 194 & 247 & 239 & 296 & 335 & 325 & 340
\end{tabular}

Source: Shetland in Statistics, 1992.

Ferries. In 1990, this cost was only 471 pounds -- Nicolson, 1991). These plans, mentioned above, may have both positive and negative inplications for the Shetland region. If tourism stands poised to shoulder some of the economic disparity left with the demise of oil, ecological and sociological guidelines need to be endorsed similar to those adopted for the Sullom Voe Terminal which has a high reputation for impact minimisation (Butler and Nelson, 1992).

\subsection{THE MODEL WITHIN THE SHETLAND CONTEXT}

The model introduced in Chapter 2 was discussed as a vehicle by which to understand the behaviour of tourist groups, in space and time, in virtually any type of tourism locale. An important feature of the model, apart from the time, S.E.E, and perceptual components, is its emphasis on location - the subdivision of a region into 
areas or distinct access zones. The model is clearly applicable to this research, and provides a framework that emphasises the importance of the core-periphery relationship in the context of Shetland's archipelagic geography (Figure 3.9).

\subsubsection{The Tourists and Study Regions of Shetland}

Five types of tourists (excluding the "other" tourist category) have been hypothesised based on a prior knowledge of the natural, historical, and social characteristics of Shetland. These five are identified as a function of the primary activity or activities undertaken by tourists while visiting Shetland. The proposed activity-based groups are as follows:

1. Natural history: individuals interested primarily in activities associated with flora and fauna (including geology), other tian birds.

2. Birding: individuals whose prime reason for travel to Shetland is to observe and identify birds.

3. Loch fishing: individuals whose prime reason for travel to Shetland is to fish the freshwater lochs of the island.

4. Histor /Archaeology: individuals whose prime reason for travel to Shetland is to visit and understand the history of human involvement in Shetland.

5. General sightseeing: individuals whose prime reason for travel to Shetland is to observe, generally, any and all of the features of the islands.

All four data gathering techniques (space-time budget, questionnaire, interviews, and observations) are used in order to uncover the amount of time that each tourist group spends at each access location. Time, then, is a factor that can help delineate betwoen these groups (e.g., their activities necessarily result in different space-time patterns). 


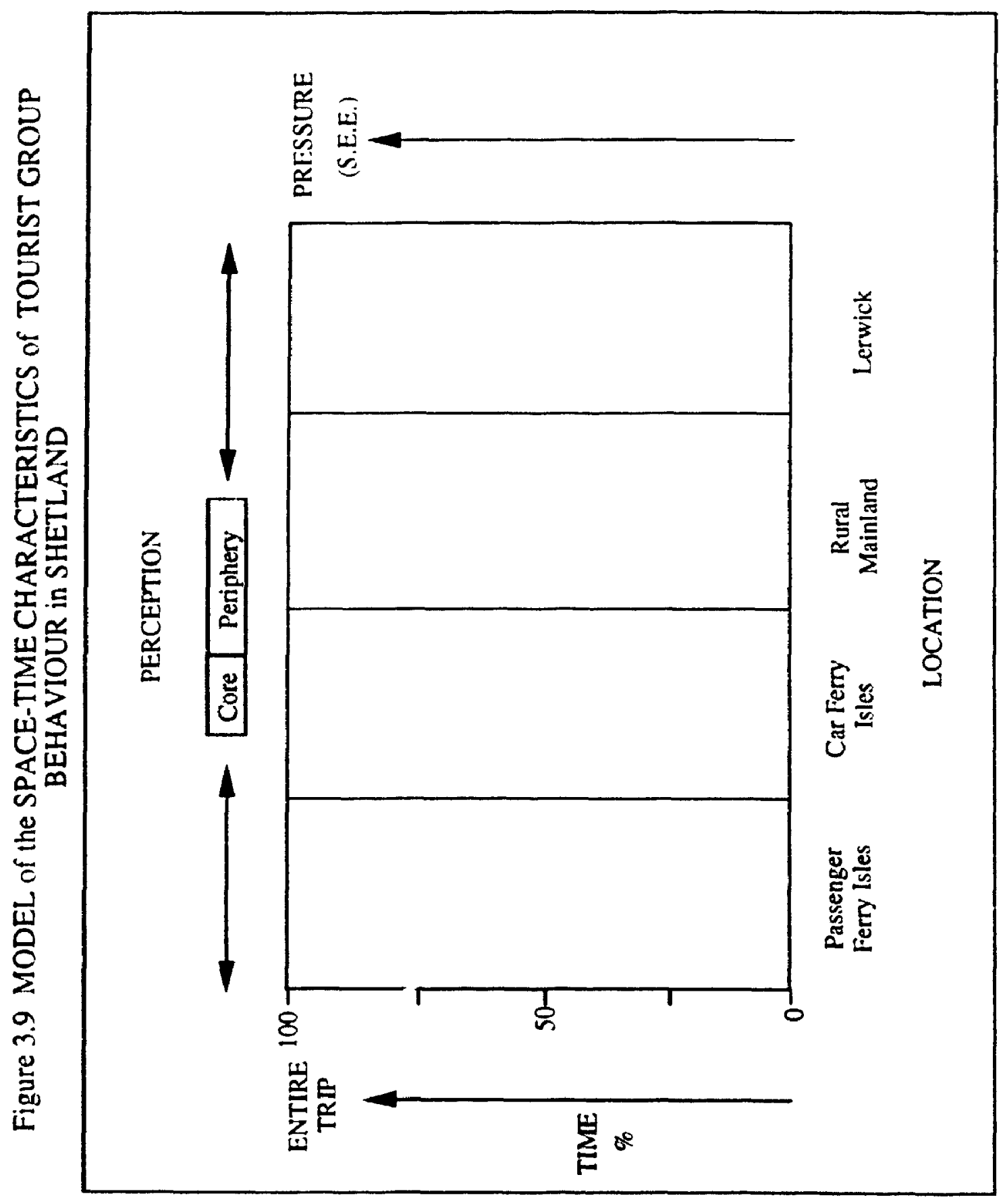


Four functional zones that have been ideitified on the basis of access (Figure 3.9):

1. Urban mainland: This refers to the city of Lerwick, the main urban centre in Shetland.

2. Rural mainland: This location refers to all other settlements on the Shetland mainland.

3. Car Ferry isles: This zone refers to those islands that are directly accessible to travellers through the Shetland Ro Ro (Roll-on, Roll-off) ferry system. Regularly scheduled departure times are offered to travellers who are on foot or in vehicles. Islands included are Unst, Yell, Fetlar, Bressay, Whalsay, and Outskerries

4. Passenger Ferry isles: This zone refers to those islands that are connected by regular ferry service. These ferry services do not carry vehicles. Islands included are Foula, Fair Isle, Noss, Mousa, and Papa Stour.

\subsubsection{Elements in Space-Time}

This research utilises the four elements of accommodation, transportation, attractions and facilities in order to gain information on the movement of travellers in Shetland. Butler and Fennell (1992) made reference to the fact that the quality of both transportation and accommodation in Shetland had been improved considerably as a result of the impact of oil development in the region. Heightened demand and the injection of capital were among the most important factors responsible for transforming the Shetland infrastructural base to a level higher than that in many other areas in the U.K. Roads, aipports, and hotel establishments were renovated in order to sustain the impact of ten years of demanding oil-related activity. In more recent years the number of types of accommodation units (as presented in Chapter Three) increased to meet touristic demand, providing an outlet that allowed individuals to bolster houschold incomes. 
The findings of Butler and Fennell (1992) reveal that a resurgence of tourism occured in the mid-1980s in response to the decline of oil in Shetland. Accommodation capacity levels of previous years had to be restored throughout the tourism industry. The Shetland Tourist Organisation, through heavy advertising, has been able to utilise the variable natural and archaeological attraction base to attract visitors. Facilities were designed and improved to cater directly to the tourist population. The present study attempts to gather data on the movement of travellers to the various attractions and facilities in Shetlind. In an effort to better categorise data, the following definitions have been established:

Accommodation Any establishment which is designed to provide travellers with overnight lodging (and possibly food), and which operates within the context of the industry's established guidelines or norms.

Transportation A form or class of movement, mechanical or non-mechanical, that enables travellers to move to and within a travel destination. Included are the infrastructure and resource needs for transport (roads, water, etc.) and the established guidelines (e.g., speed limits, etc.) and timetables that ensure the smooth functioning of the system. A definition of transport, therefore, has two elements: the form of movement, and the system that allows for movement.

Facility

A spatial unit (area, object or person) that is identified by a marker and is part of a broader system and/or region. Facilities ensure a one-way or two-way exchange of material, and therefore are based on a concrete product.

Attraction A spatial unit (area, object or person) that has unique characteristics. This "space" is identified by a marker(s) and is part of a broader system and/or region. The attraction leaves the tourist with an experience rather than anything of a concrete nature.

The interrelationship of the above four elements are discussed within the broader context of tourist types and regions stated above. 


\subsection{METHODOLOGICAL FRAMEWORK}

It was the purpose of the researcher to obtain information regarding the travel dynamics of tourists to Shetland (subdivided into the aforementioned five sample groups) througn the implementation of a time budget study, a self-administered questionnaire, interviews, and observations. The framework outlined in Figure 3.10, Methodological Structure, identifies the various data-gathering techniques, and their relationships, used in the study. This framework attempts to illustrate that each of the four approaches (interview, observation, space-time budget, and questionnaire) are to be considered both as independent, and also as parts of a continuum that provide a foundation for inductive and deductive reasoning. Their roles characteristically interplay in the process of moving to, and from, a research problem. Two-way arrows in the outer realm of the model (Figure 3.10) outline this interplay.

The inductive paradigm (interview and observation) will rely upon spocif:c observational methods to detect patterns of social behaviour in different travellers to Shetland. These patterns may ultimately contribute to the formation of problems, theories or universal principles. Single arrows moving from "interview" and "observation" to the Research Problem depict this process.

Directional arrows moving away from the Research Problem in Figure 3.10 provide a visual representation of the process of deduction. Both the questionnaire and space-time budget are tools that will test the series of hypothesis regarding tourist group travel in the research area. 


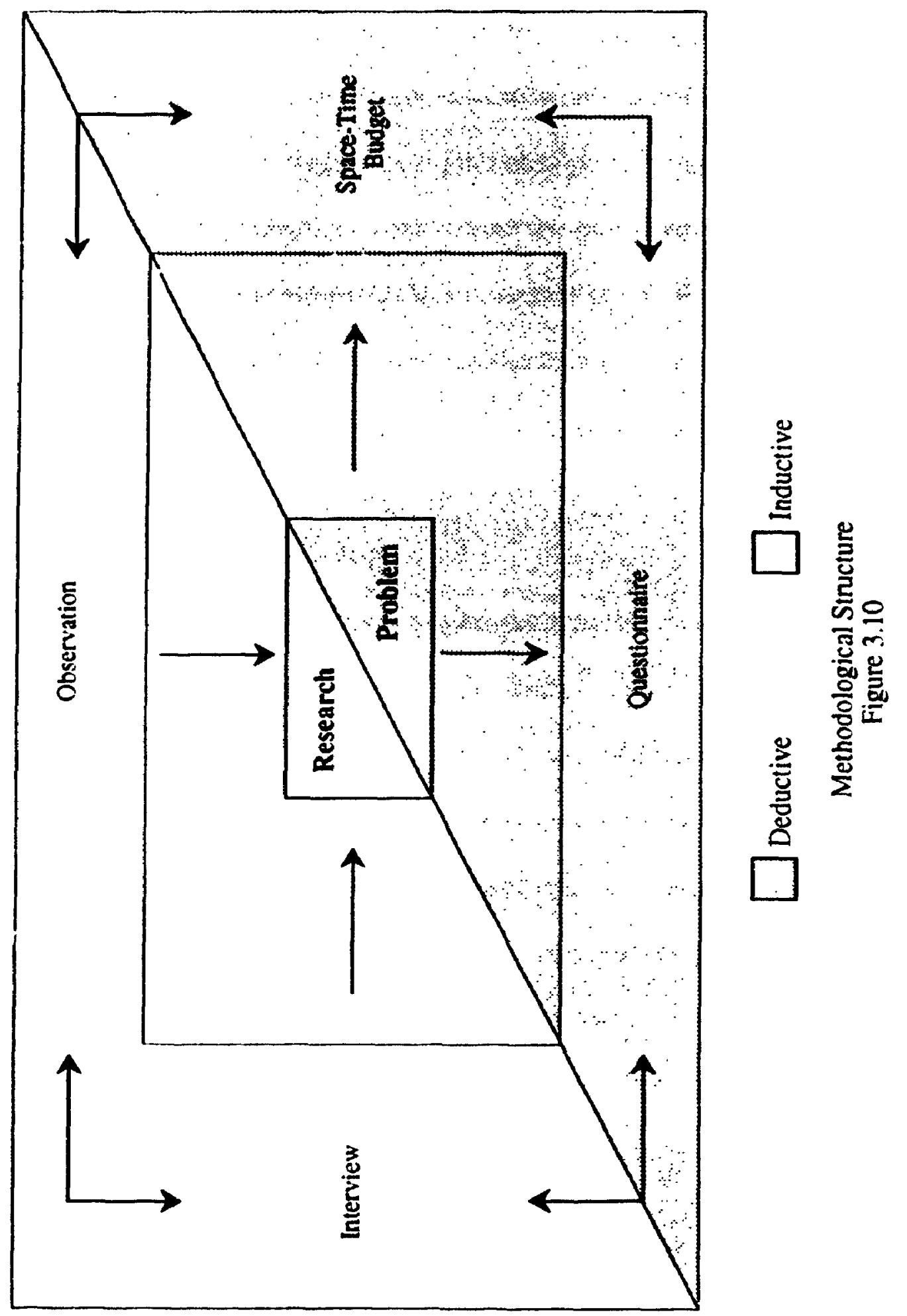


The rationale for implementing a multiple methodology (triangulation) is that it introdures, inherently, an element of flexibility to the research. The doductive approach allows for the formulation of hypotheses to be tested through the observations generated by the self administered questionnaire and the space-time budget. Conversely the inductive approach, through interviews and observations, enables the researcher to generate themes and patterns from observations of select tourist groups in the study area. Both approaches, as outlined at the onset of Chapter 4, are important in strengthening the study design.

\subsection{HYPOTHESES}

Figure 3.11 (a to $f$ ) is a graphic representation of hypotheses related to the six tourist groups considered in this analysis. Due to the fact that each group was scrutinized using the same set of measures, the way each group fits within the proposed framework of the model may be considered important in illustrating perceived group differences. The hypotheses, as outlined, assume a somewhat perfect correlation between space and time, meaning that for some forms of touristic behaviour time may not be spent in preferred locations in light of the total time of all touristic activity while in Shetland. From the context of this research, it is expected that tourists inherently accept and apply limits to their involvement in chosen activities. Assessing these limits at an individual level is difficult. Still, the researcher must operate under the assumption that tourists and tourist groups engage in freely chosen activities, and move to and within regions as a means by which to balance space and time in achieving desired benefits. 
Jigure 3.11 The Space-Time Characteristics of Each Tourist Group (Hypothetical)
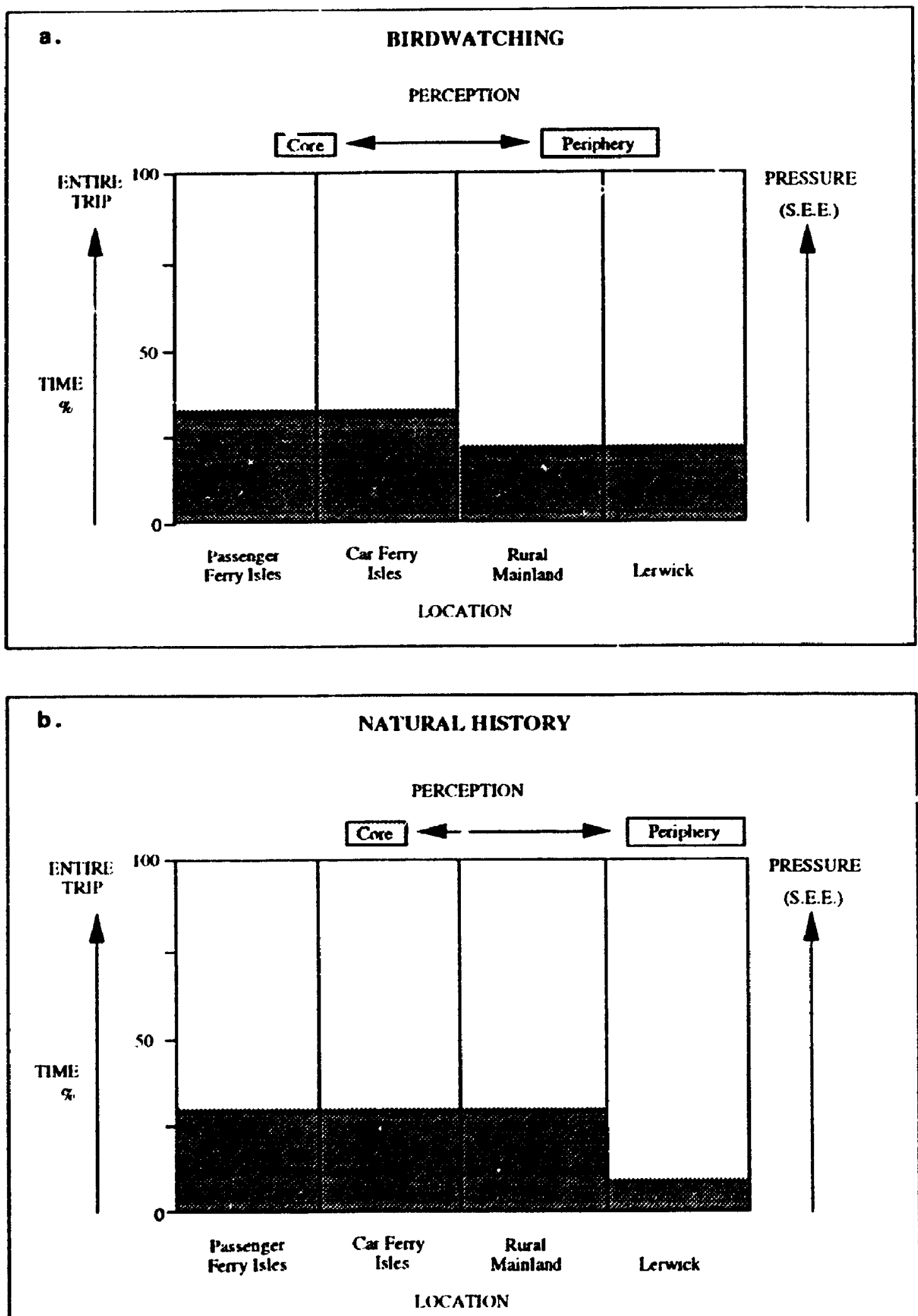
Figure 3.11 (Continued)
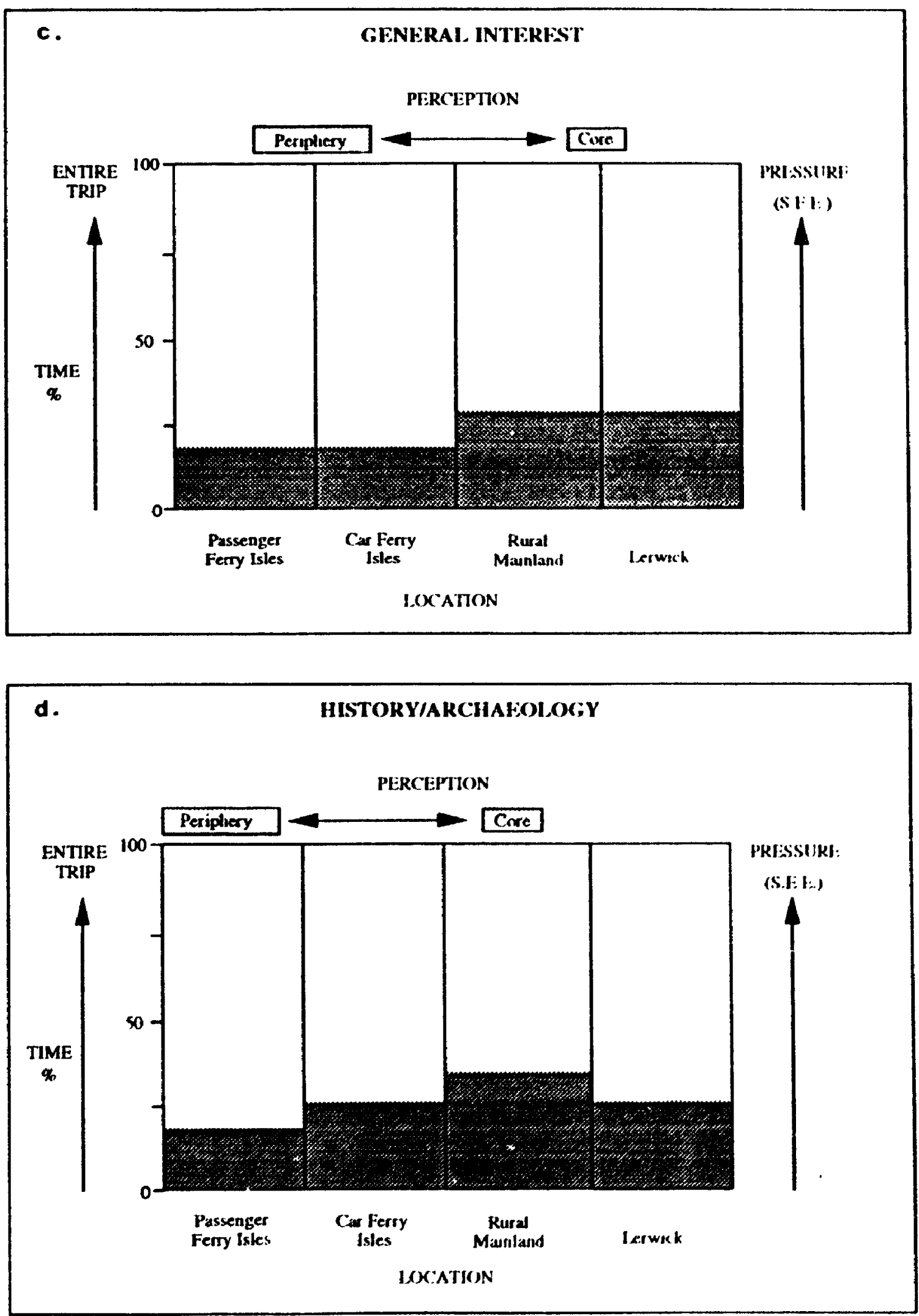
Iigure 3.11 (Continued)
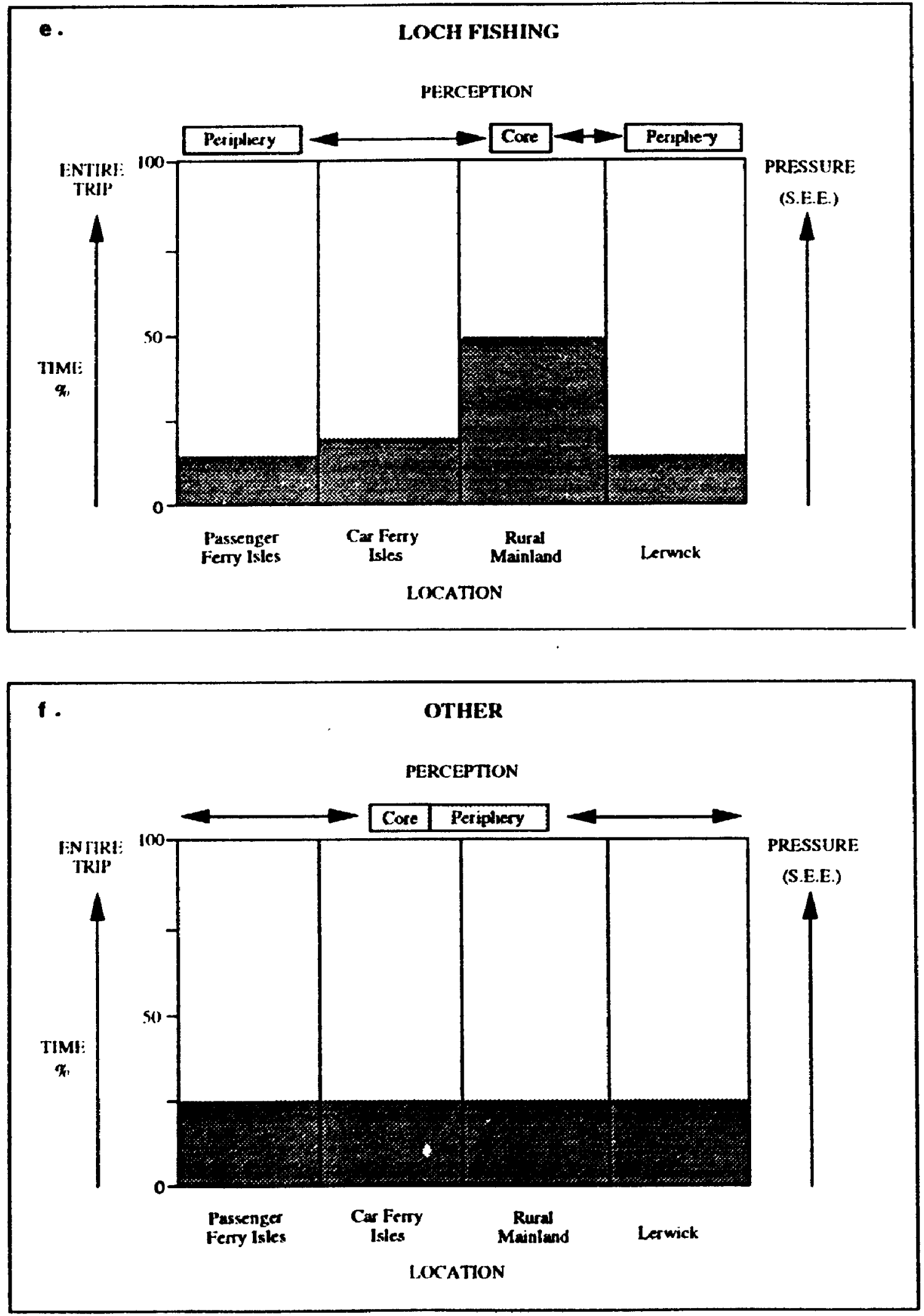
The characteristics of the six groups were hypothesized as follows:

1. Birdwatching: This tourist group will centre its space-time characteristics away from Lerwick, interacting more with the car ferry and passenger ferry isles.

2. Natural history: This tourist group will centre its space-time characteristics away from the Lerwick (urban mainland), interacting primarily with the openness of the rural mainland and car ferry isles.

3. General interest: This tourist group will centre its space-time characteristics primarily in the Lerwick area and between towns of the rural mainland. The frequency of travel to passenger and car ferry isles may b : limited to isolated occurrences.

4. History/Archaeology: This tourist group will centre its space-time characteristics primarily on the rural mainland, with short day trips undertaken to outer-lying zones.

5. Loch fishing: This tourist group will centre its space-time characteristics away from Lerwick, interacting more with the openness of the rural mair' and and car ferry isles, but with a specific focus on the water bo ies).

6. "Other": This tourist group will be quite variable. Because the dynamics of tourists in this group are unknown, the core-periphery relationship is not skewed.

Each of these six groups was perceived to be unique, and it was important to understand their space and time characteristics, and the potential pressure of each on the physical and human environments of Shetland.

\subsection{CONCLUSION}

Shetland has a rich history in regard to linkages outside the realm of the archipelago. From a more recent perspective, these linkages have resulted in a major transformation of the economy and people of Shetland that has enabled the region to compete, economically, in an international arena. 
In studying the geographical implications of global tourism, hoivever, Barbier (1989) has suggested that there are a number of trends that have emerged. First, tourism has taken on the form of a migration to increasingly less frequented peripheral regions. Second, most international travel is largely intra-regional travel (travellers moving within the major world region with which one is associated). Finally, Europe, as a major world region is dominant and att acts about two-thirds of all international tourist traffic. The implications of these trends for Shetland are both positive and negative. Economically, the tourism industry may gain more momentum in Shetland as a recognised and integral component of a growing economy. However, as tourists search further into the periphery, care needs to be taken of Shetland's landscape, highly regarded for its uniqueness and remoteness. Steady increases in Shetland visitation have not been examined in light of the potential physical and human pressure which the tourism industry can inflict. Much can be learned from examining the behaviour of both individual tourists and tourist groups in this regard. 


\section{Chapter 4}

\section{THE STRUCTURE OF INOUIRY}

A man travels the world over in search of what he needs and returns home to find it.

George Moore

This chapter discu: 'es the methods used in gathering Shetland tourist data for analysis. The following components will be elaborated upon: triangulation, methods and sampling (with regard to both quantitative and qualitative approaches), and study limitations.

\subsection{TRIANGULATION}

An important means of strengthening a study is through the use of an approach referred to as triangulation. This type of procedure uses a combination of methodologies, both quantitative and qualitative, in the study of the same phenomenon. Patton (1990) labels this methodology as the "paradigm of choices". Ianni and Orr (1979), Reichardt and Cook (1979), and Trend (1979) all provide convincing arguements that both quantitative and qualitative approaches are legitimate, and that great advantages 
can be obtained through their combination. Denzin (1978) identifies four types of triangulation:

1. data triangulation - the use of a variety of data sources in a study.

2. investigator triangulation - the use of several different researchers or evaluators.

3. theory triangulation - the use of multiple perspectives to interpret a single data set.

4. methodological triangulation - the use of multiple methods to study a problem.

Because each type reveals different aspects of empirical reality, Denzin suggests that as a final methodological principle, "multiple methods should be used in every investigation" (Denzin, 1978: 28).

Hartmann (1988) expressed concern over the fact that tourists may not wish to reflect on, or express real travel motives. In an effort to bridge such preconceived limitations, multiple methods may have a decided utility. Using a combination of data types increases validity as the strengths of one approach (Sieber, 1973) compensate for the potential weaknesses of another. Van Maanen (1983) inferred that graduate training usually prepares students to use one method or another, but not to combine methods. This latter author implied it is probable that the triangulation approach is embedded in many doctoral theses which, when packaged into articles, tend to highlight only the quantitative methods. In this analysis, the particular form of triangulation (outlined by Denzin) used was data/methodological. A series of quantitative and qualitative data types were collected through a number of approaches (time budget, questionnaire, interviews and observations). 


\subsection{METHODS AND SAMPLING}

The following discussion explores the methods and procedues used in the implementation of the study tools (operationalisation). Both quantitative and qualitative approaches are discussed at length, in addition to the differing sampling methods incorporated for each approach.

\subsubsection{The Quantitative Approach}

After tourists were identified (procedure noted below), each was given a package containing time budget sheets, a written questionnaire, and self-addressed, stamped envelope (Appendix 1). Tourists were encouraged to have all aspects of the survey finished prior to leaving Shetland (with a stipulated questionnaire drop-off point at the tourist centre or any mail slot). In the event that they could not (or would not) drop off the questionnaire prior to departure, the envelope could be used to mail back the questionnaire at a more convenient time. Tourists were requested to recall information during the day, at the end of the day, or the next day, regarding the use of transportation, accommodation, facility use, and attraction use/visitation, at the locations that they chose to visit.

Zuzanek (1980) noted that evidence has shown that time budgets provide solid behavioral and quantitative evidence of an individual's lifestyle preferences. Zuzanek defined the time budget as a method of measuring the duration and sequence of activities engaged in by an individual during a specific period of time, usually 24 hours. As a 
logical extension to this type of record, a space-time budget includes the spatial coordinates of activity locations (Anderson, 1971).

A problem with some time budgets, however, is their reference to the division of all aspects of a day into segments as small as ten minutes. Recalling information and activities in these segments makes a survey difficult to complete, especially for tourists who may wish to relax and avoid such initiatives. Alternatively, respondents could record when each new activity began and ended to produce a more accurate record of the timing of each activity (Burton, 1971; Chapin, 1974; Cullen and Godson, 1975). However, as Pearce (1988: 113) implies:

Recording activities in this way...is much more demanding of respondents, and while it might be successful in day long studies, it is likely to generate resistance in surveys over a longer period, as indeed would a structured approach using fine intervals (e.g., of a quarter or a half an hour).

It was considered appropriate in this study to request tourists to respond to four elements:

1. What transportation they used during the day, and where they went;

2. What facilities they used during the day in these locations (zones);

3. What activities they engaged in during the day in these zones; and

4. What accommodation they used during the day.

Tourists were asked to associate an amount of time with each of these four elements, as exactly as possible. Therefore, if a tourist visited an attraction for two hours, he or she would list this under the "attractions" heading and give the approximate amount of time involved in getting there and returning (give or take five minutes upon arrival and departure). 
A map of Shetland was prinied on the back of each time budget sheet. Tourists were requested also to map their movements that day, as each day's sheet was filled out. At the end of the trip, therefore, the researcher had a graphic representation of the daily movement of respondents. It was important to understand how this spatial movement was related to tourist perceived activity centres: places where the sample could "get what they came for".

The maps were utilised in understanding how members of each tourist group moved throughout Shetland. Tourist group movement could ultimately be preserited in a variety of forms (maps) representing patterns of time and space. With this information, the researcher was able to graphically compare the spatial characteristics of all tourist groups in each of the identified access zones of Shetland.

The unstructured nature of the modified space-time budget may have some of the inherent characteristics of "beeper-studies". In these analyses, subjects carry electronic pagers with them and respond to random signals in reporting on their activities and internal psychological states (Mannell, 1983). In the present study however, it was hoped that tourists could be triggered not by a pager, but by the transitions associated with movement between transportation, facilities, and activities.

The written questionnaire that respondents were requested to answer towards the end of their trip was short and succinct. The questionnaire dealt with experiential aspects (behaviour), socio-demographics (age, sex, household income, and education), and made an effort to elicit responses geared towards travel characteristics and tourist group 
pressure. More specifically, the questionnaire sought information from questions related to (Appendix 1):

1. visitation, including first and previous visits; prime reason for travel to Shetland; personal itinerary; information on free brochures; and the purchase of any interpretive materials.

2. familiarity with Shetland's natural and archaeological history; travel companions; mode of travel; sources of information used in choosing Shetland as destination; intended regions of visitation; and information associated with personal logs or observations.

3. reasons for visiting Shetland; the rating of accommodation, food, transportation, and weather; comments on the effects of poor weather; and indications as to the extent to which respondents had travelled to other locations in the past.

4. listing terms that could be used to describe Shetland as a tourist destination; interaction with other tourists in Shetland; engaging in activities with tourists; the suitability of Shetland in satisfying respondents' pursuit of chosen activities; wether respondents would travel to Shetland again; and recommendations tourists might have to their friends regarding Shetland.

5. attraction sites under the categories of: Archaeological, Natural, and Houses and Buildings of Interest. Respondents were requested to check all those attractions they visited on these lists.

6. attraction sites under the categories of: Industrial Interest, Craft Centres, and Other Places of Interest. Space was provided for respondents to include other attraction sites visited, not on the aforementioned lists. Demographic data requested annual household income, level of education, age, and sex.

The tochniques required to analyze the quantitative questionnaire revolved around

the use of a variety of statistical tests including:

1. t-test: assessing the significance of differences among means of two different groups, for interval or ratio level data.

2. Chi Square: testing the relationship between two discrete level variables.

3. Various measures of density of use as they apply to the pressure tourists may place on regions of Shetland. 
4. Spatial statistics to compare concentrations, dispersions, and central tendencies of each group.

The population of individuals to be analyzed in this study was selected from the possible actors associated with the Shetland tourist experience. Six main samples were projected to characterise the majority of tourists in Shelland, as discussed earlier, and include: natural history tourists, birders, loch fishermen, archaeology tourists, general sightseeing tourists, and "other" tourists.

There are two principal ways in which tourists reach Shetland: by ferry from the Scottish mainland and Scandinavia, and via scheduled airline services. Both of these transport modes arrive and depart Shetland on regular schedules. Tourists also arrive in much smaller numbers by private yacht and chartered plane. Due to the fact that this study could not involve a true probability sample, because of logistic constraints, three procedures were followed to access tourists and to minimise sampling bias:

A. The researcher waited for tourists to disembark from their ferry/plane transport. At this time, the investigator approached every second tourist group, or individual, introducing them to the study. An alternative manner with which to accomplish this task would have been to disseminate surveys aboard the vessels with the cooperation of P\&O Ferries and British Air. If tourists were made aware of the research while aboard vessels, they could have a longer opportunity to decide whether they would like to participate. It would then have been possible to greet tourists as they disembarked, providing a detailed introduction to the study group. This approach, however, proved impossible because of an inability to secure cooperation from the carriers. 
B. The second distributional procedure involved handing out questionnaires through the Tourist Office. This office is centrally located at Market Cross, in the middle of downtown Lerwick (a very accessible tourist site). Every second tourist (or group) entering the Centre was approached and asked to participate.

C. In order to control the fact that some tourists might not visit the tourist office during their vacation, some questionnaires had to be distributed in other ways. The best way to access other tourists was through the attraction sights themselves. It was appreciated, however, that distribution through any or all sites, might misrepresent all types of tourist groups. Many attractions in Shetland get very little visitation. The researcher, therefore, enquired (using the expertise of Shetland Tourism) to locate "universal" attractions where a broad range of tourists types would visit. Jarlshof, Mousa, and Hermaness were considered the most universal, based on accessibility and diversity (keeping in mind the importance of representing the study regions of Shetland). The Shetland Official Tourist Guide (1992), provided an extensive description of these attractions; descriptions that acknowledge their consideration as primier, universal sites:

Jarlshof,

Near the old mansion house of the Sumburgh Hotel is Jarlshof, an outstanding archacological site spanning 3,000 years of settlement from Neolithic to Viking times. Jarlshof was the name given to the medieval farmhouse in Sir Walter Scott's novel "The Pirate" and the name is now used for the whole site. It was discovered in 1905 when a violent storm partially uncovered the remains. An excellent interpretive centre brings to life its past inhabitants. (A leaflet and guidebook are available).

Mousa,

Trips to this lovely, uninhabited island are weather-dependent and no dogs are allowed. The island is famous for Mousa Broch, the best-preserved 
example in Britain, which stands $43 \mathrm{ft}$. (13m.) high. Built in the Iron Age, from local sandstone, it has chambers, galleries, an internal staircase and an open parapet. (A guidebook is available from the Tourist Information centre)...The island has its own peaceful atmosphere and is a summer home to hundreds of nesting seabirds and waders. The white-sand beach at West Voe is an excellent place to watch Common Seals.

\section{Hermaness,}

Hermaness National Nature Reserve is of international importance consisting of 2,422 acres (980 hectares) of moorland and dramatic coastal scenery with cliffs up to $558 \mathrm{ft}$. $(170 \mathrm{~m})$. Over 100,000 breeding birds injlude seabirds such as Gannets and the largest number of Puffins in Shetland. Moorland species include skuas, waders and Red-throated Divers. Good footwear is important and particular care should be taken near cliff edges. The numerous offshore Stacks and Skerries include Muckle Flugga, the most northerly inhabited island in Britain. The lighthouse, completed in 1858, is manned by three keepers. Beyond Muckle Flugga is Out Stack - the end of Britain.

Having identified these sites, the researcher visited each on a random time basis for the purpose of distributing questionnaires. As with the two prior situations, every secund tourist, or tourist group, was targeted for distribution.

The selection of sampling units was straightforward when dealing with individual tourists. Latham (1991) however, implied that researchers must be careful in structuring procedures that use groups as sampling units. Bias is created in group situations because the spokesperson is not necessarily representative of the group. Due to the nature of the study area though (and low number of tourists), it was possible to identify both individual tourists and groups at each of the three distribution sites. Regarding tourist groups, the second individual in each group was consistantly approached and asked to participate in the study (as long as the individual was deemed 18 years of age or older). No tourist group was encountered, however, where all group members were under this age specification. If a "couple" was encountered and the second tourist was under the age 
of 18 , then the first tourist of the pair would be petitioned. The third or fourth (etc.) tourist in groups of three or more was approached in the event that the second tourist did not fit the age requirement.

The following format was used to introduce the questionnaires to prospective respondents:

"Good moming (afternoon, etc.), my name is David Fennell, I am a Canadian PhD student doing a study on different tourist groups in Shetland, in association with the Shetland Tourist Office. I was wondering if you had recently arrived in Shetland as a tourist?"

$$
\text { if yes, }
$$

"The reason I ask is that I am distributing a short, straightforward questionnaire that involves five minutes of your time, for each day of your acation. Do you think that you might be interested in taking part, or learning more about this study?"

The questionnaire format was then explai ied, and the respondent was urged to read the instructions carefully if they chose to participate. A note was also attached to the survey asking if respondents would like to have the space-time budget sheets sent to their home later as a recurd of their Shetland trip. Space was provided for respondents to write down their home addresses. This positive feature was brought to the attention of the tourists as the study was being introduced to them.

The researcher typically tried to distribute questionnaires when tourists had finished viewing an attraction. In this way, tourists would not be conscious of having to carry the survey around with them during their experience. It was also important, in this sense, not to disturb their interaction. Usually tourists were on their way to a car, 
bicycle, or coach, after visiting the attraction. More time was available to discuss the study during these periods than during the experience.

\subsubsection{The Qualitative Approach}

The qualitative element of the proposed triangulation approach included two separate elements. The first involved an informal interview of tourists at a variety of different locations and attractions. The second included making a series of observations at the Shetland Tourist Office, and at selected attractions throughout Shetland. As such, it was the purpose of the interviews and observations to provide a more holistic understanding of the travel patterns and attitudes of Shetland tourists.

Patton (1987) provides a comprehensive discussion of qualitative interviewing. He suggests that three interview approaches involve different types of preparation, conceptualisation, and instrumentation. These include:

1. The informal conversational interview,

2. The general interview guide approach, and

3. The standardised open-ended interview.

This study adopted the interview guide approach. The characteristics, strengths, and weaknesses of the interview guide are outlined by Patton (1987: 116):

Characteristics

Topics and issues to be covered are specified in advance, in outline form; interviewer decides sequence and wording of questions in the course of the interview. 
Strengths

The outline increases the comprehensiveness of the data and makes data collection somewhat systematic for each respondent. Logical gaps in data can be anticipated and closed. Interviews remain fairly conversational and situational.

\section{Weaknesses}

Important and salient topics may be inadvertently omitted. Interviewer flexibility in sequencing and wording questions can result in substantially different responses, thus reducing the comparability of responses.

Conversations, therefore, were broad-based, but some effort was made to concentrate the discussion towards a set of pre-planned questions. There were no visual aids utilised by the researcher to ask questions; a necessary feature to maintain the informal discussion format. Responses to questions were recorded - notes were hand-written - during the interview and for a period after the meeting (interview quide questions found in Appendix 2).

A number of conditions were introduced in an effort to standardise the interview procedure. Importance was placed on interviewing tourists in all of the four regions of Shetland. Tourists were interviewed at what were considered to be major attraction sites (including outer isles such as Foula). As with the quantitative sampling procedure, every second tourist (group) was desired for enquiry. However, due to the nature of the interviews -- quite often the researcher had to walk long distances with respondents, or sit with them for long periods of time - this procedure had to be periodically abandoned. Further adaptations had to be arranged in remote regions (Foula, for instance), where only four separate tourist groups were encountered over a four day visit. Faced with this type of adversity, the interviewer endeavoured to contact each of these groups. 
The second element of the qualitative aspect involved the implementation of an observational role. Powdermaker (1966) suggests that the relation between involvement and detachment is a determining factor in the nature of the research produced by paracipant observers, where total immersion may lead to the researcher ceasing to conde st research. The researcher must gather data by participating in the daily life of the group or organization he or she studies "watching the people they are studying to see what situations they ordinarily meet and how they behave in them" (Eyles and Smith, 1988: 113). There are four basic types of participant observation. These include:

1. complete participant - observation role is concealed.

2. participant as observer - the relationship between the researcher and others is defined by the research.

3. observer as participant - the distinctiveness of the researcher's role is made clear from the onset.

4. complete observer - there is no contact between researcher and those being researched.

The participant observation role assumed in this study was that of complete observer. The researcher observed members of tourist groups in each of the four access zones of the study area (taking into consideration that not all tourist gluups may be observed in each zone). Information was sought regarding the time that groups, and individual tourists, visited the tourist office and selected attractions.

In observing tourists at the Tourist Centre, the researcher randomly selected one week of the research period to study how many tourists went in, and how long tourists were spending at the centre. This procedure involved selecting one hour of the day during which to observe. Times were randomly selected, each representing a one-hour 
time period between eight and six o'clock (the hours of operation of the Tourist Centre). One of these hours was selected for each day of the observation period (one hour blocks, randomly selected, were felt to be adequate in determining daily and weekly Tourist Centre use).

It was important to continue observations for more than the scheduled hour, pending the time tourists remained in the office past the hour. If a 9:00 to 10:00 hour was selected, a tourist could have realistically entered and stayed in the office from 9:58, until 10:20. This late observation, as a result, would still have to be completed.

A similar strategy was used in observing tourists at selected attractions in Shetland. The Shetland Official Tourist Guide identifies 11 different tourist regions to be explored. Again, through a random selection, one region was identified for analysis (South Mainland). Arbitrarily, the researcher selected four major attractions in this region (Sumburgh Head, Jarlshof, Loch of Spiggie, and the Croft House Museum), and four minor attractions (Catpund, Loch of Brandister, Fladdibister Lime Kilns and Cliffs, and Hollanders Knowe). The major attractions were characterised by containing roadway signposting, on-site interpretation, and easy access. On the other hand, minor attractions of the South Mainland were characterised by no signposting, and no on-site interpretation. These minor attractions, though, were also easily accessible. Both major and minor attractions were fully outlined on the Official Shetland Tourist Map publication.

One hour of observation was devoted to each of these attractions. Minor attractions were observed for five days one week, the major attractions for five days the 
following week. The purpose of this strategy was to gather information in order to better understand visitation patterns of attraction types. Inferences then might be drawn on the importance of signposting, interpretation, and so on. Admittedly, word of mouth and other promotions could not be controlled in this process, which were understood to be of importance in drawing people to specific attractions Mullay (1991). If tourists were not overtly recognisable (as Shetlanders did visit their own attractions), they were identified by license plates, or car stickers indicating the rental of a vehicle.

An important consideration in developing methods for qualitative analysis is the implementation of a sampling design. Babbie (1986: 246-247) suggests that in field research, if one samples at all, they are likely to employ a purposive sample:

Here you select a sample of observations that you believe will yield the most comprehensive understanding of your subject of study, based on the intuitive feel for the subject that comes from extended observation and reflection.

According to Patton (1987) the power of purposeful sampling lies in selecting information-rich cases for study in depth; what Walker (1985) refers to as theoretical rather than representative consideration.

Patton pushes his analysis of purposive sampling further by recognising 10 distinct strategies. Of relevance to the goals of this research is maximum variation sampling. The aim of this type of purposive sampling is to capture and describe common patterns that emerge from the great variation of participants or programmes. In other words, in this study, it was felt important to analyse a number of different types of tourists in a variety of settings in Shetland. 
Quota sampling also has value as a design capable of capturing information on groups of Shetland tourists. McCall and Simmons (1969) describe quota sampling as a method that enables researchers to identify tourists that are members of certain formal categories. Those categories, according to these authors, may be modified, increased, or subcategorised depending on potential persons or events.

The dynamic nature of field observations suggests that researchers ought to be prepared for the changing composure of conditions and participants, in collecting data. Patton (1987) clearly stated that it is often prudent for observers to use a number of approaches at varying times, for different parts of the data collecting process. Based on this reasoning, quota sampling was felt to be most applicable to the interview stage of this research. A quota-type sampling procedure served to satisfy each of the hypothesised tourist groupings. On the other hand, observations of tourists occured from the complete observer perspective. The characteristics of maximum variation sampling applied best in this regard. Tourists were not approached by the researcher for purposes of interaction or conversation. Determining quotas on the basis of tourist group affiliation, in this case, was deemed unimportant.

Cohen (1988) in a discussion of sociological research techniques, inferred that informal qualitative research methods were useful in attaining basic insights, at best. The size of observation and interview samples used in this study (restricted by financial and temporal constraints) made it virtually impossible, therefore, for observation and interview methods to stand by themselves. The role of the qualitative component was 
considered subordinate to the quantitative approach but was, however, important in order

to:

1. help substantiate, connect or refute results of the space-time budget and questionnaire surveys;

2. aid in the discussion involving the implications of tourist group travel in Shetland.

3. determine "other" types of activity-based tourist groups in addition to the five specified; and

4. to provide a categorisation of sites (observed) based on access to attractions, time spent at the site, as well as how people get to these sites.

This element of the methodology was felt to be important as an approach by which the researcher could gain a more enriched understanding of tourists and their particular characteristics.

A logical extension of the type of data sought and collected through the triangulation approach included insights, interpretations, and theories that evolved through periods of observation and thought. These projections were applied to the results of the qualitative and quantitative approaches in the discussion component of this dissertation, as a meaningful part of the study.

\subsection{LIMITATIONS}

The study was limited in that it is not a longitudinal analysis. The surveys were administered over part of one tourist season, but consideration must be given to the fact that Shetland tourism is directly affected by seasonality. It was anticipated that the sample derived was a reasonable representation of the population of tourists that visit this destination throughout the year. It was important to note, however, that due to the 
nature of the sample, some tourist groups were not represented. Select groups (for example, birders) may have deliberately avoided the "typical" tourist season - June to August - in order to secure a more personal experience, anu to be present at peak migration times (Spring and Fall). The methodology may also have posed certain limitations with respect to replication, which is always exceedingly difficult for multiple methodologies such as the triangulation method adopted in this study.

Shetland visitation numbers may be subject to fluctations, from one year to another, caused by external political and economic forces. The Gulf war of 1991 and the more recent tanker disaster off the coast of the southern mainland of Shetland are noteable examples. These crises probably will not result in significant permanent changes, but rather affect total numbers over a few years.

\subsection{SURVEY COMPLETION AND RETURN}

Certain problems and successes arose in the distribution of the space-time budget - questionnaire packages at various points. Trouble was encountered in drawing the attention of tourists at the input terminals (P\&O and British Air). It was discovered that as tourists arrived in Shetland they became concerned with a variety of variables, including car rentals, taxis, luggage, and overall organisation. Only 11 surveys, therefore, were distributed in this situation.

An effective point to disperse survey packages was found to be at the Tourist Centre. At the Centre, tourists appeared to be more relaxed and receptive. However, 
it was important to approach potential respondents after they had made their arrangements at the Centre. Fifty-four surveys were disseminated in this location.

Another favourable location for dispersing surveys was through, or at the designated attraction sites (Jarlshof, Mousa, and Hermaness). Again, it was critical to approach tourists at the end of their experience to avoid distracting them from their enjoyment. From a subjective point of view, this approach was most effective, and easiest, with regard to survey distribution. Thirty-five surveys were handed-out at these sites.

Due to the small nature of the sample - 100 surveys - it was important to treat survey package distribution delicately. Packages were dispersed personally to respondents, therefore, in an effort to try to maximize response. Study participants quite often asked why the researcher did not simply leave surveys at the Tourist Centre or the Hotels. It was firmly believed that, because of the length and involvement of the study, response would have been substantially lower if surveys were distributed in a nonpersonal fashion. To the researcher's satisfaction, some respondents made comments to this effect. That is, they acknowledged and supported a more personal approach. These same respondents -- some respondents were encountered during their vacation -suggested that they would not have endeavoured to complete the survey if the researcher had not presented himself, and explained the study to them.

Most surveys were distributed to respondents during the first two days of their vacation. The researcher was hesitant to disseminate surveys to tourists after this point, due to a perceived difficulty with recall of activities, facilities, etc. A number of 
potential respondents were declined as a result. There was a low percentage of respondents, however, who insisted that they be allowed to take part in the study even though they had been in Shetland for up to five days. They explained that their personal logs were so detailed, that recall of all activities and movements in Shetland could be revived simply through a review of their diaries. In such cases, and to avoid offending the tourist(s), the survey package was distributed.

In total, 100 survey packages were distributed through the three designated points. Of this number, 68 surveys were retumed (mailed or dropped off) at the Tourist Centre. Four surveys were mailed directly to the University of Western Ontario. The total response rate then was 72 per cent. This return appears to be very favourable in light of the structure of the task. Respondents had to remain involved with the space-time budget on a daily basis throughout their vacation. For individuals on vacation, this task seemed extensive.

Difficulty was anticipated regarding the length of time it took to introduce the survey format. If, in explaining the study, the researcher took too long, there was a risk of losing the attention of the prospective respondent. A precise synopsis was required, therefore, in order for each of the respondents to fully understood the task. It was also felt that some of the english-as-a-second-language respondents may have had difficulty in understanding the study. This may have had an impact (although it is impossible to be sure) on the response rate of this part of the population.

Of the 72 survey packages returned, the space-time budget sheets varied with respect to the rigour in which they were completed. Eight respondents, for example, did 
not fill in the maps on the back of their space-time budget sheets in any way. All of the self-administered questionnaires but one were filled out (the researcher could not determine the "tourist type" of this traveller, therefore, 71 questionnaires were ultimately used in this study). It was felt that after the effort required to complete the space-time budget component of the study, the self-administered questionnaire might have scemed relatively straightforward, in terms of the time needed to complete it. Furthermore, twenty-three respondents requested to have the space-time budget sheets retumed to their homes as a record of their Shetland trip.

The researcher was pleased, in reflecting on the data collection process, to have been given mostly positive support by respondents. This support came verbally, and in a written form through letters included with the packages that participants mailed, or dropped off.

The interview and observation data-gathering process revealed that interviewees, in general, were eager to provide detailed information regarding their Shetland experience. The informal nature of the interview techrique was felt to have fostered a "friendly" atmosphere of interaction. In total, 18 travellers were questioned, in all of the designated regions of Shetland.

The amount of qualitative data collected in this study was by no means exhaustive. This type of data, though, gave the researcher the potential to draw comparisons and contrasts between quantitative and qualitative samples. Although it was the initial purpose to evaluate observational data strictly from a qualitative standpoint, it became apparent that the nature of this type of data, as pointed out earlier, lent itself 
more to analysis from a quantitative perspective. Observations and interviews provided the means by which to analyse more tourists, in a variety of different ways. The triangulation approach has thus evolved into a data-oriented scheme (the use of a variety of data sources in a study), rather than one that was based upon the comparative value of qualitative and quantitative methodologies.

\subsection{CONCLUSION}

It has been hypothesised that each tourist group holds separate travel patterns, and that their perceptions of core and periphery differ on the basis of the type of experience sought. The research methodology employed, triangulation, sought to elicit both quantitative (space-time budget survey and self-administered questionnaire) and qualitative (interview and observation) data. The results of the triangulation methodology are organised and presented in the following three chapters. 


\section{Chapter 5}

\section{A OUESTIONNAIRE ANALYSIS OF TOURIST GROUPS IN SIIETLAND}

A traveler has a right to relate and embellish his adventures as he pleases, and it is very impolite to refuse that deference and applause they deserve.

Rudolf Erich Raspe

\subsection{INTRODUCTION}

Reid and Andereck (1989: 24) suggested that much of tourism literature has neglected to establish a firm basis for understanding descriptive and inferential statistics. The authors concluded that researchers tended to ignore, altogether, descriptive statistics that may have been ideal in providing an enhanced understanding of a particular phenomenon. Conversely, inferential statistics that have been used, often failed to be "clearly identified and justified". Both types of statistics are presented in this study, as they pertain to data associated with the questionnaire (and space-time budget, interviews, and observations in subsequent chapters). The statistics and accompanying tochniques provide the means by which to bet describe the nature of Shetland travellers in space and time. This section examines questionnaire (Appendix 1) response data and, in keeping with the objectives of the study, determines similarities and/or differences 
between distinct groups of travellers (groups established based on the main reason for travel to Shetland).

\subsection{OUFSTIONNAIRE RESULTS}

Of the 72 survey packages returned, only one respondent had not attempted to complete the questionnaire. Seventy-one questionnaires, therefore, were organised into six distinct tourist groups. These groups, in addition to their per cent representation within the entire population, are illustrated in Table 5.1:

\begin{tabular}{lcr}
\hline & & \\
& Table 5.1 & \\
& Tourist Group Representation & \\
\hline Tourist & n & $\%$ \\
\hline 1. Fishers & & \\
2. Birders & 3 & 4.2 \\
3. General Sightseeing & 8 & 11.3 \\
4. Natural History & 36 & 50.7 \\
5. Archaeology/History & 7 & 9.9 \\
6. Other & 7 & 9.9 \\
\end{tabular}

The final group, "Other", contained ten travellers visiting Shetland for the following main reasons: sailing (4), photography (3), visiting friends and relatives (2), and quiet/remote island environment (1).

Frequencies were examined for all 71 tourists involved in the study. However, a point of concern regarding the aforementioned tourist groups, surrounded the small size of all except the General Sightseeing, or General Interest cohort. Such a limitation meant 
that drawing statistically significant relationships from the samples was next to impossible. To rectify this problem, in an effort to ensure statistical viability, all Special Interest tourist groups (Fishing, Birding, Natural History, History/Archacology, and "Other") were collapsed into one group of 35 tourists, to be refened to as the "Specialised", or "Special", or "Special Interest" tourist group. Direct comparisons were then made, under more statistically-acceptable conditions, between this new group and the General Sightseeing sample containing 36 tourists. All of the Tables and Figures that follow are presented as results from the surveys conducted through this research unless otherwise indicated.

Despite the fact that the select Special Interest groups could not be analysed separately, it was decided that some basic information on each group was needed for the following reasons:

1. To better understand the composition of the Special Interest cohort;

2. To directly compare each of the groups, regardless of their size; and

3. To enable the reader to further his/her understanding of Shetland travellers. Information is presented for each of the groups according wage, sex, houschold income, education, and accommodation (number of accommodation unit types used, and number of nights staying in Shetland).

The data associated with age illustrated that the Birders had the highest average age in relation to the other groups (49.5 years). Fishers reported having the next highest average age (45.7 years), followed by the "Other" group ( 44.1 years), the General Interest group (42.9 years), Natural History tourists (35.7 years, and finally by the 
History/Archaeology group (32.6 years). Overall, these figures point to the fact that the entire sanuple was variable with respect to age.

The statistics for the sample indicated a significant dominance of male versus female respondents. Over seventy per cent (71.4 per cent) of the History/Archaeology group was male (the most male-oriented sub-sample). The "Other" group also had a high percentage of males ( 70.0 per cent), followed by the Fishers ( 67.0 per cent), the Birders (62.5 per cent) and the General Interest group (58.3 per cent). The Natural History group was the only sub-sample dominated by females (57.1 per cent as females).

In regard to household income, the data were variable among the select groups. The Fishing group reported having the highest household income of all groups, by far, at 50,000 pounds per year (over 13,000 pounds more than the next highest group). Following the Fishers, the General Interest group reported earning, on average, 36,912 pounds per year, while the History/Archaeology group had an annual household income of 32,500 pounds. The Natural History sub-sample earned 30,000 pounds per year, followed by the "Other" group $(29,000$ pounds per year), and the Birders $(25,000$ pounds per year).

Despite the low income reported by the Birders, this group reported having the highest level of education at 3.4 (the continnum ranged from a score potentail of 1.0 for those with "Some Highschool" to 4.0 for those with a "Graduate Degree"). The General Interest group also had a high level of education (3.3), as did the "Other" group (3.2). The History/Archaeology group had an average education score of 3.0, while the Natural 
History group reported a score of 2.9. The Fishers maintained the lowest average education score (2.3), substantially lower than the other groups.

A vast array of information was collected and recorded on accommodation throughout Shetland. However, as a means for comparison at this stage of analysis, only the number of types of accommodation units used by the groups (e.g., B\&B, hotel, etc.), in addition to the number of nights stayed in Shetland will be reported in this section. Due to the large number of General Interest travellers $(n=36)$, in relative terms, this group ended up staying at more types of accommodation units than the other groups (7 types in all). However the Birders and "Other" groups were also variable in their selection of accommodation (6 types respectively). The History/Archaeology and Natural History groups each stayed in 5 types of accommodation, while the Fishers $(n=3)$ stayed in only 3 different types (in all likelihood due to the low number of tourists in this group, or limited choice near lochs).

Average length of stay in Shetland (nights) provided a more objcctive basis on which to compare each of the select groups of the sample. The Birders, on average, stayed longer than any other group (9.9 nights), followed by the Natural History group (8.3 nights), the History/Archaeology group (6.1 nights), and the "Other" and "Fisher" groups (6.0 nights). The group spending the least amount of time in Shetland, on average, was the General Interest group (5.7 nights). 


\subsubsection{Socio-Demographics}

Information was sought regarding certain personal characteristics of each respondent group. Four basic socio-demographic questions were included that dealt with age, sex, household income (in pounds), and level of education. Each were considered important in generating comparisons and contrasts between travel groups.

The pattern of age groupings (Table 5.2) differs slightly between General and Special Interest tourist groups. The predominant age category for both groups was the 40-49 years cohort. Half of all General Interest tourists were represented in this category, whereas just under 30 per cent of Special Interest tourists were between 40 and 49 years of age. Apart from the significance of this age category, there does not appear to be any unique numerical pattern, either within or between tourist groups, with respect to age. The average age of General (42.9 years) and Special (41.4 years) groups was very similar, with only 1.5 years as the difference.

Significant among respondents of both tourist groups was the incidence of male representation over female. Males comprised 58.3 per cent of the General tourist group and 62.9 per cent of Special Interest travellers.

Household income (in pounds) was an important consideration in gauging tourist group differences. A series of 10,000 pound categories were provided, ranging to 70,000 and up. A very unequal distribution of income was found within the General Interest group. The category with the highest frequency of representation in this group was the 10,000 to 19,999 (35.3 per cent). The next highest category of representation in the General Interest tourist group was the 70,000 pounds and up (14.7 per cent), 
Table 5.2

Socio-Demographic Characteristics by Tourist Group

\begin{tabular}{|c|c|c|c|c|}
\hline \multirow[b]{2}{*}{ Characteristic } & \multicolumn{2}{|c|}{ General } & \multicolumn{2}{|c|}{ Special } \\
\hline & n & $\%$ & $\mathbf{n}$ & $\%$ \\
\hline $\begin{array}{r}\text { AGE (years) } \\
20-29 \\
30-39 \\
40-49 \\
50-59 \\
60-69\end{array}$ & $\begin{array}{c}5 \\
6 \\
18 \\
3 \\
4\end{array}$ & $\begin{array}{c}13.9 \\
16.2 \\
50.0 \\
8.3 \\
11.1\end{array}$ & $\begin{array}{c}9 \\
5 \\
10 \\
7 \\
3\end{array}$ & $\begin{array}{c}26.5 \\
14.7 \\
29.4 \\
20.6 \\
8.8\end{array}$ \\
\hline mean: & & & & \\
\hline $\begin{array}{l}\text { male } \\
\text { female }\end{array}$ & $\begin{array}{l}21 \\
15\end{array}$ & $\begin{array}{l}58.3 \\
41.7\end{array}$ & $\begin{array}{l}22 \\
13\end{array}$ & $\begin{array}{l}62.9 \\
37.1\end{array}$ \\
\hline
\end{tabular}

HOUSEHOLD INCOME (pounds)

\begin{tabular}{lcccc} 
less than 10,000 & 3 & 8.8 & 6 & 18.2 \\
10,000 to 19,999 & 12 & 35.3 & 6 & 18.2 \\
20,000 to 29,999 & 4 & 11.8 & 8 & 24.2 \\
30,000 to 39,999 & 3 & 8.8 & 4 & 12.1 \\
40,000 to 49,999 & 2 & 5.9 & 4 & 12.1 \\
50,000 to 59,999 & 1 & 2.9 & 2 & 6.1 \\
60,000 to 69,999 & 4 & 11.8 & 1 & 3.0 \\
70,000 and up & 5 & 14.7 & 2 & 6.1 \\
\hline mean: & & 36,912 & & 30,151
\end{tabular}

LEVEL OF EDUCATION ${ }^{b}$

Some Highschool

Highers/A Levels

Undergraduate Degree

Graduate Degree
3

8.3
11.1

22.2

58.3

8

21

2

5.7

3.3

3.1

mean: ${ }^{\bullet}$

11

22.9

31.4

40.0

- Mean value based on the following formula: $\left[\left(m_{i}\right)\left(n_{i}\right)\right] / N$

"Scale: 1 = "some highschool;" 4 = "graduate degree" 
although this category was not considerably higher than others. Special Interest tourist income appears to be more evenly distributed among the first five categories, with the majority earning between 20,000 and 29,999 pounds per year.

An attempt was made to arrive at a specific mean household income value for each tourist group. To achieve this, the following formula was used (based on the midpoint of each represented income category):

$$
\bar{x}=\frac{\sum_{1-1}^{\infty}\left(m_{1} n_{1}\right)}{N}
$$

Where " $\mathrm{m}$ " was the midpoint of an income category, and " $\mathrm{n}$ " was the frequency of respondents within each category. These two values were multiplied in arriving at a figure for each category. Categories were then summed and divided by the total frequencies of responses ("N"). The result of this formula was only an approximation of income for each category and therefore for each tourist group. Also, the final category (70,000 pounds and up) cannot be accurately approximated due to constraints associated with identifying its limits. The calculated average then, should not be considered as exact.

Under the above conditions it was discovered that the General Interest group earned approximately 36,912 pounds per year compared to the 30,151 pounds earned by the Special Interest tourist group. The difference of 6,761 pounds between the two groups is considered significant, and suggests that those travelling to Shetland for General Interest purposes earn more, on average, than Special Interest travellers. 
Table 5.2 also contains information associated with level of education. A mean value was calculated for both tourist groups from an overall response pattern from each individual within each group. The four response options (some highschool, highers/A levels, undergraduate degree, graduate degree) meant that an average group response could range, theoretically, from 1.0 to 4.0 (four denoting the highest level of education). Comparatively, the General Interest tourist group had a mean education level of 3.3, while Special Interest tourists averaged slightly less at 3.1. Age may help explain this result, as $\mathbf{2 6 . 5}$ per cent of Special Interest travellers were less than 30 years of age (a factor that may also explain their lower level of income). A closer analysis indicates that over half (58.3 per cent) of General tourists had a graduate degree and 22.2 per cent had an undergraduate degree (a total of 80.5 per cent university training). Conversely, 40.0 per cent of Special Interest tourists had a graduate degree, with 31.4 per cent having an undergraduate degree (a total of 71.4 per cent with university training).

\subsubsection{Repeat Visitation}

Table 5.3 provides data that pertain to characteristics of repeat visitation. Both General and Special Interest tourist groups were compared in two ways (in this question and in subsequent questions). Due to the fact that there is an unequal number of tourists in both groups ( $n=36$, General Interest; $n=35$, Special Interest) both groups' response patterns were averaged before being compared in order to arrive at a viable, internallybased foundation for comparison. The first, per cent Intergroup response, is the reflection of the percentage of each group in the overall response concerning how many 
tourists were visiting Shetland two or more times. The data indicates that 54.8 per cent of the sample that were repeat visitors to Shetland were Special Interest tourists. Conversely, 45.2 per cent of repeat visitors were of the General Interest sub-sample.

\section{Table 5.3}

Characteristics of Repeat Visitors

\begin{tabular}{lll}
\hline Tourist & \% Intergroup & \% Intragroup \\
Group & Response & Response
\end{tabular}

General Interest

45.2

13.9

Special Interest

54.8

17.1

$$
\text { Mean }=.845 ; \text { s.d. }=.364
$$

Per cent Intragroup response is a means with which to better understand withingroup response characteristics. Subtle differences between tourist groups were noticed, as both groups did not have the same number of respondents (General, $n=36$; Special, $n=35$ ). The measure, then, portrays the actual per cent representation of a particular group in the overall response. Table 5.3 illustrates that 17.1 per cent of Special Interest tourists were involved in the response, whereas 13.9 per cent of all General Interest tourists were represented as repeat visitors.

\subsubsection{Characteristics of a Planned Itinerary}

Respondents were asked to indicate whether or not they had consciously prepared a planned itinerary prior to leaving home. Such a measure would provide information on how prospective tourist groups approached or organised their Shetland vacation. 
Table 5.4 indicates that 62.0 per cent of the Special Interest group had an itinerary, whereas 38.0 per cent of General Interest tourists organised themselves in this manner.

Table 5.4

Characteristics of a Planned Personal Itinerary

\begin{tabular}{lcc}
\hline \multicolumn{1}{c}{ Tourist Group } & $\begin{array}{c}\text { \% Intergroup } \\
\text { Response }\end{array}$ & $\begin{array}{c}\text { \% Intragroup } \\
\text { Response }\end{array}$ \\
\hline General Interest & 38.0 & 19.4 \\
Special Interest & 62.0 & 31.4 \\
\hline
\end{tabular}

$$
\text { Mean }=.257 ; \text { s.d. }=.440
$$

Intragroup itinerary dynamics data suggest that just under one-third of Special Interest tourists (31.4 per cent) constructed an itinerary. On the other hand, only about one-in-five (19.4 per cent) of the General Interest group were represented in this response. The mean value of $0.257(s . d .=.440)$ provides evidence to suggest that the vast majority of respondents chose not to prepare an itinerary at all. Data of this nature are interesting, in speculation, as they suggest that most types of tourists prefer not to limit themselves to pre-defined plans while travelling in Shetland.

\subsubsection{Accumulation of Free Brochures}

Interpretive material on Shetland as a travel destination is readily available through both domestic and international travel agencies. Travellers also have the option of using the Shetland Tourist Organisation, which distributes information on a wide variety of attractions and services. Interpretive information is also available to tourists, 
while in Shetland, again through the tourist office, and via shops and larger attractions. This pool of readily-available information prompted the researcher to pursue how and where travellers attained interpretive information on Shetland. Table 5.5 provides data on where tourist groups attained free brochures on Shetland, if at all. Most tourists accumulated brochure information "While in Shetland" $(n=46)$. Of these 46 respondents, 51.5 per cent were General Interest travellers, while slightly less (48.5 per cent) were Special Interest tourists. Two-thirds of all General Interest tourists attained free brochures "While in Shetland", while 62.9 per cent of the Special Interest group acted in like fashion.

\section{Table 5.5}

\section{Statements Associated with the Accumulation} of Free Brochures

\begin{tabular}{lccc}
\hline Statement & Tourist & $\begin{array}{c}\text { \%Intergroup } \\
\text { Response }\end{array}$ & $\begin{array}{c}\text { \%Intragroup } \\
\text { Response }\end{array}$ \\
\hline
\end{tabular}

While in Shetland

Yes $(n=46 ; 64.8 \%)$

1

2

Before Visiting Shetland

Yes $(n=39 ; 54.9 \%)$

Did Not Collect
Yes $(n=8 ; 11.3 \%)$
$\mathbf{1}$
49.1
50.9
11.1
11.4

51.5

48.5

66.7

62.9

53.2

46.8

58.3

51.4

Tourist group representation: 1 = General, 2 = Special 
Just over half (54.9 per cent) of all tourists sought brochures "Before Visiting Shetland". The pattern of this accumulation is similar to the previous statement ("While in Shetland") with respect to tourist group dynamics. Of the 39 respondents indicating "yes", just over half (53.2 per cent) were General Interest tourists, while 46.8 per cent were Special Interest tourists. Again, both groups attained over 50 per cent representation in their response to this question. Only eight tourists in total did not collect any free interpretive material at all. Those who did not were equally distributed between the two tourist groups.

Table 5.6 takes a different approach to the idea of interpretive material: that which was bought (by group) associated with prime reason for travel to Shetland. Fourteen different types of interpretive material were purchased representing 95 individual pieces of literature. Twenty-four respondents indicated purchasing archaeological guides in association with their prime reason for travel to Shetland. Of these $24,50.0$ per cent were purchased by both tourist groups equally. The high frequency of response for archaeological guides contrasts markedly with the number of tourists visiting Shetland for archaeology as their prime reason (7), as outlined in Table 5.1. In explaining this discrepancy, two scenarios need to be considered. First, respondents may have misinterpreted the question. Theoretically, in this case, only seven respondents should have indicated purchasing archaeological guides as material associated with their "Prime Reason for Travel to Shetland". The second scenario follows that the sample maintained a number of latent or secondary reasons/motivations for travel to Shetland. 
Table 5.6

Interpretive Material Bought Associated with Prime Reason for Travel to Shetland

\begin{tabular}{|c|c|c|c|c|}
\hline \multirow[b]{2}{*}{ Material } & \multicolumn{2}{|c|}{ General } & \multicolumn{2}{|c|}{ Special } \\
\hline & $\mathbf{n}$ & $\overline{\%}$ & $\mathbf{n}$ & $\overline{\%}$ \\
\hline Archacology Guides & 12 & 50.0 & 12 & 50.0 \\
\hline Bird Guides & 5 & 26.3 & 14 & 73.7 \\
\hline Maps & 12 & 80.0 & 3 & 20.0 \\
\hline Official Tourist Guide & 7 & 70.0 & 3 & $\mathbf{3 0 . 0}$ \\
\hline Transport Timetable & 6 & 100.0 & - & - \\
\hline Shetland Place Guides & 2 & 33.3 & 4 & 66.7 \\
\hline Scotland Guides & 3 & 75.0 & 1 & 25.0 \\
\hline Fishing Guides & - & - & 2 & 100.0 \\
\hline Sea Charts/Guides & - & - & 2 & 100.0 \\
\hline Shetland Video & 2 & 100.0 & - & - \\
\hline Walling Guide & 1 & 50.0 & 1 & 50.0 \\
\hline Bobby Tulloch Guide & 1 & 100.0 & - & - \\
\hline Shetland Bus & - & - & 1 & 100.0 \\
\hline Wild Flower Guide & 1 & 100.0 & - & - \\
\hline
\end{tabular}

A similar outcome is observed with respect to the purchase of bird guides. Previously (Table 5.1) only eight respondents indicated birding as their prime reason for travelling to Shetland. However, 19 respondents bought bird guides. Of significance though is the fact that 73.7 per cent of those 19 were Special Interest tourists.

Another statistic of consequence is the purchase of what might be termed "secondary guides" (e.g., maps, official tourist guides, and transport timetables). These guides, in themselves, are not directly related to the prime reasons for visiting Shetland; however, they do provide the impetus for travellers to find their favoured sites of interest. Using the example of the three secondary guides mentioned above, it is 
interesting to note the uneven group purchase dynamics of these guides. Thirty-one of these guides were purchased by the sample. Of these $31,80.6$ per cent were bought by the General Interest tourist group.

\section{2 .5 Information Sounces}

Of considerable interest to tourism marketing officials is the manner by which tourists gain information about deciding to visit travel destinations. Such information is valuable in producing strategies to target market selected segments of domestic or international regions. The questionnaire distributed to Shetland travellers provided eight options in determining how respondents were able to "become informed" of Shetland. The sample was also given the opportunity to rank those sources (if more than one was selected) that were of importance. Table 5.7 summarises this information in a format that provides a series of different sets of data. Each of the sources in Table 5.7 were compared on the basis of number of times ranked, the wtal numerical value of the frequency ranked, a rank average based on the two previously mentioned categories, in addition to a group average calculated by dividing rank values by the frequency ranked for cach tourist group. The sources appear in ascending order based on the rank average (the lower the rank, the more important the information source). It should be noted that there is a discrepancy between the " $n$ " value of some sources, and the associated "frequency ranked" (in theory these two numbers should be the same). Due to the fact that some respondents ticked a response rather than provided a numerical rank, no accurate reading of true rank could be recorded. 


\begin{tabular}{|c|c|c|c|c|c|}
\hline \multicolumn{6}{|c|}{ Information Sources Ranked by Tourist Group } \\
\hline Source & $\begin{array}{l}\text { Frequency } \\
\text { Ranked }\end{array}$ & $\begin{array}{l}\text { Rank } \\
\text { Value }\end{array}$ & $\begin{array}{l}\text { Rank } \\
\text { Ave. }\end{array}$ & $\begin{array}{l}\text { Tourist } \\
\text { Group }\end{array}$ & $\begin{array}{l}\text { Group } \\
\text { Ave. }\end{array}$ \\
\hline \multicolumn{6}{|l|}{ Newspaper } \\
\hline Yes $(n=3 ; 4.2 \%)$ & 3 & 3 & 1.00 & $\begin{array}{l}1 \\
2\end{array}$ & 1.00 \\
\hline \multicolumn{6}{|l|}{ Other } \\
\hline Yes $(n=17 ; 23.9 \%)$ & 11 & 14 & 1.27 & $\begin{array}{l}1 \\
2\end{array}$ & $\begin{array}{l}1.17 \\
1.40\end{array}$ \\
\hline \multicolumn{6}{|l|}{ Books } \\
\hline Yes $(n=31 ; 44.3 \%)$ & 26 & 36 & 1.38 & $\begin{array}{l}1 \\
2\end{array}$ & $\begin{array}{l}1.60 \\
1.10\end{array}$ \\
\hline \multicolumn{6}{|l|}{ Friends/Family } \\
\hline Yes $(n=33 ; 46.5 \%)$ & 31 & 45 & 1.45 & $\begin{array}{l}1 \\
2\end{array}$ & $\begin{array}{l}1.67 \\
1.32\end{array}$ \\
\hline \multicolumn{6}{|l|}{ Travel Agent } \\
\hline Yes $(n=6 ; 8.5 \%)$ & 5 & 8 & 1.60 & $\begin{array}{l}1 \\
2\end{array}$ & $\begin{array}{l}1.25 \\
3.00\end{array}$ \\
\hline \multicolumn{6}{|l|}{ Travel Brochure } \\
\hline Yes $(n=19 ; 26.8 \%)$ & 16 & 28 & 1.75 & $\begin{array}{l}1 \\
2\end{array}$ & $\begin{array}{l}1.90 \\
1.50\end{array}$ \\
\hline \multicolumn{6}{|l|}{ Television } \\
\hline Yes $(n=4 ; 5.6 \%)$ & 3 & 6 & 2.00 & $\begin{array}{l}1 \\
2\end{array}$ & $\begin{array}{l}2.50 \\
1.00\end{array}$ \\
\hline \multicolumn{6}{|l|}{ Magazine } \\
\hline Yes $(n=3 ; 4.2 \%)$ & 1 & 4 & 4.00 & $\begin{array}{l}1 \\
2\end{array}$ & $\begin{array}{c}4.00 \\
-\end{array}$ \\
\hline \multicolumn{6}{|c|}{$\begin{array}{l}\text { Discrete response options were ranked, one denoting the most important. } \\
\text { Rank Average calculated by dividing Rank Value by Frequency Ranked. } \\
\text { Group Average calculated by dividing associated Rank Values by } \\
\text { Frequency Ranked for each tourist group. }\end{array}$} \\
\hline
\end{tabular}

"Newspaper" appeared as the most important information source. Although it was only ranked three times, it was ranked $f_{w i}$ st each time. 11 addition, only the General 
Interest tourists found newspapers to be a valuable information source on Shetland. As the second most important source, "Other" caused some concern regarding an interpretation of the question. More than half of those tourists who ranked "Other" confused sources of inisrmation with motivation. On one hand some respondents selected legitimate "Other" sources such as "sailing club", "a colleague", "previous visits", and "maps". Conversely, some included "magazine", "always wanted to visit islands", "love of islands", "Lerwick tourist office", "coach operators tour brochure", "curiosity", and "one place no one in family has visited".

"Books" and "Friends/Family" both had the highest frequency of response among respondents (44.3 per cent and 46.5 per cent respectively). "Books" had a ranked average of 1.38 , with the Special Interest group (1.10) finding this source to be more important than the General Interest group (1.60). Similarly, the Special Interest group (1.32) found "Friends/Family" to be of more importance than the General group (1.67). The "Travel Agent" (1.60) had more utility for the General tourist group, while "Travel Brochures" (1.75) were an information source valued more by the Special group. Both "Television" and "Magazines" had a low frequency of response, with a corresponding low ranked average compared with the above mentioned sources.

\subsubsection{Natural History and Archaeological Familiarity}

It has been noted previously that there exist two overriding themes that characterise Shetland: nature and archaeology. The former has been a valued attraction for centuries, while the latter has been emphasised more recently as archaeologists 
continue to piece together Shetland's Stone, Bronze, and Iron Age past. Regarding the survey tool, importance was placed on trying to understand how familiar respondents were with respect to both of these different types of attractions (Table 5.8).

\section{Table 5.8}

Familiarity with Natural History and Archaeology

\begin{tabular}{llllll}
\hline & \multicolumn{2}{c}{ General } & & \multicolumn{2}{c}{ Special } \\
\cline { 2 - 3 } \cline { 5 - 6 } Characteristic & mean & s.d. & & mean & s.d. \\
\hline Natural & 3.46 & 1.15 & & 2.71 & 1.02 \\
Archaeology & 3.40 & 1.06 & & 3.06 & 1.14
\end{tabular}

$$
\begin{aligned}
& \text { Based on a 5-point scale: } 1 \text { = very familiar, } \\
& 5=\text { not at all familiar. }
\end{aligned}
$$

This Table provides data concerning natural history and archaeology familiarity for both General and Special Interest tourist groups. Mean and standard deviation statistics were provided based on the response to a five-point scale (one denoting the highest level of familiarity). The largest difference between tourist groups was discovered from an analysis of natural history familiarity. Comparatively, Special Interest tourists $(\operatorname{mean}=2.71 ;$ s.d. $=1.02)$ had a higher degree of familiarity than General Interest tourists $(\operatorname{mean}=3.46$; s.d. $=1.15)$, with a response profile that was more concentrated. The Special Interest group was also found to be more familiar with archaeology $($ mean $=3.06 ;$ s.d. $=1.14)$ than the General group of travellers (mean $=$ 3.40; s.d. $:=1.06$ ), although the difference between the two groups was not so marked as the natural history data. 
In general, Table 5.8 does not illustrate results that are indicative of a group of tourists that were overly familiar with natural history and archaeology. If anything, the data suggest an "average" or "working" knowledge of the two types of attractions which might not, in speculation, set these tourists apart from other types of travellers.

\subsubsection{Travel Companionship}

The characteristics of travel companionship are outlined in Table 5.9. Six different options were available to respondents in providing the researcher with another dimension concerning the dynamics of the two travel groups. Of the entire sample, 35.2 per cent travelled "With Spouse" as the highest representation of travel companionship. Slightly more of these tourists were affiliated with the General Interest group (55.7 per cent) and an accompanying higher representation within that group. Other significant companions included "With a Friend" (28.2 per cent of the sample), and "With Family" (22.5 per cent of the sample). Both of these types of companions showed a similar evensplit between General and Special Interest tourists, and an associated low within-group representation based on the low overall frequency of response.

Less significant (in terms of frequency of response) were travelling "Alone" ( $n=$ 6; 8.5 per cent), "Other" ( $n=6 ; 8.5$ per cent), and "With a Tour" ( $n=3 ; 4.2$ per cent). Most of those who travelled alone (82.4 per cent) were Special Interest tourists, while two-of-three tourists who went with a tour were General Interest tourists. The six "Other" travel companions (dog, mother, two friends, mom, brother, and friends from Brae) illustrate that for some, the question was either poorly worded or they were 
Table 5.9

Characteristics of Travel Companionship

\begin{tabular}{lccc}
\hline Companion & $\begin{array}{c}\text { Tourist } \\
\text { Group }\end{array}$ & $\begin{array}{c}\text { \%Intergroup } \\
\text { Response }\end{array}$ & $\begin{array}{c}\text { \%Intragroup } \\
\text { Response }\end{array}$ \\
\hline
\end{tabular}

With Spouse

$\begin{array}{llll}\text { Yes }(n=25 ; 35.2 \%) & 1 & 55.7 & 38.9 \\ & 2 & 44.3 & 31.4\end{array}$

With a Friend

$\begin{array}{llll}\text { Yes }(n=20 ; 28.2 \%) & 1 & 49.1 & 27.8 \\ & 2 & 50.9 & 28.6\end{array}$

With Family

$\begin{array}{llll}\text { Yes }(n=16 ; 22.5 \%) & 1 & 55.6 & 25.0 \\ & 2 & 44.4 & 20.0\end{array}$

Alone

$\begin{array}{cccc}\text { Yes }(n=6 ; 8.5 \%) & 1 & 17.6 & 2.8 \\ & 2 & 82.4 & 14.3\end{array}$

Other

$\begin{array}{llll}\text { Yes }(n=6 ; 8.5 \%) & 1 & 49.1 & 8.3 \\ & 2 & 50.9 & 8.6\end{array}$

With a Tour

$\begin{array}{llll}\text { Yes }(n=3 ; 4.2 \%) & 1 & 65.9 & 5.6 \\ & 2 & 34.1 & 2.9\end{array}$

Tourist group representation: $1=$ General, $2=$ Special

confused. In hindsight, and to avoid confusion, certain response options for this question might have been altered. For instance, "With a Family" might have read "With Family" to imply single or plural emphasis. Similarly, "With a Friend" might have read "With Friend(s)" also to imply single or multiple friends.

In conclusion, most respondents travelled in Shetland primarily with their spouse, followed by friends, and then with family. Very few travelied alone, in "Other" ways, or with a tour. 


\subsubsection{Travel Mode Characteristics}

Four travel mode response options were provided in the questionnaire and are reported in Table 5.10. Type of travel was thought to provide information that would lead to inferences on freedom of movement (e.g., car) compared to other modes (e.g., bus), that would have implicit, imposed spatial-temporal limitations to movement. Clearly the "Car" (52 respondents travelled in this way) was the predominant mode of travel. Further analysis suggests that there was a measurable but not significant difference between General (45.6 per cent) and Special (54.4 per cent) Interest group usage. The value of the car to each group was determined in the per cent intragroup response. Here, 80.0 per cent of all Special Interest and two-thirds of all General Interest tourists used this form of transport.

Thirty-five respondents indicated use of "Other" forms of transportation, which included ferry/boat (26 times), walking (9 times), hitchhiking ( 2 times), air ( 1 time), taxi (1 time), and camping car ( 1 time). Just over fifty-nine per cent of this use was General and $\mathbf{4 0 . 8}$ per cent was Special Interest. Thirty-one per cent of all respondents used a "Bus" (either as a coach tour or route service) with the majority of these users (58.1 per cent) General Interest. Coach tours ran as day trips to selected attraction sites, while the bus route service shuttled tourists and/or locals along scheduled mainland routes.

Very few tourists ( 9.9 per cent) chose to travel by "Bicycle". Shetland, as a relatively small destination, is conducive to travel by bicycle. It has an excellent road network and the ferry system readily accepts bikes at a reduced fare. Potential limitations to bicycle travel are primarily weather related (strong winds and rain) and 


\begin{tabular}{|c|c|c|c|}
\hline Table 5.10 & Mode Ch & cteristics & \\
\hline Mode & $\begin{array}{l}\text { Tourist } \\
\text { Group }\end{array}$ & $\begin{array}{l}\text { \%Intergroup } \\
\text { Response }\end{array}$ & $\begin{array}{l}\text { \%intragroup } \\
\text { Response }\end{array}$ \\
\hline $\begin{array}{l}\text { Car } \\
\text { Yes }(n=52 ; 73.2 \%)\end{array}$ & $\begin{array}{l}1 \\
2\end{array}$ & $\begin{array}{l}45.6 \\
54.4\end{array}$ & $\begin{array}{l}66.7 \\
80.0\end{array}$ \\
\hline $\begin{array}{l}\text { Other } \\
\qquad \text { Yes }(n=35 ; 49.3 \%)\end{array}$ & $\begin{array}{l}1 \\
2\end{array}$ & $\begin{array}{l}69.2 \\
40.8\end{array}$ & $\begin{array}{l}58.3 \\
40.0\end{array}$ \\
\hline $\begin{array}{l}\text { Bus } \\
\text { Yes }(n=22 ; 31.0 \%)\end{array}$ & $\begin{array}{l}1 \\
2\end{array}$ & $\begin{array}{l}58.1 \\
41.9\end{array}$ & $\begin{array}{l}36.1 \\
25.7\end{array}$ \\
\hline $\begin{array}{l}\text { Bicycle } \\
\qquad \text { Yes }(n=7 ; 9.9 \%)\end{array}$ & $\begin{array}{l}1 \\
2\end{array}$ & $\begin{array}{l}55.0 \\
45.0\end{array}$ & $\begin{array}{l}11.1 \\
8.6\end{array}$ \\
\hline
\end{tabular}

possibly cost and difficulty of bringing a bicycle with one.

\subsubsection{Repional Visitation}

As outlined in Chapter Four, Shetland was disided into four functional regions based on a combination of access and the physiographic nature of these areas (urban mainland, rural mainland, passenger ferry isles, car ferry isles). The overall size of Shetland, approximately 130 road kilometres from north to south, and the availability of regularly scheduled ferry crossings, suggests that intraregional travel between the main islands in the archipelago is achieved with ease. 
Table 5.11

Group Propensity to Visit All Regions of Shetland

\begin{tabular}{lcc}
\hline $\begin{array}{l}\text { Tourist } \\
\text { Group }\end{array}$ & $\begin{array}{c}\text { \% Intergroup } \\
\text { Response }\end{array}$ & $\begin{array}{c}\text { \%Intragroup } \\
\text { Response }\end{array}$ \\
\hline General & 51.4 & 36.1 \\
Special & 48.6 & 34.3 \\
\hline
\end{tabular}

$$
\text { Mean }=.352 ; \text { s.d. }=.481
$$

This accessibility provided the impetus for understanding whether tourists felt compelled to visit all of the major regions of Shetland. It was discovered (Table 5.11) that of the entire sample, most did not "Visit all Regions of Shetland" (mean $=.352$; s.d. $=.481)$. Of those who did, there was very little difference between General and Special Interest tourists (51.4 per cent and 48.6 per cent respectively). The intragroup response rate suggests a low and fairly even split between tourist groups with respect to group membership.

\subsubsection{Travel Diary}

As noted earlier, little work has been devoted to the analysis of tourist travel diaries. There seems to be potential in unlocking very personal perceptions and motivations of individuals on vacation, first-hand. Although it is beyond the scope of this research to conduct such analysis, it was thought that General and Special Interest tourists might differ in their need to record travel events. It was envisioned that the act of reflecting on one's experiences at a destination, was one way of separating types of 
tourists, perhaps on the basis of Cohen's (1979) phenomenology of tourist experiences. Those who kept diaries might be considered to have a higher level of self-awareness.

\begin{tabular}{|c|c|c|}
\hline \multicolumn{3}{|c|}{ Tourrist Group Travel Diary Recordings } \\
\hline $\begin{array}{l}\text { Tourist } \\
\text { Group }\end{array}$ & $\begin{array}{c}\text { \% Intergroup } \\
\text { Response }\end{array}$ & $\begin{array}{c}\text { \% Intragroup } \\
\text { Response }\end{array}$ \\
\hline $\begin{array}{l}\text { General } \\
\text { Special }\end{array}$ & $\begin{array}{l}52.1 \\
47.9\end{array}$ & $\begin{array}{l}50.0 \\
45.7\end{array}$ \\
\hline \multicolumn{3}{|c|}{ Mean $=.486 ;$ s.d. $=.503$} \\
\hline
\end{tabular}

Table 5.12 illustrates that there is little difference with respect to those touristsGeneral and Special Interest - who kept a diary (52.1 per cent and 47.9 per cent respectively). Per cent intragroup response indicates that half of all General Interest tourists maintained a diary, whereas 45.7 per cent of the Special group kept a diary of daily activities. The mean value of $.486($ s.d. $=.503)$ suggests that slightly fewer than half of all tourists felt the need to keep a daily travel record.

\subsubsection{Reasons for Visiting Shetland}

Several authors (McIntosh and Goeldner, 1990; Mathieson and Wall, 1982; Dann, 1981; Mayo and Jarvis, 1981; and Crompton, 1979) have explored how motivation may contribute to an explanation of tourist behaviour. Important in much of their work is an understanding of why tourists visit certain destinations. Some of their ideas have been integrated into this study as a tool in evaluating Shetland travellers (Table 5.13). 
Table 5.13

Items Describing Reasons for Visiting Shetland (Ranked by Tourist Group)

\begin{tabular}{lccccc}
\hline Items & $\begin{array}{c}\text { Frequency } \\
\text { Ranked }\end{array}$ & $\begin{array}{c}\text { Rank } \\
\text { Value }\end{array}$ & $\begin{array}{c}\text { Rank } \\
\text { Ave. }\end{array}$ & $\begin{array}{c}\text { Tourist } \\
\text { Group }\end{array}$ & $\begin{array}{c}\text { Group } \\
\text { Ave. }\end{array}$ \\
\hline $\begin{array}{l}\text { Other } \\
\text { Yes }(n=24 ; 34.3 \%)\end{array}$ & 17 & 26 & 1.53 & 1 & 1.78 \\
& & & & 2 & 1.25 \\
$\begin{array}{l}\text { Wish Fulfillment } \\
\text { Yes }(n=33 ; 47.1 \%)\end{array}$ & 23 & 61 & 1.85 & 1 & 1.79 \\
& & & & 2 & 1.93
\end{tabular}

Relaxation

Yes $(n=56 ; 80.0 \%)$

47

92

1.96

1

1.92

$2 \quad 2.00$

Strengthen Family

$$
\text { Yes }(n=9 ; 12.9 \%)
$$

16

2.00

1

1.00

$2 \quad 2.14$

Educational Opportunity

$$
\text { Yes }(n=28 ; 40.0 \%)
$$

26

65

2.50

$\begin{array}{ll}1 & 2.56 \\ 2 & 2.40\end{array}$

Escape Job, etc.

$$
\text { Yes }(n=30 ; 42.9 \%)
$$

26

65

2.50

1

2.36

Social Interaction

$$
\text { Yes }(n=14 ; 20.0 \%)
$$

9

34

3.78

1

Shopping

$$
\text { Yes }(n=11 ; 15.7 \%)
$$

8

34

$\begin{array}{ll}4.25 & 1 \\ & 2\end{array}$

Prestige

$$
\text { Yes }(n=5 ; 7.1 \%)
$$

3

17

$\begin{array}{ll}5.67 & 1 \\ & 2\end{array}$

Tourist group representation: $1=$ General, $2=$ Special.

Discrete response options were ranked; one denoting most important. Rank Average calculated by dividing Rank Value by Frequency Ranked. Group Average calculated by dividing the associated Rank Values by Frequency Ranked for each tourist group. 
The data presented in Table 5.13 mirror the style of data presented in Table 5.10 (number of times an item was ranked, total numerical value of the frequency ranked, a rank average, and a group average calculated by dividing rank values by the frequency ranked for each tourist group). As with Table 5.10, there is a discrepancy between the " $n$ " value and "frequency ranked" due to the fact that some respondents ticked a response, rather than ranking it numerically. As such, only ranked values were used.

Of the nine items presented in Table 5.13, "Other" emerged as having the lowest rank score (the lower the rank score, the more important the item). Of all tourists, 34.3 per cent stated an "Other" item as a reason for visiting Shetland. These items included: birds/wildlife/nature $(n=8)$, sailing $(n=3)$, see Scottish Islands $(n=3)$, photography $(n=2)$, shell collecting $(n=1)$, to escape hot climate of Italy,$\mu=1)$, summer holiday $(n=1)$, visit friend $(n=1)$, and study $(n=1)$. The group average statistic illustrates that Special Interest tourists (1.25) felt that these "Other" items were more important than General Interest tourists (1.78).

General Interest tourists, conversely, felt that items such as "Wish Fulfillment" (1.79), "Relaxation" (1.92), "Strengthen Family Bonds" (1.00), "Escape Job, etc." (2.36), "Social Interaction" (3.60), "Shopping" (4.20), and "Prestige" (5.00) were, compared to Special Interest tourists, more important in visiting Shetland. An exception to this overwhelming trend lies with "Educational Opportunity" which Special Interest (2.40) travellers found to be alightly more important than the General group (2.56). 


\subsubsection{Trip Satisfaction}

Trip satisfaction, Table 5.14, was determined through the incl...' on of the following four factors: "Accommodation", "Transportation", "Food", and "Weather". Each were felt to be basic physiological needs of considerable importance in gauging feelings regarding the success of any trip.

\section{Table 5.14}

\section{Trip Satisfaction}

\begin{tabular}{|c|c|c|c|c|}
\hline \multirow[b]{2}{*}{ Aspect } & \multicolumn{2}{|c|}{ General } & \multicolumn{2}{|c|}{ Special } \\
\hline & mean & s.d. & mean & s.d. \\
\hline $\begin{array}{l}\text { Accommodation } \\
\text { Transportation } \\
\text { Food } \\
\text { Weather }\end{array}$ & $\begin{array}{l}1.65 \\
1.83 \\
2.15 \\
2.29\end{array}$ & $\begin{array}{l}0.81 \\
1.11 \\
1.10 \\
1.02\end{array}$ & $\begin{array}{l}1.83 \\
1.91 \\
2.24 \\
2.37\end{array}$ & $\begin{array}{l}0.79 \\
1.09 \\
1.00 \\
1.09\end{array}$ \\
\hline
\end{tabular}

$$
\begin{aligned}
& \text { Based on a 5-point scale: } 1 \text { = very satisfied, } \\
& 5=\text { not at all satisfied. }
\end{aligned}
$$

An emergent theme in the data of Table 5.14 is the pattern of response of both groups. General and Special Interest tourists ranked (mean values are presented of a five-point scale, 1.0 denoting the highest level of satisfaction) each of the four aspects in the same order ("Accommodation" first, "Weather" last). Also of significance is the fact that the General group was more satisfied with each of these aspects, than was the Special Interest group. In speculating on the reasons for this trend, one might assume either that General Interest tourists have a higher tolerance to travel infrastructure/conditions, or that Special Interest tourists maintained higher expectations 
or standards. The difference between mean values, however, is not so pronounced to warrant drawing significant conclusions from the four aspects independently. What is perhaps more significant is the pattern of response indicating a higher level of satisfaction for all four aspects by the General Interest group.

\subsubsection{Activities Intermupted by Poor Wenther}

The results of the previous section (Table 5.14) provided the rationale for including this type of question in the survey format. Although it was found that tourists were at least mildly satisfied with the weather, this question might pose as an interesting comparison of a region noted for its harsh, kaleidoscopic weather patterns. It was discovered that $(\operatorname{mean}=.366 ;$ s.d. $=.485)$ more than one-third of respondents reported having activities interrupted by poor weather (Table 5.15). The per cent intergroup response data indicated that General Interest tourists ( 57.5 per cent) felt the impact of weather more than the Special Interest group (42.5 per cent).

\section{Table 5.15}

Tourist Activities Interrupted by Poor Weather

\begin{tabular}{lcc}
\hline $\begin{array}{l}\text { Tourist } \\
\text { Group }\end{array}$ & $\begin{array}{c}\text { \% Intergroup } \\
\text { Response }\end{array}$ & $\begin{array}{c}\text { \% Intragroup } \\
\text { Response }\end{array}$ \\
\hline General & 57.5 & 41.7 \\
Special & 42.5 & 31.4 \\
\hline
\end{tabular}

$$
\text { Mean }=.366 ; \text { s.d. }=.485
$$




\subsubsection{Terms Describing the Shetland Travel Experience}

A variety of terms were presented to respondents in the questionnaire as descriptives of the Shetland travel experience. Tourists were requirad to indicate which of these terms were important in describing their trip. In addicion, those terms indicated were to be ranked in order of importance (one denoting the term that was most important in describing the travel experience). As with Tables 5.10 and 5.13, Table 5.16 combines data concerning frequency rank of each term, rank value, rank average, and group average. Data derived from this measure were considered instrumental in further defining the characteristics of travel groups in Shetland. The question moves away from the notion of perception or precursors to travel, to actual on-site experiential feelings of the destination region.

Although the sample felt more inclined to describe Shetland as "Natural" $(n=47$; 66.2 per cent), "Isolated" ( $n=27 ; 38.0$ per cent) was the term ranked firs، $(2.04)$, on average, over all others. Both "Beautiful" ( $n=40 ; 56.3$ per cent) and "Relaxing" ( $n=$ 41; 57.7 per cent) were also among the highest in terms of frequency ranked. These fell short of "Isolated", "Natural", and "Rugged", however, when considering rank average.

Of considerable interest is the position of "Other" terms (2.65) relat; , e to the importance of "Other" found in Tables 5.10 and 5.13 (Information Sources and Reasons for Visiting Shetland). This may be attributed to the fact that the terms used in Table 5.16 were perhaps more applicable than the sources or items used in these other measures. "Other" terms $(n=22 ; 31.0$ per cent) identified to describe the Shetland travel experience included "quiet"/"calm" $(n=5)$, "fascinating"/"spectacular" $(n=3)$, 
Trble 5.16

Terms Used to Describe the Shetland Travel Experience

\begin{tabular}{lccccc}
\hline & Frequency & Rank & Rank & Tourist Group \\
Term & Ranked & Value & Ave. Group Ave.
\end{tabular}

Isolated

Yes $(n=27 ; 38.0 \%)$

Natural

Yes $(n=47 ; 66.2 \%)$

Rugged

Yes $(n=23 ; 32.4 \%)$

Beautiful

Yes $(n=40 ; 56.3 \%)$

Untamed

Yes $(n=12 ; 16.9 \%)$

Relaxing

Yes $(n=41 ; 57.7 \%)$

Other

Yes $(n=22 ; 31.0 \%)$

Remote

$$
\text { Yes }(n=25 ; 35.2 \%)
$$

Stimulating

$$
\text { Yes }(n=20 ; 28.2 \%)
$$

Romantic

$$
\text { Yes }(n=8 ; 11.3 \%)
$$

Fun

$$
\text { Yes }(n=2 ; 2.8 \%)
$$

27

$55 \quad 2.04$

$\begin{array}{ll}1 & 2.27 \\ 2 & 1.87\end{array}$

47

104

2.21

$\begin{array}{ll}1 & 2.08 \\ 2 & 2.35\end{array}$

23

$52 \quad 2.26$

1

2.36

2.11

40

$93 \quad 2.32$

1

2.30

2.35

12

$\begin{array}{lll}30 & 2.50 \quad \\ & & 2\end{array}$

2.75

$2 \quad 2.37$

41

106

2.59

1

2.62

$2 \quad 2.60$

31

82

2.65

$\begin{array}{ll}1 & 2.37 \\ 2 & 2.93\end{array}$

25

$67 \quad 2.68$

$1 \quad 2.79$

$2 \quad 2.55$

20

$\begin{array}{llll}57 & 2.85 & 1 & 3.14 \\ & & 2 & 2.69\end{array}$

8

$\begin{array}{llll}26 & 3.25 & 1 & 2.50 \\ & & 2 & 3.50\end{array}$

2

Tourist group representation: $1=$ General, $2=$ Special 
"interesting"/"impressive' $(\Lambda=3)$, "unspoiled"/"undisturbed" ( $=3$ ), "different"/"unique" $(n=3)$, "peaceful"/"friendly" ( $n=3)$, "windy" $(n=2)$, "exciting "/"adventuresome" $(n=2)$, and "desolate", "dramatic", "northerly", "British", "ancient", "raw", and "scenic" (all with $n=1$ ). Respondents chose to rank "Remote" (2.68), "Stimulating" (2.85), "Romantic" (3.25), and "Fun" (3.50) as items less likely to describe the Shetland experience.

Tourist group rankings in Table 5.16 are not uniform. General Interest travellers place more importance on terms such as "Natural", "Beautiful", "Other", "Romantic", and "Fun", in describing Shetland. Conversely, Special Interest tourists placed more importance on terms such as "Isolated", "Rugged", "Untamed", "Relaxing", "Remote" and "Stimulating".

\subsubsection{Tourist Interaction}

Table 5.17 provides a medium with which to understand the tendencies of tourists with regard to interaction both with other tourists, and through shared activities with other tourists. It was thought that some types of tourists, Special Interest for example, might be prone to involvement with other like-minded individuals (Birding, Natural History, Archaeology, etc.). Results of Table 5.17 indicate, however, that there is no significant difference between the two tourist groups in terms of interaction. The frequency of response for interaction "With Other Tourists" was substantially higher than that of "Shared Activities" (72.5 per cent and 9.0 per cent resuectively). This suggests 
that tourists interact informally in Shetland, but do not pursue these relationships further through planned/shared activities.

\section{Table 5.17}

Characteristics of Touristic Interaction

\begin{tabular}{lccc}
\hline Interaction & $\begin{array}{c}\text { Tourist } \\
\text { Group }\end{array}$ & $\begin{array}{c}\text { \% Intergroup } \\
\text { Response }\end{array}$ & $\begin{array}{c}\text { \% Intragroup } \\
\text { Response }\end{array}$ \\
\hline $\begin{array}{l}\text { With Other Tourists } \\
\text { Yes (n=50; 72.5\%) }\end{array}$ & 1 & 45.4 & 63.9 \\
& 2 & 54.6 & 77.1 \\
Shared Activities & & & \\
Yes (n=6; 9.0\%) & 1 & 49.1 & 8.3 \\
& 2 & 50.9 & 8.6 \\
\hline
\end{tabular}

Tourist group representation: $1=$ General, $2=$ Special

Special Interest tourists were more likely to interact "With Other Tourists" (54.6 per cent of all tourists) and this figure represented 77.1 per cent of the Spocial Interest sub-sample, as compared to 63.9 per cent of the General Interest aggregation. Despite the low frequency of response for "Shared Activities", both tourist groups were equally prone to act in this fashion.

\subsubsection{Activity Satisfaction}

Previous discussion on trip satisfaction (Table 5.14) dealt with trip aspects that might be considered physiological in orientation (accommodation, transportation, food, and weather). Table 5.18, on the other hand, considers the suitability of Shetland in satisfying chosen activities. It tries to uncover, therefore, whether tourist groups were 
able to attain a high level of satisfaction with their activity-based reason(s) for visiting Shetland (what might be referred to as psychological needs). As with Table 5.14, a fivepoint scale was implemented, one denoting "Very suitable," five denoting "Not at all suitable". As might be expected, the Special Interest tourist group (mean = 1.66; s.d. $=.91)$ found Shetland to be slightly more suitable in satisfying chosen activities than General Interest tourists $($ mean $=1.76 ;$ s.d. $=.71)$. Both group responses indicated a very high level of satisfaction with Shetland, and when combined, illustrate a higher satisfaction level than any of the aspects in Table 5.14.

\section{Table 5.18}

Suitability of Shetland in Satisfying Chosen Activities

\begin{tabular}{lll}
\hline Tourist Group & Mean & s.d. \\
\hline General & & 1.76 \\
Special & 1.74 & 0.71 \\
& & 0.98
\end{tabular}

$$
\begin{gathered}
\text { Based on a 5-point scale: } 1=\text { very suitable, } \\
5=\text { not at all suitable. }
\end{gathered}
$$

\subsubsection{Willingness to Return}

The positive response data of Tables 5.14 and 5.18, for both tourist groups, indicates a high level of satisfaction. A logical follow-up to these questions, was to ask tourists whether they would be willing to retum to Shetland (no time period specified) as a tourist. Overall (Table 5.19), tourists responded positively to this question $($ mean $=.783 ;$ s.d. $=.415)$. 
Table 5.19

Willingness to Return to Shetland as a Tourist

\begin{tabular}{ccc}
\hline Tourist Group & \% Intergroup & \% Intragroup \\
\hline General & 47.4 & 72.2 \\
Special & 52.6 & 80.0 \\
& & \\
\hline
\end{tabular}

Of the seventy-eight per cent of the sample who responded, 52.6 per cent were Special and 47.4 per cent were General Interest tourists; an equal group representation. Finally, 80.0 per cent of all Special Interest tourists said they would travel to Shetland again, while 72.2 per cent of General Interest tourists would do the same.

\subsubsection{Recommending Shetland to Friends}

The data presented in Table 5.20 imply that satisfaction with Shetland was complete to a level trat would enable 91.5 per cent of all respondents to recommend Shetland as a travel destination to their friends. All (100 per cent) General Interest tourists (54.6 per cent of the intergroup response) and 82.9 per cent of Special Interest tourists (45.4 per cent of intergroup response) would act in this fashion.

\subsubsection{Archaeological Aftractions}

The Shetland Islands Tourism Brochure (1992) suggests that Stone, Bronze and Iron Age incomers all left a rich archaeological heritage that can be easily explored by tourists. In fact, it has been reported (Linklater, 1990) that Shetland boasts more 
Table 5.20

Those Recommending Shetland as a Destination to Their Friends

\begin{tabular}{ccc}
\hline Tourist Group & $\begin{array}{c}\text { \% Intergroup } \\
\text { Response }\end{array}$ & $\begin{array}{c}\text { \% Intragroup } \\
\text { Response }\end{array}$ \\
\hline General & 54.6 & 100.0 \\
Special & 45.4 & 82.9 \\
\hline \multicolumn{3}{c}{ Mean $=.915 ;$ s.d. $=.280$}
\end{tabular}

archaeological sites per unit area than anywhere else in Britain. Thirty-eight of these sites were included in the travellers' questionnaire to be completed by the respondents (Appendix 3). A list of Shetland attraction sites most frequently visited by respondents is contained in Appendix 4. Five different attraction types, including archacological, have been included.

The most popular attraction by far was Jarlshof $(n=58 ; 81.7$ per cent $)$ and it was visited equally by General and Special Interest tourists (by over 80 per cent of each group). Mousa Broch was the next most popular archaeological attraction, to which 52.1 per cent of all tourists managed to travel. Again, there is an almost even split for both tourist groups in terms of intergroup response. Half of the General Interest tourist group and 54.0 per cent of the Special group spent time at Mousa Broch.

There is a significant drop in level of visitation to the other attractions included in Appendix 3. Only six sites (Mavis Grind, Noss Sound Broch, Fort at Sandness, Jamie Cheynes Loch, Caims at Bridge of Walls, and Papil Church at West Burra) recorded visitation by between 10 and 20 per cent of the overall respondent sample. More 
revealing though, is the fact that less than 10 per cent of all tourists in the sample visited any of 26 archeaological attractions listed in the questionnaire (Appendix 3). Jarlshof and Mousa are unique among the archaeological attractions in Shetland. They are spectacular sites that are easily accessible, well promoted and documented, and have established highway signposting and on-site interpretation. These factors are important in considering the one-sided visitation dynamics. None of the other sites share both of the above mentioned characteristics to the same magnitude.

In total, the sample recorded making 237 archaeological attraction visits. On average, these attractions were visited by the sample 7.0 times. Taking away the impact of Jarlshof and Mousa, the average visitation figure drops to 4.4. Finally, twelve of the seventeen top visited 34 archaeological attractions were located on the Shetland mainland. This figure drops to eight of seventeen when considering the lower half of the attractions. It is apparent that those attractions on the mainland were visited more, and this visitation might be attributed directly to accessibility.

\subsubsection{Natural Attractions}

The questionnaire contained 15 of the most popular natural attractions in Shetland (based on the information provided in the Shetland Tourist Map and Official Tourist Guide, in fact all of the attractions outlined in the survey were marked in these two publications). The overali: sample indicated visiting 14 of these 15 sites (Table 5.22).

Of particular interest was the fact that the three most frequently visited natural attractions were all very accessible, and each have other types of attractions (e.g., 
archaeological) on or near the natural site. The Tombolo at St. Ninian's Isle $(n=41$; 57.7 per cent) was a case in point. The Tombolo connects the mainland to St. Ninian's Isle, site of the ruins of a 12th Century church, and a hoard of Pictish Silver (now in the Royal Scottish Museum). Slightly more General Interest tourists visited this site, with over 50 per cent representation of each tourist group. Sumburgh Head $(n=38 ; 53.5$ per cent) is the site of the most southerly mainland point, and sustains a substantial population of sea birds. However, there is an impressive lighthouse on this site, and the Jarlshof settlement is approximately $1 / 2$ kilometre from the cliffs. Of 38 visitors to Sumburgh Head, 61.2 per cent were Special Interest tourists and 38.8 per cent were General Interest types. Almost two-thirds of all Snecial Interest tourists visited Sumburgh Head.

The Isle of Mousa ( $n=29 ; 40.8$ per cent) harbours a rich diversity of bird life (the most unique being Storm Petrels) in addition to a colony of Common Seals. These natural features share common ground with what is the finest preserved Broch in the whole of Britain. The combination of natural and archaeological attractions strengthens the appeal of Mousa and contributes significantly to its overall popularity, despite its limited accessibility.

National Nature Reserves at both Noss and Hermaness are important habitats for a variety of bird species. Noss $(n=24 ; 33.8$ per cent) is quite accessible from Lerwick (approximately four kilometres by car ferry or tour boat), and regularly scheduled daily tours provide an interesting half-day trip for tourists. An equal number of both tourist types were represented in this response category. On the other hand, the Hermaness 
Table 5.22

Natural Attractions Visited

\begin{tabular}{|c|c|c|c|}
\hline Attraction & $\begin{array}{l}\text { Tourist } \\
\text { Group }\end{array}$ & $\begin{array}{l}\text { \% Intergroup } \\
\text { Response }\end{array}$ & $\begin{array}{l}\text { \% Intragroup } \\
\text { Response }\end{array}$ \\
\hline \multicolumn{4}{|l|}{ Tombolo, St. Ninians Isle } \\
\hline Yes $(n=41 ; 57.7 \%)$ & $\begin{array}{l}1 \\
2\end{array}$ & $\begin{array}{l}52.9 \\
47.1\end{array}$ & $\begin{array}{l}61.1 \\
54.3\end{array}$ \\
\hline \multicolumn{4}{|l|}{ Sumburgh Head } \\
\hline Yes $(n=38 ; 53.5 \%)$ & $\begin{array}{l}1 \\
2\end{array}$ & $\begin{array}{l}38.8 \\
61.2\end{array}$ & $\begin{array}{l}41.7 \\
65.7\end{array}$ \\
\hline \multicolumn{4}{|l|}{ Mouse } \\
\hline$Y \operatorname{es}(n=29 ; 40.8 \%)$ & $\begin{array}{l}1 \\
2\end{array}$ & $\begin{array}{l}51.0 \\
49.0\end{array}$ & $\begin{array}{l}41.7 \\
40.0\end{array}$ \\
\hline \multicolumn{4}{|l|}{ Noss (N.N.R.) } \\
\hline Yes $(n=24 ; 33.8 \%)$ & $\begin{array}{l}1 \\
2\end{array}$ & $\begin{array}{l}49.1 \\
50.9\end{array}$ & $\begin{array}{l}33.3 \\
34.3\end{array}$ \\
\hline \multicolumn{4}{|l|}{ Hermaness (N.N.R.) } \\
\hline \multirow[t]{2}{*}{ Yes $(n=22 ; 31.0 \%)$} & 1 & 40.3 & 25.0 \\
\hline & 2 & 59.7 & 37.1 \\
\hline \multicolumn{4}{|l|}{ Spiggie Loch (R.S.P.B.) } \\
\hline Yes $(n=16 ; 22.5 \%)$ & $\begin{array}{l}1 \\
2\end{array}$ & $\begin{array}{l}49.1 \\
50.9\end{array}$ & $\begin{array}{l}22.2 \\
22.9\end{array}$ \\
\hline \multicolumn{4}{|l|}{ Kergond Woods } \\
\hline \multirow[t]{2}{*}{ Yes $(n=16 ; 22.5 \%)$} & 1 & 43.0 & 19.4 \\
\hline & 2 & 57.0 & 25.7 \\
\hline \multicolumn{4}{|l|}{ Tidal Pool, Virkie } \\
\hline$Y \operatorname{es}(n=8 ; 11.3 \%)$ & $\begin{array}{l}1 \\
2\end{array}$ & $\begin{array}{l}36.7 \\
63.3\end{array}$ & $\begin{array}{l}8.3 \\
14.3\end{array}$ \\
\hline \multicolumn{4}{|l|}{ Fair Isle (N.N.R.) } \\
\hline $\operatorname{Yes}(n=6 ; 8.5 \%)$ & $\begin{array}{l}1 \\
2\end{array}$ & $\begin{array}{l}32.9 \\
67.1\end{array}$ & $\begin{array}{c}5.6 \\
11.4\end{array}$ \\
\hline \multicolumn{4}{|l|}{ Fetlar Owls } \\
\hline Yes $(n=5 ; 7.0 \%)$ & $\begin{array}{l}1 \\
2\end{array}$ & $\begin{array}{l}39.4 \\
60.6\end{array}$ & $\begin{array}{l}5.6 \\
8.6\end{array}$ \\
\hline \multicolumn{4}{|l|}{ Bleck Park Reserve, Yell } \\
\hline Yes $(n=5 ; 7.0 \%)$ & $\begin{array}{l}1 \\
2\end{array}$ & $\begin{array}{l}39.4 \\
60.6\end{array}$ & $\begin{array}{l}5.6 \\
8.6\end{array}$ \\
\hline \multicolumn{4}{|l|}{ Lumbister Reserve, Yell } \\
\hline $\operatorname{Yes}(n=4 ; 5.6 \%)$ & $\begin{array}{l}1 \\
2\end{array}$ & $\begin{array}{l}49.1 \\
50.9\end{array}$ & $\begin{array}{l}5.6 \\
5.7\end{array}$ \\
\hline \multicolumn{4}{|l|}{ Keen of Hamer (N.N.R.) } \\
\hline Yes $(n=4 ; 5.6 \%)$ & $\begin{array}{l}1 \\
2\end{array}$ & $\begin{array}{l}24.6 \\
75.4\end{array}$ & $\begin{array}{l}2.8 \\
8.6\end{array}$ \\
\hline \multicolumn{4}{|l|}{ Yell Sound/Remna Stacks } \\
\hline \multirow[t]{2}{*}{ Yes $(n=2 ; 2.8 \%)$} & 1 & 49.1 & 2.8 \\
\hline & 2 & 50.9 & 2.9 \\
\hline
\end{tabular}


Reserve is located at the north end of the most northerly isle, Unst. Of the 22 visitors to Hermaness (31.0 per cent), almost 60 per cent were Special Interest tourists, perhaps attracted also by the presence of the North Atlantic's only albatross, which has inhabited the area for several years.

Other frequently visited sites included Spiggie Loch and Kergord Woods (each visited by $\mathbf{2 2 . 5}$ per cent of the entire sample). Numbers of visitors fell off substantially when considering the other sites in Table 5.22. Considering all of the natural attraction sites, there seemed to be a slight predominance of Special Interest visitors (in general); however, there is no established pattern among all of these attraction sites.

In total, 221 natural attraction visits were made by the sample (an average of 15.8 visits per natural attraction). With the influence of the two most frequently visited attractions removed, there still remained 11.8 visits per attraction, substantially higher than the previous discussion on archaeological attractions. Finally, four of the first seven natural attractions are found on the mainland. This figure drops to one in seven of the final attractions when considering mainland affiliation.

\subsubsection{Houses and Buildings of Interest Visited}

The Shetland Official Tourist Guide identifies a number of Houses and Buildings of Interest that have had an influence on the region from the past to the present. Examples of these structures include castles, museums, pubs, and Lerwick Town Hall. Of all of the different types of attractions outlined in the questionnaire, these buildings (Appendix 3, Table 5.23) were visited most by the sample. Respondents recorded 345 
visits, with an average of 13.8 visits per building (11.7 visits per building taking : way the two top attractions).

Scalloway Castle - as the most conventional of these structures - was by far the most frequently visited building ( $n=50 ; 70.4$ per cent), with no significant difference demonstrated between each tourist group. Both tourist groups were represented by at least two-thirds of their total affiliation at this attraction. Less than $\mathbf{4 0}$ per cent of the sample recorded visits to the other 24 attraction sites in this category. The Croft House Museum ( $n=27 ; 38.0$ per cent) and The Booth at Hillswick $(n=23 ; 32.4$ per cent) were preferred by the General Interest tourist group over Special Interest travellers. Attractions such as the Library and Museum ( $n=26 ; 36.7$ per cent) and Town Hall ( $n=$ 21; 29.6 per cent) were more likely to be visited by the Special Interest travel group.

Comparatively, it is of interest to note that 14 Building attractions were visited by at least 15 per cent of the sample. However, only seven natural and three archaeological attractions attained this level of use. Also of interest is the fact that $\mathbf{1 1}$ of the top 13 Building attractions were located on the mainland, whereas only four of the final 12 attractions were located in this region. This statistic illustrates that those attractions that seem to be more accessible were definitely those that were more frequently visited. 


\subsubsection{Places of Industrial Interest}

The diversification of the Shetland economy has been discussed previously in light of the impact that non-traditional industries such as oil, tourism, and fish farming have had. Oil, in particular, has had the largest impact on Shetland, not only in terms of cash flow, but also socially, politically and environmentally. The Sullom Voe Oil Terminal $(n=31 ; 43.7$ per cent) drew the attention of both General and Special Interest tourists, with little difference between intergroup representation (Table 5.24). As is the case with the overall per cent visitation ( 43.7 per cent), less than 50.0 per cent of the members of each group saw Sullom Voe (visitation to the site on an individual basis is difficult, tours may be arranged for groups under certain circumstances).

Considerably fewer tourists stopped at the Spinning Mill in Sandness $(n=11$; 15.5 per cent). Of this low number, the majority were tourists affiliated with the General Interest group (64.3 per cent). Only 5.6 per cent of the sample managed to visit the Smokehouse at Skeld.

\subsubsection{Craft Centres Visited}

The tourism industry in recent years has increased the demand for products of the unique craftsmanship that occurs in Shetland. Crafts are based on a variety of resources, some of which are indigenous to the island (e.g., serpentine, wool, etc.) and some that are imported (e.g., silver). Both Shetland Silvercraft $(n=19 ; 25.8$ per cent) and Hjaltasteyn ( $n=18 ; 25.4$ per cent) make and sell handcrafted jewelery (Table 5.25), 


\section{Table 5.24}

\section{Places of Industrial Interest Visited}

\begin{tabular}{cccc}
\hline Place & $\begin{array}{c}\text { Tourist } \\
\text { Group }\end{array}$ & $\begin{array}{c}\text { \% Intergroup } \\
\text { Response }\end{array}$ & $\begin{array}{c}\text { \% Intragroup } \\
\text { Response }\end{array}$ \\
\hline $\begin{array}{cccc}\text { Sullom Voe Terminal } \\
\text { Yes (n=31; 43.7\%) }\end{array}$ & 1 & 50.9 & 44.4 \\
& 2 & 49.1 & 42.9 \\
Spinning Mill, Sandness & & 35.7 & 11.1 \\
Yes ( $=11 ;$ 15.5\%) & 1 & 64.3 & 20.0 \\
& 2 & 49.1 & 5.6 \\
Smokehouse Skeld & 1 & 50.9 & 5.7 \\
Yes (n=4; 5.6\%) & 2 & & \\
& & & \\
\hline
\end{tabular}

Tourist group representation: $1=$ General, $2=$ Special

Table 5.25

Craft Centres Visited

\begin{tabular}{lccc}
\hline Centre & $\begin{array}{c}\text { Tourist } \\
\text { Group }\end{array}$ & $\begin{array}{c}\text { \% Intergroup } \\
\text { Response }\end{array}$ & $\begin{array}{c}\text { Intergroup } \\
\text { Response }\end{array}$ \\
\hline $\begin{array}{c}\text { Shetland Silvercraft } \\
\text { Yes }(n=19 ; 26.8 \%)\end{array}$ & 1 & 52.0 & 27.8 \\
Hjaltasteyn & 2 & 48.0 & 25.7 \\
Yes $(n=18 ; 25.4 \%)$ & 1 & 60.5 & 30.6 \\
Simply Shetland & 2 & 39.5 & 20.0 \\
Yes (n=1; 1.4\%) & 1 & 100.0 & 2.8 \\
& 2 & - & - \\
\hline
\end{tabular}

Tourist group representation: 1 = General, 2 = Special 
and are located approximately four kilometres apart along the main highway of the mainland, north of Lerwick. Individuals, therefore, who were particularly interested in purchasing crafts, were drawn to this area. The data associated with Table 5.25 indicate that it was the General Interest tourist who was more likely to visit these centres.

Only one tourist made the trip to North Roe (Simply Shetland). The fact that this centre is located in the most remote corner of the north mainland is probably a contributing factor to this weak response.

\subsubsection{4 "Other" Attractions Visited}

Table 5.26 contains a number of "Other" places of interest that did not fall under any of the above attraction categories, but which were given an independent category in the Official Tourist Map (as were each of the above categories). Eleven attractions were listed in the survey, and all were visited by the sample.

The most frequently visited "Other" attraction was St. Ninian's Isle ( $n=38 ; 53.5$ per cent). Looking back to Table 5.22, the Tombolo connecting the mainland to St. Ninian's Isle was a heavily used natural attraction. Forty-one respondents indicated visiting the Tombolo, while 38 of these tourists went further on to the Isle. As mentioned previously, it is important to acknowledge the fact that the combination of attractions in a confined area 3 probably a logical explanation for heightened visitation to these areas. Table 5.26 illustrates that there was little difference between the :umber of tourists from Special and General Interest groups visiting St. Ninian's Isle (53.3 and 46.7 per cent respectively). 
Table 5.26

"Other" Places of Interest Visited

\begin{tabular}{lccc}
\hline \multirow{2}{*}{ Place } & Tourist & \% Intergroup & \% Intragroup \\
& Group & Response & Response
\end{tabular}

St. Ninian's Isle

Yes $(n=38 ; 53.5 \%)$

$1 \quad 46.7$

50.0

2

53.3

57.4

Haroldswick P.O.

Yes $(n=24 ; 33.8 \%)$

1
2

53.5

36.1

$46.5 \quad 31.4$

Law Ting Holm

Yes $(n=22 ; 31.0 \%)$

1

52.9

38.9

37.1

22.9

Stenness, Eshaness

Yes $(n=20 ; 28.2 \%)$

1

69.5

38.9

30.5

17.1

Muckle Flugga

Yes $(n=1.3 ; 18.3 \%)$

1

37.8

13.9

62.2

22.9

Weisdale Mill

$$
\text { Yes }(n=8 ; 11.3 \%)
$$

1
2

49.1

11.1

50.9

11.4

Greenwalls Booth

$$
\text { Yes }(n=5 ; 7.0 \%)
$$

1
2

Quendale Mill

$$
\text { Yes }(n=5 ; 7.0 \%)
$$

1
2

Gloup Voe, Yell

Yes $(n=4 ; 5.6 \%)$

Norse Watermill, Unst

79.3

20.7

11.1

2.9

59.3

8.3

40.7

5.7

49.1

5.6

50.9

5.7

Yes $(n=3 ; 4.2 \%)$

1

32.9

2.8

67.1

5.7

Bard Head, Bressay

Yes $(n=2 ; 2.8 \%)$

1

49.1

2.8

50.

2.9

Tourist group representation: $1=$ General, $2=\overline{\text { Special }}$ 
Little difference was also exhibited between tourist groups visiting the Haroldswick Post Office on Unst ( $n=24 ; 33.8$ per cent). However, General Interest tourists were more likely to visit Law Ting Holm $(n=22 ; 31.0$ per cent) in Tingwall, and Stenness ( $n=20 ; 28.2$ per cent) in Eshaness, while a larger difference existed in favour of Special Interest travellers who saw the Muckle Flugga lighthouse $(n=13 ; 18.3$ per cent) adjacent to the Hermaness National Nature Reserve. Five of the 11 "Other" attractions received less than 10 per cent visitation by both tourist groups combined.

Space was provided at the end of the attractions section for respondents to list any attractions visited that were not contained in the above six categories. These attractions and the number of visits to each by both groups are as follows:

* Clickimin Broch, Lerwick (9),

* $\quad$ Fort Charlotte, Lerwick (2),

* Islesburgh Community Centre, Cunningsburgh (2),

* Judane Knitwear Factory, Lerwick (2),

* Bressay Lighthouse (1),

* Walls Agri- sltural Show (1),

* White Lady, Yell (1),

* Fetlar Interpretive Centre (1), and

* $\quad$ Ship Factory, Lerwick (1).

One respondent expressed his/her discontent by writing "litter on Yell, Unst, and Fetlar", as an "Other" attraction.

\subsubsection{Attraction Dynamics}

Table 5.27 is a summary of the different types of attractions presented in the previous sections. Data pertains to the number of times (and per cent) that each attraction type was visited by the sample, in addition to the average number of sites 
visited by each of the two tourist groups. About one-third of all respondents visited "House and Building" attractions ( $n=345 ; 33.5$ per cent), followed by "Archaeological" $(n=237 ; 23.0$ per cent), "Natural" $(n=221 ; 21.4$ per cent) and "other" $(n=144 ; 14.0$ per cent) attractions. Both "industrial Interest" and "Craft Centre" attractions were visited less often, reflecting the small number of sites provided in the survey.

Table 5.27

Total Attraction Visitation Dynamics by Group

\begin{tabular}{lccc}
\hline \multicolumn{1}{c}{ Attraction } & $\begin{array}{c}\text { No. of Attraction } \\
\text { Sites Visited }\end{array}$ & $\begin{array}{c}\text { Tourist } \\
\text { Group }\end{array}$ & $\begin{array}{c}\text { Ave. No. of } \\
\text { Sites Visited }\end{array}$ \\
\hline House and Building & 345 & 1 & 5.0 \\
Archacological & 237 & 2 & 4.7 \\
& & 1 & 3.1 \\
Natural & 221 & 2 & 3.5 \\
& & 1 & 2.8 \\
"Other" & 144 & 2 & 3.4 \\
& & 1 & 2.2 \\
Industrial Interest & 46 & 2 & 1.9 \\
& & 1 & 0.6 \\
Craft Centre & 38 & 2 & 0.7 \\
& & 1 & 0.6 \\
& & 2 & 0.5 \\
\hline \multicolumn{2}{c}{ Tourist group representation: 1 = General, 2 = Special } \\
\hline
\end{tabular}

Regarding intragroup differences, General Interest tourists were more likely to visit "House and Building" $(\mathrm{n}=5.0)$ and "Other" $(\mathrm{n}=2.2)$ attractions, while 
comparatively, the Special Interest group visited "Archaeological" $(n=3.5)$ and "Natural" ( $n=3.4)$ attractions more on average.

The results of the Shetland travel questionnaire survey were useful in understanding both the entire sample, as well as Special and General Interest tourist groups. It may be concluded from these results that the "representative" Shetland tourist is predominantly male, in his 40 s, earns a substantial annual household wage, and is very well educated. Many of the sample were first time visitors and found their Shetland trip to be quite satisfying. Most said that they would retum to Shetland as a tourist, while more respondents stressed that they would tell their friends about the archipelago. The majority of travellers used a car, either with their spouse, friend, or family. In general, the data suggested that at most, there were only subtle differences between General and Special Interest tourist groups.

\subsubsection{Staiistical Tests}

The forejoining analysis concentrated on the presentation of frequencies, and the combination of these frequencies into a means by which to compare General and Special Interest travel groups. It is the purpose of this section to enhance the understanding of these travel groups by making inferences on the relationship of the two groups based on a number of variables.

The majority of questions in the questionnaire sought data of a discrete (nominal) form, while only three questions were urganised in order to uncover interval-level data. 
With this in mind, the two travel groups (General and Special Interest) are compared in the following section on the basis of two tests: chi square and t-test.

The chi square is a non-parametric test that enables researchers to determine whether two variables are related in the population. The test is very flexible and is applicable in one, two, or more than two sample situations (Norusis, 1988; Ebdon, 1992). Norcliffe (1982) and Silk (1979) outlined the following assumptions to be considered for use for the chi square procedure:

1. The oata must be measured at the nominal scale or any higher level of measurement;

2. There must be at least two mutually exclusive categories into which the observations are placed; and

3. No category should have an expected frequency less than one, and not more than one category in five should have an expected frequency less than five.

For this test, a null hypothesis assumes that the difference between samples is due to chance in the sampling scheme. In an investigation, one might hypothesize (null hypothesis) that there is no difference between Special and General Interest tourists in terms of their need to escape their job by travelling to Shetland. If, upon calculation of the chi square value, the value was found to be greater than the critical value (one degree of freedom at the chosen 0.05 significance level $=3.84$ ), the null hypothesis would be rejected. This would suggest that it is unlikely that the observed difference between General and Special Intereit travellers is due only to chance in the sampling process. Since the chi square statistic is calculated by SPSS/PC + , the interpretation of the statistic is dependent upon the significance level. Therefore, if $p$ is greater than 0.05 , the null hypothesis wouid be accepted. One may conclude, then, that there is not a relationship 
between the two variables. Conversely, if $p$ is less than or equal to 0.05 , the null hypothesis would not be accepted.

The t-test statistic, on the other hand, is a parametric test that determines the difference between two samples measured on an interval-level scale. The null hypothesis for a t-test implies that two sets of data are random samples from a common, normally distributed populativin, or from two identical normally distributed populations (Ebdon, 1992). For example, the null hypothesis might follow that there is no difference between the means of the population from which General and Special Interest travel group samples were taken. As was the case for chi square, the null hypothesis for t-test assumes that the observed difference between the samples is due to chance in the sampling process. Taking into consideration the size of the sample of this research, the critical value of $t$ for a two-tailed test at the 0.05 significance level is 2.00 . Therefore, if the calculated value of $t$ is less than the critical value of 2.00 , the null hypothesis must be accepted at the 0.05 significance level. It would then be safe to assume that there was no difference between the mean values of the two samples. Conversely, if the calculated value of $\mathrm{t}$ was greater than or equal to 2.00 , the null hypothesis would be rejected.

Given the precading discussion, the following are general hypotheses to be tested using the chi square and t-test techniques:

\section{Chi square}

$\mathrm{H}_{\mathrm{o}}$ : There is no difference between General and Special Interest travellers (hypothesis for those questions preceded by an asterisk).

$\mathbf{H}_{\mathrm{o}}$ : There is a difference between General and Special Interest travellers (hypothesis for those questions not preceded by an asterisk). 
test

$H_{\mathrm{o}}$ : There is no difference between the means of the population from which the General and Special Interest travel group samples were taken (hypothesis for those questions preceded by an asterisk).

$\mathrm{H}_{\mathrm{o}}$ : There is a difference between the means of the population from which the General and Special Interest travel group samples were taken (hypothesis for those questions not preceded by an asterisk).

Table 5.28 presents data on the scores determined by the chi square analysis. Only two of the statements were discovered to have statistical significance. Special Interest travellers felt, more so than the General group, that a trip to Shetland would help "Strengthen Family Bonds". The difference between the two groups was found to be significant at 0.05 level $(6.248 ; p=0.012)$. The hypothesis, suggesting that there is a difference between the two travel groups, is to :e accepted. There was also a significant difference between the two travel groups with respect to "Recommending Shetland As A Travel Destination To Your Friends", $(6.741 ; p=0.009)$. In fact, General Interest travellers were more likely to recommend Shetland than the Special group, prompting the need to reject the null hypothesis suggesting that there was no difference between the two groups.

Responses to those remaining questions with an asterisk, "Educational opportunity" (0.952; $p=0.329)$, "Shopping" (0.108; $p=0.743)$, "Tour" . ?.319; $p=0.572)$, "Did You Keep A Personal Log" $(0.229 ; p=0.632)$, and "Would You Travel To Shetland Again" $(0.660 ; p=0.417)$, illustrate that there is no difference between the two travel groups. The null hypothesis suggesting that there is no difference between these groups, is accepted. Notwithstanding, those remaining questions without an 
Table 5.28

Chi Square Scores

Statement
ITEMS THAT FIT CLOSELY WITH
REASONS FOR VISITING SHETLAND

Strengthen family bonds

Wish fulfillment

6.248

0.012

Social interection

1.433

0.231

*Educational opportunity

1.429

0.232

Relaration

0.952

0.329

Prestige

0.357

0.550

*Shopping

0.215

0.643

To escape

0.108

0.743

0.000

1.000

HOW DID YOU TRAVEL WHILE IN SHETLAND

Car

Bus

1.610

0.897

0.205

Bicycle

0.129

0.344

0.720

WITH WHOM DID YOU TRAVEL

Alone

3.038

0.433

0.081

Spouce

0.319

0.511

*Tour

0.006

0.572

Friend

0.004

0.941

Family

0.229

1

0.632

*WOULD YOU TRAVEL TO

SHETLAND AGAIN

0.660

1

0.417

*RECOMMEND SHETLAND AS A DESTINATION TO YOUR FRIENDS

6.741

1

* Statements with an asterisk reflect a null hypothesis that states that there is no difference between General and Special Interest tourists.

All other statements pertain to a null hypothesis that states that there is a difference between General and Special Interest wourists.

Bolded p values indicate a statistically significant difference between General and Special Interest tourists at the 0.05 level. 
asterisk, "Wish fulfillment" (1.433; $p=0.231)$, "Social interaction" $(1.429 ; p=0.232)$, "Relaxation" (0.357; $p=0.550)$, "Prestige" (0.215; $p=0.643)$, "To escape" (0.000; $p=1.000)$, "Car" (1.610; $p=0.205)$, "Bus" (0.897; p=0.344), "Bicycle" (0.129; $p=0.720)$, "Alone" (3.038; $p=0.081)$, "Spouse" (0.433; $p=0.511)$, "Friend" (0.006; $p=0.941)$, and "Family" $(0.004 ; p=0.949)$, also illustrate that there is no difference between the travel groups (reject null hypothesis).

The utility of the chi square test has been in its ability to statistically confirm that there is very little difference between the General and Special Interest travel groups based on their responses to all but two of the questions contained in Table 5.28. A difference was found to exist between the two groups (at the 0.05 significance level) in response to questions that dealt with Shetland as a means to "Strengthen family bonds", and the "Need to Recommend Shetland as a Travel Destination to Friends".

Table 5.29 presents data associated with the scores of the $t$-test component of this research. The Table illustrates that there was a significant difference in the means of the two travel groups for only one statement, "Natural history" $(t=-2.87 ; p<0.05)$. The Special Interest tourist group, in this case, indicated having a stronger familiarity with Shetland's natural history. Consequently, the null hypothesis stating no difference in the means of the two groups, is rejected. It was also hypothesised - for statements with an asterisk -- that there would be no difference in the means of the two travel groups for familiarity with "Archaeological history" $(t=-130 ; p<0.05)$, and satisfaction with "Weather" $(t=0.34 ; p<0.05)$. As these values were not greater than or equal to the critical value of 2.00 , the null hypothesis, in both cases is accepted. 
Table 5.29

t-test Scores

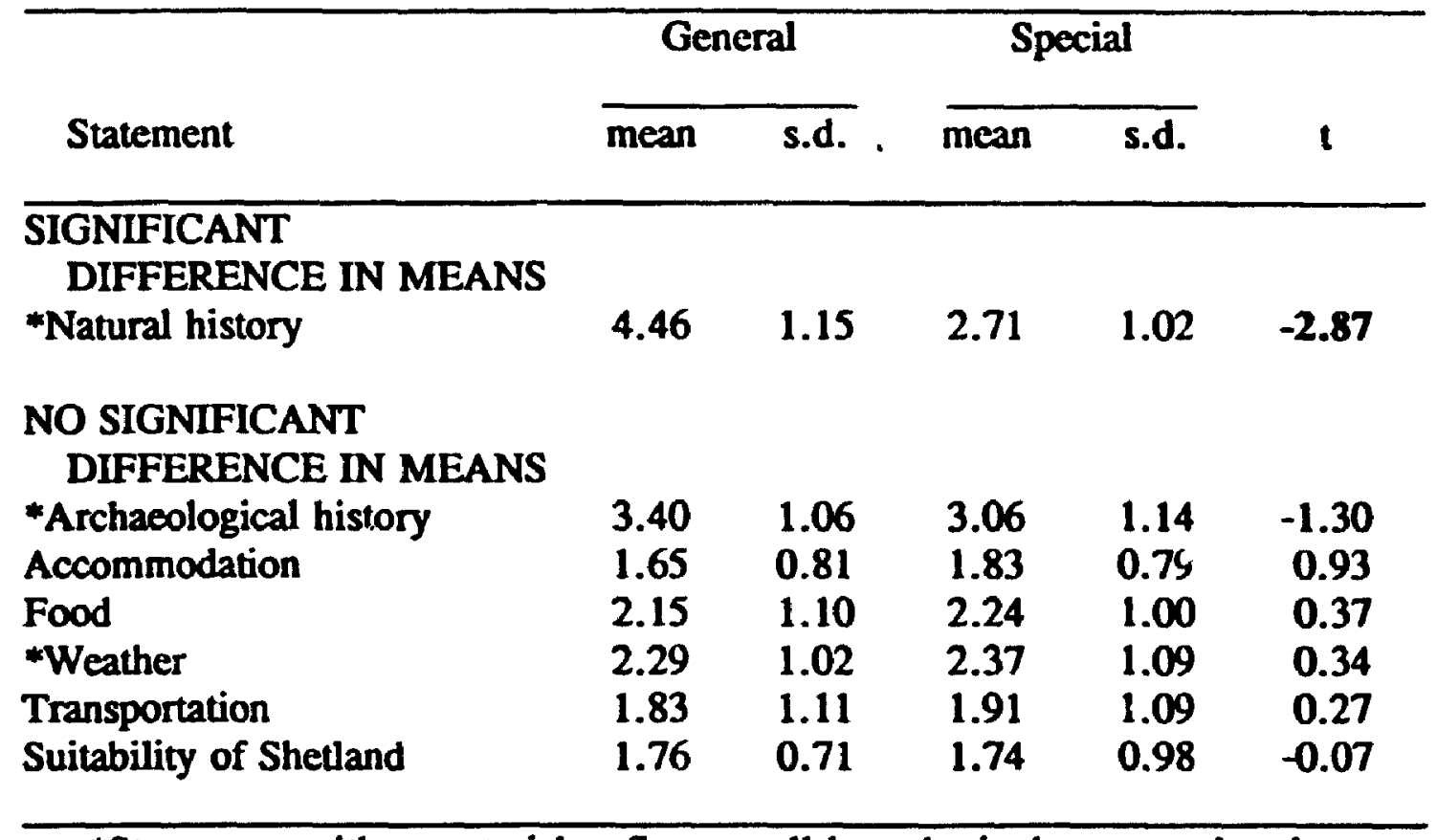

*Statements with an asterisk reflect a null hypothesis that states that there is no difference in the means of General and Special Interest tourist groups.

All other statements reflect a null hypothesis that states that there is a difference in the means of General and Special Interest tourist groups.

Finally, there was not a significant difference in the means of the two sample travel groups for statements such as satisfaction with "Accommodation" $(t=0.93$; $p<0.05)$, "Food" ( $(=0.37 ; p<0.05)$, "Transportation" $(t=0.27 ; p<0.05)$, and "suitability of Shetland in satisfying the pursuit of chosen activities" $(t=-0.07$; $p<0.05)$. As the null hypothesis suggested that there is a difference in the means of the General and Special Interest tourist groups, it is prudent to reject such an hypothesis.

These results indicate, as did the chi square analysis for Table 5.28, that there is not an overall significant difference between both travel groups on the basis of the 
questions put-forth in Table 5.29. The only difference between the two samples was in regard to familiarity with the "Natural history" of Shetland (the Special Interest group, by their response pattern, was more familiar).

\subsection{CONCLUSION}

The results of the self-administered questonnaire (frequencies related to sociodemographics, on-site characteristics, motivations, and attitudes) indicate that, at best, marginal differences exist between Special Interest and General Interest groups regarding a variety of travel-related variables. Regarding socio-demographics, both travel groups were in their early forties, predominantly male, earned a substantial household income, and were highly educated.

Travel group similarities were reinforced through the implementation of both chi square and t-test statistics. Differences were discovered between the two groups in regard to strengthening family bonds (as a reason for visiting Shetland), recommending Shetland to friends as a travel destination, and knowledge of Shetland natural history. 


\section{Chapter 6}

\section{A SPACE-TIME BUDGET ANALYSIS OF SHETLAND TOURIST GROUPS}

For a moment of night we have a glimpse of ourselves and of our world islanded in its stream of stars -- pilgrims of mortality, voyaging between horizons across the eternal seas of space and time.

Henry Beston

\subsection{INTRODUCTION}

As the second element of the respondent quantitative survey, the space-time budget provided a means by which to evaluate travel groups (Special and General Interest), Jased on five features: accommodation, transportation, facility use, attraction use, and spatial movement. Respondents were to complete one space-time budget sheet for each day of their vacation. It was important, therefore, to design these sheets so that they would not prove to be a burden, or interfere in the normal, daily affairs of the sample. Tourists were encouraged to be as exact as possible in recording times associated with the above mentioned features. However, whereas "to-the-minute" recordings (e.g., 10:47 to 11:04) were encountered, most tourists ultimately found it easier -- or more practical - to record time values to the nearest five or ten minute block 
(e.g., 10:55 to 11:20). Data associated with each of the five aspects of the space-time budget are presented here both in table and, in some cases, map format. This combined approach is felt to be an effective manner with which to illustrate the spatial and temporal characteristics of each travel group.

\subsection{ACCOMMODATHON}

The previous discussion (Table 5.14) suggested that respondents were pleased with the accommodation situation in Shetland. Space-time budget data was able to uncover much more, however, with respect to which types of units (and where) were preferable to both General and Special Interest tourist groups. Table 6.1 views accommodation through a breakdown of tourist group visitation by unit. Each unit was ranked according to the combined averages of both travel groups. This average was derived by dividing the total number of nights stayed at a particular unit, by the number of reports for a unit type.

The highest visitation average overall for both travel groups was recorded under "Private Residence", although only one General Interest (ave. = 7.00) and five Special Interest tourists (ave. $=8.00$ ) stayed at this type of unit. "Self-Catering" establishments were almost as popular (as "Private Residence") in terms of the average number of nights stayed. More of the Special Interest tourist group stayed in "Self-Catering" units (and for longer) than individuals of the General travel group.

"Bed and Breakfast" (B\&B) establishments were by far the most popular aniong the sample in terms of frequency of visitation. The data suggest, though, that 
Table 6.1

Group Accommodation Statistics by Unit

\begin{tabular}{|c|c|c|c|c|c|c|}
\hline \multirow[b]{2}{*}{ Unit Type } & \multicolumn{3}{|c|}{ General } & \multicolumn{3}{|c|}{ Special } \\
\hline & $\begin{array}{c}\text { Total } \\
\text { Nights }\end{array}$ & $\begin{array}{c}\text { No. } \\
\text { Reports }\end{array}$ & Ave. & $\begin{array}{c}\text { Total } \\
\text { Nights }\end{array}$ & $\begin{array}{c}\text { No. } \\
\text { Reports }\end{array}$ & Ave. \\
\hline Private Residence & 7 & 1 & 7.00 & 40 & 5 & 8.00 \\
\hline Self Catering & 39 & 6 & 6.50 & 64 & 3 & 8.00 \\
\hline Campsite & 28 & 8 & 3.50 & 9 & 2 & 4.50 \\
\hline B. and $B$. & 79 & 32 & 2.47 & 74 & 25 & 2.96 \\
\hline Hotel & 34 & 13 & 2.62 & 30 & 11 & 2.73 \\
\hline Guest House & 8 & 5 & 1.60 & 10 & 3 & 3.33 \\
\hline Hostel & -- & -- & -- & 9 & 2 & 4.50 \\
\hline Wild Camping & 9 & 6 & 1.50 & 6 & 2 & 3.00 \\
\hline Personal Boat & - & -- & -- & 14 & 4 & 3.50 \\
\hline In Car & -- & -- & -- & 2 & 1 & 2.00 \\
\hline
\end{tabular}

Units ranked by combined highest group average.

respondents typically move among these units more than other types of establishments. Special Interest tourists (ave. $=2.96$ ) stayed slightly longer than General Interest travellers (ave. $=2.47$ ) at B\&B units. "Self-Catering" and "Bed and Breakfast" units combined, represented 55 per cent of sample visitation to all types of units.

Special Interest travellers chose to stay longer, on average, at "Hotels" and "Guest Houses" than their General counterparts. As with "B\&B" establishments, "Hotels" were popular with respect to total $\mathrm{ni}_{\mathcal{L}}$ hts, but lower regarding average number of nights stayed. General Interest tourists tended not to stay in the "Hostel", on a "Personal Boat", or in their "Car" which might indicate that the Special Interest traveller is slightly different both in activity (e.g., sailing) and budget. 
A more general comparison of both travel groups is found in Table 6.2. The data suggest that General Interest tourists $(n=36)$ stayed in more "listed" accommodation units than Special Interest respondents, "known" refering to those units that were identified through the Shetland Accommodation Guide (Shetland Islands Tourism, 1991a). Some Information, therefore, was missing both on the space-time data sheets, and for accommodation units that had recently opened for business). Based on the number of tourists affiliated with each group, the General group stayed in more units on average $(n=2.0)$ than the Special Interest group $(n=1.8)$. This indicates that the former group was more prone to move between units over the length of their vacation. By contrast, Special Interest travellers stayed in Shetland for more nights than General Interest tourists ( $n=258 ; n=204$, respectively), 1.7 nights longer on average.

\section{Table 6.2}

\section{Tourist Group Accommodation Statistics}

\begin{tabular}{lcc}
\hline \multicolumn{1}{c}{ Statistic } & $\begin{array}{c}\text { General } \\
\text { n }\end{array}$ & $\begin{array}{c}\text { Special } \\
\mathbf{n}\end{array}$ \\
\hline No. Tourists & 36 & 35 \\
No. Types of Units Stayed & 7 & 10 \\
Total No. Knowr. Units Stayed & 71 & 63 \\
Unit/Tourist Average & 2.0 & 1.8 \\
Total Known Nights Stayed & 204 & 258 \\
Average Nights Stayed & 5.7 & 7.4 \\
Total Actual Nights Stayed & 223 & 276 \\
Average Actual Nights Stayed & 6.2 & 7.9 \\
& \\
\hline
\end{tabular}

Data on the actual number of nights stayed in Shetland are also presented in Table 6.2. These statistics ignore the missing space-time data in providing as. indication of 
actual total visitation by group. Special Interest travellers $(n=276)$ stayed 1.7 days longer than the General group $(n=223)$, as was the case previously when considering only the known sites (missing data).

A central objective of this research was to determine spatial variations in tourist group movement in Shetland. The availability of sound space-time data and the Shetland Accommodation Guide (Shetland Islands Tourism, 1991a), enabled the researcher to identify the total number of nights stayed by both travel groups in the known units of a particular region. Accordingly, " $n$ " in Table 6.3, is a reflection of the information provided in the Accommodation Guide, and the amount of information that was provided by each tourist. Tourists occasionally wrote down the type of accommodation unit visited, but neglected to indicate where that unit was located. In these cases, the particular datum entry could not be used in a regional comparison. It is for this reason that group visitation numbers differ in Table 6.3 from previous figures.

Two types of information are provided in Table 6.3, Intergroup percentage (a comparison of General and Special Interest tourist responses), and Intragroup per cent (a breakdown of each tourist group independent of the other), as they apply to the selected regions of Shetland. The number of minutes use for each accommodation unit was divided by the number of individuals in each tourist group first. This type of format was used with questionnaire data previously and will continue to be used throughout this section as the best perceived method for direct group comparison.

Intergroup per cent data indicates that slightly more of the General Interest group (50.9 per cent) stayed in "Mainland" units than did individuals of the Special Interest 
Table 6.3

Tourist Group Accommodation Unit Visitation by Region

\begin{tabular}{|c|c|c|c|c|c|c|}
\hline \multirow[b]{2}{*}{ Region } & \multicolumn{4}{|c|}{ General } & \multicolumn{2}{|c|}{ Special } \\
\hline & $\mathbf{n}$ & $\begin{array}{c}\text { Intergrp } \\
\%\end{array}$ & $\begin{array}{c}\text { Intragrp } \\
\%\end{array}$ & $\mathbf{n}$ & $\begin{array}{c}\text { Intergrp } \\
\%\end{array}$ & $\begin{array}{c}\text { Intragrp } \\
\%\end{array}$ \\
\hline Mainland & 82 & 50.9 & 53.9 & 77 & 49.1 & 49.7 \\
\hline Lerwick & 59 & 57.7 & 38.8 & 42 & 42.3 & 27.1 \\
\hline Car Ferry Isles & 11 & 28.7 & 7.2 & 27 & 71.3 & 17.4 \\
\hline Passenger Ferry & & & & & & \\
\hline Isles & -- & -- & -- & 9 & 100.0 & 5.8 \\
\hline
\end{tabular}

cohort (49.1 per cent). This trend is replicated when viewing "Lerwick" units, but changes dramatically when considering "Car Ferry Isles". In this case, 71.3 per cent of Special Interest travellers (compared to only 28.7 per cent of General tourists) stayed in "Car Ferry" establishments. Only Special Interest tourists $(n=9)$ stayed in units on "Passenger Ferry Isles". Comparatively, General Interest travellers frequented those accommodation units that were more accessible ("Mainland" and "Lerwick") than did respondents of the Epecial Interest group.

Consideration of Intragroup per cent data (Figure 6.1) confirms the fact that General Interest travellers preferred accommodation that was more centrally located. Over 92 per cent of all General travel group visitation was in "Lerwick" and "Mainland" units. Conversely, only 76.8 per cent of the Special Interest group stayed in "Lerwick" and "Mainland" accommodation units. Over 23 per cent of this sub-sample stayed in the 
Figure 6.1 The Space-Time Characteristics of Regional Accommodation Visitation
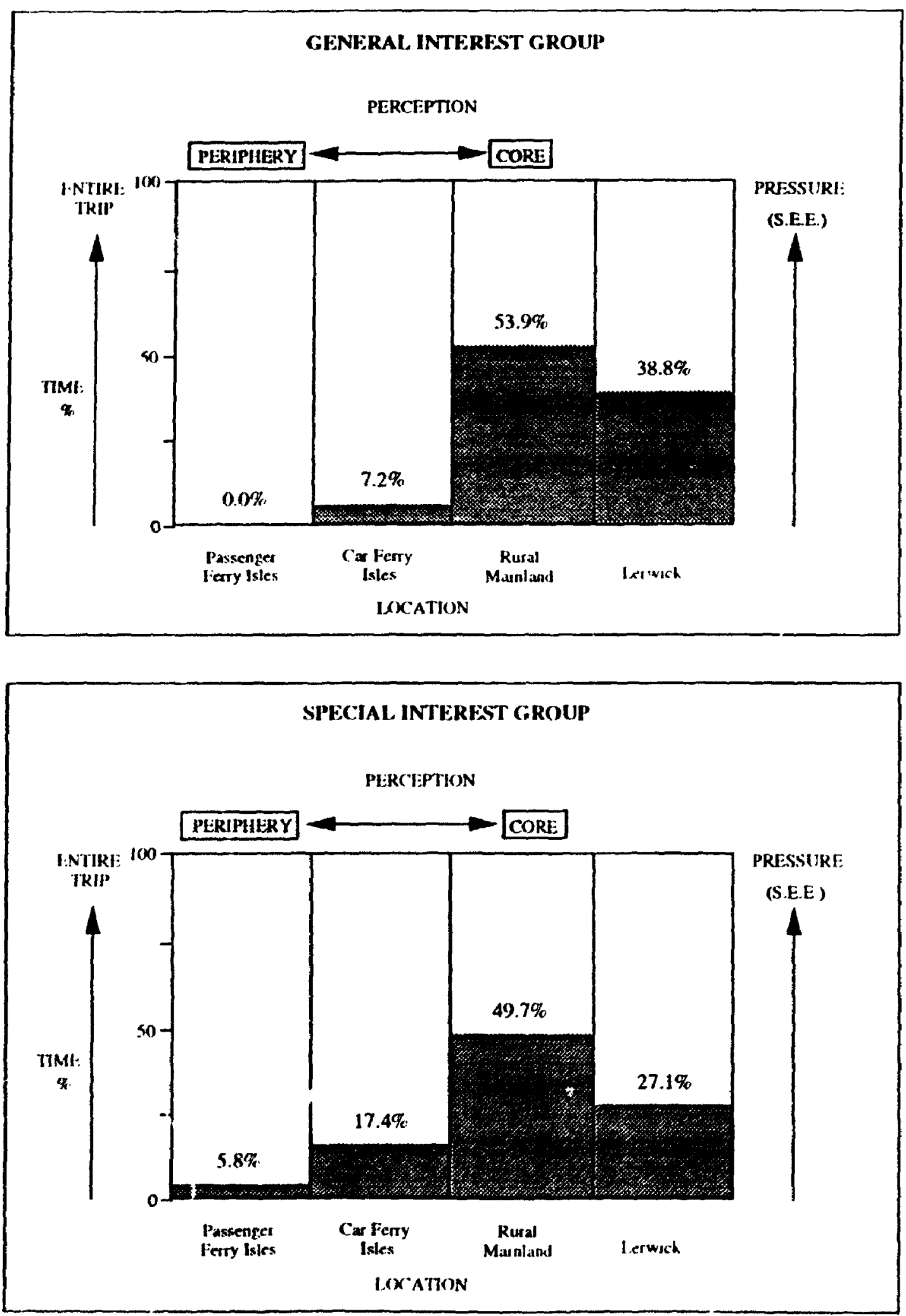
other two regions (Car and Passenger Ferry Isles), substantiating the fact that the Special Interest traveller had a more diffuse spatial accommodation pattern.

The spatial extent of both tourist groups regarding accomn:odation has boen determined through the calculation of mean centre. Silk (1979: 24) referred to this measure as a representation of "average location, not an average of the characteristics of the phenomena to be found at the location". As such, the mean centre value could be located within or outside the boundaries of a study area (e.g, outside of an L-shaped region). This statistic is "located by a pair of coordinates that provide that point which is more typical or representative of the distribution of a large number of points representing some tourism phenomenon" (Smith, 1990). Mean centre is calculated for " $x "$ and " $y "$ coordinates of accommodation using the following formula:

$$
\bar{x}=\frac{\sum_{x-1}^{n} x_{1}}{n}
$$

where: $\quad x=x$-coordinate of mean centre;

$x_{i}=$ horizontal coordinate of point $;$;

$\mathbf{n}=$ number of points.

Repeat for the y-coordinates.

A second mean centre was determined by involving a weighted factor lut cach accommodation unit. The " $x$ " and " $y$ " coordinates of a unit were multiplied by the frequency of visitation for that unit. This weighted mean centre is expressed as follows:

$$
w \bar{x}=\frac{\sum_{1-1}^{w}\left(w_{1} x_{1}\right)}{\sum_{1-1}^{0} w_{1}}
$$


where: $\quad \mathrm{w}_{\mathrm{j}}=$ weight of point ${ }_{\mathrm{i}}$; other variables are as defined above.

Figure 6.2 , illustrates both the mean centre and weighted mean centre for both General and Special Interest tourist groups. As the majority of Passenger and Car Ferry Isles are located to the north of Lerwick and parts of the Mainland, it follows that the Special Interest tourist group would be repres _..ied closer to these regions (reflecting back to Table 6.3). The weighted mean centre for the Special Interest tourist group was located more to the heart of the Mainland when compared to the mean centre. This weighted representation is a more realistic indicator of actual levels of accommodation use. The General Interest weighted mean centre was located south of the mean centre, and closer to the main urban centre of Lerwick, implying that Lerwick was a more desirable region for accommodation for this group.

\subsection{TRANSPORTATION}

A second feature included on the space-time budget survey was transportation, as a means to understand how tourists were moving about Shetland, and at what times. An important factor associated with the analysis of this transportation data is the varied nature of the response patterns of the overall sample. Tourists were required to record, on the space-time sheet, each time they undertook a journey (the time they started, until the time the movement was finished). However, due to the fact that transport was required to each facility, attraction, and back to respective accommodation units, this feature of the space-time budget was the most detailed. While some sample members were quite conscientious in their responses to this feature (indicating correct times for 


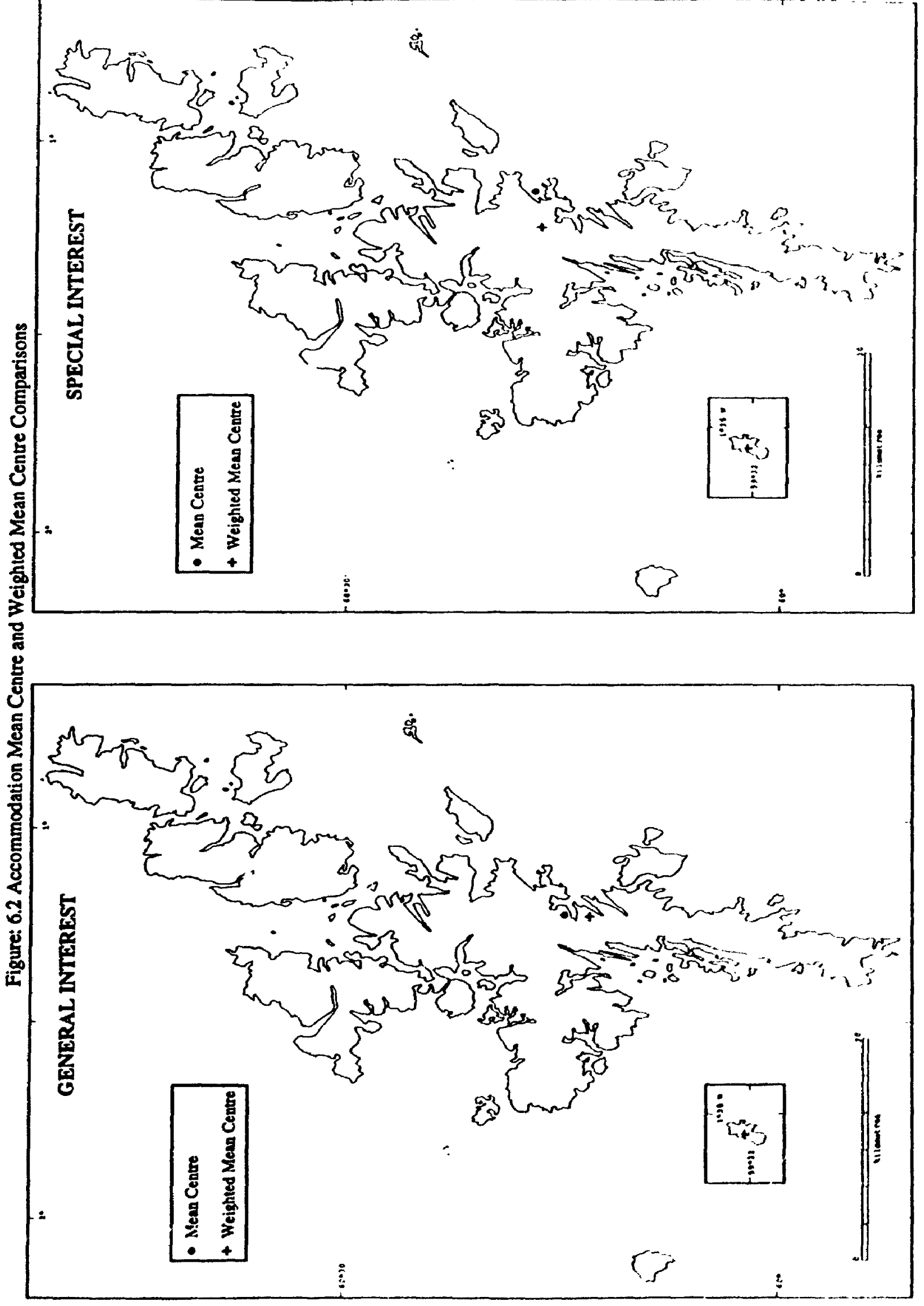


each journey), many were not so keen. Often tourists simply acknowledged the type of transport (e.g., car) and then proceeded to write down when they first used the car in the morning, to when they finished with it at night (e.g., 9:00 a.m. to 6:60 p.m.). These types of responses could not be used in the analysis, therefore, and constituted missing data. This discrepancy illustrates either ambiguity in the space-time budget measure (although it was explained to each tourist and instructions were included in a letter of introduction), or simply that some tourists could, or would not, become involved in this aspect of the study to the required level.

Table 6.4 is a compendium of each of the modes respondents used in their movement throughout Shetland. Ten modes are presented and ranked according to the combined total time (in minutes) that each particular mode was used. The "Car" was used more often, and on more days than any other mode of transport. Comparatively, Special Interest tourists used the "Car" for 14,475 minutes compared to 9,760 minutes by the General Interest travel group. This Table also suggests that missing data were prevalent among both General ( $n=81$ days) and Special $(n=109$ days) Interest groups regarding the use of a car. It was those modes that were used more extensively such as "Car", "Bicycle", and "Walking", that have high missing data values. Both travel groups used the "Car" between 1 and 1.5 times per day, averaging 73.4 minutes for General, and 76.2 minutes for Special Interest travellers. By contrast, there are little or no missing data for those modes that were used infrequently, or for short periods of time by the sample (examples in Table 6.4 include "Taxi", "Plane", "Hitchhiking", "Passenger Ferry", and "Coach Tour"). 


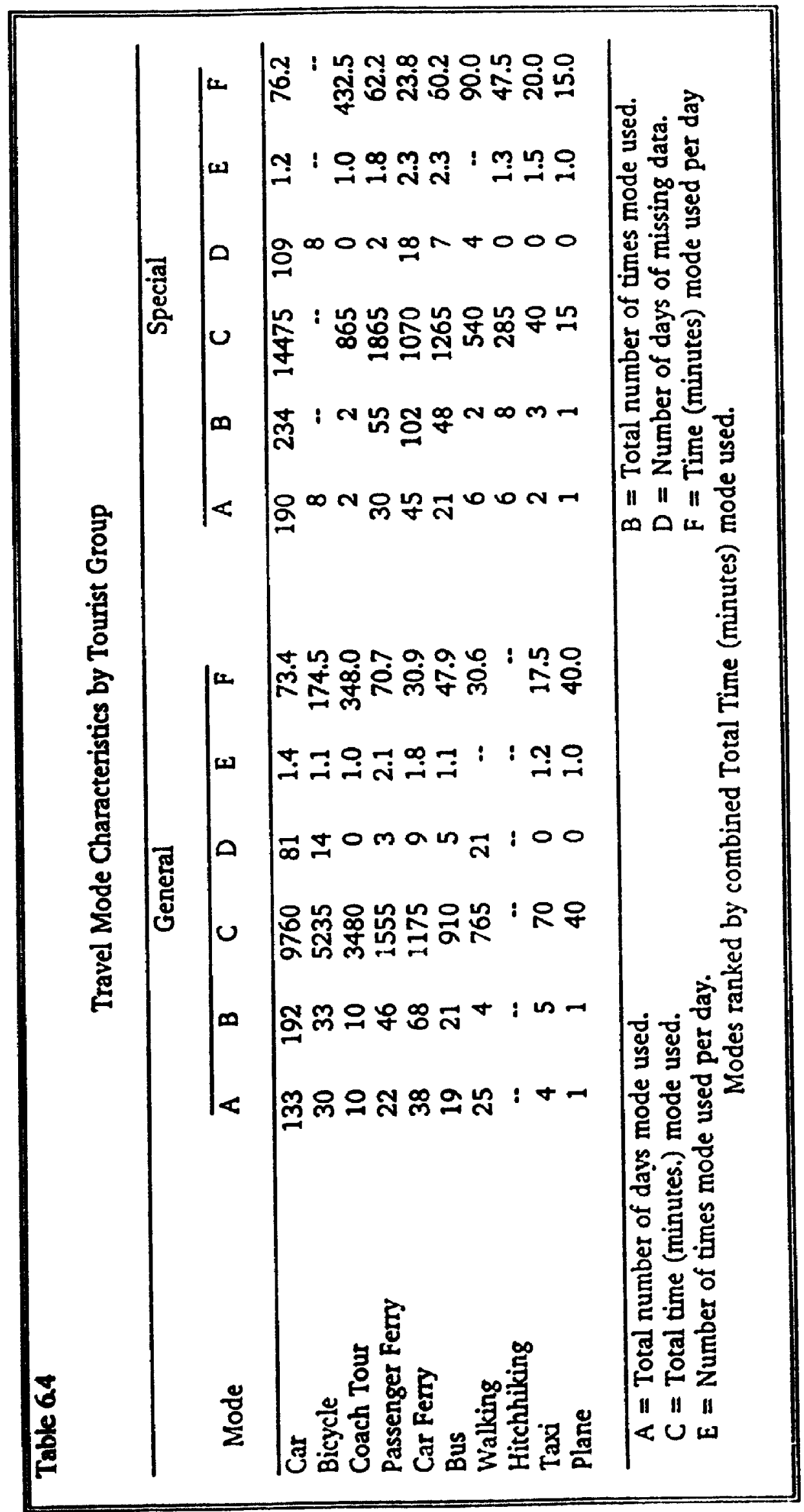


There is a significant difference between the two travel groups when considering "Bicycle" use. General Interest respondents registere. 30 days of use, and totalled 5,235 minutes. Statistic "E" (number of times mode used per day) indicates that General Interest tourists used the "Bicycle" 1.1 times per day. This result represented a further example of the difficulty in recording transport for modes that respondents depended on for an entire day. The researcher, through observation, witnessed cycle tourists stopping frequently during a typical day, both at facilities and attractions. Special Interest tourists on the other hand, used the "Bicycle" sparingly with no recorded time values.

General Interest travellers (3480 minutes) also relied on "Coach Tour" travel more frequently than Special Interest (865 minutes) tourists. This type of travel has a predetermined time limit. Tourists could sign-up for any one of fourteen tours (offered by two companies), that ranged in length from 1 hour to 9.5 hours of a particular day. These tours had itineraries that arranged a variety of stops over the round-trip. Statistic "E" implies that tourists, of both groups, considered the "Coach Tour" round-trip as one use, instead of multiple-use based on the number of facilities and attractions (stops) visited over the course of the trip. The predetermined time limit of each tour may have ultimately contributed to a feeling of "one excursion" instead of various joumeys to different attractions via the Coach mode.

Column "F" (time mode used per day) indicates that Special Interest tourists (432.5 minutes) travelled longer by "Coach Tour", on average, than the General (348.0 minutes) group. The data support the notion that Special Interest travellers (although 
there are only two reported cases), were using the Coach to visit attractions that were spatially more distant than the tours chosen by General Interest tourists.

Statistics associated with the "Passenger Ferry" mode indicate greater Special Interest use (55 times used, representing 1865 minutes), and a tendency for this type of traveller to visit regions that were more remote. It is the Passenger Ferry system that transports tourists to islands such as Noss, Mousa, Papa Stour, and Fair Isle. The General Interest group reported using this ferry system 46 times, for 1555 minutes. This use was reported to have both a higher frequency per day $(n=2.1)$, and higher time per day $(n=70.7)$ average, however, than the use by Special Interest tourists. The same pattern is not demonstrated with respect to "Car Ferry" use. Special Interest tourists, on average, used this system more (2.3 times per day), but less (23.8 minutes use per day) than their General Interest counterparts (1.8 times per day; 30.9 minutes per day).

These data imply that the Special Interest group, when they did use the passenger ferry system, were travelling more often between regions on a daily basis. It can be deduced, therefore, that the Special Interest group had more exposure to passenger ferry isles, staying among these isles for a longer period of time.

The information available for "Walking" as a mode of transport in Table 6.4 is difficult to interpret due to missing data. Despite the limitation on data, what did emerge were results that suggest that Special Interest tourists walked longer during the tourist day than General Interest travellers $(n=90.0$ and 30.6 minutes per day, on average, respectively). 
The final three modes, "Hitchhiking", "Taxi", and "Plane", were used much less often than most of the before-mentioned modes. Only Special Interest tourists reported "Hitchhiking" as a travel mode $(n=1.3$ times per day; 47.5 minutes per day), while overall, eig!ti respondents reported using the "Taxi" service. Finally, two Plane trips were recorded among both travel groups, to Fair Isle.

\subsection{FACILITY USE}

The space-time budget sought information related to the use of facilities by the sample in their daily Shetland routines. Tourists were left to interpret their own facility use, given the following example: "Shops, Banks, etc". A number of facilities were ultimately identified by respondents, those of which arc located in Table 6.5. Most of these facilities are presented as they were recorded in the survey, however, some (e.g., "Shops/Shopping") were combined. Due to the vague, overlapping nature of response associated with some of these facilities, it was logistically easier to handle them combined rather than risk misrepresenting them independently. All of the facilities in Table 6.5 were ranked according to the highest combined group average.

"Pubs" emerged as a facility that was heavily usod by all respondents. Although more General Interest tourists frequented "Pubs" $(n=29 ; 1845$ minutes; ave. = 63.6), it was the Special Interest tourist sub-sample that maintained a higher average stay $(n=$ 12; 1435 minutes; ave. $=119.6$ ) despite their lower overall visitation. Data in Table 6.5 also indicate that "Restaurant" and "Hotel to Eat" were popular throughout the sample, with high average use values. 
Table 6.5

Facility Use by Tourist Group

\begin{tabular}{|c|c|c|c|c|c|c|}
\hline \multirow[b]{2}{*}{ Facility } & \multicolumn{3}{|c|}{ General } & \multicolumn{3}{|c|}{ Special } \\
\hline & $\begin{array}{l}\text { No. } \\
\text { Reports }\end{array}$ & $\begin{array}{l}\text { Total } \\
\text { Min. }\end{array}$ & Ave. & $\begin{array}{c}\text { No. } \\
\text { Reports }\end{array}$ & $\begin{array}{l}\text { Total } \\
\text { Min. }\end{array}$ & Ave. \\
\hline Theatre/Arts & 2 & 380 & 190.0 & -- & -. & -- \\
\hline Pub & 29 & 1845 & 63.6 & 12 & 1435 & 119.6 \\
\hline Restaurant & 21 & 2100 & 100.0 & 9 & 605 & 67.2 \\
\hline Other & 2 & 135 & 67.5 & 6 & 420 & 70.0 \\
\hline Hotel to Eat & 42 & 2850 & 67.9 & 34 & 2140 & 62.9 \\
\hline Shops/Shopping & 67 & 3715 & 55.4 & 75 & 2120 & 28.3 \\
\hline Coffee Shop & 39 & 1415 & 36.3 & 25 & 730 & 29.2 \\
\hline Fish and Chips & 7 & 225 & 32.1 & 10 & 200 & 20.0 \\
\hline Knitwear & 20 & 625 & 31.2 & 6 & 125 & 20.8 \\
\hline \multicolumn{7}{|l|}{ Bus/Car/Plane/ } \\
\hline Boat Station & 21 & 560 & 26.7 & 9 & 190 & 21.1 \\
\hline Tourist Office & 39 & 930 & 23.8 & 28 & 510 & 18.2 \\
\hline Bookstore & 4 & 70 & 17.5 & 9 & 215 & 23.9 \\
\hline Camera Shop & 5 & 115 & 23.0 & 2 & 30 & 15.0 \\
\hline Newsagent & 24 & 390 & 16.2 & 42 & 545 & 13.0 \\
\hline Post Office & 19 & 360 & 18.9 & 14 & 140 & 10.0 \\
\hline Petrol Station & 9 & 85 & 9.4 & 14 & 120 & 8.6 \\
\hline Bank & 7 & 46 & 6.6 & 21 & 188 & 9.0 \\
\hline
\end{tabular}

Facilities ranked by combined highest group average

Both travel groups used facilities that were included under the heading of "Other". The General Interest tourist group cited "Church" $(n=2 ; 135$ minutes), while Special Interest travellers, though, included "Church" $(n=1)$, in addition to "Leisure Centres" $(n=2)$, and "Swimming Pools" $(n=3)$, as "Other" facilities that represented 420 minutes of use (70.0 minutes on average). 
Facilities that were not used extensively included "Newsagent", "Post Office", "Petrol Station", and "Bank". These facilities have a purpose that is markedly different than some of the higher ranked facilities (e.g., "Restaurant", "Shops/Shopping", "Tourist Office", etc.). They also do not have a leisure-related, or combined function (a restaurant has a combined function in that it provides food, bit also atmosphere that can be enjoyed with others, over a variable period of time). As such, this second group take little time to use, and therefore involve less of the tourist's day. Overall, the General Interest group dominated the use of facilities in terms of the average length of time per report. Only "Pubs", "Other", "Bookstore", and "Bank" in Table 5.32 were visited for longer periods, on average, by the Special Interest tourist group.

Table 6.6 shows the relationship between facility use and tourist group based on a comparison of Intergroup and Intragroup percentage. A limiting feature of the spacetime budget was that it did not assess the spatial aspects of facility use. This inconsistancy will be discussed further in chapter 8 . Intergroup per cent presents facility use data by comparing the total number of minutes that each facility was used by both groups. "Shops/Shopping" emerged as a facility type that occupied a very significant amount of the sample's time. Comparatively, the General Interest group (63.0 per cent) shoppod more than their Special Interest (37.0 per cent) counterparts. Other highly frequented facility types included "Hotel to Eat", "Pub", "Restaurant", and "Coffee Shop". All of these facilities, except "Pub", were used more by the General Interest group, on average, in terms of overall time (minutes) spent. Data associated with "Tourist Office" use provides a further basis for comparative investigation. The General 
Interest travel group (63.9 per cent) was to use the services of the Tourist Office (presumably for making bookings and gathering information) more often than the Special Interest traveller ( 36.1 per cent). Overall, the Intergroup per cent statistic indicates that facilities were used, on average, more by the General Interest group.

Table 6.6

Comparison of Group Facility Characteristics

\begin{tabular}{|c|c|c|c|c|c|c|}
\hline \multirow[b]{3}{*}{ Facility } & \multicolumn{3}{|c|}{ General } & \multicolumn{2}{|c|}{ Special } & \multirow[b]{2}{*}{ Intragrp } \\
\hline & \multicolumn{3}{|c|}{ No. Intergrp Intragrp } & \multicolumn{2}{|c|}{ No. Intergrp } & \\
\hline & & $1 . \%$ & $\%$ & \multicolumn{2}{|c|}{ Min. $\%$} & $\%$ \\
\hline Shops/Shopping & 3715 & 63.0 & 23.9 & 2120 & 37.0 & 21.8 \\
\hline Hotel to Eat & 2850 & 56.4 & 18.3 & 2140 & 43.6 & 22.0 \\
\hline Pub & 1845 & 38.5 & 11.9 & 1435 & 61.5 & 14.8 \\
\hline Restaurant & 2100 & 77.1 & 13.5 & 605 & 22.9 & 6.2 \\
\hline Coffee Shop & 1515 & 66.9 & 9.7 & 730 & 33.1 & 7.5 \\
\hline Tourist Office & 930 & 63.9 & 6.0 & 510 & 36.1 & 5.3 \\
\hline \multirow{2}{*}{\multicolumn{7}{|c|}{ Bus/Car/Plane/ }} \\
\hline & & & & & & \\
\hline Boat Station & 560 & 74.1 & 3.6 & 190 & 25.9 & 2.0 \\
\hline Knitwear & 625 & 82.9 & 4.0 & 125 & 17.1 & 1.3 \\
\hline Other & 241 & 23.8 & 0.9 & 405 & 76.2 & 4.2 \\
\hline Post Office & 360 & 71.4 & 2.3 & 140 & 28.6 & 1.4 \\
\hline Fish and Chips & 225 & 52.3 & 1.4 & 200 & 47.7 & 2.1 \\
\hline Bookstore & 70 & 24.0 & 0.4 & 215 & 76.0 & 2.2 \\
\hline Bank & 46 & 19.1 & 0.3 & 188 & 80.9 & 1.9 \\
\hline Pertol Station & 85 & 40.9 & 0.5 & 120 & 59.1 & 1.2 \\
\hline Camera Shop & 115 & 78.7 & 0.7 & 30 & 21.3 & 0.3 \\
\hline
\end{tabular}

Facilities ranked by combined intragroup percentage

Intragroup percentage, conversely, provides an understanding of how each group spent time among each of the various facilities. The nverriding trend indicates that both General and Special Interest travei groups spent similar amounts of time at these facilities with respect to the order they are presented in the Table. 
Table 6.7 attempts to approximate facility use based on data that were missing (facility use was indicated but time values were not) from the space-time budget sheets. Since missing data varied between tourist groups and between facilities, it was important to devise a means with which to objectively estimate the overall pattern of use for each facility. The following formula was applied:

$$
A T=\left(m_{1}\right)\left(\bar{x}_{1}\right)+t_{1}
$$

where: $\quad \quad \quad \mathbf{A T}=$ the adjusted time value;

$m=$ number of missing time values for facility $;$;

$\mathbf{x}=$ mean number of minutes/report for facility $;$;

$t=$ total minute value for facility $i$.

Although it was impossible to arrive at an exact time for each facility, it was important to try and determine whether such a formula might uncover differences in how facilities were used ar ! ranked (and therefore different from the results in Table 6.6). Changes did occur regarding facility use in two areas (comparing Table 6.6 and Table 6.7). First, overall use of "Coffee Shop", after being adjusted, replaced "Restaurant" use. The Intergroup percentage of both of these facilities increased for the General Interest group. A second change occurred with the positioning of "Bus/Car/Plane/Boat Station". This facility, after being adjusted, fell three spaces to below "Knitwear", "Other", and "Post Office" in Table 6.7.

Overall, a number of minor changes occurred with respect to Intergroup and Intragroup percentage, for both travel groups, as a result of the adjustment procedure. However insignificant, these changes imply that such a measure might have continued utility in estimating tourism or recreational use of facilities in similar studies in the 
Table 6.7

Comparison of Adjusted Group (grp.) Facility Characteristics

\begin{tabular}{|c|c|c|c|c|c|c|}
\hline \multirow[b]{2}{*}{ Frcility } & \multicolumn{3}{|c|}{ General } & \multicolumn{3}{|c|}{ Special } \\
\hline & $\begin{array}{l}\text { Adjusted } \\
\text { Min. }\end{array}$ & $\begin{array}{c}\text { Intergrp } \\
\mathscr{x}\end{array}$ & $\begin{array}{c}\text { Intragrp } \\
\not 0\end{array}$ & $\begin{array}{l}\text { Adjustad } \\
\text { Min. }\end{array}$ & $\begin{array}{c}\text { Intergrp } \\
\mathbf{x}\end{array}$ & $\underset{\%}{\text { Intragtp }}$ \\
\hline Shops/Shopping & 4824.0 & 66.0 & 22.3 & 2487.5 & 34.0 & 20.5 \\
\hline Hotel to Eat & 2985.7 & 53.6 & 13.8 & 2517.4 & 46.4 & 20.8 \\
\hline Pub & 1908.6 & 49.2 & 8.8 & 1913.4 & 50.8 & 15.8 \\
\hline Coffee Shop & 2503.4 & 72.9 & 11.6 & 905.2 & 27.1 & 7.5 \\
\hline Restaumat & 2700.0 & 78.0 & 12.5 & 739.4 & 22.0 & 6.1 \\
\hline Tourist Office & 1025.4 & 61.0 & 4.7 & 637.4 & 39.0 & 5.3 \\
\hline Newsagent & 520.0 & 41.0 & 2.4 & 727.0 & 59.0 & 6.0 \\
\hline Knitwear & 812.5 & 80.8 & 3.7 & 187.4 & 19.2 & 1.6 \\
\hline Other & 135.0 & 22.6 & 0.6 & 450.0 & 77.4 & 3.7 \\
\hline Post Office & 663.2 & 72.9 & 3.3 & 240.0 & 17.1 & 2.0 \\
\hline \multicolumn{7}{|c|}{ Bus/Car/Plane/Bost/ } \\
\hline Station & 613.3 & 72.0 & 2.8 & 232.2 & 28.0 & 1.9 \\
\hline Fich and Chips & 385.7 & 55.5 & 1.8 & 300.0 & 44.5 & 2.5 \\
\hline Bookstore & 122.5 & 27.7 & 0.6 & 310.6 & 72.3 & 2.6 \\
\hline Bank & 111.7 & 28.1 & 0.6 & 278.0 & 71.9 & 2.3 \\
\hline Petrol Station & 198.3 & 58.4 & 1.0 & 137.2 & $4: 6$ & 1.1 \\
\hline Camera Shop & 161.0 & 72.3 & 0.8 & 60.0 & 27.7 & 0.5 \\
\hline
\end{tabular}

"Adjusted Min." determined by multiplying the number of missing time values for a facility by the average number of minutes/report and adding this figure with the total minutes for each facility.

future.

\subsection{ATTRACTIONS}

Tables 5.21 to 5.26 (contained in the previous chapter) provided a detailed ranking of a number of different types of attractions based on data that were extracted from the self-administered questionnaire. As the space-time budget results should mirror the questionnaire results with respect to visitation, it is not the purpose here to repeat those results in attaining similar or marginally dissimilar conclusions. Instead, this 
section presents space-time budget attraction data in a combined form as it applies to Shetland regions, and to attraction type.

The four functional regions of Shetland are identified in Table 6.8, along with the amount of time tourist groups spent at attraction sites within each region. The data are presented in a form that summarises visitation for all types of attractions (natural, archaeological, etc.). The number of minutes in Table 6.8 reflects the total time that each group spent at all attractions in each region (regions ranked according to the combined Intragroup per cent statistic).

Table 6.8

Time Spent by Tourist Groups (grp.) at Regional Attractions

\begin{tabular}{|c|c|c|c|c|c|c|}
\hline \multirow[b]{2}{*}{ Region } & \multicolumn{3}{|c|}{ General } & \multicolumn{3}{|c|}{ Special } \\
\hline & $\begin{array}{l}\text { No. } \\
\text { min. }\end{array}$ & $\begin{array}{c}\text { Intergrp. } \\
\%\end{array}$ & $\begin{array}{c}\text { Intragrp. } \\
\%\end{array}$ & $\begin{array}{l}\text { No. } \\
\text { min. }\end{array}$ & $\begin{array}{c}\text { Intergrp. } \\
\%\end{array}$ & $\begin{array}{c}\text { Intragrp. } \\
\%\end{array}$ \\
\hline $\begin{array}{l}\text { Mainland } \\
\text { Passenger }\end{array}$ & 10490 & 41.6 & 44.2 & 14295 & 58.4 & 32.9 \\
\hline $\begin{array}{l}\text { Ferry Isles } \\
\text { Car Ferry }\end{array}$ & 5415 & 26.3 & 22.8 & 14750 & 73.7 & 34.0 \\
\hline Isles & 5300 & 32.0 & 22.3 & 10960 & 68.0 & 25.2 \\
\hline Lerwick & 2510 & 41.6 & 10.6 & 3425 & 58.4 & 7.9 \\
\hline
\end{tabular}

Regions ranked by combined intragroup average.

"Mainland" attractions were the most frequently visited by the entire sample. The Special Interest group (58.4 per cent) represented over half of the visitation to attractions of the mainland, compared to the General Interst group (41.6 per cent). Yet, within group comparisons illustrate that mainland visitation accounted for only 32.9 per cent, 
for the Special Interest group, compared to $\mathbf{4 4 . 2}$ per cent for the General Interest group. It is indeed significant that when compared to the General Interest group, the Special Interest faction represented most of the visitation in all four regions of Shetland (Intergroup per cent). This statistic is most pronounced when considering "Passenger Ferry Isles", where the Special Interest group was responsible for 73.7 per cent of all visits, compared to 22.8 per cent by the General Interest tourist group. Both of the travel groups spent the least amount of time at the attractions of Lerwick. Although the Special Interest group (3425 minutes) spent morc time, on average, than their General counterparts (2510 minutes), the Special Interest intragroup statistic ( 7.9 per cent) illustrates a lower reliance on the attractions of Lerwick than the general group (10.6 per cent). These results point to the fact that the Special Interest group stayed for longer periods of time at attractions, and were spatially more widely distributed to attractions away from the core (Lerwick) than the General group.

Intragroup per cent (Figure 6.3) data illustrate that Spocial Interest travellers spent slightly more time on "Passenger Ferry Isles", than on the "Mainland". These islands are so small (approximately 5 square kilometres, on average), with little infrastructure and attraction diversity, that the researcher has categorized them (as does the Shetland Tourist Map) as attractions in themselves. This raises the possibility that even though tourists may have stayed on Fair Isle, for example, for four or five days, such a length may contribute to a biased attraction time value. The researcher tried to control for this by eliminating the hours tourists were engaged in preparatory, sleep-related, and nonleisure-related activities per day (approximately fourteen hours per day). The resulting 
Figure 6.3 The Space-Time Characteristics of Regional Attraction Visitation
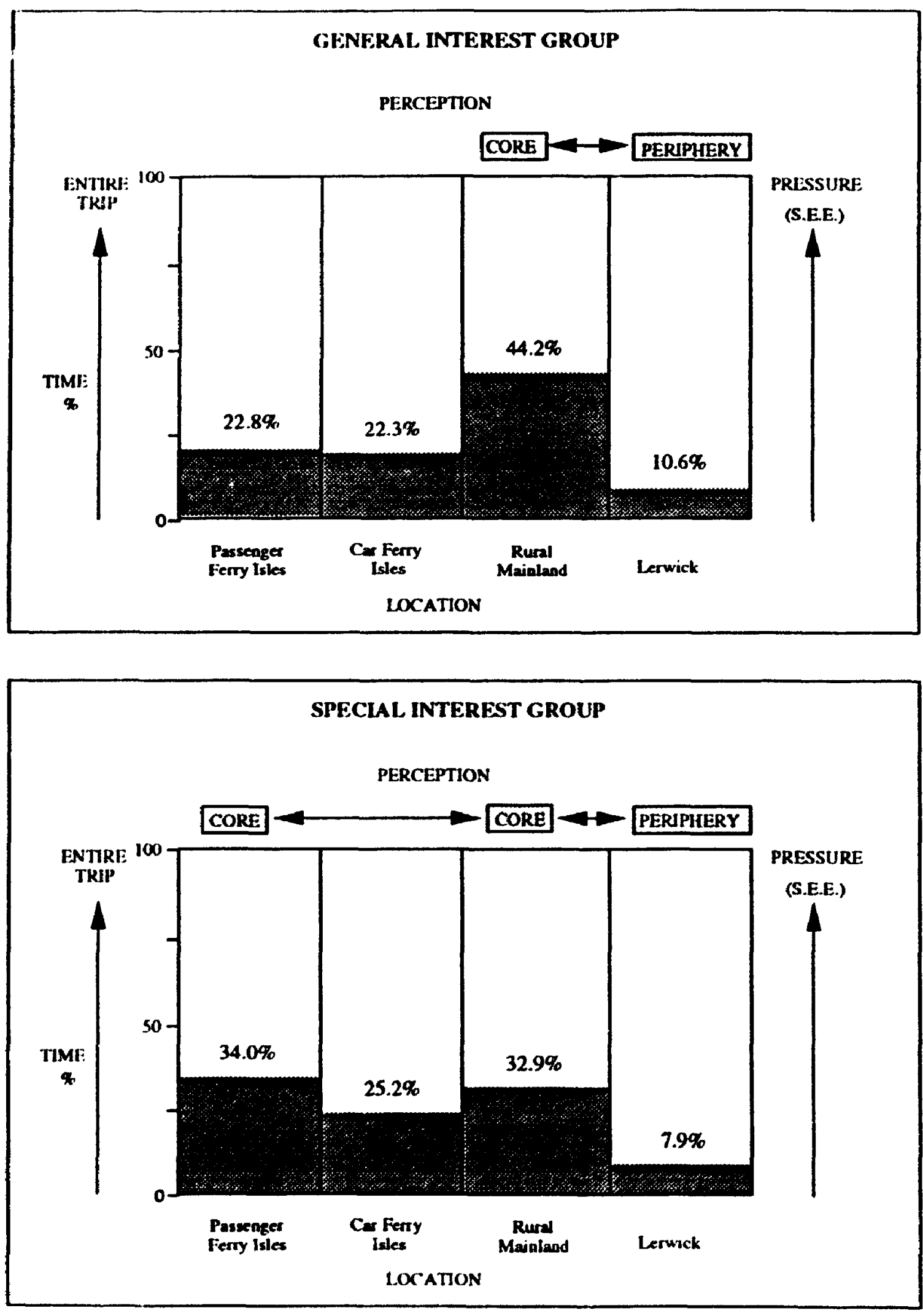
time value might better reflect a truer attraction-visit report arproximation. It is also important to realise that a visit to small, peripheral islands such as Mousa, Papa Stour, Noss, and Fair Isle, must be considered different from a visit to a Mainland, Lerwick, or even Car Ferry Isle attraction. These small islands offer very few individual attractions; attractions that may be perceived as one "experience". It should be acknowledged that there is a very fine line between attraction and experience in these cases. One might suggest, for example, that people visiting Mousa might either be interested in the Broch and/or the Common Seal population. The fact remains though that individuals are transported, by Passenger Ferry, to a very small island for a specified period of time. Tourists can spend time at the Broch, with the Seals, stroll about the island, or simply spend time looking at the horizon. These latter two activities are not attractions, but must be considered as part of the peripheral island experience; an experience that occurs over a specified period of time.

The visitation impact to a region changes when the time each tourist group has spent in these areas is examined in relation to other criteria. The land area of each of the four regions identified in Table 6.9 is presented as a per cent of the 1367 square kilometres of Shetland represented through tourist visitation (the sample did not visit Foula or the many non-inhabited small islands in the archipelago, with the exception of St Ninian's Isle). In Table 6.8, "Maunland" registered the highest ranking with respect to overall time. This distinction changes markedly though when the regions are considered with respect to the time/area function (Min./Area per cent determined by dividing the number of minutes of attraction visitation, by the per cent of land area of 
Table 6.9

Group Attraction Visitation by Regional Area Percentage

\begin{tabular}{|c|c|c|c|c|c|}
\hline \multirow[b]{2}{*}{ Region } & \multirow[b]{2}{*}{ (\%) } & \multicolumn{2}{|c|}{ Gencral } & \multicolumn{2}{|c|}{ Spocial } \\
\hline & & $\begin{array}{l}\text { No. } \\
\text { Min. }\end{array}$ & $\underset{\%}{\text { Min./Area }}$ & $\begin{array}{l}\text { No. } \\
\text { Min. }\end{array}$ & $\begin{array}{c}\text { Min./Area } \\
\%\end{array}$ \\
\hline $\begin{array}{l}\text { Lerwick } \\
\text { Passenger }\end{array}$ & $(0.37)$ & 2510 & 64.77 & 3425 & 48.76 \\
\hline $\begin{array}{l}\text { Ferry Isles } \\
\text { Car Ferry Isles } \\
\text { Mainland }\end{array}$ & $\begin{array}{l}(1.61) \\
(31.09) \\
(66.93)\end{array}$ & $\begin{array}{r}5415 \\
5300 \\
10490\end{array}$ & $\begin{array}{r}32.11 \\
1.63 \\
1.50\end{array}$ & $\begin{array}{l}14750 \\
10960 \\
14295\end{array}$ & $\begin{array}{r}48.26 \\
1.86 \\
1.12\end{array}$ \\
\hline
\end{tabular}

Min./Area percent determined by dividing No. Min. by the percent of land area (km. squared) of each region. The resulting figure is a percent of the overall Shetland study land area.

each region) of Table 6.9. General Interest tourists spent the largest portion of their time/area in "Lerwick" (64.8 per cent) as did the Special Interest group (48.8 per cent). Special Interest travellers also spent a significant amount of time (48.3 per cent) in the "Passenger Ferry Isle" region, while General Interest tourists, comparatively, spent just less than one-third of their time in this region. The min./area ratio indicates that both travel groups spent far less time on "Car Ferry Isles" and the "Mainland", when compared to the overwhelming frequency of use (per area) in the top two regions.

Characteristics of visitation to attraction "type" are organised and presented in Table 6.10. General and Special Interest travel groups were compared on the basis of number of reports to each type of attraction, the total number of minutes at these attractions, and average number of minutes per report. The data illustrate that both travel groups spent more time, on average, at "Natural" attractions than any other type; 
Table 6.10

Characteristics of Attraction Type Visitation by Group

\begin{tabular}{|c|c|c|c|c|c|c|}
\hline \multirow[b]{2}{*}{ Attraction Type } & \multicolumn{3}{|c|}{ General } & \multicolumn{3}{|c|}{ Special } \\
\hline & $\begin{array}{c}\text { No. } \\
\text { Reports }\end{array}$ & $\begin{array}{l}\text { Total } \\
\text { s Min. }\end{array}$ & Ave. & $\begin{array}{c}\text { No. } \\
\text { Reports }\end{array}$ & $\begin{array}{l}\text { Total } \\
\text { s Min. }\end{array}$ & Ave. \\
\hline Natural & 65 & 7355 & 113.2 & 84 & 18055 & 214.9 \\
\hline Other & 79 & 5635 & 71.3 & 94 & 12035 & 128.0 \\
\hline Archaeology & 69 & 6235 & 90.4 & 80 & 8375 & 104.7 \\
\hline House and Building & 96 & 4270 & 44.5 & 82 & 4280 & 52.2 \\
\hline Industrial & 6 & 125 & 20.8 & 10 & 380 & 38.0 \\
\hline Craft & 4 & 95 & 23.7 & 9 & 260 & 28.9 \\
\hline
\end{tabular}

however, a significant difference is observed between groups. Special Interest tourists (ave. $=214.9$ ) spent over one hundred minutes more, on average, at "Natural" attractions than did General Interest respondents (ave. $=113.2$ ). In fact, Special Interest tourists spent more time at every attraction type than members of the General Interest cohort. Very few tourists of either group visited or spent long periods of time at "Industrial" or "Craft Centre" attraction sites.

Table 6.11 provides further information on attraction type, through an analysis of Intergroup and Intragroup per cent. There was a very even and high concentration in use (Intragroup per cent) of "Natural" (31.0 per cent), "Other" (23.8 per cent), and "Archaeology" ( 26.3 per cent) type attractions by the General Interest travel group. Comparatively, Special Interest tourists spent much more time at "Natural" (41.6 per cent) and "Other" (27.7 per cent) attractions, when matched against the remaining types. 
The Intragroup per cent statistic also confirms that very few individuals of either travel group spent time at "Industrial" or "Craft Centre" attractions relative to all other types.

Table 6.11

Comparison of Group Attraction Characteristics

\begin{tabular}{|c|c|c|c|c|c|c|}
\hline \multirow[b]{2}{*}{ Attraction Type } & \multicolumn{3}{|c|}{ General } & \multicolumn{3}{|c|}{ Special } \\
\hline & $\begin{array}{l}\text { No. } \\
\text { Min. }\end{array}$ & $\begin{array}{c}\text { Intergrp } \\
\%\end{array}$ & $\begin{array}{c}\text { Intragrp } \\
\%\end{array}$ & $\begin{array}{l}\text { No. } \\
\text { Min. }\end{array}$ & $\begin{array}{c}\text { Intergrp } \\
\%\end{array}$ & $\begin{array}{c}\text { Intragrp } \\
\%\end{array}$ \\
\hline Natural & 7355 & 28.4 & 31.0 & 18055 & 71.6 & 41.6 \\
\hline Other & 5635 & 31.3 & 23.8 & 12035 & 68.7 & 27.7 \\
\hline Archacology & 6235 & 42.0 & 26.3 & 8375 & 58.0 & 19.3 \\
\hline House and Building & 4270 & 49.2 & 18.0 & 4280 & 50.8 & 9.9 \\
\hline Industrial & 125 & 24.2 & 0.5 & 380 & 75.8 & 0.9 \\
\hline Craft & 95 & 26.2 & 0.4 & 260 & 73.8 & 0.6 \\
\hline
\end{tabular}

Very little difference is observed in how these attractions are ranked, when adjusted through the use of missing data (Table 6.12). As was the case with the previous discussion regarding facilities, adjustments were determined by multiplying the number of missing time values for each attraction, by the average number of minutes per report, and adding this figure with the total number of minutes for each attraction:

$$
A T=\left(m_{1}\right)\left(\bar{x}_{1}\right)+t_{1}
$$

None of the attraction type rankings were displaced through this procedure, with very little change in Intergroup and Intragroup percentages. This result indicates that attraction data were better reported when compared to the reports made for facility use. In speculating on this, attractions may have been more important to tourists than 
facilities, or perhaps tourists were more conscious of their movement to and between attractions than they were between facilities.

\section{Table 6.12}

Comparison of Adjusted Group Attraction Characteristics

\begin{tabular}{|c|c|c|c|c|c|c|}
\hline \multirow[b]{2}{*}{ Attraction Type } & \multicolumn{3}{|c|}{ General } & \multicolumn{3}{|c|}{ Spocial } \\
\hline & $\begin{array}{l}\text { Adjusted } \\
\text { Min. }\end{array}$ & $\begin{array}{c}\text { Intergrp. } \\
\mathscr{x}_{0}\end{array}$ & $\begin{array}{c}\text { Intragrp. } \\
\%_{0}\end{array}$ & $\begin{array}{l}\text { Adjusted } \\
\text { Min. }\end{array}$ & $\begin{array}{c}\text { Intergrp. } \\
\mathbf{8}\end{array}$ & $\begin{array}{c}\text { Intragrp. } \\
\varnothing\end{array}$ \\
\hline Natural & 8486.5 & 27.5 & 30.1 & 21709.0 & 72.5 & 46.2 \\
\hline Other & 7132.9 & 32.2 & 25.3 & 14595.6 & 62.8 & 25.6 \\
\hline Archseology & 7138.6 & 41.4 & 25.3 & 9840.6 & 58.6 & 17.3 \\
\hline House and Building & 5248.5 & 48.7 & 18.6 & 5376.1 & 51.3 & 9.4 \\
\hline Industrial & 229.2 & 29.5 & 0.8 & 532.0 & 70.5 & 0.9 \\
\hline Craft & 261.2 & 46.8 & 0.9 & 288.9 & 53.2 & 0.5 \\
\hline
\end{tabular}

Determinod by multiplying the number of missing time values for each attraction by the average number of minutes per report, and adding this figure with the total number for each attraction.

Figure 6.4, provides an indication of the spatial location of each tourist group when considering all of the attractions in Shetland. Both mean centre and wcighted mean centre data are presented through the formula introduced in section 6.2. Mean centre values for both groups were centrally located at the approximate middle of the Shetland archipelago (the Special Interest mean centre is north and east of the General Interest value). When weighted, though, both mean centres were located further south, and closer together. This data indicates that both travel groups were ultimately visiting similar attractions and in equal numbers.

As was the case with the previous mean centre values for accommodation, the attraction mean centres were located in the same general area of Shetland. This location is north of Lerwick, and to the eastern part of the mainland. In the overall spatial 


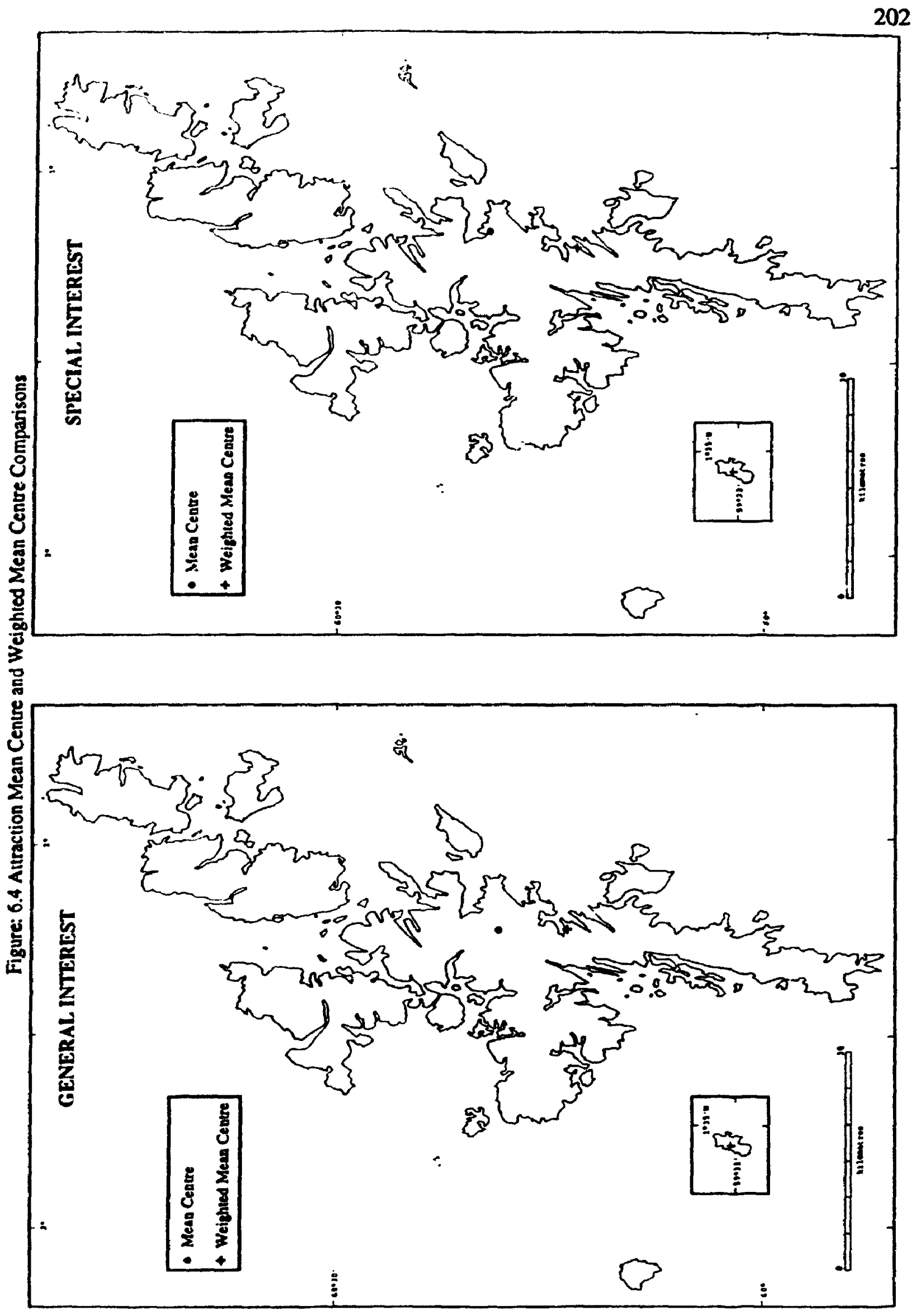


context of the archipelago, these values are, generally speaking, slightly south of the midpoint of the islands, and approximately centre to the west-east axis.

\subsection{REGIONAL TRANSPORT VISITATION}

The information presented in Table 6.13 is a summary of the data reported on the maps found on the back of each space-time budget sheet. Each day respondents were asked to trace their regional transport visitation (spatial movement) in Shetland in order to allow the researcher to accurately assess where each tourist travelled, and hence, the travel patterns of members of an entire travel group. Over 100 place names were outlined on the space-time budget map. These were ultimatcly used to measure the movement of both Special and General Interest travel groups. Every time a particular place name was visited, it would be recorded as one report. For the purposes of this research, and to avoid congestion, place names are not presented individually, but rather in a regional form (Mainland, Car Ferry Isles, etc.) in order to provide regional scores and comparisons.

Included in Table 6.13 are data for each tourist group based on the number of place names in each region ("No. Sites"), the number of visits to these sites ("No. Visits"), and an average value ("Visits/Site") derived from the two previously mentioned criteria. Intergroup and Intragroup (Figure 6.5) per cent were determined through the use of the Visits/Site statistic. The data illustrate that "Lerwick" was found to have a major gravitational pull on tourists of both groups (over 76.0 per cent of all regional travel for the entire sample). Comparatively, Special Interest tourists (56.0 per cent) 


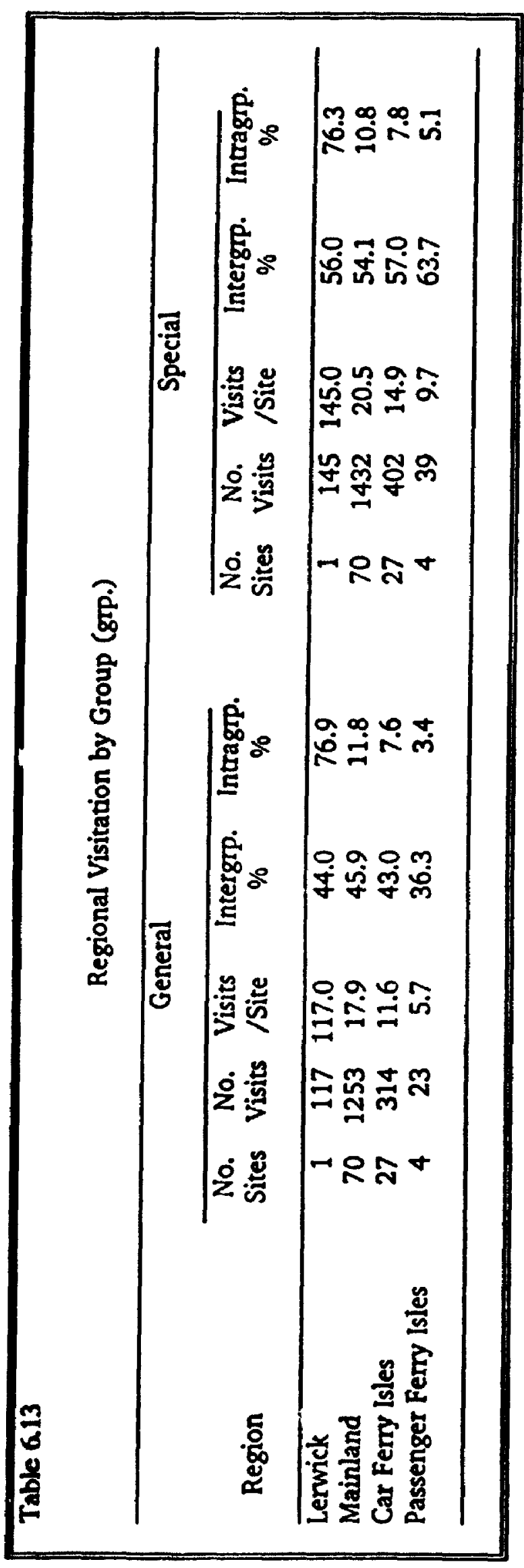


were responsible for more movement to and from Lerwick, on average, than their General Interest counterparts (44.0 per cent). The "Mainland" was the next highest visited region, with 11.8 per cent and 10.8 per cent Intragroup visitation by General and Special Interest groups respectively. Again, in a comparative sense, Special Interest travellers were responsible for more of the travel on the "Mainland" (54.1 per cent) than the General Interest group. This trend continues when viewing movement to both the "Car Ferry" and "Passenger Ferry Isles". Overall, therefore, the Special Interest travel group, when compared to the General traveller, moved more extensively throughout the four functional regions of Shetland.

Mean centre and weighted mean centre values were calculated for both sub-sample groups in light of their travel through the place names identified on the map of each space-time budget data sheet (Figure 6.6). The spatial distribution of both travel groups was found to be very similar (although the General Interest group is located slightly north of the Special Interest group). The proximity between travel groups changes very little through an analysis of weighted mean centre. Weighted values, though, are approximately 15 kilometres south of the mean centre values, suggesting that there is a higher concentration of use of place names closer to the main centre of Lerwick.

The General Interest group mean centre values are west of the values recorded for the Special Interest group. This difference might be explained by the fact that the spatial movement of the General group was restricted more to the road network of the mainland. Conversely, the Special Interest travel group travelled more extensively throughout Shetland, in particular, to the isles of Yell and Unst which are located more 
I-igure 6.5 The Space-Time Characteristics of Regional Transpont Visitation
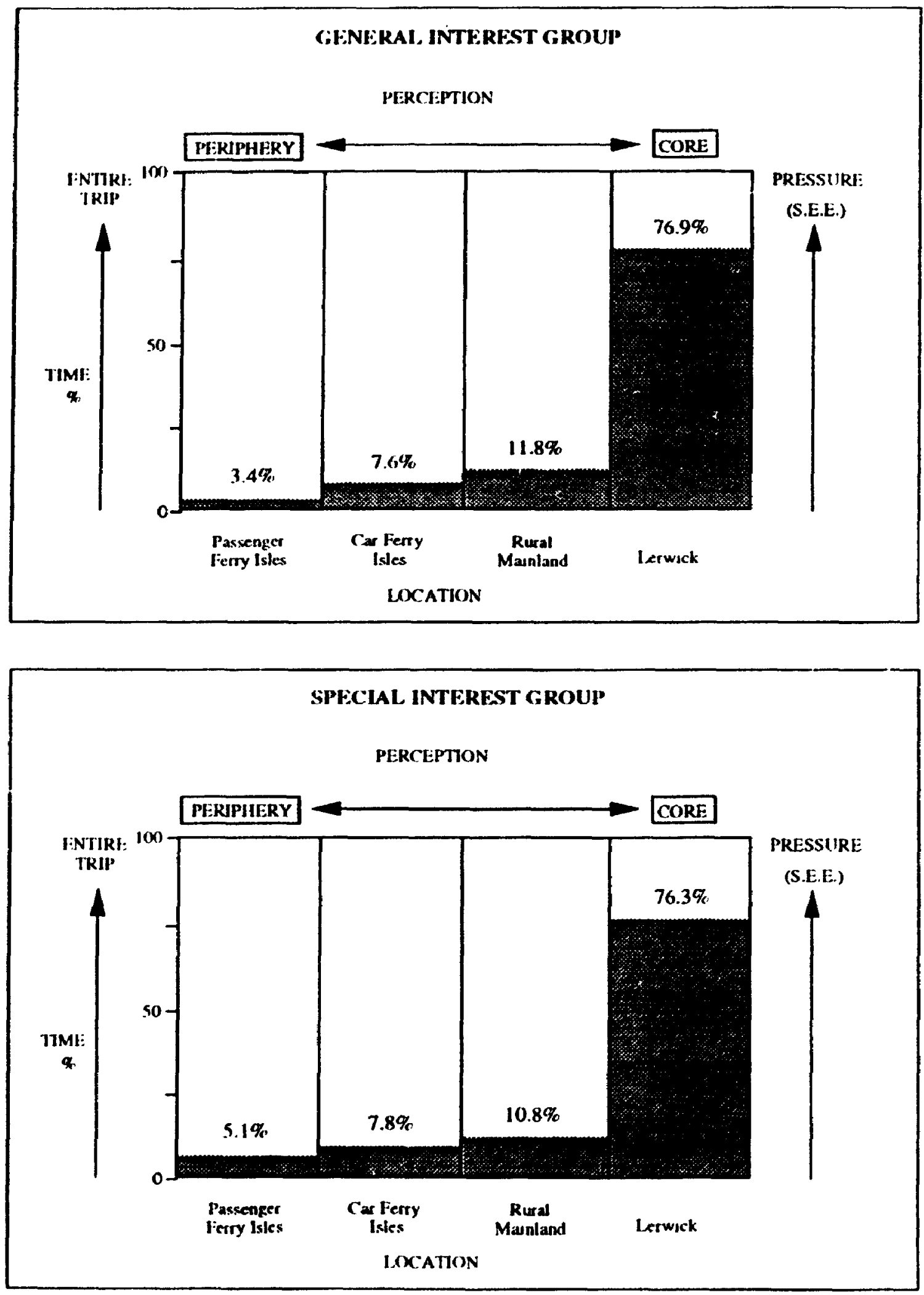


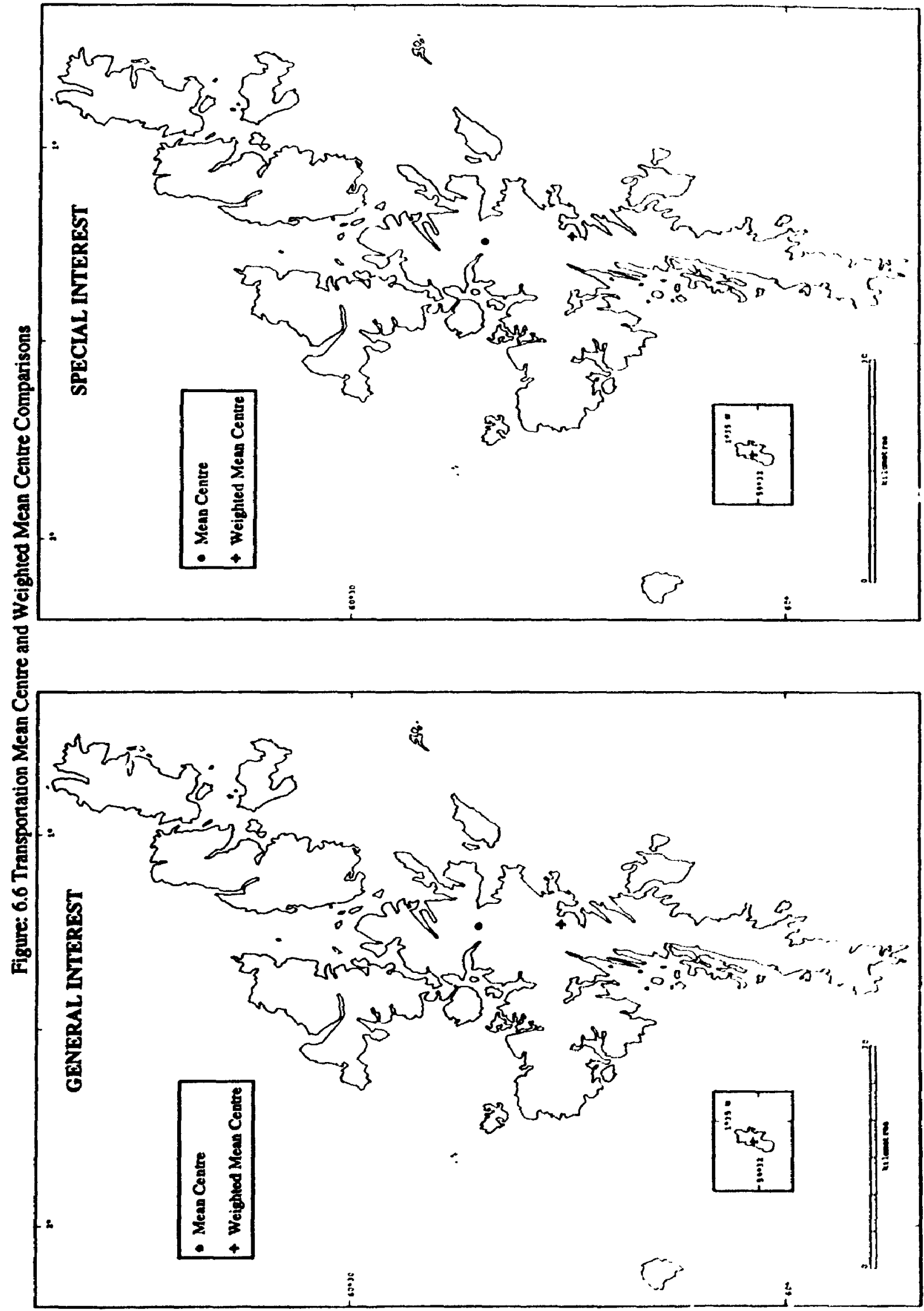


to the east (as are the mean centre and weighted mean centre values for this group).

Figure 6.7 provides an overall view of the space-time dynamics of both Shetland travel groups (the Figure presents values for each region that are averages based on the combined percentages of the previous data that dealt with Regional Accommodation Visitation, Regional Attraction Visitation, and Regional Transport Visiatation). From this overall analysis, it was found that there is a pattern of decline in involvement (use) from the urban core (Lerwick) out to the perimeter (Passenger Ferry Isles) for both travel groups. However, it was discovered that the decline is less pronounced in the data associated with the Special Interest group. That is, use was more evenly distributed throughout the various access regions, so that the differentiation between core and periphery was not so pronounced. This finding supports the previous results stating that the Special Interest groups' space-time characteristics were more peripherally-oriented than their General counterparts. Figure 6.7 is revealing in that it provides a body of evidence to suggest that there was a difference between groups in regard to their overall space-time dispersion among the four regions of the study area.

\subsection{CONCLUSION}

Space-time budget data provided a variety of results suggesting that General and Special Interest tourists are both variable in their use of accommodation, transportation, facilities, and attractions. The data in this chapter suggest that both groups stayed for extended periods of time at "Private Residence" and "Self-Catering" accommodation units, although "B\&B" units occupied the greatest per cent of overall bed-nights. Special 
Figure 6.7 Overall Space-Time Characteristics
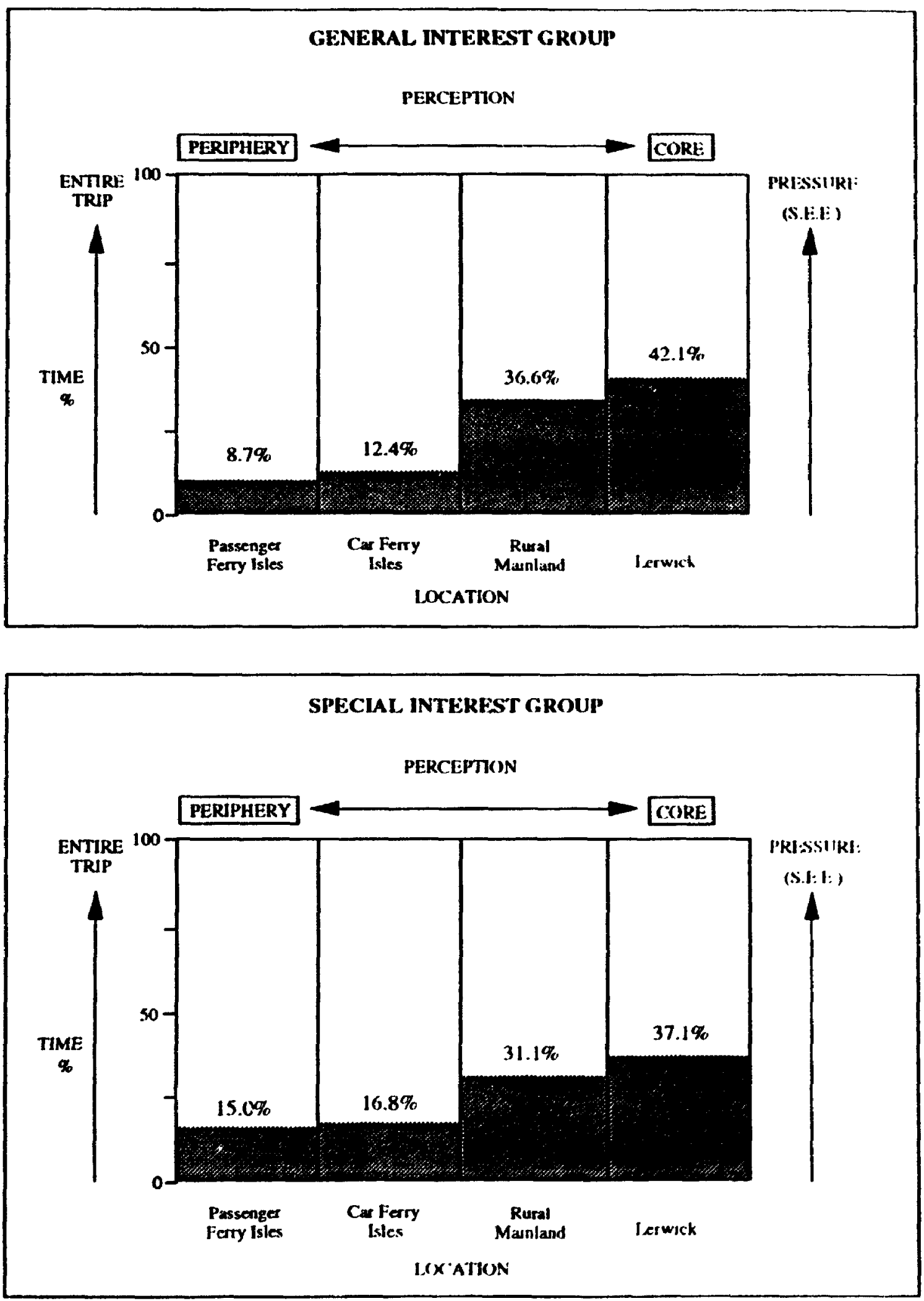
Interest travellers stayed longer, on average, than their General counterparts (1.7 days), while General tourists preferred accommodation that was more centrally located ("Mainland" and "Lerwick"). The "Car" was the most popular form of transportation for both groups, although the Special Interest respondents used it more times. General tourists were more prone to using transportation such as "Bicycle" and "Coach Tour".

"Pub", "Restaurant", and "Hotel to Eat" were popular facilities among the sample. Facilities such as "Newsagent", "Post Office", Petrol Station", and "Bank" were used less with respect to time/report. Overall, the General Interest travel group dominated the use of facilities on an average length of time per report.

"Mainland" attractions were the most frequently visited by the entire sample, while Special Interest travellers spent more time at attractions in each of the four regions of Shetland. "Lerwick" emerged as the region with the highest concentration of attraction use, for both groups, when viewed through a time/per cent land area function. Special Interest tourists spent more time, and visited more, "Natural" attractions (the most frequently visited attraction type) than the General Interest group. Other attraction types visited included "Other", "Archaeology" and "House and Building".

Finally, space-time budget map data indicated a high concentration of activity (movement) in the "Lerwick" region. The Special Interest sub-sample illustrated a higher propensity to move among the various named locations of Shetland than the General travel group. 


\section{Chapter 7}

\section{INDEPENDENT INTERVIEW AND OBSERVATION DATA}

Travel, in the younger sort, is a part of education; in the elder, a part of experience. He that traveleth into a country before he hath some entrance into the language, goeth to school, and not to travel.

Francis Bacon

\subsection{INTRODUCTION}

The two elements of the qualitative approach to this study (interview and observation), were envisioned to hold utility as a means by which to gain a diversified perspective of the typical Shetland traveller. The interview component of the research represented an entirely different sample of tourists from the sample drawn in the quantitative section of the study. Both qualitative elements, and their associated data, are contained in this chapter. However, what are not found in this chapter are the series of valued relationships, ideas, theories, etc., that emerged from the process of collecting this type of data. These ideas are presented in the following chapter as a means by which to help substantiate the results of both quantitative and qualitative approaches. 


\subsection{NTERVIEW DATA}

Interviews were conducted in each of the four regions of Shetland and, in total, 18 interviews were incorporated into the study. The interview guide format was structured in order to evaluate tourists from two main perspectives. Questions were designed around eliciting responses both from a tourist industry side, as well as from an experiential side (Appendix 2, tourist industry questions identified with a single asterisk, experiential questions identified with a double asterisk). Tourism industry questions sought to identify the interaction and impact of travellers on the Shetland tourism infrastructure (length of time in Shetland, accommodation, regional visitation, etc.). Experiential questions, on the other hand, sought to explore the overall satisfaction and use by travellers of elements such as attractions, landscape, people, and prices (among other elements). Both were felt to be important in ultimately determining a typology of travellers in Shetland.

Foremost, each of the 18 respondents were asked what their main reason was for visiting Shetland. From their responses to this question, interviewees were associated with one of three groups:

1. General Group $(n=4)$ : no specific or peripheral interests identified.

2. Mid-Range Group $(n=7)$ : no specific attraction or interest identified, respondents usually cited a number of peripheral interests as important (e.g., scenery, environment, people, remote/quiet destination).

3. Special Group $(n=7)$ : travellers indicated one specific aspect of the Shetland environment as their main reason for visiting the region (e.g., birding or archaeology). 
From this point, the researcher created a continuum or pattern of responses to each question to be used in order to directly compare each respondent. For example, respondents were asked what their favourite attraction site was in Shetland. The pattem that emerged from the responses to this question, from all of the interviews, was as follows:

1. No favourite site,

2. Other types of sites (other than archaology or nature), and

3. Archaeology/nature sites.

As well, responses were structured using a combination of criteria. In order to understand use patterns of different accommodation units, respondents were asked to report on which types of units they visited. However, it became apparent that household income could have implications concerning where respondents ultimately chose to stay (a feature that would bias results). It was decided to rank scores on the frequency of types visited. Respondents were given a score of " 1 " for visiting one type of accommodation in Shetland. Alternatively, travellers were provided a score of "2" for staying at two or more different types of units.

The response pattern established was a result, therefore, of two processes: The patterns identified in the interview responses, as well as a ranking feature that enabled the researcher to objectively determine tourist industry, or experiential differences. Respondents who had higher responses to the typology established for cach question, were said to have attained either a higher level of experiential satisfaction, or were observed/recorded to be further immersed into the Shetland tourist industry infrastructure 
(Figure 7.1, outlines the typology for each question). Consequently, the lower the response pattern for each question, the lower the level of satisfaction, and tourist industry involvement.

Table 7.1, presents data associated with individual and travel group interview scores (scores summed for each group, divided by the number of tourists in each group, then divided again by the number of questions in the interview). Total interview scores for each group indicated that the General group $(n=104)$ had a much lower score than the Mid Range $(n=242)$ and Special $(n=243)$ groups. However, it is the "per cent of total" statistic which provides a better comparison of each group. Each of the three score totals was divided by the number of tourists in each group prior to per cent calculation. In this way an average value provided a means with which to make direct group comparisons. "Per cent of total" also indicates the average response by each group, as a per cent response for all three groups.

The General group accounted for $\mathbf{2 7 . 3}$ per cent, on average, of the entire sample. Comparatively, the Mid Range (36.3 per cent) and the Special (36.4 per cent) groups responded similarly, and significantly higher to the response options of each question than did the General group. "Higher" as suggested earlier, infers that respondents of the Mid Range and Special groups were either more satisfied (experientially) with their Shetland trip, and/or used more of the elements of the Shetland tourism industry (accommodation, transportation, etc.). 
Interview Guide Typology

1. Main reason for visiting Shetland:

1. General Interest.

2. Mid-Range Interest (scenery/remote/quiet/etc)

3. Specific Interest (archaeology, birding, etc.).

2. Length of time in Shetland:
1. 1-7 days.
2. 1-14 days.
3. 1-21 days.
4. 1-28 days.

3. Accommodation type:

1. one type stayed at.

2. more than one type stayed at.

4. Number of times visiting Shetland as a tourist:

1. First time.

2. Second time.

3. Three or more times.

5. Background reading:

1. No reading, nothing available.

2. Some reading, non-specific.

3. Already had enough information/knowledge.

4. Specific topic, a lot of reading.

6. Intended regions of visitation:

1. Lerwick.

2. Lerwick and mainland.

3. Lerwick, mainland and other islands.

7. Favourite attraction sites:

1. No type of favourite site.

2. Non-specific sites (e.g., nature, archaeology).

3. Specific sites (e.g., Hermaness, Jarlshof, etc.).

8a. Regional visitation dynamics (regional visitation):

1. Visit new regions each day, make plans as we go.

2. Visit new regions every couple of days/ get to know an area before moving on. 
Figure 7.1 (continued)

8b. Regional visitation dymamics (length of time at attraction sites in region:

1. Depends on other plans.

2. As long as possible/ better part of the day.

9. Items brought from home to maximise travel experience:

1. Non-specialised items (car, clothes, camera).

2. Specialised items (special camera gear, clothes for specialised activities, etc.).

10. Transport mode (main mode):

1. one main mode (e.g., car).

2. multiple main modes (e.g., car, plane).

11. Description of landscape of Shetland:

1. Dreary.

2. Nice on nice days.

3. Like it/ enjoyed it/ nice.

4. Loved it/ really enjoyed it/ beautiful.

12. Description of people of Shetland:

1. Not impressed.

2. No interaction.

3. Friendly/ nice.

4. Very nice/ very hospitable.

13. Description of prices:

1. Higher than other destinations.

2. O.K. but expensive to get here.

3. O.K./ not too bad/ no complaints.

4. Good.

14. Satisfaction of Shetland travel experience:

1. Not as nice as other vacations.

2. Satisfied.

3. Very satisfied.

4. Best va ation of all time.

15. Specific dislikes of the Shetland travel experience:

1. More than two.

2. two.

3. one.

4. No comment.

5. Nothing but positive comments on Shetland. 
Each of the three interview groups was broken-down further through an analysis of questions that sought to uncover experiential and tourism industry-related data specifically (Tables 7.2 and 7.3). Each of the eight experiential questions $(5,7,9,11,12,13,14,15)$ are outlined in Table 7.2 , in addition to the scores for these questions, for all three tourist groups. Despite the fact that the General group $(n=65)$ contained only four interviewees, the "per cent of total" statistic (based on the average response of members of each group) is significantly lower (26.2 per cent) than that of the Mid Range (36.9 per cent) and Special (36.9 per cent) groups.

Of particular interest is the fact that both the Mid Range and Special travel groups scored comparably in Table 7.2. This suggests that there is no difference betwoen these groups when considering all questions of experience and satisfaction of Shetland tourism. A break-down of questions revealed that the latter two groups responded similarly to questions dealing with "Background Reading on Shetland", "Items Brought from Home", "Description of Landscape", and "Satisfaction with Overall Experience". The Special group responded "higher" to questions that dealt with "Favourite Attraction Sites", and "Likes and Dislikes". Conversely, Mid Range interviewees responded higher to questions that dealt with "Descriptions of People", and "Descriptions of Prices". The General travel group responded positively, relative to the other two groups, in describing the people of Shetland. 
Table 7.1

Individual and Travel Group Interview Scores (by Tourist Number)

\begin{tabular}{|c|c|c|c|}
\hline \multirow{2}{*}{$\begin{array}{l}\text { Tourist } \\
\text { Num'ser }\end{array}$} & \multicolumn{3}{|c|}{ Travel Group } \\
\hline & $\overline{\text { General }}$ & $\overline{\text { Mid Range }}$ & Special \\
\hline 1 & & & 30 \\
\hline 2 & & & 34 \\
\hline 3 & & & 41 \\
\hline 4 & & 37 & \\
\hline 5 & 39 & & \\
\hline 6 & & & 30 \\
\hline 7 & & 34 & \\
\hline 8 & & 31 & \\
\hline 9 & 18 & & \\
\hline 10 & & & 40 \\
\hline 11 & & 38 & \\
\hline 12 & & 36 & \\
\hline 13 & 20 & & \\
\hline 14 & 27 & & \\
\hline 15 & & 37 & \\
\hline 16 & & & 33 \\
\hline 17 & & & 35 \\
\hline 18 & & 29 & \\
\hline Total & 104 & 242 & 243 \\
\hline \% of total & 27.3 & 36.3 & 36.4 \\
\hline
\end{tabular}


Table 7.2

Experiential Interview Question Scores

(by Group;

Travel Group

Question

Number

$\overline{\text { General }} \overline{\text { Mid Range }} \overline{\text { Special }}$

\begin{tabular}{lrrr}
\hline 5 & 8 & 18 & 18 \\
7 & 6 & 15 & 20 \\
9 & 6 & 12 & 13 \\
11 & 10 & 25 & 24 \\
12 & 31 & 31 & 28 \\
13 & 9 & 19 & 14 \\
14 & 7 & 20 & 19 \\
15 & 8 & 20 & 24 \\
& & & \\
\hline Total & 65 & 160 & 160 \\
\% of total & 26.2 & 36.9 & 36.9 \\
\hline
\end{tabular}

Score totals divided by the number of tourists in each group prior to \% calculation.

Questions 2,4,6,8a,8b, and 10 of the interview guide were designed to elicit responses on specific components of the Shetland tourist indust-y (Table 7.3). As was the case with the two previous Tables, Table 7.3, illustrates that the Mid Range and Special interview groups had similar scores ( 82 and 83 respectively). Relative to past results, the General group responded higher to questions that dealt with the tourist industry. Data illustrates that the "per cent of total" statistic of 29.3 in Table 7.3, is significantly higher than the "per cent of total" statistic (26.2) in Table 7.2. 
Table 7.3

Tourist Industry Interview Question Scores

(by Group)

Question

Number

Travel Group

Number

\begin{tabular}{lrrr}
\hline 2 & 6 & 16 & 18 \\
3 & 4 & 10 & 10 \\
4 & 6 & 10 & 11 \\
6 & 6 & 13 & 13 \\
$8 \mathrm{a}$ & 4 & 9 & 8 \\
$8 \mathrm{~b}$ & 7 & 14 & 12 \\
10 & 6 & 10 & 11 \\
\hline Total of total & & & \\
\% o & 39 & 82 & 83 \\
\hline
\end{tabular}

- Score totals divided by the number of tourists in each group prior to \% calculation.

The response pattern of the three interview groups was more evenly distributed in Table 7.3, than in the previous Table. There were, for instance, fewer large fluctuations between questions, and little difference between the response patterns of Mid Range and Special group respondents for each of the eight questions. In general, the Special respondent group responded more favourably to questions related to, "Length of time in Shetland", "Number of times visiting Shetland", and "Transport Mode". Conversely, the Mid Range interview group responded more favourably to the question dealing with "Daily Visitation Dynamics". 


\subsection{OBSERVATIONAL DATA}

It was the purpose of the observational component of this study to contribute to a better overall understanding of the dynamic nature of Shetland tourists: where and how long they spent time among the various attractions of the archipelago. As it was impossible to record observations in every region of the islands (due to constraints of time and money), it was decided to concentrate on recording observations at the Lerwick Tourist Office, and at selected major and minor attractions of the southern mainland. In each of these "places", observations were made over a period of five days, for a period of one hour per day. The results of these observations are recorded below through Tables 7.4 to 7.7.

Lerwick Tourist Centre observation data is presented in Table 7.4. The Table is structured in order to provide information on the "Day" of observation; the "Number of Groups" of tourists (individuals counted as one group); "Number of Tourists" recorded that day; the Gender of those observed; the "Group Time", or time that the individuals of one party, as a whole, were at the Tourist Office; the "Group Average" (average number of minutes spent by each group at the Tourist Centre); "Individual Time", representing the amount of time spent by each tourist at the Office regardless of whether they were part of a group or not; and finally, "Individual Average", that illustrates the average number of minutes that each individual tourist spent at the Tourist Centre, regardless of group affiliation. "No. of Tourists", therefore, is comipnsed of all tourists, including all individuals of each of the groups. 


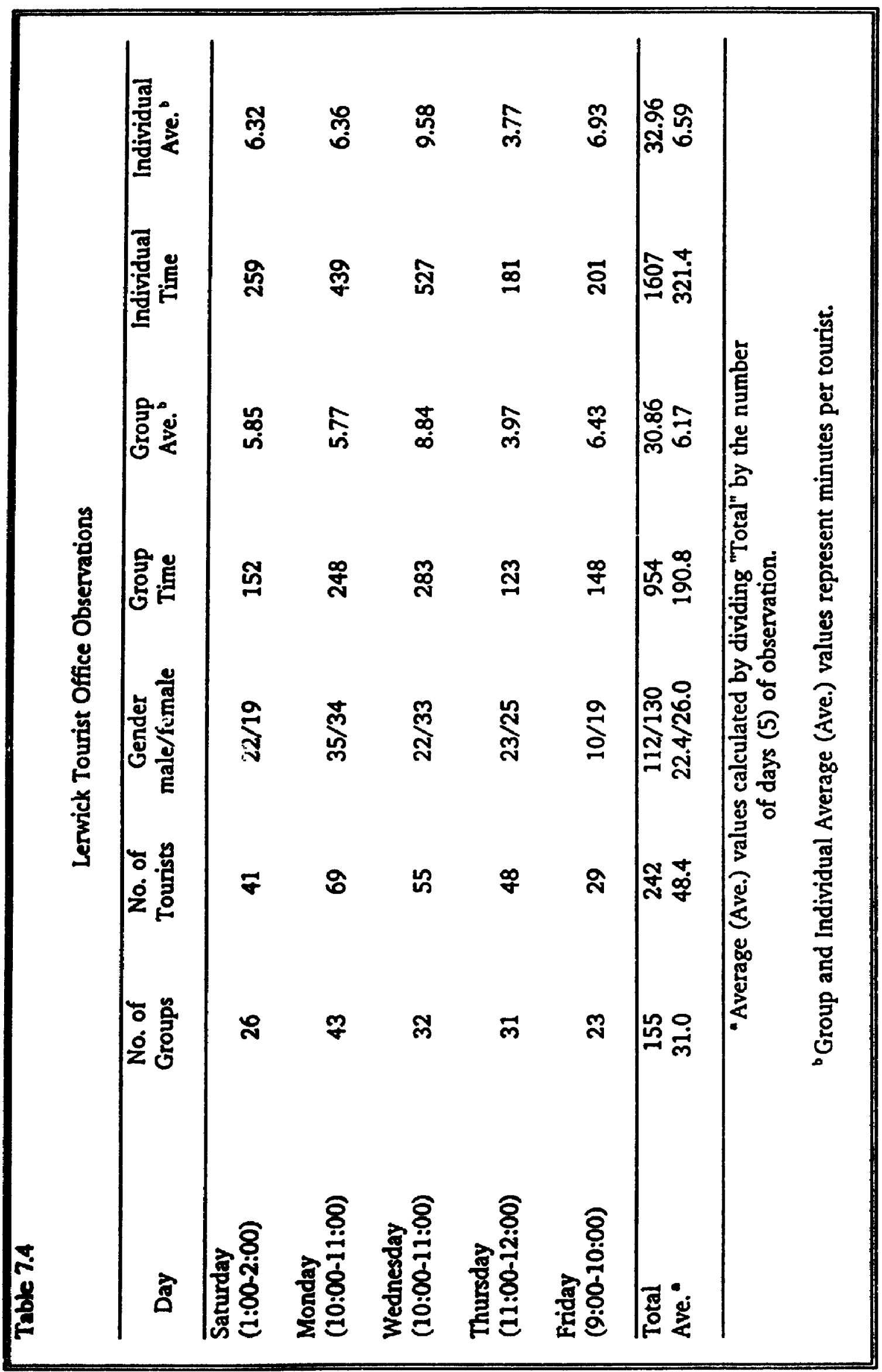


The data associated with Table 7.4 portray a variable pattern of both frequency of use (number of tourists), as well as duration of use (the time spent per visit), by both groups and individuals. It does appear though that there were substantially fewer visits on Friday ( $n=29$ ). As the bulk of tourists arrived in Shetland on Saturdays, Friday may be a day in which people are getting ready to leave, or who have attained most of their travel information on previous days. Monday was the day with the highest frequency of visitors $(n=69)$, while this frequency fell-off throughout the week (e.g., Wednesday, $n=55$; Thursday, $n=48 ;$ Friday, $n=29$ ). Although it is difficult to determine whether time of day influenced the propensity to visit, the data suggest that from 10:00 to 11:00 a.m. (Monday and Wednesday) was the most popular time to visit the Centre.

On average, more females visited the Centre $(n=130)$ than males $(n=112)$. This is significant given the fact that, as pointed out in the questionnaire results, there were more males that visited Shetland than females. Table 7.4 further illustrates that when men visited the Tourist Centre more often than women, it was during the earlier days of the vacation week (Saturdays and Mondays).

An analysis of Group and Individual Time illustrates that, when viewed on an average basis (minutes per tourist), it is clear that both individuals and groups spent more time at the Centre (9.58 and 8.84 respectively) on Wednesday. However, despite the low frequency of visits on Friday, those groups and individuals that did visit the Tourist 
Centre spent a significant amount of time (6.43 and 6.93 minutes per tourist respectively).

Tables 7.5 through 7.7 present results of the major and minor attraction observations. The style and structure of these Tables mirrors that of the preceeding Table, both for ease of interpretation and to standardise results for more effective interpretation. The first major attraction of the south mainland was "Loch of Spiggie". This attraction is well known for its fishing and birding attractiveness. However, out of five days of observation, only four tourists, in total, were observed, and these travellers were observed during the first day. Observations for Spiggie were conducted between 9:30 and 10:30 a.m. All four tourists were male, were fishing, and stayed longer than the one hour period of observation (a Table for Spiggie was not created due to the lack of users during the period of observation).

Table 7.5 contains data on Sumburgh Head, as a major attraction site. Of the total of 38 tourists observed at this site over the five days, nearly half $(n=18)$ were observed on Friday. Friday also had the highest Number of Groups $(n=6)$ relative to all other days. There was an even gender split between each of the five days of observation. Friday and Monday, together, represented 316 of 512 total minutes of Group Time, while these two days represented 927 total minutes of 1305 Individual Time minutes. It is the other days with less frequency of visitation that have the highest minute per tourist Group averages (Tuesday, $n=43.00$; Sunday, $n=40.50$; and Wednesday, $n=36.00$ ). This trend follows for Individual Time averages for Tuesday 


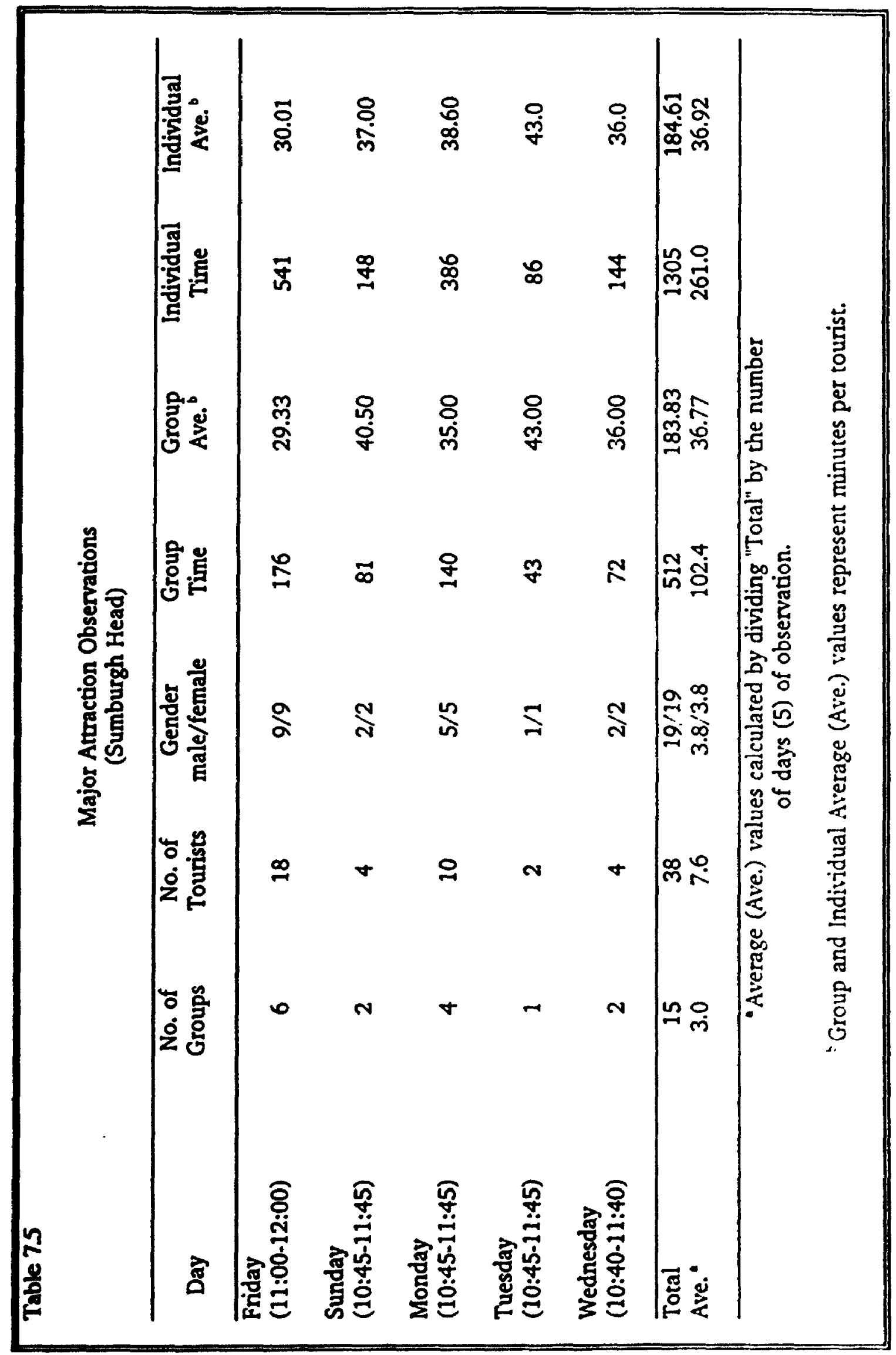


$(n=43.0)$. However, similar averages were recorded for Monday $(n=38.60)$; Sunday $(n=37.0)$; and Wednesday $(n=37.0)$. The day with the highest frequency of visitation (Friday), though, had the lowest Individual minute per tourist average (n = 30.01). The assumption might be made that with a higher frequency of use, tourists could not enjoy the resource as long due to the higher incidences of contact. The data certainly points to this as an explanation, as the day with the lowest frequency of use (Tuesday), had the highest minute per tourist values.

The Jarlshof settlement (Table 7.6) attraction $-1 \mathrm{~km}$ in distance away from Sumburgh Head - had the highest frequency of visitation of all the major attractions (n $=67$ ). Of those 67 visits, 25 were on Friday, whereas only six were on Wednesday. As with the previous attractions, there was a variable "Number of Groups" visiting Jarlshof throughout the week. Like Sumburgh Head, visitors to Jarlshof were split evenly between male and female ( 34 and 33 respectively). The "Group Time" statistic provided an indication of the overall length of time that each tourist group spent at Jarlshof. Of interest are the data associated with Sunday and Monday (respectively, $n=3$ groups, 164 minutes; $n=4$ groups, 165 minutes). Although the visitation dynamics are similar, they change significantly when viewed as a "Group Average". The number of minutes spent by the travel groups on Sunday $(n=54.67)$ greatly surpasses that of Monday $(n=41.25)$. On average, travel groups spent the least amount of time at Jarlshof on Wednesday (39.0 minutes per group). 


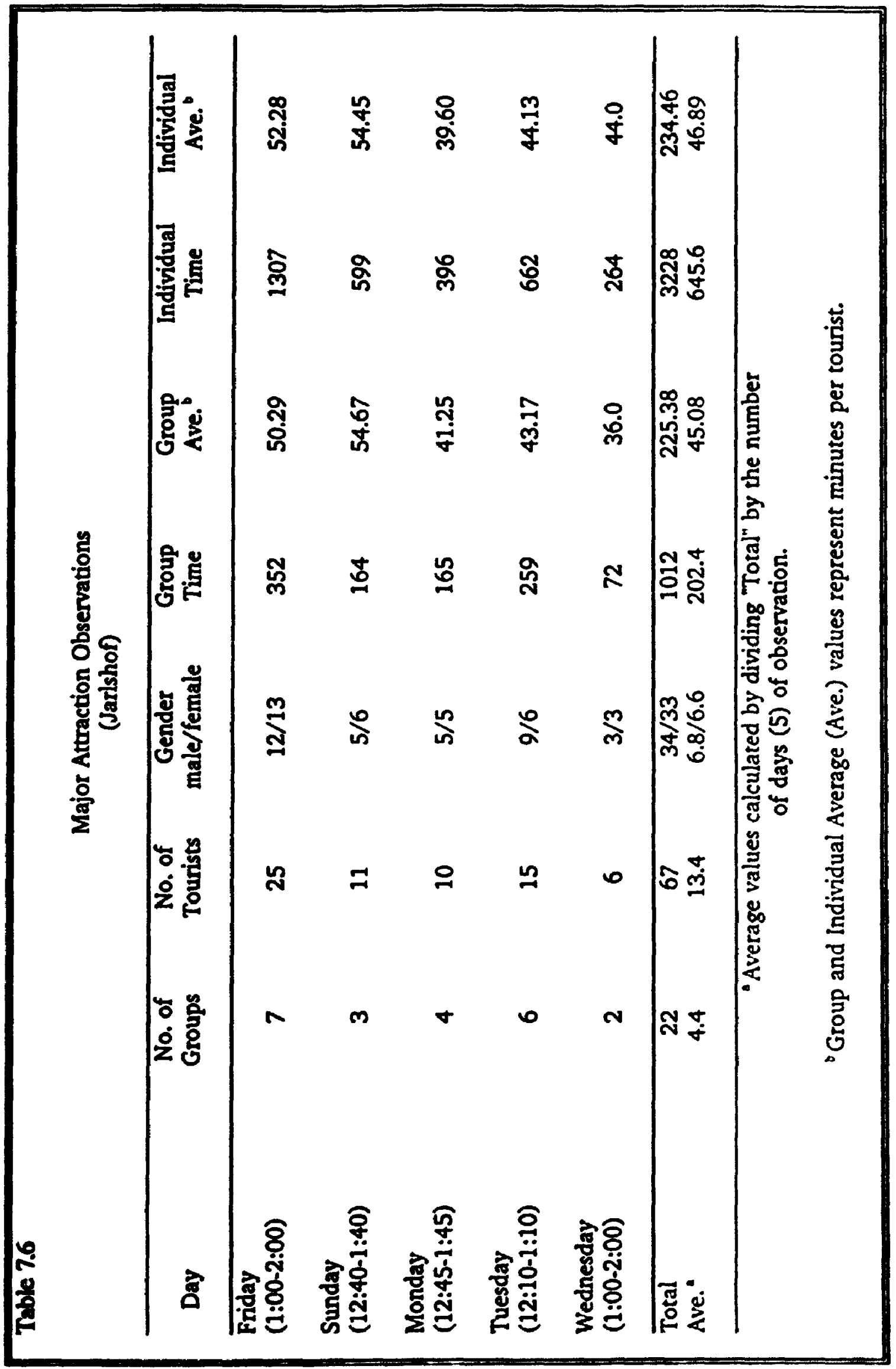


"Individual Average" statistics for Table 7.6 illustrate that when counted as individuals ("Number of Tourists"), travellers were spending more time at the Jarlshof attraction than when considered on the basis of "Group Average". The day with the highest time spent per tourist was Sunday $(n=54.45)$. Conversely, Monday emerged as the day when tourists, on average, spent less time at this attraction.

Table 7.7, Croft House Museum, is an example of a major attraction that experienced large fluctuations in visitation over the week of observation. The "Number of Groups" visiting the attraction oscillated between one and six. Consequently, the "Number of Tourists" fluctuated between two (Monday), and 34 (Wednesday). Table 7.7 also illustrates that more females $(n=37)$ visited this attraction cach day, than did males $(n=28)$.

The "Group Average" statistic supports the notion that this group of visitors was quite variable in their length of stay at this attraction. The three groups on Monday, for instance, stayed on average, 24.0 minutes. This statistic rose to 45.0 minutes, however, on Friday. Visitors on those days with the highest number of groups over the hour of observation (Sunday and Wednesday) did not stay as long as the visitors in the fewer groups who visited the attraction on other days. This conclusion can also be drawn when considering "Individual Average" data. Sunday and Wednesday were the two days where tourists stayed at the attraction for the least amount of time.

The Croft House Museum is a small two-room building, with low ceilings. Its size limits the number of people that can comfortably enter the establishment 


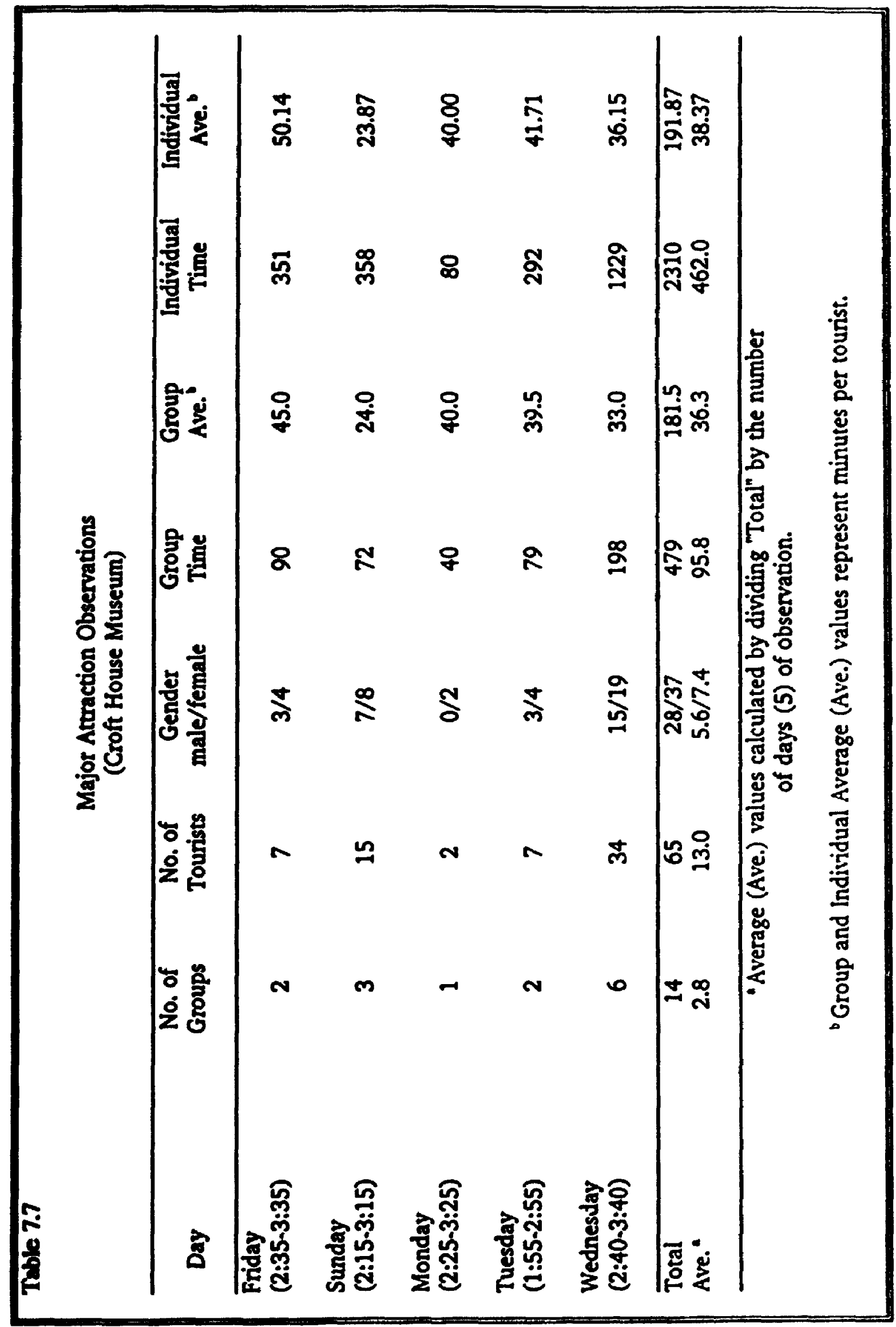


(approximately ten), and access the gentleman responsible for interpretation. In speculation, it may be for these reasons that tourists in large groups (and numbers of groups), do not - or will not - stay for extended periods of time at the Museum.

An equal amount of time (one hour) was spent at four minor attractions in the South Mainland over the course of one week. The attractions that were selected included Brindister Loch, Catpund, Fladdibister, and Hollanders Knowe. Each of these attractions, like the major attractions, were identified on the Official Shetland Tourist Map (Shetland Islands Tourism, 1991b), and in the Official Tourist Guide (Shetland Islands Tourism, 1992). The difference between the major and minor attractions, however, was the fact that unlike the major attractions, minor attractions did not have associated road signs, on-site interpretation, attraction site markers, or easy access.

Ne to rists were observed at any of these sites over the observation period. The conclusion can be drawn that, for one reason or another, there is a very unequal distribution of visitation at selected attraction sites in Shetland. Various factors may account for the differences. The major attractions may in fact be more spectacular, they may be better advertised, or word-of-mouth may have contributed to their popularity. At any rate, these results indicate that, at least in part, tourists spent their time visiting those attractions that had a higher profile.

These observations have also illustrated that tourists spent less time at the Tourist Centre or major attractions when the density of visitors was higher. The results serve 
to indicate that the actual times that tourists spent at an attraction maybe a function of density (contact ratios).

\section{7,4 CONCLUSIONS}

It was discovered through this data gathering process that the qualitative component of the study lert itself more to quantitative analysis than initially anticipated. From the perspective of interviews, a typology was established that identified three groups of tourists: General, Mid Range, and Special. It was discovered that when these grcups were compared on the basis of tourist-industry and experiential type questions, the General group gave less favourable responses to both types of questions, than the other two groups. Conversely, the Mid Range and Special groups responded similarly and more positively to both types of questions.

Observational data portrayed a variable pattem of both frequency of use (number of tourists), and duration of use (time spent per visit) at the Tourist Centre. Days earlier in the week (e.g., Monday) showed a higher frequency of Tourist Centre use than the latter days of the week; while females were more prone to Tourist Centre use than males. Observational data also indicated that there was a distinct difference between what might be labellud "major" and "minor" attractions of Shetland's south mainland. While no tourists were observed at the minor attractions at all, a variable number were observed at each of the major attractions selected for observation in this study. 


\section{Chapter 8}

\section{IMPLICATIONS OF SHETLAND TOURISM IN SPACE AND TIME}

...in fertile savannahs and pampas there may appear no signs of human occupancy, but the traveller knows that eventually the advancing tide of humanity will come with its flocks and herds, and the ancient silence and desolation will be no more.

\section{W.H. Hudson}

\subsection{INTRODUCTION}

The multifaceted approach adopted in this study has uncovered an array of data that has provided a better understanding of the space-time characteristics of tourist group travel in Shetiand. The proposed model was an effective means by which to organise a series of comprehensive concepts (space-time, core-periphery, typologies) for the purpose of gaining a more holistic view of an island destination and its visitors. Smale (1988) has suggested that questions can arise as to the theoretical and practical relevancy of new models, especially as alternatives to existing perspectives. This avenue of thinking has been recognised and supported by others. Dartnall and Store (1990) established that there has been a trend towards thinking that each piece of research is an isolated event. 
These authors suggest that the failure to build on the work of others "is a wasteful repetition of effort" (Dartnall and Store, 1990: 51).

The logic of these authors had to be balanced, in this research, with the notion that tourism research is at an early stage of development. As an interdisciplinary field, as implied earlier, tourism has strong ties to psychology, sociology, anthropology, economics, geography, environmental studies, and recreation and leisure studies. On the basis of this, and through a review of literature in geography, tourism, and associated fields, it was felt that a new model was required - one that incorporated a number of components of past tourism research - in order to satisfy some of the initial queries and objectives that evolved through an approach to this unique case study.

With this in mind, it is the task here to fit this model, and the results of the research, into the context of past research. Yet, it is prudent to ask specific questions about the relevancy of the proposed model, and about its strengths and weaknesses. Consequently, it is hoped that what results is a dialectic that provides the means by which to point the way to improvements in this model (and research), and to the needs of future research in tourism.

\subsection{METHODOLOGICAL CONSIDERATIONS}

The methodological stance adopted in this research (quantitative and qualitative elements) provided two different, effective, bases for study. However, the study evolved to the point that it became apparent that the data, in all respects, lent itself more to quantitative analysis than qualitative analysis. Also of significance was the influence of 
experience in Shetland: personal observation, discussions, and local interaction that provided a unique "snap-shot" of Shetland that was nurtured by three separate trips and nearly three months of travel through all four regions of the study area.

It should be recognised that this study could have been organised and completed in other ways. Methodological approaches might have been different, sampling procedures could have changed, and the size of the sample could have been larger. Yet, because of the nature of the objectives and purpose of the study, a great deal of information was needed from each respondent. As such, care in the distribution of the questionnaire tools was of the utmost importance. Several respondents mentioned, in subsequent meetings, that they would not have attempted to complete the questionnaire and space-time budget if the researcher had not personally introduced himself, and explained the particulars of the research. At first glance, the study questionnaire and space-time budget sheets had potential to appear overly extensive. However, after explaining the procedures, tourists felt more comfortable in deciding to participate.

Tourists displayed a variety of overt "states" or emotions when approached to participate, with a continuum that ranged from flat-out refusal, to a genuine interest in wanting to help out. Tourists with English as a second or third language used their inability to understand English as a reason not to participate. Contrarily, some used the time component as an excuse, suggesting that they would be of little use to the study by being in Shetland for only one or two days. Others forcefully insisted that they were on vacation, that they left their paper work at home, and therefore would not participate. This latter kind of refusal reinforced the fact that social science researchers are faced 
with some unique challenges compared to their physical-based colleagues. Each traveller is different, with different needs, wants, attitudes, motivations, expectations, and levels of satisfaction. In an effort to tap a certain population of travellers, at a particular destination, one is certain to become exposed to this kaleidoscope of uniqueness. That has been the challenge of past tourism-related work, as it was the challenge here.

It was further discovered through this research, that not only do different tourists have varied personality characteristics, but each may manifest different characteristics over time or in different environments. This idiosyncrasy became evident when encountering one particular tourist in two regions of the study area: Lerwick, and the passenger ferry isle of Foula. In Lerwick, this individual, when approached to participate in the study, flat-out refused, was rude, and left the tourist office where he was approached. Two weeks later this same individual was encountered in Foula, where he, his friend, and the researcher were the only tourists at the hostel. After an hour of informal conversation with this individual, independent of any mention of the study, he remembered the previous encounter and wanted to know if he could be of any assistance.

Shetland, as an archipelago, provided a challenge in the establishment of a series of study regions. Although the Shetland Tourist Organisation had developed 11 regions, these regions have no clear spatial delineation that can give-way to a measurable understanding of core/periphery in some regions (e.g., mainland). The regions associated with the islands offer utility in terms of distance and location, however, the access to some of these regions is mixed (e.g., the west mainland region of the tourist organisation includes the small isle of Papa Stour - a car ferry isle). With this type of 
locational and accessibility variability, it was important to devise a measure that would homogenise regions based on a certain criterion. Access was viewed as the key, as it implied a distinct movement from one region and its characteristics, to another. Especially from the core-periphery perspective, the movement away from the core (Lerwick) to the outer islands represented a change in mode of travel, and character of Shetland. Car ferry and passenger ferry access differentiation was important as it established that a change was encountered as one moved further out to the perimeter (e.g., no infrastructure to carry cars or support transportation networks).

Even within regions, though, there were marked differences. Although each of the regions is characterised by access, tourists elected to visit some parts in large numbers and other parts of a region in small numbers (if at all). It can be noted that within these access regions, there were intraregional layers subject to tourist industry and non-tourist industry-related factors. Transportation, accommodation, facilities, and attractions are the prime industry-related factors. Time, location (space) and perceptions of place appear to be some of the non-tourist industry-related factors. Each of these will be discussed in detail in the following sections.

Although the format adopted for this study (questionnaire, space-time budget, interviews, and observations) provided a wealth of data, other questions could have been implemented within these measures. Of particular interest is the notion of long-staying versus short-staying tourists and tourist groups. There is very little, beyond implications, that can be inferred from the data to understand the social, environmental, and economic (S.E.E.) impacts of tourists in terms of length of stay in Shetland. Each component of 
S.E.E. represents a dissertation in itself, and can not be effectively satisfied through a handful of questions annexed to a study. The very difficult time researchers have had measuring such impacts, provides an indication of how much more needs to be accomplished in the study of tourism impacts. Nevertheless, researchers might endeavour to study the variable impact of tourists who visit a destination for longer or shorter periods of time. As such, the model proposed in this research might be altered to consider the long and short-staying characteristics of tourists affiliated with General and Special Interest travel groups. Their impact on attractions might also be a fruitful avenue for research. Long-staying tourists might stay at attractions longer, where time becomes less a limiting factor at each attraction and over the period of each day of the vacation. Conversely, it might be discovered that longer-staying visitors do not have more of an adverse impact, physically, on attractions, than tourists who stay for shorter periods (and who may be more numerous).

Consequently, long-staying and short-staying tourist groups (within group, and between group) might be compared in view of their expectations and satisfaction when visiting attractions and regions of a destination. In such a case, the research associated with carrying capacity might provide in-roads to understanding the dynamic nature of perceived crowding and levels of density.

An interesting methodological addition to this study would have been to combine methods of questionnaire distribution. Half of the questionnaires could have been distributed personally (as was the case with this research), and the other half through the tourist office (a more impersonal method). Each of the questionnaires would have been 
marked, and these marks could have been used to determine the response rate of both distribution methods. Especially with the limited number of studies to date on space-time budget research, these results would prove useful in subsequent related work.

Finally, it should be noted that the Special Interest group was more heterogeneous in nature than expected. Due to the fact that several types of tourists groups had to be amalgamated (due to low group representation), all of the distinct groups - Fishers, Birders, etc., -- were put into the Special Interest category. This in itself may account for a hidden variability within the Special Interest travel group. The ideal scenario would have been to have six distinct, well-represented groups. Due to time and monetary constraints, however, this proved impossible. As such, the responses within the Special group may, in some respects, have canceled each other out. From this perspective, there may have been a continuum of tourist types within the Special Interest group. It was impossible to account for this continuum, or variability, and the responses, therefore, had to be taken at face-value.

\subsection{THE APPLICATION OF THE MODEL IN SPACE AND TIME}

The principle objective of the model was to establish a typology of tourists based on the hypothesis that tourists having common reasons for visiting Shetland, might display similar characteristics in space and time. The implications of their movement, spatially and temporally, were deemed important and the overriding context from which to derive plausible conclusions from a sample of tourists. These conclusions come in the form of an analysis of typologies, the core-periphery concept, accommociation, 
transportation, facilities and attractions, and interviews and observations of unique relevance.

\subsubsection{Tourism Typologies: A New Perspective}

Two different tourism types may not be unlike two species coexisting or competing in the same environment, using similar resources. In a biological context, Gause's law, or the principle of competitive exclusion, implies that two species cannot indefinitely live together and interact with the environment in the same way (Wallace, King and Sanders, 1981). Under laboratory conditions, Gause found that two species of Paramecium could not coexist. The most efficient feeder out-competed the other when dining on the same bacterial source; consequently, the other species died off. On the other hand, it has been argued that competition in the wild rarely results in extinction, but rather in a subdivision of habitat (MacArthur, 1957). Each species adapts and comes to live where it does best.

From a touristic point of view a fleeting analogy can be drawn that corresponds to how two types of tourist groups compete among the various resources at a destination: competition that may be different at different types of attractions, different times of the year, and different based on the prior expectations of tourist types prior to visiting an attraction. Murphy (1983) made an analogy between parts of an ecological community, to those of a tourism community. Just as plants, animals, predators and prey have to coexist, so do natural tourist attractions, local resident reactions, the industry's investment and retum, and visitor satisfaction. Specifically, Murphy equated the tourist 
industry with predators, and the visitor as its prey. The rationale followed that "visitors are prey because the community, especially the tourist industry, feeds on them and the revenue they bring" (Murphy, 1983: 187).

This analogy can be extended, however, by including the resource-base as prey to both the tourist industry as well as to various tourist groups. It is true that the tourist industry thrives off tourists; however, it first uses the resource-base as a means to supply different types of tourists. As such, tourist groups can be prey, but also predatory themselves in how they utilise resources. It is suggested here that different types of tourists have different characteristics as groups (notwithstanding the differences that occur within groups). Space and time emerge as important principles in this predator-prey relationship, which involves the resource-base (transportation, facilities, accommodation, and attractions), tourists, and those who manage the industry. Although it was not the purpose to research local interests, local people fit into this conceptualisation as they perceive different types of tourists, their impacts, and how each (locals and tourists) compete with the diversity of resources.

Examples of the differences that exist between tourists were observed in Shetiand. At the Croft House Museum, 22 coach tour tourists were observed entering the Museum in various numbers. Tourists that were already at the site (the Museum as explained earlier, is quite small), and who arrived by car, upon seeing the influx of coach visitors, either left the site or walked away into the surrounding farm complex. These "car" tourists could not, or would not compete with the coach tour visitors. However, it was observed that many of the coach tour travellers also chose not to experience the 
attraction. The coach only stayed for about half an hour, and many of the coach tour visitors entered the Museum for periods of less than five minutes.

Space, time and density must be considered when analysing a situation such as the one above. All of the tourists may have stayed if the resource (Museum) had been larger, thus reducing the density. Also, because time was a factor (only half an hour) space can become congested (Nysteun (1963). Space and time, therefore, interplay in defining levels of participation and satisfaction.

Transport mode may be one means by which to classify tourists based on their abilities to tolerate certain conditions of space and time, at least from a daily perspective. The coach tour may not change tourist values and deep-seated motivations. For some, however, it may change their expectations of what to expect and how to act on a coach day trip.

Similar observations were conducted at Mousa Broch over a period of seven days. On more than one day, the researcher observed a number of coach tour visitors moving towards the Broch, immediately on arrival at the island. Consequently, smaller travel groups that had spread themselves out had noticed the approach of the coach tour visitors, and changed their spatial approach to the islands' attractions. These smaller independent groups openly commented on how glad they were to have avoided the large group; they had intentionally chosen to visit the Broch when the coach tour was gone, while some wouldn't even come close to the Broch if any groups were present, regardless of whether others were with the coach tour or not. 
This discussion has broader implications for the nature of different types of tourists travelling in Shetland. Although, from an absolute perspective, the number of tourists in Shetland at any one time is not extensive, from a site specific perspective it appears that at least with some attractions, at some times, there is pressure or an imbalance. The result may be that smaller groups get displaced, having to return to an attraction at a later time, or perhaps not to return at all. It is impossible to determine whether, in these cases, Special or General Interest tourists were affiliated with the coach tour and independent groups mentioned above. It is important to realise, however, that attractions, facilities, etc. are resources and that tourist groups of various sizes compete for availability, space, and time in order to secure what cach perceives as a quality travel experience.

Wall (1993: 57) argued that "[tourism] typologies would be of great value in the establishment of types of tourism which are appropriate to particular places". From this premise, Wall incorporated the elements of attraction type, location, spatial characteristics, and development status in recognising that:

1. different types of tourism are likely to be appropriate for different areas; and

2. sustainable types of tourism must be types which are compatible with indigenous (host) uses and cultures, sensitive to the capabilities of the resource base, and economically viable.

There are a number of measures that can be used to establish a typology of tourism. From a cursory perspective, General Interest and Special Interest travel groups can be compared on the basis of travel companionship and travel mode - coach tour travellers versus car travellers - as mentioned above. In this study it was discovered that 
both General and Special Interest tourist groups held a higher propensity for travel "With a Spouse", followed by "With a Friend," than "With Family". Only 4.2 per cent of the overall sample travelled with a coach tour. This fact illustrates that the sample was quite independent of the coach tour experience, and that there was a higher dispersion of smaller travel groups in Shetland at any one time. Group travel mode characteristics support the above finding in that "car" was the preferred mode of travel (Special Interest travellers relied more heavily on the car). "Other" as a mode of travel (hitchhiking, walking, ferries, etc.) were also quite popular as a combined group, but with more General type travellers moving in this fashion. Coach tour and local bus travel statistics when combined illustrated that although Spocial Interest travellers had a higher frequency of use, it was the General group that spent more time on the coach/bus, indicating that they were travelling further on organised coach tours.

These examples represent only a fraction of the depth of research that could potentially contribute to a better understanding of tourism groups. The bulk of the remaining discussion centres around a typology of General and Special Interest travellers based on their space and time characteristics, and their use of accommodation, transportation, facilities, and attractions.

\subsubsection{Travel Grouns and Core-Periohery}

The human condition as it relates to movement across the earth's surface has been well documented. In particular, the implications of the world-wide movement of humans have been defined by those with inherent interests in preserving nature. The 
superabundance of humans in all parts of the world prompted Thoreau to declare that "It is difficult to conceive of a region uninhabited by man. We habitually presume his presence and influence everywhere" (Finch and Elder, 1990). By the mid twentieth century, Leopold was to draw similar conclusions, but in reference specifically to the travel industry:

the local Chamber of Commerce, at first quiescent at the novelty of a hinterland officially labeled as 'wild,' tastes its first blood of tourist money. It then wants more, wilderness or no wildemess. The jeep and the airplane, creatures of the ever mounting pressure from humanity, thus eliminate the opportunity for isolation in nature (Loopold, 1966: 289).

Loopold recognised the relationship that existed between core and periphery, as it related to the travel industry:

Like ions shot from the sun, the week-enders radiate from every town, generating heat and friction as they go. A tourist industry purveys bed and board to bait more ions faster, further...Bureaus build roads into new hinterlands, then buy more hinterlands to absorb the exodus accelerated by the roads" (Loopold, 1966: 280-81).

Shetland, as a peripheral region, represents an example that perpetuates this need for humanity to experience remote, isolated destinations. To some travellers, a trip to Shetland may embody the peripheral limit of Britain (as Shetland is perceived as one region). To others, Shetland may be thought of as being composed of successive layers of cores and peripheries. For these tourists, the main centre of Lerwick is simply a stepping-stone in the process of uncovering the outer limits of the archipelago.

The model associated with this research has attempted to uncover the dynamic nature (in space and time) of the travel characteristics of two distinct groups in four spatially distinct regions. The regions were established on the basis of access, and could 
therefore be regarded as a means with which to quantify group movement in these four regions.

It was discovered that overall, as a group, the Special Interest travellers spent more time in peripheral areas of Shetland. This finding is supported through an analysis of accommodation, attractions, and regional visitation (visitation based on travel through selected town sites of Shetland regions). Conversely, ine General Interest traveller illustrated a tendency to remain in Lerwick and Mainland regions, based on an analysis of the same elements.

In visualising spatial differences that exist between groups of tourists, Shields (1991) has constructed a thorough analysis of core-periphery through a description of marginal places. Such places are regions that "are not necessarily on geographical peripheries but, first and foremost, they have been placed on the periphery of cultural systems of space in which places are ranked relative to each other" (Shields, 19y1: 3). Important in his discussion, is the fact that "margins" are largely resultant from social systems, but by nature are systems of centres and peripheries and, therefore, are geographically oriented. These spatial systems are established in a series of binary relationships (social, political, economic, etc.) of centre and periphery, so that margins signify everything that the centre denies or represses (Shields, 1991). Our sociopolitical-economic paradigm is constantly exercising this binary scenario, and it reaches to the furthest outposts of physical space and humanity. The implications of this relationship to the global tourism network are both wondrous and daunting. 
Zurick (1992), as noted earlier, made reference to a spatial hierarchy that is reflected, from a geographical sense, in how tourists seek-out adventure peripheries. His model illustrates how, in searching for authentic experiences, travellers are propelled into more remote regions. It is this movement to peripheral or marginal places that is important to the understanding of tourist movement in Shetland. The point of establishing a typology of tourist groups stems from this notion of determining real differences between the temporal and spatial manifestations of travellers. By virtue of their travel to selected regions, tourists are exhibiting characteristics of "type" (motivations, attitudes, and needs).

How tourists come to be motivated to visit a region is largely a result of their perceptions of that region. These perceptions may be formed by society (as the margins established by Shields), by the tourist industry (through advertisements and promotions, etc.), or more personally through education, word-of-mouth, or by prior exposure to the region. Shetland, as a travel destination, would seem to be caught in this system of binary relationships of core and periphery. The systems might be formed socioculturally, by the travel industry, or personally. However, when these factors are coupled with a specific reason to visit a destination (Birding, Archaeology, Natural History, Loch Fishing, or "Other"), a viable means is established to compare the movement of each group.

The following is a framework that has evolved from past research (Zurick, 1992), the above discussion, as well as from the observation of tourists in each of the four regiuns of Shetland. As tourists travel to a particular destination, they move through a 
hierarchy in search of their chosen or perceived region of choice (movement takes place through an international gencrating region, to a domestic generating region, and finally to a destination region (Shetland). The franework is applicable to Shetland as the main destination; as such, the steps might change when or if multiple destinations are involved. Furthermore, the hierarchy will differ for domestic and international travellers. Consequently, the framework should be understood possibly to change depending on the destination involved (many destinations may not have such a large succession of peripheral tiers).

Intermational Generating Region

1. Home environment core (London, Ontario);

2. Home travel core (Toronto).

Domestic Generating Region

1. Vacation travel core (London, England);

2. Vacation travel semi-core (Aberdeen, Scotland).

\section{Destination Region}

1. Regional cure (Lerwick);

2. Regional semi-periphery (Rural Mainland);

3. Regional periphery (Car Ferry Isles);

4. Regional perimeter (Passenger Ferry Isles).

The traveller moves from a home environment core (a place of residence) to a home travel core such as a large urban centre. From here, he/she travels to the Domestic Generating Region, typically the vacation travel core. From this point, the traveller may move to a vacation travel semi-core, or make their way straight to the Destination Region. The Destination Region will typically have the infrastructure to support incoming travellers (e.g, Lerwick), which would act as the destination regional core. 
Travellers may then choose to move off into successive tiers of the periphery. As they go, however, they shed away aspects of the previous regions, and experience a perception of change. This change may be different for different types of travellers, or for travellers of the same affiliation (group). The movement into further peripheries may occur spontaneously (a response to what is lacking at the original region of choice), or be pre-determined based on prior knowledge or motivations that have stemmed from the activity-based wishes of the tourist (e.g., certain species of birds found in remote regions only). With this outward movement, the tourist's mind-set alters upon reaching successive outward regional peripheries. This change may be attributed to a number of different factors, including:

\section{Distance from Home}

This occurs in combination with other factors. That is, a vacation to Sydney, Australia from rural Canada represents a large distance, but does not necessarily represent a cultural periphery.

Familiarity with the Destination

A lack of knowledge about an environment or culture may add to the uniqueness or authenticity of travel and therefore represent a perceived periphery.

\section{Unscheduled Change}

Movement that occurs spontaneously, or that is not pre-planned (e.g., from a regional periphery to the regional outer-periphery.

\section{Psychological and/or Physiological Change}

Personal adaptations that have to be made in order to feel comfortable or maximise feelings of satisfaction or pleasure (culture, language, personal hygiene, food, shelter). 


\section{Distance from Amenities}

This is a function of the previous factor, but reinforces the notion that a particular peripheral region does not, can not, or will not offer goods and services that can be found at regions closer to the core.

\section{Adaptation}

As tourists move out to the new periphery, their psychological state changes. Perturbations such as inadequate transport, fewer shops, poor facilities, etc., that are found at regions closer to the core, are accepted in regions of the perimeter. The state of the infrastructure plays less of a role in satisfying the tourist. With distance away from the core, comes a sacrifice of personal needs. Poor weather may also not pose a problem because a more "frontier-like" attitude is adopted. (Apart from tourism where tourists bring along with them elements of home, such as what might be found -- the home environment - on a cruise liner).

\section{Population Density}

Regions with a lower tourist and local population density may provide an indication that the periphery has, or is being reached.

\section{Authenticity}

As this density decreases, the authenticity and/or incidence of natural and cultural attractions may increase in relation to the characteristics of the region. (The character of the region is important, as Costa Rica may have a higher species diversity in urban areas than Shetland has at the perimeter.)

\section{Scale of Attraction}

It is the region itself that may take on characteristics of "attraction" in the outer-periphery or perimeter. For example, Lerwick has many attractions, Foula, conversely, has few attractions and because of this, and the nature of its limited infrastructure and small size, may be the attraction itself.

\section{Symbolism}

The periphery or perimeter may be represented by experiential, environmental, or cultural phenomena (symbols). Such phenomena include lochs, mountains, wind, solitude, barrenness, a rainforest, or lack 
of banking machines. Consiquently, the more these symbols are experienced, the greater might be the feeling of reaching the perimeter. Fear may also act as a symbol, as may the realisation that there is a lack of knowledge of a region and its characteristics. Fear or anxiety of the unknown is an important feature of adventure tourism (characteristics that Csikszentmihalyi, 1975, has reported on regarding risk-taking in rock climbers).

The perimeter, as put forth in this study, may be different for different tourist groups, and within tourist groups. However, by analysing tourism groups in a normative capacity - as a typology of groups - researchers can begin to understand how tourism groups may differ with respect to regional travel.

\subsubsection{Facilities and Attractions: Their Importance in an Activities-Based Analysis}

The structure of the tourism industry includes those elements that enable tourists to achieve their goals at a destination. The eiements satisfy both the basic needs of tourists, and the affective needs associated with expectations and motivations. In this study, there were four such aspects: accommodation, transportation, facilities, and attractions. However, as the main purpose of this research was "activity", emphasis will be placed in this section on the importance of facilites and attractions within the research (acknowledging the value of transportation as an activity beyond the movement of tourists between destinations, facilities, accommodation, and attractions). Special emphasis will be placed on attractions, but also on trying to achieve a more holistic definition of "facility" and "attraction". 


\subsubsection{Facilities}

The space-time budget was an effective means by which to gather data associated with each of the four structural aspects. However, facility-use data became restricted in that there was no consideration of a spatial element. It was impossible to determine the facilities that tourists used in ixact locations of Shetland because of the nature of the space-time budget. The rationale that was part of this type of measure suggested that there was a risk of over-taxing respondents by asking them to record each facility they used, by name and by region (many facilities were used during the course of a day). A request of this nature would have congested and/or confused responses on the space-time budget for both respondents and the researcher. Notwithstanding, a variety of facilities were used by respondents -- and their associated time values -- and these provided an adequate measure with which to compare the two travel groups.

In this research, it was important to try to effectively differentiate between facilities and attractions, as some researchers (Lew, 1989: 554) acknowledge the difficulty in discerning between "attractions and non-attractions." A definition of each (facility and attraction) was provided in chapter 3 that specifically outlined their similarities and differences. The data from this research, however, have provided the means with which to modify these definitions (the definition of attraction to follow in the early discussion of the following section). The definition of a facility has thus evolved into the following:

A facility is a spatial unit (area, object, or person) that is identified by a marker(s) and that is part of a broader management system and/or region. Facilities foster a one-way or two-way exchange of material (e.g., money, guidebooks, etc.) and therefore are most often based on a concrete product 
(except in the case where people act as facilitators of information independent of recognised concrete facilities, such as a tourist centre). Facilities have to be perceived as such by both management and tourists alike. Facilities "facilitate" basic physiological and psychological needs to put tourists in a position, or frame of mind, to satisfy their chosen pursuits.

Future research needs to be directed towards the distinct function of facilities -as spatial units different than attractions -- in the tourism system. The space-time budget format was found to be a viable means by which to gather facility-related data. However, future research might endeavour to categorise facilities for tourists on each of the space-time sheets. Categories might be structured in the following way:

* entertainment facilities;

* eating facilities;

* food shopping facilities;

* travel facilities;

* etc.

Although an approach of this nature might make coding of sheets easier, researchers would not obtain the rich array of facility types that can be found in a more open-ended format. The coded space-time sheets (refered to above) could also include a box or brackets in which to place a single number that related to each of the four regions of Shetland (e.g., 1 to 4). This approach would provide a spatial measure that is lacking in this research.

\subsubsection{Attractions}

Attractions represented a significant part of this research. Past studies have tended to rely more heavily on the understanding of attractions over other elements such as accommodation, transportation, and facilities because, as Gunn (1972: 24 ; 1988) 
suggests, "they represent the most important reasons for travel to destinations". As stated earlier, accommodation, transportation, and facilities act as elements to provide the support needed for tourists to achieve their purpose of gaining satisfaction through leisure and use of the large continuum of natural and cultural attractions.

As was the case with the discussion on facilities, this research has provided the basis for change regarding the definition proposed earlier for attractions. Given this discussion, and the discussion that is to follow, the definition has evolved into the following:

An attraction is a spatial unit (area, object or person), that has unique characteristics. Most attractions are sedentary (buildings, etc.), while some are transitory (people, wildlife, a travelling art show, etc.). This space is identified by a marker(s) and is part of a broder management system and/or region. There is a two-way exchange ijetween the tourist (the experience gained from the attraction), and attraction (concrete impacts tourists have on a site). This spatial unit has to be perceived as an attraction by both management and tourists alike.

An appropriate way by which to understand both General and Special Interest travel groups was to measure both groups against their tendencies to visit different types of attractions in Shetland. It was the purpose of the questionnaire to uncover the extent of their attraction visitation by providing a series of archacological, natural, house and building, industrial, craft centre, and "other" place attractions in all four regions of the study area.

It was found that there was very little difference between both travel groups regarding visitation to these types of attractions. The largest difference was discovered through an analysis of natural attraction visitation, where only 0.6 more sites were visited, on average, by the Special Interest group compared to the General group. These 
similarities were substantiated through an analysis of mean centre for total attraction visitation. Although there was a tendency for the Special group to visit attractions to the north and east of the General group, the weighted mean centre figure illustrates the close proximity of both groups.

A more concerted analysis of regional visitation, over time, implied that there were subtle differences between the two groups. The Special Interest group spent far more time at attractions in each of the four regions than did the General group. For both groups, the rural mainland logically had the highest rate of visitation, but was followed next by passenger ferry isles, car ferry isles, and finally Lerwick.

However, a measure was needed to provide a better understanding of the impact on each of the regions in terms of attraction visitation. It was rationalised that because Lerwick was so small in relation to the other regions in terms of area, visitation might not be truly represented in time spent at attractions per area of a region. As such, the minutes/area function translated into far different results. At only approximately 0.37 per cent of the Shetland land area, the number of minutes spent by the General 'nterest group in Lerwick represented almost 65 per cent of the minutes/area percentage for attractions visitation for all of Shetland. Conversely, the Special Interest group spent equal amounts of time/area in the passenger ferry isles and Lerwick (approximately 48 per cent in total), whereas the General group spent only 32.1 per cent of their time/area in the passenger ferry isles. Both groups spent under 3.2 per cent minutes/area at attractions in the car ferry islands and rural mainland combined. 
This type of analysis has significant implications to the establishment and maintenance of attractions and infrastructure in the various regions of Shetland. Although a high degree of maintenance should be the norm in all regions, planning needs to consider both the temporal and spatial components of travel. Furthermore, data of this type might be useful to the Shetland tourist industry to market or improve the disparities that exist in attractions of those regions (rural mainland and car ferry isles) that are visited far less often. These results also have implications for local owners in these latter two regions. They may not be able to continue to offer services if visitation to their regions continues to be low. Competition for productive space (accommodation units, for instance) in these regions may ultimately become so intense that those units experiencing a low frequency of use could ultimately disappear. This process could result in an accommodation capacity level that accurately reflects the time tourists spend in these areas, if such a process has not already occurred.

The attraction data of this study also uncovered the fact that although natural attractions had a lower overall frequency of use (than other types of attractions), on average, both travel groups were found to have spent substantially more time at these types of attractions (than other types) per visit. One reason for this trend is that the natural attractions are spatially more extensive. It would have been interesting, although beyond the scope of this research, to compare the average length of time spent at an attraction type, to the area of all the attractions associated with each type (as was done with the attractions in each region). From this perspective, researchers would be able 
to determine the amount of use in time/area of each type of attraction (e.g., natural, archaeological, etc.).

It has been discussed earlier (Walmsley and Jenkins, 1991) that tourists at a destination show basically two types of behaviour: space-searching and space-sitting. Space-searchers, it was suggested, visit a great many attractions, travel widely, and enjoy a wide range of activities. It was also mentioned that tourists may elicit characteristics of both space-searching and space-sitting during the same holiday. Another spatial typology of tourists, visiting attractions, has been put-forth by Leiper, 1990: 374). He analysed attraction nuclei from the context of a hierarchy: primary, secondary and tertiary units, that are likely to have different degrees $\mathrm{uf}$ significance, as some attractions are seen as being more important than others for an individual, or entire tourist group.

\section{Primary}

an attribute of a place, a potential tourist destination, which is influential in a traveler's decision about where to go. That implies infurmation is available to the traveler about the attribute and is active, pre-visit, in stimulating motivation in the person to travel towards the place where the attribute can be experienced.

\section{Secondary}

is an attribute known to a person pre-visit, but not significant in decisions about the itinerary.

\section{Tertiary}

is an attribute unknown pre-visit, but discovered by the individual after arriving in a destination region.

The type of thinking associated with the above frameworks was considered in Shetland. But, unlike that of Walmsley and Jenkins, this study is concemed with analysis of visitors 
at a particular attraction. Furthermore, unlike Leiper, the present study is solely applicable to the actual visit, in situ, trot pre-visit motivations. As such, it provides a site-specific level of categorisation of behaviour. For example, in Lerwick it was observed that tourists showed characteristics of three types of behaviour with respect to their level of activity, these include:

Goal Directed Behaviour

Tourists had a direct goal or purpose to their movement. Their manner was focused, and they were less aware or cognitive of other attractions, people, ete. in their general vicinity. Time was more of a factor, or seemed to be an element to be considered in this movement (movement to the tourist office, post office, etc.).

\section{Activity-Searching Behaviour}

Tourists were observed actively planning or searching for leisure or recreational pursuits. Their purpose was to uncover new information or stimuli about activities, shops, interpretation, etc., that the tourist could involve him/herself with presently, or in the future.

\section{Activityless Behaviour}

Time did not appear to be a factor in demonstrating this type of behaviour. Tourists moved without a direct purpose, or pre-conceived spatial itinerary; in fact they may not have moved at all.

As a framework not grounded with sufficient empirical evidence, it remains difficult to clearly define each of these types of behaviour within a region or at an attraction. A tourist may, as suggested by Walmsley and Jenkins (1991), demonstrate all of the types of behaviour, but under different circumstances. The presence of other visitors at an attraction may also change the activity of an individual, for example, from activityless to goal-searching, depending on conditions of crowding and competition. Multiple individuals in a party may demonstrate the characteristics of one type of 
behaviour, whereas one individual may also cause others in the same group to alter their behaviour pattern. External phenomena - considerations not associated with the attraction itself -- may also be a factor in determining the behaviour of tourists or tourist groups at an attraction (e.g., other engagements, other attractions to visit, etc.).

A pattern of spatial behaviour was also observed at Mousa. Here, most tourists elicited goal-directed behaviour upon arrival at the island by immediately seeking to visit the Broch. Conversely, other tourists, perhaps after sceing this exodus from the ferry, either demonstrated goal-directed behaviour (by moving to the other end of the island where a community of seals presided), or activity-searching behaviour through their movement away from the mass of tourists. Their initial goal of seeing and spending a substantial time at the Broch may have bec $n$ displaced because of the numbers of other people actively seeking the Broch. Activity-searching for other attractions of interest on the island, for these temporarily displaced individuals, became more important. For others who had seen the attractions of the island and who were forced to wait for the return of the boat, activityless behaviour, moving slowly or sitting, with no direct purpose seemed to prevail.

This sort of behaviour has potential as a means by which to further define similarities or differences in travel groups. Consequently, tourist groups may show different types of behaviour in different regions of a destination, at different attractions of the same region, or at the same attraction - as described above. Space, time, and other extemal factors would help to explain their behaviour in these different attractions or regional units. 
The Official Tourist Map (Shetland Islands Tourism, 1992) of Shetland illustrates well over 100 natural and cultural attractions in each of the four study regions of the archipelago. Yet, with all of these attractions illustrated on the map, many attractions appeared not to be visited at all, while many had a high concentration of use. With this in mind, it became important, at least partially, to determine some of the factors that were responsible for this visitation "lop-sidedness". Many of the attractions of Shetland were visited by the researcher, and from this experience, it became apparent that there existed a substantial continuum of appeal, presentation, and management, between attractions. From the perspective of observation and interviews, there also existed a continuum of satisfaction concerning these attractions, demonstrated by the tourists. One of the major concerns was the lack of information provided on the difference between attractions (both major and minor), and secondly, on how to find some of the smaller, more remote attractions. These concerns have been organised into the following list:

\section{Sale of Attractions}

Maps do not provide enough information to direct tourists to smaller attractions (e.g., a standing stone).

\section{Signposting}

A significant number of the smaller attractions in Shetland could not be found, or were difficult to find, due to a lack of adequate signposting along roadways.

\section{Access}

Some attractions either offered confusing points of access, or no acce is to attractions at all. In certain areas this became a problem as roadways were particularly narrow in nearly all places in Lerwick and the 
surrounding countryside (Catpund at Cunningsburgh, and Clickimin Broch in Lerwick are two such examples).

Interpretation

Many of the larger attractions (i.e., Jarlshof and Scalloway Castle) have excellent interpretive resources. However, a significant number of smaller attractions have no interpretation at all. Visitors are visually keyed to small attractions on the Official Tourist Map and Official Tourist Guide but, from these sources, given very little information.

When respondents did disclose their feelings on trying to locate some of the smaller attractions, they likened their expei, ices to a game or "treasure hunt". However, whit time constraints entered the equation, tourists became frustrated and disappointed at not being able to locate sites, or wasting petrol in the process. These types of experiences detracted from their Shetland vacation. It was suggested that even one well-placed sign could have been advantageous in tracking down a small attraction.

The heavy reliance on "major" aitractions over their "minor" counterparts has been identified in the previous chapter. There, it was discovered that four "minor" attractions (those surgested to have attributes such as no signposting, poor access, or no interpretation) had no visitation from the perspective of five hours of observation over five separate days. Conversely, there was a high degree of visitation to four major attractions in the same region of Shetland.

From this observation it became important to examine the factors or properties that have contributed to this trend. Gunn (1988) proposed that location is of considerable importance when analysing the success cf attractions. Attractions that are easily accessible, are close to service centres, and supported by natural a : cultural resource assets. wire said to he more successful than those without such attributes. 
Certainly the aforementioned factors are important in the success of an attraction. Yet, these have to be analysad in a context that is broader. From this research it was noticed that certain cultural and natural attractions were able to capture both a larger percentage of visitation, and a variety of types of visitors. This "attraction universality" was appealing to both General and Special Interest travel groups. Certain properties were inherent in these "universals" that perpetuated their high level of visitation. These properties are associated with the pre-trip, and with the destination itself.

\section{Pre-trip}

* Word-of-mouth,

* Advertisement,

* Knowledge attained personally (e.g., reading).

\section{Destination}

* Spatial: centre/periphery location, relationship to other attractions.

* Temporal: time of year, length of time at a destination or attraction.

* Structural: signposting, on-site interpretation, accessibility.

* Promotional: word-of-mouth, advertisement.

* Perceptua: appeal, authenticity (a function of all of the preceding properties).

The above discussion implies that there exists a type of hierarct.:- or class of attractions at a destination. Universal sites become the comerstones in the overall matrix of attractions in a region or destination. This universality, however, needs to be placai in the context of both space and time. Spatially it is difficult ' or tourists to visit attractions if they are unable to reach them over the course of their vacation, due to extreme distance. This cannot be said for Shetland. The archipelago represents a region that contains a network of attractions, all of which are accessible over relatively short periods of time (hours). 
Some authors, Pearce (1982), Gunn (1988), and Leiper (1990), have made reference to the fact that attractions occur on various hierarchies of scale: "From the smallest specific object within a site, to entire countries and continents" (Pearce, 1982: 99). This scale variability further complicates the analysis of attractions as both sites and regions.

Gunn (1972) produced a mudel of tourist attraction that contained three separate zones. These include:

Nuclei:

Inviolate belt:

Zone of closure:
Core of the attraction;

Space needed to set the nuclei in a context;

Desirable tourism infrastructure such as toilets and information.

Gunn argued that an attraction missing one of these zones will be incomplete and difficult to manage. However, Pearce (190ij implied that because many tourist attractions have multiple nuclei, problems can occur with respect to the planning of these attractions. Pearce writes that, the solution may be to "consider each attraction as separate with its own inviolate belt and $z c$ of closure" (Pearce, 1991: 51). Scale, therefore, is an important variable in the analysis of attractions. Further rerearch needs to examine the spatial hierarchy of attraction regions and sites, and suggest means by which to appropriately plan and present such attractions. In Shetland, for instance, attractions can be measured at the following four scales:

Auraction as Destination: Shetland, Attraction as Region: Attraction as Cluster: Passenger Ferry Isles, Attraction as Site: Hermaness NNR, Bird species, Standing Stone. 
In Shetland, and from Pearce's (1991) perspective, a reason for the negligible visitation at a significant number of "micro" attractions may be because of the lack of an inviolate belt, and/or zone of closure associated with these sites. However, it does not seem appropriate to have all attractions planned and "developed" in the same context of scale. Large attractions need the support of infrastructure and space. In the context of Shetland, the planning and presentation of attractions might best occur within the hierarchy established earlier. Micro attractions need only "appear", or "exist", with a small scale of support (e.g., small signs that at least acknowledge the location of the site, reasonable access, and interpretation that does not interfere or overpower the scale of the attraction).

In addition, what has been perpetuated in past research is the fact that attractions are sedentary, physical entities of a cultural or natural form (Gunn, 1988). Although Gunn acknowledges wildlife as a foundation for attractions, it has been clear through this research that wildlife are not simply foundations of attractions, but attractions in and of themselves. To a birder, individual species become attractions of the most specific, and most sought-after kind. A case in point is the annual return of a single albatross at the Hermaness National Nature Reserve of Unst. The arrival of this species prompted some of those who had an interest in birding to immediately change their plans in an effort to travel to Hermaness. The albatross has become a major attraction for these types of tourists, while Hermaness, in a broader context, acted as a medium or habitat (attraction cluster) by which to present the attraction (bird). 
Natural attractions can therefore, be transitory: spatial units in time. This time may be measured for particular species in seconds, hours, days, weeks, months, seasons, or years. For tourists who travel with the prime reason to experience these transitory attractions, their movement is both a source of challenge and frustration.

From this discussion, it is implied that there exists a series of attraction cores and attraction peripheries, within different regions, between regions, and from the perspective of the types of tourists who visit them. Spatially, and with the influence of time, the number and type of attractions visited by tourists and tourist groups creates a niche; a role certain types of tourists occupy within a vacation destination. Through an analysis of space and time, tourists can be fitted into a typology or niche, based on their utilisation and travel between facilities, accommodation units, transportation networks, and attractions.

\subsection{CONCLUSIONS}

It was the purpose of this chapter to identify and expand upon the implications of this research. Substance was given to the relevent characteristics and findings of the study as they applied to Shetland and to the future of tourism studies. In particular, importance was placed on the value of the methodological structure in addition to the application of the model in space and time (typologies, core/periphery, regions, facilities, and attractions). The composure of the study (and results) enabled the researcher to view past research from a new perspective. The result has been a discussion that presents new ideas that may merit further examination in the future. 


\title{
Chapter 9
}

\section{CONCLUSIONS}

So here I sit in the early candle-light of old age - I and my book -casting backward glances over our travel'd road.

\author{
Walt Whitman
}

Space and time have been studied independently in the past, as seen through the discussion on theoretical foundations in the first chapter of this research. Yet, this research has provided the means by which to appreciate the utility of combining space and time into a meaningful framework in the pursuit of achieving a better understanding of tourism types in Shetland. The marriage of space and time is not new (Anderson, 1971). Geographers have, for some time, recognised the synergistic utility of projects undertaken from this perspective. Boulding (1985) suggested that both space and time could be conceived as regions. It was from this premise that the model associated with this research evolved into the consideration of a vacation (space) as a measure of a 
temporal region: the life path established by Hagerstrand (1970) or more recently, the travel career established by Pearce (1993).

Space and time in and of themselves, provide sound rationale for the establishment of a thesis. However, they also provide the basis by which to explore other avenues of research (e.g., typologies, core-periphery, and impacts). By asking tourists their activity-based motivations for visiting Shetland, the researcher was able to compartmentalise tourists according to their main reason for visiting the isles. From this point, all data were used to compare and contrast these separate groups based on their space and time, or core and periphery characteristics.

Primarily an economic theory, core-peripher: s:volved into both a locational and mental measure by which to better understand the elements of space and time in four access zones of the study area. Core areas were likened to the "zone of absolute reality" established by Cohen (1979). Although the overall regional core for both groups was Lerwick, the perceptual centre or core, for General and Special Interest groups, was found to change based on a number of measurement criteria (accommodation, regional transport visitation, and attractions). While the General group spent approximately five per cent more time in Lerwick and the Mainland region, the Special group was spendir;; about the same additional amount of time in the Passenger and Car Ferry Isles. It was also discovered that within access zones, there were successive tiers of core/periphery. These were found to be largely a function of the infrastructure (accommodation, roads, etc.), in addition to the network of attractions within each region. 
All tourists relied heavily on Lerwick as a center for regional transport visitation. As a very small archipelago, this reliance was natural, as Lerwick may have represented the only centre in Shetland where certain goods and services could be found. From the context of accommodation use, the Rural Mainland - due to its overwhelming size and number of units -- was the "centre" for both groups. This region was also an important centre for attraction visitation; however, Special Interest group data illustrated that the attractions of the Passenger Ferry Isles were more important, despite this regions smaller size (when compared to the Rural Mainland).

No region of Shetland experienced an overall saturation from tourist group pressure. The data confirm that both types of tourists spread themselves out according to the infrastructural capacity of each of the four regions. However, it was impossible to draw any empirically-based inferences on the social, environmental, and oconomic impact of tourist visitation. Keeping in mind that the contact ratio in Shetland (tourists:locals) is not in excess compared to other areas, the space-time dispersion of tourists indicated a level of pressure below the probable capacity of each of the four regions.

Butler and Fennell (1992) concluded that the future for tourism in Shetland is positive. Shetland's geographical location, coupled with high transport costs have made it unlikely that boat and air access will increase in the near future. Furthermore, the people of Shetland have accepted the tourism industry, despite its non-traditional roots. Tourism has enabled households to engage in tourism-related enterprise, at a variety of 
scales, on a part-time or full-time bases. These inherent, positive attributes, have placed the Shetland tourism industry at a point of sustainable development (Butler and Fennell, 1992).

In reaching this point, one cannot discount the importance of community ethics that have evolved in Shetland. Due in part to its peripheral location, and the legacy of dependency, Shetlanders have nurtured a philosophy of self-preservation: the need to survive through diversity, while maintaining an acceptable quality of life for local inhabitants. A recent test of this philosophy has been through the involvement of oil firms in the archipelago for over twenty years, yet Shetland responded by prospering from oil, and at the same time maintaining both cultural and ecological integrity.

By successfully facing such a metropolitan force (internationally-based oil firms) head-on, and achieving community goals, Shetlanders have positioned past and future independence of the region foremost. In achieving a measure of sustainable development, Nelson (1992) has advocated a move from a preoccupation with development and environment, to a socio-cultural realm consisten ;ith heritage and human ecology perspectives. One cannot associate the cultural diversity of Shetland with contemporary metropolitan centres. However, the region has strongly supported its human history, which dates back thousands of years. A more recent example of cultural identity has surfaced in Shetland through the annual Folk Festival, and the Hamefarin festivals of 1960 and 1985 . These festivals were organised to procure a sense of identity and community in Shetland through the invention of tradition (Church, 1990). 
Shetlanders who emigrated from the region (to seek economic advantages elsewhere), during these years, were invited back to celebrate and witness the socio-economic viability of the archipelago. This sense of community has also manifested itself in the form of environmental measures responsible for controlling the impact of oil-related involvement in Shetland (Nelson and Butler, 1993).

The same recourse will have to be applied to the tourism industry. The future may hold a time when Shetland tourism experiences periods of heightened demand. If accessibility and visitation increase (as it has in critical habitat areas such as the Galapagos Islands, despite strict measures of control), the Shetland Islands Council must be prepared to accept changes or undertake measures to control numbers according to a perceived carrying capacity.

From the above scenario, if tourism-related change is to occur in Shetland, an important concern should be what Pigram (1990: 3) has termed "irreversibilities": The concept of irreversibility involves "resource management decisions that call for a tradeoff between mutually exclusive alternatives, and, in some cases, may involve the loss of valued options". Pigram notes that the development of tourism in sensitive areas represents an example of a situation where irreversible changes to certain characteristics of an area are experienced. Irreversibilities, therefore, are a "function of the resilience of the resource base, the spatial and temporal pattern of impacts and the scope for compensatory managerial response" (Pigram, 1990: 2). Just as the involvement of oil prompted the establishment of organisations to control and monitor the effects of oil, the 
political structure of Shetland must be sensitive to both positive and negative impacts caused by tourism.

Writing on the future for tourism attractions, Martin and Mason (1993: 37) suggest that coming decades will spawn a set of new values and lifestyles. In particular, consumers will become more thoughtful, with established priorities and characteristics. The thoughtful tourist would have concern for:

1. an active lifestyle;

2. green concerns;

3. reducing inequalities;

4. time valued as a resource;

5. flexibility in work and leisure;

6. new approach for retirement;

7. social market economy (balance between personal and public spending);

8. redistribution of income (guaranteed minimum income);

9. consuming with a mission; and

10. buying for use not show.

These values suggest that travellers will be more selective regarding the attractions they visit in the future. Their purposes will involve decisions based on both the authenticity and integrity of chosen sites.

The state of the development of the tourism industry, coupled with the social and environmental attractiveness of the region, suggests that Shetland would fit well as a destination option for such travellers of the future. With this in mind, it is important that the Shetland tourism industry proceed with caution, with a goal of maintaining their social and ecological integrity (elements which have been damaged by tourism in other similar archipelagos) in the race for economic prosperity. 
A discussion with a shop owner on the north mainland cast some light on the relationship that currently exists between locals and tourists. The shop owner felt that "overall, the type of tourist that comes to Shetland is the right type, very nice. They like the remoteness of Shetland, and although they have different interests, their interests tend to overlap. The Shetland tourist is interested in a number of things". Such a description rings clearer now, at the end of this research, as it aptly describes much of what has been uncovered through these pages. 


\section{APPENDIX 1 \\ SPACE-TIME BUDGET SHEET AND QUESTIONNAIRE}

The copies of the space-time budget and questionnaire included in this Appendix have been altered to fit the guidelines of this dissertation. For purposes of size/weight manageability, both appeared as double-sided when distributed to respondents (the map of Shetland was located on the back of the facility, attraction, transportation, and accommodation use sheet). A letter of introduction also appeared with this package, and it is located at the end of this Appendix. 
PART A

FACILITY AND SER VICE USE

(shops, hanks, etc.)

Facility

TRANSPORTATION USE

(car, ferry, bus, etc.)

Transport

Time Time

from: 10:
ATTRACTION SIIES VISTTII)

(Jarlsikuf, Ness. ch.)

Attraction

Time Time

trom: II).
ACCOMMODATIION

(botel, guestlinuse. (c) !

Name

Liscallons 


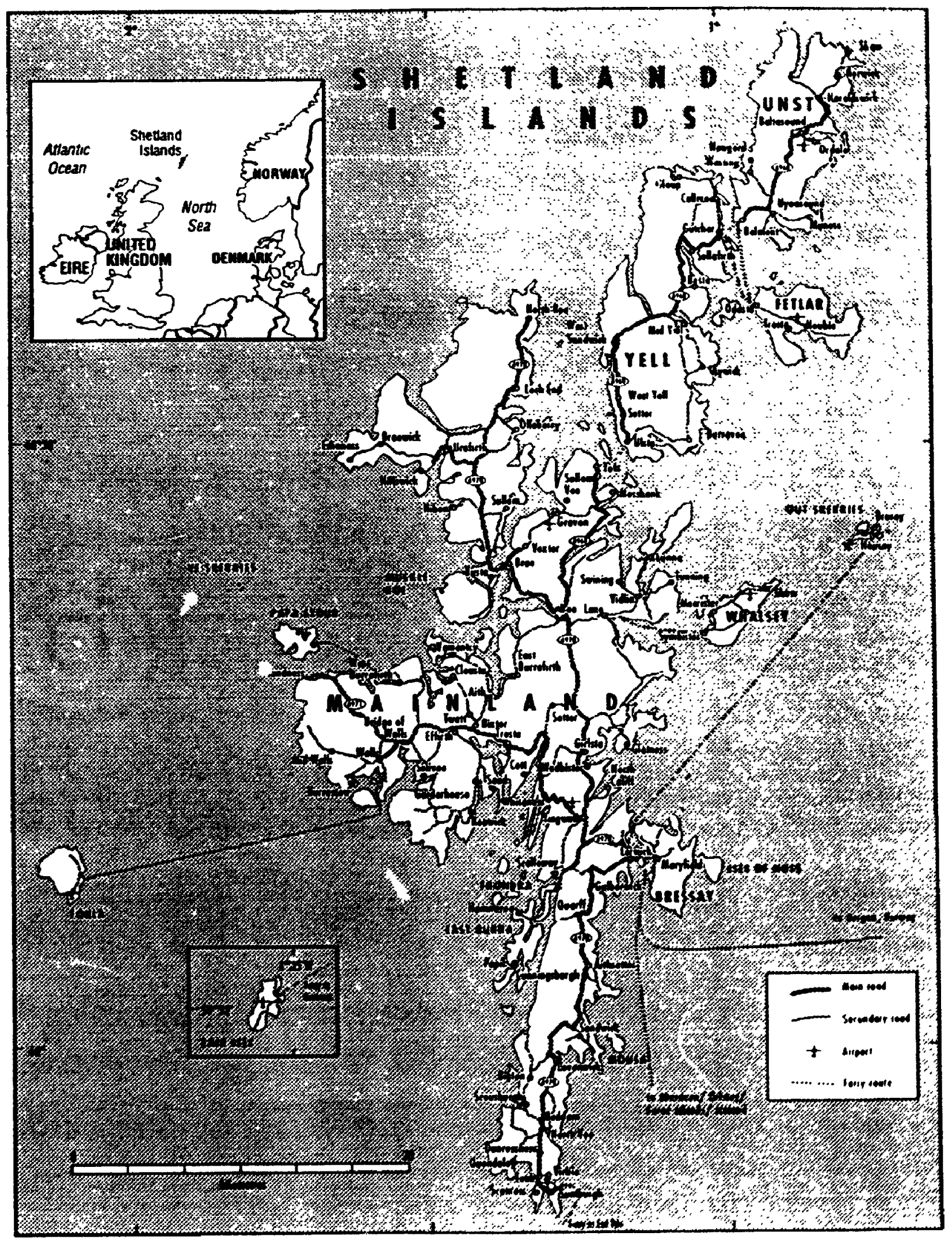


Ih. Iollowngy questlons are designed to understand the basic eleinents of your travel motives an! In'blaviour. Please clieck $|\sqrt{ }|$ the appropriate $h$ ox(es) for each question, or provide brief written responses where required.

1. In thes your furs visul to Shetland?

$$
\text { I I Yes } \quad 11 \text { No }
$$

11 not, did you visit Shetland previously as a husiness traveller or a tourist?

$$
\text { I | Business | | Tourist }
$$

2. What was the prince reason for your travelling to Shettand (please select one only)?

1 | risling

I | Gencral Sightsceing

I I History/Archacology

I I Other (please indicate):
1 ] Birdwalchung

I ] Natural History

1 ] Craft/Knitwear

3. Did you have a personal itinerary of Shetland planned prior to leaving home?

$$
\text { I I Yes } \quad 11 \text { No }
$$

4. Did you obtain any tree brochures associated with your prime reason for visiting Shetlind? Please tick the appropriate statement(s):

1 ] Before visiting Shetland

| | While in Shetland

I ] Did not collect

5. I Did you buy any interpretive material that was specifically associated with your prime feason for visiting Shetland (c.g, hird guides)? Please list these materials: 


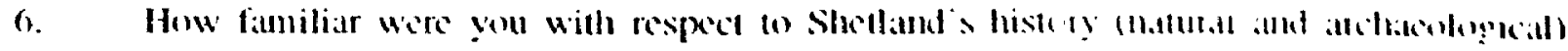
hefore you arrived in Shetland? (cirele one mumber)

very fitmiliar

Naturat hisitory

Archateological history

7. With whom did you travel while in Shetland!

$\begin{array}{ll}\text { I I Alone } & \text { I I With souse } \\ \text { I I With a family } & \text { | I With a filend } \\ \text { I I With a tour } & \text { I I Other: }\end{array}$

8. How did you travel while in Shetland? (check all that apply)
I I Car
I I Bicycle
| | Bus
1 Other:

9. Which of the following sources of information did you use in making you decision to visit Shetland? (if more than one source, please tank with one demoting! most important).

$\begin{array}{ll}\text { I I Television } & \text { | I Travel bochure } \\ \text { 1 I Newspaper } & \text { | I Travel agent } \\ \text { 1 ] Magazine } & \text { 1 I Friends/family } \\ \text { 1 I Books } & \text { 1 I Other: }\end{array}$

10. Because Shetland may be considered a small island region, did you inteml to visit all parts of the Shetland islands?

$$
\text { I I Yes } \quad \mid \text { | No }
$$

11. Did you keep a personal log, or write down any observations, other than the observations needed for the time/space component of the study?

$$
\text { I I Yes } \quad \text { I No }
$$


12. Which of the following items fits most closely with your rasons for visiting Shetland! Pleasc rank all that apply, with one (1) denoting the most miportant.

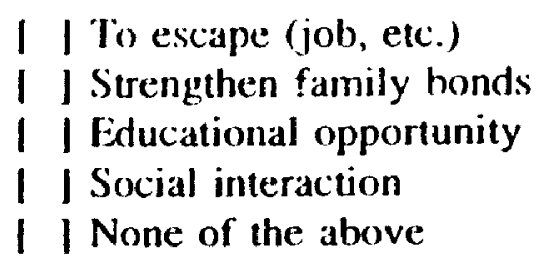
I J Relaxation
1 Prestige
I ] Wish fulfillment
I ] Shopping
I ] Other:

13. Please rate (with a circle) each of the following according to how satisfied you were with the particular aspect of your trip to Shetland

\begin{tabular}{lccccc} 
& Very satisfied & & \multicolumn{2}{c}{ Not at all satisfred } \\
Acconmodation & 1 & 2 & 3 & 4 & 5 \\
Food & 1 & 2 & 3 & 4 & 5 \\
Transportation & 1 & 2 & 3 & 4 & 5 \\
Weather & 1 & 2 & 3 & 4 & 5
\end{tabular}

14a. Did poor weather interrupt any of the activities you were engaging in?
1 I Yes
I Jo

If yes, which activities:

14b. How many days of your trip did poor weather interrupt, or not allow you to participate in planned activities? days.

15. Which of the following destination regions have you visited as a tourist in the past? (please check any that apply).

$\begin{array}{ll}\text { I I South America; } & \text { I I Mediterranean resort } \\ \text { I An Island in the Pacific; } & \text { I I Canada; } \\ \text { I I United States; } & \text { I I South-East Asia; } \\ \text { I I Antarctica; } & \text { I I Australia/New Zealand; } \\ \text { I I Africa. } & \end{array}$


16. The following is a list of terms that could be used to kescrilke Shetland as a lourist destination. Please list the most suitable four (in order of importanc:: once being: most important) that appeal to you. You may also choose to indicatte other words as s.jbstitutes, not on the list.

stimulating, frightening, relaxing, beatuiful, untamed, isolated, tomantic, rugged, fun, natural, remote.

1 .

2.

3.

4.

17. Did you meet and interact with other tourists while visiting Shedland?
I | Yes
I I No

18. Did you engage in other types of activities with these new contacts while in Shetland?
I I Yes
I I No

19. How suitable did you find Shetland to be in satisfying your pursuil of chosen activities?

Very suitable

1

2
3
Not at all suitahle

5

20. Would you travel to Shetland again?
[ ] Yes
I I No

21. Would you recommend Shetland as a travel destination to your friends?
I J Yes
I 1 No 
22. Please check all of the following attractions which you visited while in Shetland.

\section{Archateological}

I I Vikung Howse, Skaw. Innu

I Round of Tivla, Unst

I I Aywick, Yell

I I Hjaltidins, Fetlar

I | Giants Grave, Fetlas

I I Ronas Hill

I I Culsenter, Mavis Grind

I I Brough, Whalsily

I I I sech of Huxter, Whadsiay

I I C:ain, Vementry

I I Fort, Ness of Garth, Sandness

I I Caims, Grunnavoe, Bridge of Walls

I I Jamic Cheyne's Loch. Scalloway

I I Church, Papil, W. Burra

I I Jarlshof, Sumburgh

I I Broch. Clumlie

I I Broxh. Mousia

| | Souterrain. Grimsetter, Bressiay

I I Bum Mound, Houlalic. Fair Isle

\section{Nalural}

I I N. Nature Reserve, Hermaness

I IN. Naure Reserve. Noss

I I Seabird Colonies. Sumburgh

1 i Tombolo, St. Ninian's Isle

I I Tidal Pool. Virkic

I I N. Nature Reserve, Fair Isle

I I Black Park Reserve, Yell

I 1 I umbister Reserve, Yell

\section{Houses and Buildings of Interest}

\begin{tabular}{|c|}
\hline 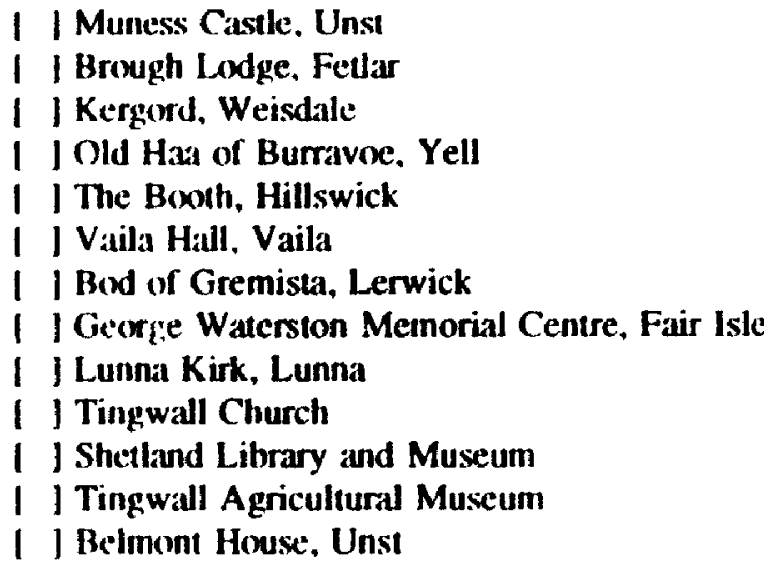 \\
\hline
\end{tabular}

I ] Broch. Underhoull. Unst

[ ] Birrier of West Sandwick, Yell

I I Broch, Gossabrough, Yell

I J Ri;ple Stone, Fetlar

f I Kame of Isbister, N. Roe

I I Punds Water, Mangaster

I I Oval House, Lunning

I I Penigarth's Hoose, Whalsay

I I Sw wacks Head, Vementry

I ] Papa Stour

I ] Pinhoulland. Bridge of Walls

I | Broch, Culswick, Skeld

I I Oval House, U. Ness. W. Burra

I ] Blockhouse, Ness of Burgi

( ) Broch, Dalsetter

I I Broch, Levenwick

I I Soap Stone, Catpund

I I Broch. Noss Sound. Bressay

I ] Oval House, Stanydale, Gruting

I ] Serpentine Flora, Keen of Hamar

[ ] Snowy Owls. Fetar

I ] Seal Colony, Mousa

I ] RSPB Reserve, Spiggie Loch

( ) Woods, Kergord

I ] N. Nature Reserve, Foula

I ] Yell Sound and Ramna Sticks

I J Scalloway Castle

I I Busta House, Brae

I J Lunna House, Lunna

I J Symbister House, Whalsay

I 1 Town Hall. Lerwick

I ] Windhouse. Yell

[ ] Croft House Museum, Boddan

I I Kirk of Lund, Unst

[ ] St. Mary's Church, Bressay

[ ] Scalloway Museum

( ] Tangwick Haa. Eshaness

[ ] Unst Heritage Centre

[ ] Lodberries. Lerwick 
Industrial Interest

I I Shetland Smokehouse. Skeld

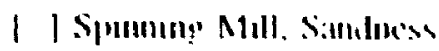

I I Sullom Voe Oil Terminal

\section{Craft Centres}

1 I Broadfool. Foula

I I Shetland Silvercraft. Weisdale

I | Hjaltasteyn, Whitenesis

I I Simply Shetlund. Nonth Rix

\section{Other Places of Interest}

I J Bard Head. Bressay

I I Greenwall's Booth, Uyeasound, Unst

I I Law Ting Holm. Tingwall Loch

I I Norse Watermill, Unst

I I St. Ninian's Isle

I ] Weisdale Mill

I I Glespl Voxe. Yell

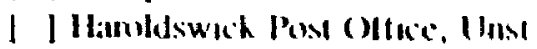

I I Muskle liluggal liphthouse, llund

I I Qukndale Mill

| | Stenmess. Evalumess

Other Attractions not Listed in the Above Categories

23. Please indicate your annual household income before taxes in Pounds, as it applies to the following categories.

I ] less than 10,000
I ] 10,000 to 19,999
I ] 20,000 to 29,999
I ] 30,000 to 39,999

1 | 40,0(1) to 49,994,

I I 50,(0)(0) $1059,(49)$

I I $60,(x)(0) 69,999$

I $70,(0)$ and up

24. What is the highest level of education you have achieved?

I I Some Highschool

I ] Highers/A Levels
I I Undergraduate degree

I I Graduate degree

25. Age: years

26. Sex:

I Male

I I Fenale

Please mail both sections (this questionnaire and the time/space budget) (ongether to the Sluetland address using the envelope provided (postage is prepaid if mailed in Hritain). If mailed outside Shetland or Britain, please send both sections to the Canadian address below. Those having to pay for postage outside of Britain will be promptly reimbursed provided they include a return address. David A. Fennell, Department of Geography, Social Science C'entre, University of Western Ontario, London, Ontario, CANAI)A, NoA 5C2.

\section{* Thank-you for participating in this study *}




\section{SIETLANDTOURISM STUWY}

Thes study is designed in provide information on where tourists go, and what they do while travellung in Slietland. It further seeks to identify different tyjes of tourist groups, based on the activitics and helaviour of these groups. It is sincerely hoped that you will participate in this dectoral research. The results, based on your responses (respondents can be assured of complete confidentiality), will help the Shetland Tourist Organisation to hetter understand the specific needs of these courist groups, and to plan and develop facilities and attractions that will maximise sattisfaction of twoh tourists and locals in an hamonious relationship. The following is a hrief ittrouluction to the two components of this survey:

\section{A. The Time/Space Budget}

Respondents are requested to please fill out one (1) time/space hudget sheet (front and back), for each day of the vacation. Four cells ase provided for you to record all information related to your use of facilities and services, attraction sites, transportation, and accommodation type and location. These time/budget sheets can he filled out immediately (c.g., as you arrive at an attraction, or drive somewhere, or use a facility), they can be filled out at the end of the day, or they call tre completed the moming after (whenever you feel most comfonahle). An example is provided on the first sheet wo illustrate the process. On the hack of each sheet, simply trace with a pen or pencil where you travelled in Shetland that day.

The times that you record for visiting facilities and altractions, Iransportation and accommodation do not have to he exact (although exact recordings are cenainly welcomed). Please try, lowever, to approximate your recordings to within 15 minutes. That is, if you visited Jarlshof. Iry to record the time that you arrived there (give or take 15 minutes) and the time you left (give or take 1.5 minutes).

\section{B. The Questionnaire}

The second component of the study involves the completion of a brief questionnaire that secks to understand some hasic aspects of your travel motives and behaviour. Study participants are asked to complete this questionmaire during the final day of their Shetland vacalion.

Please mail moth sections. A. and B., together to the Shetland address using the envelope provided (postage is prepaid if mailed in Britain). If mailed outside Shetland or Britain, please send tuth sections to the Canadian address helow. Those having to pay for postage outside of Britain will be promplly reimbursed provided they include a return address.

Mr. David A. Fennell

Department of Geography.

Social Science Centre,

University of Westem Ontario.

London, Ontario, Canada, N6A 5C2

*'Thank-you for participating in this study* 


\section{APPENDIX 2 \\ INTERVIEW GUIDE QUESTIONS}

Interview guide questions were presented to respondents in the order that follows in this Appendix. The interview guide sought to uncover data of two types: a tourist industry perspective (these questions are identified by a single asterisk), and an experiential perspective (these questions are identified by a double asterisk). 


\section{Interview Suide Questions}

1. What is your prime reason for vacationing in Shetland?

2. What is the length of time you will spend in Shetland on vacation? (*)

3. Which types of accommodation units have you/will you be staying at? (*)

4. How many times, including this one, have you vacationed in Shetland? $\left({ }^{*}\right)$

5. Did you do any background reading on Shetland prior to your visit? (**)

6. Which regions (islands) of Shetlan ${ }^{*}$ have you, or do you intend on visiting? (*)

7. Which of the attraction sites in Shetland are your most favourite? (**)

8a. Do you visit different regions of Shetland each day, or spend more time in a particular area? (*)

8b. How long do you like to spend at the attractions you visit? (*)

9. Did you bring any items from home to aid in your Shetland travel experiences? $(* *)$

10. What types of transport have you, and do you intend to use in Shetland? (*)

11. How would you describe the Shetland landscape? $\left(^{* *}\right)$

12. How would you describe the people of Shetland? (**)

13. How would you comment on the prices in Shetland relative to your expectations? $\left({ }^{* *}\right)$

14. Could you give me an indication of the level of satisfaction of your Shetland trip? $(* *)$

15. Do you have any particular dislikes of Shetland as they apply to your trip? (**) 


\section{APPENDIX 3}

\section{ARCHAEOLOGICAL ATTRACTIONS VISITED}

(Table 5.21)

HOUSES AND BUILDINGS OF INTEREST

(Table 5.23) 
Table 5.21

Archaeological Attractions Visited

\begin{tabular}{|c|c|c|c|}
\hline Attraction & $\begin{array}{l}\text { Tourist } \\
\text { Group }\end{array}$ & $\begin{array}{l}\text { \%Intergroup } \\
\text { Response }\end{array}$ & $\begin{array}{l}\text { \%Intragroup } \\
\text { Response }\end{array}$ \\
\hline \multicolumn{4}{|l|}{ Jarlshof, Sumburgh } \\
\hline Yes $(n=58 ; 81.7 \%)$ & $\begin{array}{l}1 \\
2\end{array}$ & $\begin{array}{l}59.3 \\
50.7\end{array}$ & $\begin{array}{l}80.6 \\
82.9\end{array}$ \\
\hline \multicolumn{4}{|l|}{ Mousa Broch } \\
\hline Yes $(n=37 ; 52.1 \%)$ & $\begin{array}{l}1 \\
2\end{array}$ & $\begin{array}{l}47.9 \\
52.1\end{array}$ & $\begin{array}{l}50.0 \\
54.3\end{array}$ \\
\hline \multicolumn{4}{|l|}{ Mavis Grind } \\
\hline Yes $(n=13 ; 18.3 \%)$ & $\begin{array}{l}1 \\
2\end{array}$ & $\begin{array}{l}60.8 \\
39.2\end{array}$ & $\begin{array}{l}22.2 \\
14.3\end{array}$ \\
\hline \multicolumn{4}{|l|}{ Noss Sound Broch } \\
\hline Yes $(n=10 ; 14.1 \%)$ & $\begin{array}{l}1 \\
2\end{array}$ & $\begin{array}{l}49.4 \\
60.6\end{array}$ & $\begin{array}{l}11.1 \\
17.1\end{array}$ \\
\hline \multicolumn{4}{|l|}{ Fort, Sandness } \\
\hline Yes $(n=10 ; 14.1 \%)$ & $\begin{array}{l}1 \\
2\end{array}$ & $\begin{array}{l}19.6 \\
80.4\end{array}$ & $\begin{array}{c}5.6 \\
22.9\end{array}$ \\
\hline \multicolumn{4}{|l|}{ Jamie Cheynes Loch } \\
\hline Yes $(n=9 ; 12.7 \%)$ & $\begin{array}{l}1 \\
2\end{array}$ & $\begin{array}{l}54.9 \\
45.1\end{array}$ & $\begin{array}{l}13.9 \\
11.4\end{array}$ \\
\hline \multicolumn{4}{|l|}{ Caims, Bridge of Walls } \\
\hline Yes $(n=8 ; 11.3 \%)$ & $\begin{array}{l}1 \\
2\end{array}$ & $\begin{array}{l}61.8 \\
38.2\end{array}$ & $\begin{array}{l}13.9 \\
8.6\end{array}$ \\
\hline \multicolumn{4}{|l|}{ Papil Church, W. Burra } \\
\hline Yes $(n=8 ; 11.3 \%)$ & $\begin{array}{l}1 \\
2\end{array}$ & $\begin{array}{l}36.7 \\
63.3\end{array}$ & $\begin{array}{c}8.3 \\
14.3\end{array}$ \\
\hline \multicolumn{4}{|l|}{ Clumlie Broch } \\
\hline Yes $(n=6 ; 8.5 \%)$ & $\begin{array}{l}1 \\
2\end{array}$ & $\begin{array}{l}49.1 \\
50.9\end{array}$ & $\begin{array}{l}8.3 \\
8.6\end{array}$ \\
\hline \multicolumn{4}{|l|}{ Levenwick Broch } \\
\hline Yes $(n=6 ; 8.5 \%)$ & $\begin{array}{l}1 \\
2\end{array}$ & $\begin{array}{l}32.9 \\
67.1\end{array}$ & $\begin{array}{c}5.6 \\
11.4\end{array}$ \\
\hline \multicolumn{4}{|l|}{ Oval House, Stanydale } \\
\hline Yes $(n=6 ; 8.5 \%)$ & $\begin{array}{l}1 \\
2\end{array}$ & $\begin{array}{l}49.1 \\
50.9\end{array}$ & $\begin{array}{l}8.3 \\
8.6\end{array}$ \\
\hline \multicolumn{4}{|l|}{ Ronas Hill } \\
\hline Yes $(n=6 ; 8.5 \%)$ & $\begin{array}{l}1 \\
2\end{array}$ & $\begin{array}{l}32.9 \\
67.1\end{array}$ & $\begin{array}{l}5.6 \\
11.4\end{array}$ \\
\hline $\begin{array}{l}\text { Viking House, Skaw } \\
\text { Yes }(n=6 ; 8.5 \%)\end{array}$ & $\begin{array}{l}1 \\
2\end{array}$ & $\begin{array}{l}65.9 \\
34.1\end{array}$ & $\begin{array}{c}11.1 \\
5.7\end{array}$ \\
\hline
\end{tabular}


Table 5.21 (continued)

\begin{tabular}{cccc}
\hline Attraction & $\begin{array}{c}\text { Tourist } \\
\text { Group }\end{array}$ & $\begin{array}{c}\text { \%Intergroup } \\
\text { Response }\end{array}$ & $\begin{array}{c}\text { \%Intragroup } \\
\text { Response }\end{array}$ \\
\hline
\end{tabular}

\section{Underhoull Broch, Unst}

Yes $(n=5 ; 7.0 \%)$

Blockhouse, Scatness

Yes $(n=5 ; 7.0 \%)$

Burnt Mound, Fair Isle

Yes $(n=4 ; 5.6 \%)$

Aywick, Yell

Yes $(n=4 ; 5.6 \%)$

Pinhoulland, Bridge of Walls

Yes $(n=4 ; 5.6 \%)$

Catpund, Cunningsburgh

Yes $(n=4 ; 5.6 \%)$

Dalsetter Broch

Yes $(n=3 ; 4.2 \%)$

Punds Water, Mangaster

Yes $(n=3 ; 4.2 \%)$

Gossabrough Broch, Yell

Yes $(n=2 ; 2.8 \%)$

Giants Grave, Fetlar

Yes $(n=2 ; 2.8 \%)$

Ripple Stone, Fetlar

Yes $(n=2 ; 2.8 \%)$

Kame of Isbister, N. Roe

Yes $(n=2 ; 2.8 \%)$

Brough, Whalsay

Yes $(n=2 ; 2.8 \%)$
1

2

1

2

1

2

1

2

1

2

1

2

1

2

1

2

1

2

1

2

1

2

1

2

1
49.4

60.6

5.6

8.6

59.3

40.7

8.3

5.7

24.6

2.8

75.4

8.6

74.1

25.9

8.3

2.9

24.6

75.4

2.8

8.6

24.6

2.8

8.6

65.9

34.1

5.6

2.9

8.6

49.1

50.9

2.8

2.)

49.1

2.8

50.9

2.9

49.1

50.9

2.8

2.)

49.1

2.8

50.9

2.9

5.7 
Table 5.21 (continued)

\begin{tabular}{llll}
\hline & Tourist & \%lntergrp & \%lntragrp \\
Attraction & group & Response & Response
\end{tabular}

Loch of Huxter, Whalsay

Yes $(n=2 ; 2.8 \%)$

1

2

49.1

2.8

Oval House, W. Burra

Yes $(n=2 ; 2.8 \%)$

1

2

50.9

2.9

Papa Stour

Yes $(n=2 ; 2.8 \%)$

1

2

49.1

2.8

50.9

2.9

Pettigarths Hoose, Whalsay

$$
\text { Yes }(n=2 ; 2.8 \%)
$$

1

2

49.1

2.8

50.9

2.9

Birrier, Yell

'es $(n=1 ; 1.4 \%)$

1

2

Swarbacks Head, Vementry

Yes $(n=1 ; 1.4 \%)$

Culswick Broch, Skeld

Yes $(n=1 ; 1.4 \%)$

1

2

49.1

2.8

50.9

2.9

100.0

2.8

$-$

$-$

2.9

1

2

100.0

2.8

Souterrain, Bressay

Yes $(n=1 ; 1.4 \%)$

1
2

100.0

2.8 
Table 5.23

Houses and Buildings of Interest Visited

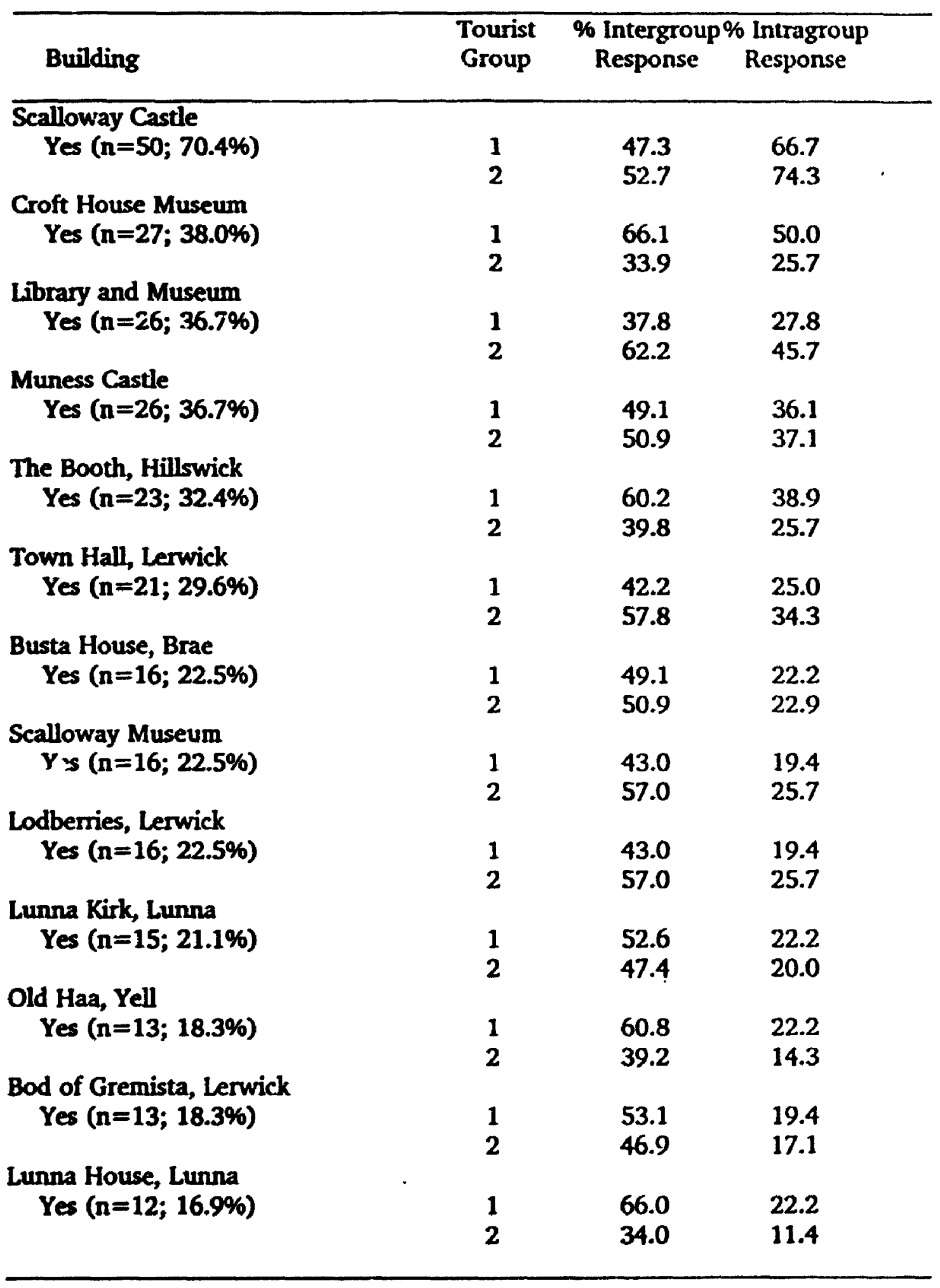


Table 5.23 (continued)

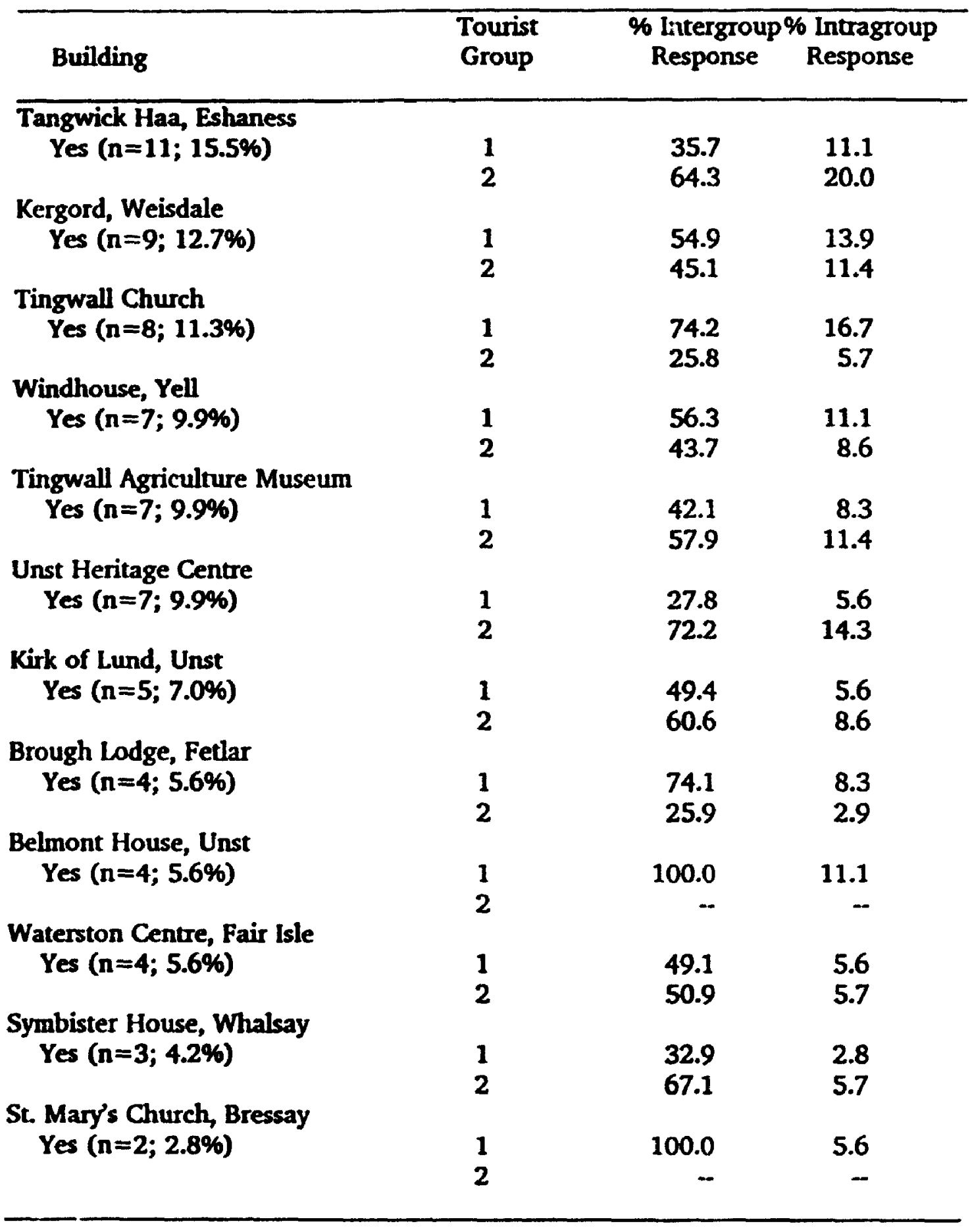




\section{APPENDIX 4}

\section{MAJOR ATTRACTION SITES OF SHETLAND}

Attractions included on the following map are those which were visited by at least 20 respondents (General and Special Interest travellers). The selection of 20 visits is an arbitrary one. Attraction names are listed below as they apply to each of the numbers located on the map. Attraction type is also identified in each case by a letter, after the attraction name, which corresponds to one of the following categories: Archaeological (A), Natural (N), Industrial (I), House and Building (H), and Other (O).

\section{Attraction Names:}

$\begin{array}{lll}1 & - & \text { Hermaness National Nature Reserve (N) } \\ 2 & - & \text { Haroldswick Post Office (O) } \\ 3 & - & \text { Muness Castle (H) } \\ 4 & - & \text { Eshaness (O) } \\ 5 & - & \text { Booth Pub at Hillswick (H) } \\ 6 & - & \text { Sullom Voe Oil Terminal (I) } \\ 7 & - & \text { Law Ting Holm Viking Site (O) } \\ 8 & - & \text { Library and Museum at Ierwick (H) } \\ 9 & - & \text { Town Hall at Lerwick (H) } \\ 10 & - & \text { Noss National Nature Reserve (N) } \\ 11 & - & \text { Scalloway Castle (H) } \\ 12 & - & \text { Mousa Broch (A) } \\ 13 & - & \text { Tombolo, St. Ninian's Isle (N) } \\ 14 & - & \text { Croft House Museum (H) } \\ 15 & - & \text { Jarlshof Settlement (A) } \\ 16 & - & \text { Sumburgh Head (N) }\end{array}$




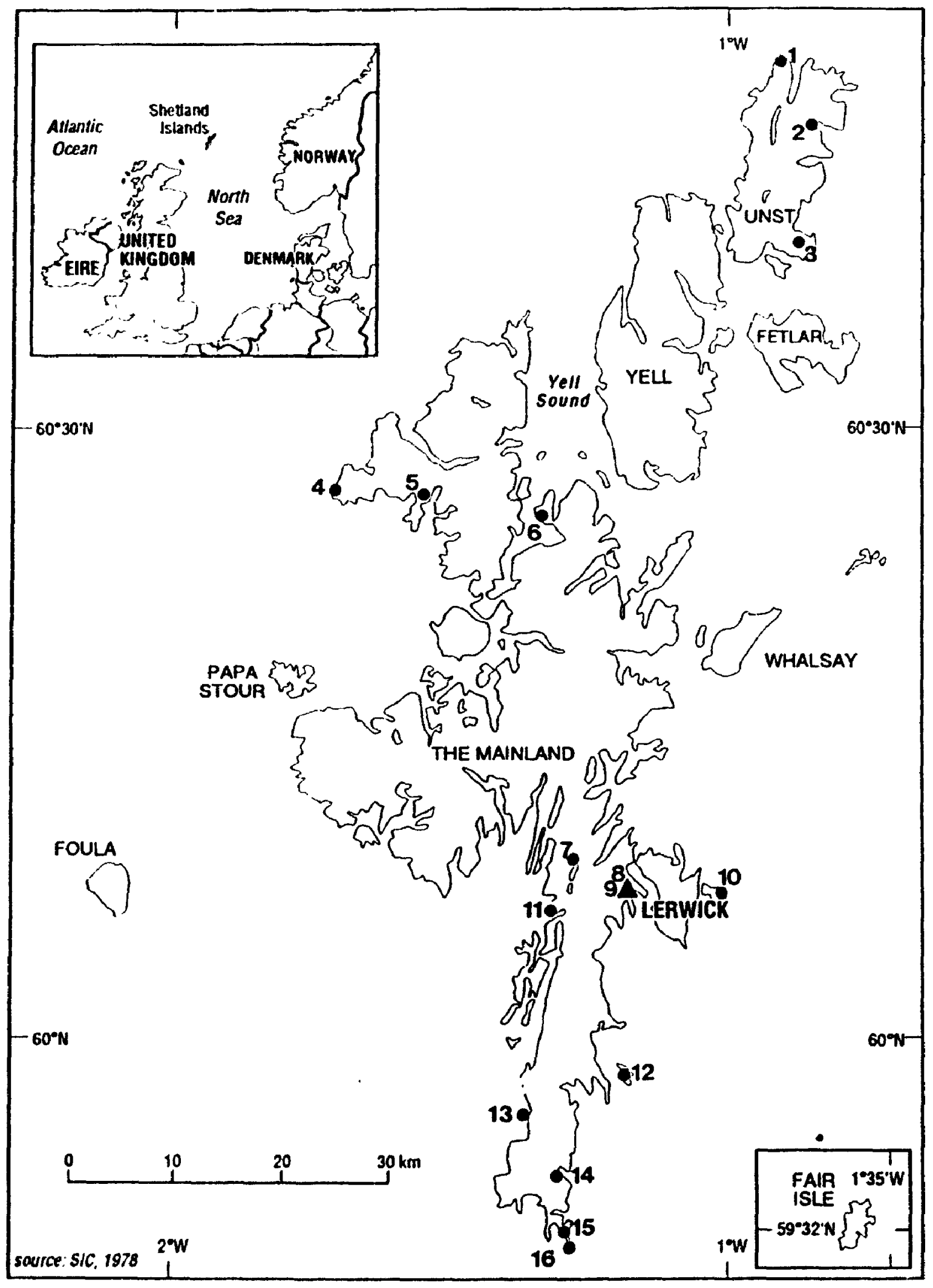




\section{REFERENCES}

Anderson, J. (1971). "Space-time Budgets and Activity Studies in Urban Geography and Planning". Environment and Planning. 3(4): 353-368.

Andronikou, A. (1987). Development of Tourism in Cyprus. Harmonisation of Tourism with the Environment. Nicosia: Cosmos.

Anon. (1797). "Account of a Letter to a Friend". The English Magazine. January.

Anon. (1870). Benjies Tour in Shetland in the Summer of 1870. Edinburgh: J. Menzies and Co.

Anon. (1963). "Focus on...Tourism in Shetland". The New Shetlander. 66: 11-14.

Anon. (1975). "Notes of a Tour in Shetland and Orkney: A Free Church Minister in 1845". Lerwick: Thuleprint Ltd.

Anon. (1991). "Travel and Tourism: The Pleasure Principle". The Economist. March: 3-22.

Applegate, J.E. and Clark, K.E. (1987). "Satisfaction Levels of Birdwatchers: An Observation on the Consumptive-Nonconsumptive Continuum" . Leisure Sciences. 9: 129-134. 
Arcos, F.; Cepeda, F.; Rodriguez, T. and Villa, J. (1988). "Plan de Zonification de la Reserva de Recursos Marinos de Galapagos". Ministry of Agriculture, Quito, Ecuador in Kenchington, 1989.

Atkinson, George Clayton (1832). An Excursion to the Shetland Islands. MS.

Babbie, Earl (1986). The Practise of Social Research. Belmont: Wadsworth Publishing Co.

Bacon, Francis (1625). "Essays". In Bartlett's Familiar Quotations. 16th edition, pg. 159. Toronto: Little, Brown and Company, 1992.

Barbier, B. (1989). "International Tourism Today: A Geographic Approach". Geojournal. 19(3): 251-255.

Battisti, Gianfranco (1982). "Central Places and Peripheral Regions in the Formulation of a Theory on Tourist Space". In Studies in Tourism Wildlife Parks Conservation. T.V. Singh and Jagdish Kaur (eds.). New Delhi: Metropolitan.

Berry, R.J. and Johnston, J.L. (1986). The Natural History of Shetland. London: Collins.

Beston, Henry (1928). "The Outermost House". In Bartlett's Familiar Quotations. 16th edition, pg. 666. Toronto: Little, Brown and Company, 1992.

Blance, D. (1963). "Shetland". The New Shetlander. 67: 15.

Boulding, Kenneth E. (1985). "Regions of Time". Regional Science Association Papers. 57: 19-32.

Boyd, S.W. (1991). "Towards a Typology of Tourism: Setting and Experience". Paper presented at the Annual Meeting of the Association of American Geographers, Ohio State University, Youngstown, Ohio. Nov. 1-2. 
Britton, R.A. (1977). "Making Tourism More Supportive of Small-state Devclupment: The Case of St. Vincent". Annals of Tourism Research. 4(5): 268-78.

Britton, S.G. (1982). "The Political Economy of Tourism in the Third World". Annals of Tourism Research. 9(3): 331-58.

Brougham, J.B. (1978). "The Social Impact of Tourism: The Case of Sleat". Unpublished Ph.D. Thesis, The University of Western Ontario.

Bull, Adrian (1991). The Economics of Travel and Tourism. Melbourne: Longman Cheshire Ltd.

Burton, T.L. (1971). Experiments in Recreation Research. London: George Allen and Unwin.

Butler, J.R. and Hvenegaard, G.T. (1988). "The Economic Value of Birdwatching Associated with Point Pelee National Park Canada, and Their Contribution to Adjacent Communities". Paper presented at University of Illinois, Urbana, June 6-9.

Butler, R.W. (1980). "The Concept of Tourist Area Cycle of Evolution: Implications for Management of Resources". The Canadian Geographer. 24: 5-12.

Butler, R.W. (1985). "Evolution of Tourism in The Scottish Highlands". Annals of Tourism Research. 12(3): 371-391.

Butler, R.W. (1994). Personal communication.

Butler, R.W. and Fennell, D.A. (1992). "Offshore Hydrocarton Development and Tourism Development". Paper presented at the Tourism in Europe Conference, July 8-11, Durham, England. 
Butler, R.W; Fennell, David A. and Boyd, S.W. (1992a). "POLAR: Priortising Operational Limits for the Administration of Rivers". Prepared under contract for the Canadian Parks Service, Heritage Rivers, Hull, Quebec.

Butler, R.W; Fennell, David A.; and Boyd, S.W. (1992b). "Application of the POLAR System to the Churchill River". Prepared under contract for the Canadian Parks Service, Heritage Rivers, Hull, Quebec.

Butler, R.W. and Nelson, J.G. (1994). "Assessing Institutional Arrangements for Controlling and Mitigating Effects of Oil Development Related Impacts: The Case of the Shetland Islands". Geoforum. (forthcoming).

Butler, R.W. and Waldbrook, L.A. (1991). "A New Planning Tool: The Tourist Opportunity Spectrum". The Joumal of Tourism Studies. 2(1): 2-14.

Campbell, C.K. (1967). "An Approach to Research in Recreational Geography". B.C. Occassional Paper: No. 7. Department of Geography, Univ. of British Columbia, Vancouver.

Carlstein, Tommy (1982). Time Resources, Society and Ecology. London: George Allen and Unwin.

Catton, W.R. (1987). "Social and Behavioral Aspects of the Carrying Capacity of Natural Environments". Behavior and the Natural Environment. 6: 269-306.

Chapin, F.S. (1974). Human Activity Pattems in the City. New York: Wiley.

Charlton, Edward (1913). "A Visit to Shetland in 1832". Orkney and Shetland Miscellany." 6: 188-89.

Cheshire, P.C. and Stabler, M.J. (1976). "Joint Consumption Benefits in Recreational Site 'Surplus'; An Empirical Estimate". Regional Studies. 10(3): 343-351. 
Christaller, Walter (1963). "Some Considerations of Tourism Location in Europe: The Peripheral Regions--Underdeveloped Countries-Recreation Areas". Regional Science Association Papers. No.6: 95-105.

Church, Jonathan T. (1990). "Confabulations of Community: The Hamefarins and Political Discourse on Shetland". Anthropological Ouarterly. 63(1): 31-42.

Clawson, Marion and Knetsch, Jack L. (1966). Economics of Outdoor Recreation. Baltimore: Johns Hopkins U. Press.

Cohen, Erik (1972). "Toward a Sociology of International Tourism". Social Research. 39(1): 164-182.

Cohen, Erik (1979). "A Phenomenology of Tourist Experiences". Sociology. 13(2): 179201.

Cohen, Erik (1988). "Traditions in the Qualitative Sociology of Tourism". Annals of Tourism Research. 15(1): 29-46.

Cooper, C.P. (1981). "Spatial and Temporal Patterns of Tourist Behaviour". Regional Studies. 15(5): 358-371.

Cooper, C. and Jackson, S. (1989). "Destination Life Cycle: The Isle of Man Case Study". Annals of Tourism Research. 16(3): 377-398.

Cowie, Robert (1871). Shetland Descriptive and Historical: Being a Graduation Thesis on the Inhabitants of the Shetland Islands; and a Topographical Description of that Country. Aberdeen: Lewis and Smith.

Crompton, J. (1979). "Motivations for Pleasure Vacations". Annals of Tourism Research. 6: 408-424.

Csikszentmihalyi, M. (1975). Beyond Boredom and Anxiety. Washington: Jossey-Bass. 
Cullen, 1. and Godson, V. (1975). "Urban Networks: The Structure of Activity Patterns". Progress in Planning. 4(1): 1-96.

Dann, Graham M.S. (1981). "Tourist Motivations: An Appraisal". Annals of Tourism Research. 8(2): 187-219.

Dann, Graham; Nash, Dennison and Pearce, Philip (1988). "Methodology in Tourism Research". Annals of Tourism Research. 15(1): 1-28.

Dartnall, Jean and Store, Ron (1990). "The Literature on Tourism". The Joumal of Tourism Studies. 1(1): 49-53.

Davidoff, Philip G.; Davidoff, Doris S. and Eyre, J. Douglas (1988). Tourism Geography. Elmsford N.Y.: National Publishers.

Debbage, K.G. (1990). "Oligopoly and the Resort Cycle in the Bahamas". Annals of Tourism Research. 17(4): 513-527.

Denzin, N.K. (1978). The Research Act: A Theoretical Introduction to Sociological Methods. New York: McGraw-Hill. in Patton, 1990.

Doxey, George V. (1975). "A Causation Theory of Visitor-Resident Irritants; Methodology and Research Inferences". The Impact of Tourism 16th Annual Conference Procedings of the Travel Research Association. San Diego: 195-8.

Driver, B.L.; Brown Perry J.; Stankey, George H. and Gregoire, Timothy G. (1987). "The ROS Planning System: Evolution, Basic Concepts, and Research Needed". Leisure Sciences. 9: 201-212.

Ebdon, David. (1992). Statistics in Geography. Oxford: Blackwell Publishers.

Edington, J. and Edington A.M. (1986). Ecology, Recreation, and Tourism. Cambridge, U.K.: Cambridge University Press. 
Erisman, H. Michael (1983). "Tourism and Cultural Dependency in the West Indies". Annals of Tourism Research. 10(3): 337-361.

Eyles, J. and D.A. Smith (eds.) (1988). Qualitative Methods in Human Geography. Cambridge: Polity Press.

Fennell D.A and P.F.J. Eagles. (1990). "Ecotourism in Costa Rica: A Conceptual Framework". Journal of Park and Recreation Administration. 8(1): 23-34.

Finch, Robert and Elder, John (eds.). (1990). The Norton Book of Nature Writing. New York: W.W. Norton \& Company.

Flinn, Derek (1989). Travellers in a Bygone Shetland. Edinburgh: Scottish Academic Press.

Flognfeldt, Thor (1992). "Area, Site or Route". Tourism Management. 13(1): 145-151.

Fodness, Dale (1990). "Consumer Perceptions of Tourist Attractions". Joumal of Travel Research. 28(4): 3-9.

Freidmann, J. and Alonso, W. (eds.) (1974). Regional Development and Planning: A Reader. Cambridge, Mass.: M.I.T. Press.

Getz, Donald (1983). "Capacity to Absorb Tourism: Concepts and Implications for Strategic Planning". Annals of Tourism Research. 10: 239-263.

Getz, Donald (1986). "Models in Tourism Planning". Tourism Management. 7(1): 2132.

Goodchild, M.F. and Janelle, D.G. (1984). "The City Around the Clock: Space-Time Patterns of Urban Ecological Structure". Environment and Planning A. 16: 807820. 
Graham, R.; Nilsen, P. and Payne, R.I. (1988). "Visitor Management in Canadian National Parks". Tourism Manazement. 9: 44-62.

Green, John (1984). Aberdeen to the Muckle Flugga: A Tour Through the Orkney and Shatland Islands. Sunderland: Harold and Daily Post General Printing Works.

Groot, R.S. (1983). "Tourism and Conservation in the Galapagos Islands". Biological Conservation. 26: 291-300.

Gunn, Clare A. (1972). Vacationscape: Designine Tourist Regions. Univ. of Texas: Bureau of Business Research.

Gunn, Clare A. (1988). Tourism Planning. New York: Taylor and Francis.

Hagerstrand, T. (1970). "What About People in Regional Science?". Papers of the Regional Science Association. 24: 7-21.

Hartmann, Rudi (1988). "Combining Field Methods in Tourism Research". Annals of Tourism Research. 15(1): 88-105.

Hartshome, R. (1959). Perspectives on the Nature of Geography. Chicago: Rand McNally and Co.

Hawkins, Donald E. and Ritchie, J.R. Brent (1991). World Travel and Tourism Review: Indicators. Trends and Forcasts (Vol, 1). Oxford: Information Press Ltd. p. 3.

Haywood, M. (1986). "Can the Tourist-Area Life Cycle be Made Operational?". Tourism Management. 7(3): 154-167.

Heron, R.P. (1990). "The Institutionalisation of Leisure: Cultural Interpretation". Paper given at 6th Canadian Congress on Leisure Research, Ontario Research Council on Leisure, Ontario, Canada. 
Hibbert, Samual (1822). A Description of the Shetland Islands Comprising an Account of their Scenery. Antiquities and Superstitions. Edinburgh: Constable and Co.

Higgins, L.R. (1971). A Tangle of Islands. London: Robert Hale.

Hills, T. and Lundgren, J. (1977). "The Impact of Tourism in the Caribbean: A Methodological Study". Annals of Tourism Research. 4(5): 248-267.

Hope, K.R. (1980). "The Caribbean Tourism Sector: Recent Performance and Trends". Tourism Management. 1(3): 175-183.

Howarth, David (1985). The Shetland Bus. London: Bath - Chivers Press.

Hsieh, Sheauhsing; O'Leary, Joseph T. and Morrison, Alastair M. (1992). "Segmenting the International Travel Market by Activity". Tourism Management. 13(2): 209223.

Hudson, W.H. (1983). "Idle Days in Patagonia". In Finch, Robert and Elder, John (eds.). The Norton Book of Nature Writing. (1990). New York: W.W. Norton and Company.

Husbands, Winston (1981). "Centres, Peripheries, Tourism and Socio-Spatial Development". Ontario Geography. 17: 37-59.

Husbands, Winston C. (1983). "Tourist Space and Tourist Attraction: An Anaysis of the Destination Choices of European Travelers". Leisure Sciences. 5(4): 289-307.

Husbands, Winston C. (1986). "Leisure Activity Resources and Activity Space Formation in Periphery Resorts: The Response of Tourists and Residents in Barbados". The Canadian Geographer. 30(3): 243-249. 
Ianni, Francis A.J. and Orr, Margaret Terry (1979). "Toward a Rapprochement of Quantitative and Qualitative Methodologies". in Cook, Thomas D. and Reichardt, Charles S. (eds.) Qualitative and Quantitative Methods in Evaluation Research. Beverly Hills: Sage Publications. pp. 87-98.

Iso-Ahola, Seppo E. (1982). "Toward a Social Psychological Theory of Tourism Motivation: A Rejoinder". Annals of Tourism Research. 9(2): 256-262.

Jakle, J.A. (1985). T.e Tourist: Travel in Twentieth-Century North America. Lincoln: University of Nebraska Press.

Jafari, Jafar (1990). "Research and Scholarship: The Basis of Tcurism Education". The Joumal of Tourism Studies. 1(1): 33-41.

Jansen-Verbeke, Myriam and Dietvorst, Adri (1987). "Leisure, Recreation, Tourism: A Geographic View on Integration". Annals of Tourism Research. 14(3): 361375.

Jenkins, C.L. (1982). The Effects of Scale in Tourism Projucts in Developing Countries". Annals of Tourism Research. 9(2): 229-49.

Johnson, Samuel (1786). "Anecdotes of Samuel Johnson." In Bartlett's Familiar Quotations. 16th edition, pg. 315. Toronto: Little, Brown and Company, 1992.

Keller, C. Peter (1987). "Stages of Peripheral Tourism Development -- Canada's Northwest "Territories". Tourism Management. 8(1): 20-32.

Kellert, S.R. (1985). "Birdwatching in American Society." Leisure Sciences. 7(3): 343360.

Kenchington, R.A. (1989). "Tourism in the Galapages Islands: The Dilemma of Conservation". Environmental Conservation. 16(3): 227-236. 
Keogh, Brian (1984). "The Measurement of Spatial Variations in Tourist Activity". Annals of Tourism Research. 11(2): 267-282.

Ker, J. (1778-82). Journal. MS. National Library of Scotland, Edinburgh.

King, Russell (1993). "The Geographical Fascination of Islands". In Lockhar, D.G; Drakakis-Smith, D. and Schembri, J. (eds.). The Development Process in Small Island States. London: Routledge.

Klaric, Zoran (1992). "Establishing Tourist Regions". Tourism Management. 13(3): 305311.

Latham, John (1991). "Bias Due to Group Size in Visitor Surveys". Journal of Travel Research. 29(4): 32-35.

Leiper, Neil (1979). "The Framework of Tourism: Towards a Definition of Tourism, Tourist, and the Tourist Industry". Annals of Tourism Research. 6: 390-407.

Leiper, Neil (1981). "Towards a Cohesive Cirriculum in Tourism: The Case for a Distinct Discipline". Annals of Tourism Research. 8(1): 69-84.

Leiper, Neil (1989). "Main Destination Ratios: Analyses of Tourist Flows". Annals of Tourism Research. 16: 530-541.

Leiper, Neil (1990). "Tourist Attraction Systems". Annals of Tourism Research. 17(3): 367-384.

Leopold, Aldo (1966). A Sand County Almanac. New York: Ballantine Books

Lew, Alan A. (1987). "A Framework of Tourist Attraction Research". Annals of Tourism Research. 14(4): 553-575. 
Linklater, Eric (1990). Orkney and Shetland: An Historical, Geographical, Social and Scenic Survey. (5th ed.) Revised by James R. Nicolson. London: Robert Hale.

Lockhart, Douglas G. and Ashton, Susan E. (1991). "Tourism in Malta". Scoltish Geographical Magazine. 107(1): 22-32.

Loukissas, Philippos J. (1982). "Tourism's Regional Development Impacts: A Comparative Analysis of the Greek Islands". Annals of Tourism Research. 9(4): 523-541.

Lubbock, B. (1937). The Arctic Whalers. Glasgow: Brown, Son and Ferguson.

Lucas, R.C. (1964). "Wilderness Perception and Use: The Example of the Boundary Waters Canoe Area". Natural Resources Joumal. 3: 394-411.

MacArthur, R.H. (195\%). "On the Relative Abundance of Bird Species". Procedings National Acadamy of Science. 43: 293-94.

MacCannell, Dean (1989). The Tourist: A New Theory of the Leisure Class. New York: Schockem Books Inc.

Mackay Consultants (1991). Study of the Economic Potential of the Shetland Economy. Inverness: H.I.D.B.

Mannell, Roger C. (1983). "Research Methodology in Therapeutic Recreation: Perspective of a Quantifier". Therapeutic Recreation Joumal. 17(4): 9-16.

Mansfeld, Yoel (1990). "Spatial Patterns of International Tourist Flows: Towards a Theoretical Framework". Progress in Human Geography. 14: 372-390.

Manson, T.M.Y. (1936). Mansons' Guide to Shetland. Lerwick: T.J. Manson. 
Mark, David M. (1981). "On the Positive Relation Between Distance and Attractivity in Recreational Travel: The Example of Birding". Ontario Geography. 17: 83-90.

Martin, Bill and Mason, Sandra (1993). "The Future of Attractions: Meeting the Neods of the New Consumers". Tourism Management. 14(1): 34-40.

Mathieson, A. and Wall, G. (1982). Tourism; Economic, Physical and Social Impacts. New York: Longman.

Mayo, Edward J. and Jarvis, Lance P. (1981). "The Psychology of Leisure Travel". Boston: CBI Publishing Co.

McCall, George J. and Simmons, J.L. (1969). Issues in Participant Observation. Reading, Mass.: Addison-Wesley Publishing Co.

McCool, Stephen F. (1989a). "Limits of Acceptable Change: Evolution and Future". In Towards Serving Visitors and Managing Our Resources: Proceedings of a North American Workshop on Visitor Management in Parks and Protected Areas. Tourism Research and Education Centre, University of waterloo and Environment Canada, Parks Service, 185-193.

McCool, Stephen F. (1989b). "Limits of Acceptable Change: Some Principles". In Towards Serving Visitors and Managing Our Resources: Proseedings of a North American Workshop on Visitor Management in Parks and Protected Areas. Tourism Research and Education Centre, University of waterloo and Environment Canada, Parks Service, 195-200.

McCormick, Donald (1974). Islands of Scotland. Reading: Osprey Pub. Ltd.

McIntosh, Robert W. and Goeldner, Charles R. (1990). Tourism; Principles, Practices, Philosophies. New York: John Wiley and Sons Inc.

McNicoll, I.H. (1975). "The Economic Impact of Tourism". The New Shetlander. 113: 16-21. 
Meyer-Arendt, K.J. (1985). "The Grand Isle, Louisiana Resort Cycle". Annals of Tourism Research. 12: 449-465.

Mill, Robert Christie and Morrison, Alaister M. (1985). The Tourism System. New Jersey: Prentice-Hall, Inc.

Mitchell, Lisle S. (1969). "Recreational Geography: Evolution and Research Needs". The Professional Geographer. 11(2): 117-118.

Mitchell, Lisle S. (19;9). "The Geography of Tourism". Annals of Tourism Research. 6(3): 235-244.

Mitchell, Lisle S. (1984). "Tourism Research in the United States: A Geographical Perspective". Geojoumal. 9(1): 5-15.

Mitchell, Lisle S. and Murphy, Peter E. (1991). "Geography and Tourism". Annals of Tourism Research. 18(1): 57-70.

Mitchell, Lisle S. and Smith, Richard V. (1985). "Recreational Geography: Inventory and Prospect". The Professional Geographer. 37(1): 6-14.

Moore, George (1900). "The Bending of the Bough". In Bartlett's Familiar Quotations. 16th edition, pg. 563. Toronto: Little, Brown and Company, 1992.

Morley, Clive L. (1990). "What is Tourism? Definitions, Concepts and Characteristics". The Joumal of Tourism Studies. 1(1): 3-8.

Mullay, Maurice (1983). "Tourism in the Eighties". Shetland Life. 32: 4-8.

Mullay, Maurice (1991). Personal Communication.

Murphy, Peter E. (1983). "Tourism as a Community Industry: An Ecological Model of Tourism Development". Tourism Management. 4(3): 180-193. 
Murphy, Peter E. and Andressen, Betty (1988). "Tourism Development on Vancouver Island: An Assessment of the Core-Periphery Model". The Professional Geographer. 40(1): 32-42.

Murphy, Peter E. and Keller, Peter C. (1990). "Destination Travel Patterns: An Examination and Modeling of Tourist Patterns on Vancouver Island, British Columbia". Leisure Sciences. 12(1): 49-65.

Neill, Patrick (1804). A Tour Through Some of the Islands of Orkney and Shetland: With a View Chiefly to Objects of Natural History, etc. Edinburgh: Constable and Co.

Nelson, J.G. (1992). "Sustainable Development: A Heritage and Human Ecological Perspective". The Operational Geographer. 10(1): 6-8.

Nelson, J.G. and Butler, R.W. (1993). "Assessing, Planning and Management of North Sea Oil Development Effects in the Shetland Islands". Environmental Impact Assessment Review. 13: 201-227.

Nicolson, James R. (1984). Shetland. Devon: David and Charles Pub, Ltd.

Nicolson, James R. (1985). "A Plan for Tourism". Shetland Life. 53: 4-7.

Nicolson, James R. (1989). "The Success of Tourism". Shetland Life. 108: 4-7.

Nicolson, James R. (1991). "A Good Season for Tourists - After a Nail-Biting Start". Shetland Life. 134: 4-6.

Norcliffe, G.B. (1982). Inferential Statistics for Geographers: An Introduction. London: Hutchinson and Co. Ltd.

Norusis, Marija J. (1988). SPSS/PC+ Studentware. Chicago: SPSS Inc. 
Nysteun, J.D. (1963). "Identification of some Fundamental Spatial Concepts". in Spatial Analysis. B.J.L. Berry and D.F. Marble (eds.). New Jersey: Prentice-Hall. pp.35-41.

O'Dell, Andrew C. (1932). The Shetland Islands. Westiminster.

O'Dell, Andrew C. (1939). The Historical Geography of the Shetland Islands. Lerwick: T.J. Manson.

Oppermann, Martin (1992). "Travel Dispersal Index". The Joumal of Tourism Studies. 3(1): 44-49.

O'Reilly, A.M. (1986). "Tourism Carrying Capacity: Concepts and Issues". Tourism Management. 7(4): 254-258.

Patton, M.Q. (1987). How to Use Qualitative Methods in Evaluation. Newbury Park: Sage Publications.

Patton, M.Q. (1990). Qualitative Evaluation and Research Methods. London: Sage Publications.

Pearce, Douglas G. (1979). "Towards a Geography of Tourism". Annals of Tourism Research. 245-272.

Pearce, Douglas G. (1987). Tourism Today: A Geographical Analysis. New York: Longman.

Pearce, Douglas G. (1988). "Tourist Time-Budgets". Annals of Tourism Research. 15(1): 106-121.

Pearce, Douglas G. (1989). Tourist Development. London: Longman. 
Pearce, Douglas G. and Elliot, J.M.C. (1983). "The Trip Index". Joumal of Trayel Research. 22(1): 6-8.

Pearce, Philip L. (1982). The Social Psychology of Tourist Behaviour. Oxford: Pergamon Press.

Pearce, Philip L. (1991). "Analysing Tourist Attractions". The Journal of Tourism Studies. 2(1): 46-55.

Pearce, Philip L. (1993). "Fundamentals of Tourist Motivation". in Tourism Research: Critiques and Challanges. Douglas G. Pearce and Richard W. Butler (eds.). London: Routledge.

Pigram, John J. (1990). "Sustainable Tourism - Policy Considerations". The Joumal of Tourism Studies. 1(2): 2-9.

Pitt, D.G. and Zube, E.H. (1987). "Management of Natural Environments". Handbook of Environmental Psychplogy. 1: 1009-1041.

Plog, S.C. (1977). "Why Destivtation Areas Rise and Fall in Popularity". In Kelly, E.M. (ed.). Domestic and International Tourism, Institute of Certified Travel Agents, Wellesley, Mass.

Powdermaker, H. (1966). Stranger and Friend. New York: W.W. Norton.

Raspe, Rudolf Erich (1785). "Travels of Baron Munchausen". In Bartlett's Familiar Quotations. 16th edition, pg. 341. Toronto: Little, Brown and Company, 1992.

Reichardt, Charles S. and Cook, Thomas D. (1979). "Beyond Qualitative Versus Quantitative Methods". In Cook, Thomas D. and Reichardt, Charles S. (eds.). Qualitative and Quantitative Methods in Evaluation Research. Beverly Hills: Sage Publications. pp. 7-32. 
Reid, L.J. and Andereck, K.L. (1989). "Statistical Analyses Use in Tourism Research". Joumal of Travel Research. 28(2): 21-24.

Rivers, P. (1973). "Tourist Troubles". New Society. 23: 250.

Ryan, Chris (1991). Recreational Tourism: A Social Science Perspective. New York: Routledge.

Sheldon, Pauline J. (1990). "Joumals in Tourism and Hospitality: The Perceptions of Publishing Faculty". The Joumal of Tourism Studies. 1(1): 42-48.

Shetland Islands Council (1974). Shetland in Statistics. Lerwick: Shetland Litho.

Shetland Islands Council (1977). Shetland in Statistics. Lerwick: Shetland Litho.

Shetland Islands Council (1980). Shetland in Statistics. Lerwick: Shetland Litho.

Shetland Islands Council (1984). Draft Tourism Development Plan. Research and Development Department, Lerwick.

Shetland Islands Council (1985). Shetland in Statistics. Lerwick: Shetland Litho.

Shetland Islands Council (1989). Shetland in Statistics. Lerwick: Shetland Litho.

Shetland Islands Council (1990). Shetland in Statistics. Lerwick: Shetland Litho.

Shetland Islands Council (1991). Shetland in Statistics. Lerwick: Shetland Litho.

Shetland Islands Council (1992). Shetland in Statistics. Lerwick: Shetland Litho. 
Shetland Islands Tourism (1991a). 1991 Holiday Accommodation. Lerwick: Shetland Islands Tourism.

Shetland Islands Tourism (1991b). Shetland and Orkney Islands Official Tourist Map. Kent: Estate Publications.

Shetland Islands Tourism (1992). Shetland Official Tourist Guide. Lerwick: Shetland Islands Tourism.

Shetland Tourist Organisation (1985). Annual Report. Lerwick, Shetland.

Shields, Rob (1991). Places on the Margin: Altemative Geographies of Modernity. New York: Routledge. pp.3-6.

Sieber, S. (1973). "The Integration of Fieldwork and Survey Methods". American Joumal of Sociology. 78: 133-159.

Silk, John (1979). Statistical Concepts in Geography. London: George Allen and Unwin.

Simpson, John M. (1983). "The Discovery of Shetland from 'The Pirate' to the Tourist Board". in Shetland and the Outside World 1469-1969. New York: Oxford University Press.

Sinclair, Catherine (1840). Shetland and the Shetlanders. New York: Appleton and Co.

Smale, Bryan J.A. (1988). "Equipotentiality in Urban Recreation Opportunities". Unpublished Ph.D. Dissertation, University of Western Ontario, London, Ontario, Canada.

Smith, John R. (1958). "Stand by to Receive Borders: Some Light-Hearted Reflections on Tourism". The New Shetlander. 47:19-20. 
Smith, Stephen L.J. (1990). Dictionary of Concepts in Recreation and Leisure Studies. New York: Greenwood Press.

Smith, Stephen L.J. (1989a). Tourism Anaysis. New York: Wiley and Sons Inc.

Smith, Stephen L.J. (1987). "Regional Analysis of Tourism Resources". Annals of Tourism Research. 14(2): 254-273.

Smith, Stephen L.J. (1982). "Reflections on the Development of Geographic Research in Recreation: Hey Buddy, Can You S'Paradigm". Ontario Geography. 19: 5-28.

Smith, Valene L. (ed.) (1989b). Hosts and Guests: The Anthropology of Tourism. Philadelphia: University of Pennsylvania Press.

Stankey, G.H. and McCool, S.F. (1984). Carrying Capacity in Recreational Settings: Evolution, Appraisal, and Application". Leisure Sciences. 6(4): 453-473.

Stevenson, Robert Louis (1878). "Travels with a Donkey". In Bartlett's Familiar Quotations. 16th edition, pg. 560. Toronto: Little, Brown and Company, 1992.

System 3 Scotland (1992). 1991 Shetland Visitor Survey. Lerwick: Shetland Islands Council.

Taylor, Libby; Allardyce, Myrtle and Macpherson, Neil. (1992). "Determining Marketing Strategies for Organizations Targeting the European Tourist to Scotland". Tourism Management. 13(1): 50-55.

The Concise Oxford Dictionary (1976). 6th edition, J.B. Sykes (ed.). Oxford: Clarendon Press.

The Globe and Mail (1994). "A Year After the Oil Spill". January 31, pg. A13. 
Tourism Working Group (1990). "Tourism Development Plan Review--Discussion Paper". Shetland Islands Council.

Trend, M.G. (1979). "On the Reconciliation of Qualitative and Quantitative Analyses: A Case Study". in Cook, Thomas D. and Reichardt, Charles S. (eds.) Qualitative and Quantitative Methods in Evaluation Research. Beverly Hills: Sage Publications. pp. 68-86.

Truong, T.P. and Hensher, D.A. (1985). "Measurement of Travel Time Values and Opportunity Cost from a Discrete Choice Model". Economic Joumal. 95: 438451.

Tumer, L. (1976). "The International Division of Leisure: Tourism and the Third World". Annals of Tourism Research. 4(1): 12-24.

Turner, L. and Ashe, J. (1975). The Golden Hordes. London: Constable.

Van Maanen, J. (ed.) (1983). Qualitative Methodology. London: Sage.

Wagar, J.A. (1964). The Carrying Capacity of Wild Lands for Recreation. Forest Science Monograph No.7. Society of American Foresters, Washington 3,21.

Walker, Robert (1985). "Evaluating Applied Qualitative Research". In Walker, Robert (ed.) Applied Qualitative Research. Aldershot: Gower Publishing. pp. 177-196.

Wall, G. (1993). "Towards a Tourism Typology". in Nelson, J.G.; Butler, R.W. and Wall G. (eds.). Tourism and Sustainable Development: Monitoting. Planning. Managing. Department of Geography Publication Series Number 37, Univ. of Waterloo, Waterloo, Ontario, Canada.

Wall, G. (1982). "Cycles and Capacity: Incipient Theory or Conceptual Contradiction". Tourism Management. 3(3): 188-192. 
Wallace, Robert A.; King, Jack L. and Sanders, Gerald P. (1991;. Biology: The Science of Life. Illinois: Scott, Foresman and Company.

Walmsley, D.J. and Jenkins, J.M. (1991). "Mental Maps, Locus of Control, and Activity: A Study of Business Tourists in Coffs Harbour". The Joumal of Tourism Studies. 2(2): 36-42.

Walsh, Richard G.; Sanders, Larry D. and McKean John R. (1990). "The Consumptive Value of Travel Time on Recreation Trips". Joumal of Travel Research. 29(1): 17-24.

Warszynska, J. and Jackowski, A. (1986). "Studies on the Geography of Tourism". Annals of Tourism Research. 13(4): 655-658.

Watson, Adam (1984). "Paths and People in the Cairngorms". Scottish Geographical Magazine. 100(3): 151-160.

Weaver, D.B. (1990). "Grand Cayman Island and the Resort Cycle Concept". Joumal of Travel Research. 29(2): 9-15.

West, J.F. (1964). "A Tourist to Shetland in 1821". The New Shetlander. 68: 31-33.

Whitman, Walt (1888). "November Boughs". In Bartlett's Familiar Quotations. 16th edition, pg. 491. Toronto: Little, Brown and Company, 1992.

Wilkinson, Paul F. (1989). "Strategies for Tourism in Island Microstates". Annals of Tourism Research. 16(2): 153-177.

Wilkinson, Paul F. (1987). "Tourism in Small Island Nations: a Fragile Dependence". Leisure Studies. 6(2): 127-146.

Wills, J. and Wamer, Karen (1993). Innocent Passage: The Wreck of the Tanker Braer. Edinburgh: Mainstream Publishing. 
Wilson, James (1861). A Voyage Around the Coasts of Scolland and the Isles. Edinburgh: Adam and Charles Black, North Bridge.

Wolfe, R.I. (1966). "Recreational Travel: The New Migration". Canadian Geographer. 10(1): 1-14.

Wolfe, R.I. (1964). "Perspectives on Outdoor Recreation: A Bibliographical Survey". Geographical Review. 54: 203-238.

Yefremov, Y.K. (1975). "Geography and Tourism". Soviet Geography. 16(4): 205-217.

Young, Bruce (1983). "Touristization of a Traditional Maltese Fishing-Farming Village". Tourism Management. 4(1): 35-41.

Zurick, David N. (1992). "Adventure Travel and Sustainable Tourism in the Peripheral Economy of Nepal". Annals of the Association of Geographers. 82(4): 608-628.

Zuzanek, Jiri (1980). Work and Leisure in the Soviet Union: A Time Budget Analysis. New York: Praeger. 